\title{
Politics by All Means
}

\section{An Enquiry into Technological Liberalism}

Govert Valkenburg

Simon Stevin Series in the Ethics of Technology 


\section{Politics by All Means \\ An Enquiry into Technological Liberalism}




\section{POLITICS BY ALL MEANS \\ AN ENQUIRY INTO TECHNOLOGICAL LIBERALISM}

\section{PROEFSCHRIFT}

ter verkrijging van

de graad van doctor aan de Universiteit Twente, op gezag van de rector magnificus, prof. dr. H. Brinksma

volgens besluit van het College voor Promoties

in het openbaar te verdedigen op vrijdag 5 juni 2009 om I3.I5 uur

door

Govert Valkenburg

geboren op 9 augustus I977

te Amsterdam 
Dit proefschrift is goedgekeurd door:

prof. dr. H.J. Achterhuis, promotor

dr. T.E. Swierstra, assistent-promotor

Samenstelling promotiecommissie

Rector Magnificus, voorzitter

prof. dr. ir. W.E. Bijker

prof. dr. T. de Cock Buning

dr. J.A. Harbers

prof. dr. J. Hoogland

prof. dr. ir. P.P.C.C. Verbeek

This thesis will be available digitally on http://www.govertvalkenburg.nl/ac. Second thoughts, errata and other news will appear there as well.

The research for this thesis has been financed by the Netherlands Organisation for Scientific Research (NWO, http://www.nwo.nl), through its program Maatschappelijke Component van het Genomicsonderzoek.

The printing of this thesis has been financially supported by the Netherlands Graduate Research School of Science, Technology and Modern Culture (WTMC, http://www.wtmc.net) and facilitated by the 3 TU.Center for Ethics and Technology

(http://www.ethicsandtechnology.eu).

(C) Govert Valkenburg, 2009

All rights reserved. No part of this publication may be reproduced, stored in a retrieval system, or transmitted, in any form or by any means, without prior permission in writing of the publisher.

Editors: Philip Brey, Peter Kroes and Anthonie Meijers

ISBN: 978-90-365-2848-I

ISSN: $1574-94 \mathrm{IX}$

DOI: I0.3990/I.978903652848I (http://dx.doi.org/I0.3990/I.978903652848I)

Copies of this publication may be ordered from the 3TU.Centre for Ethics and Technology, info@ethicsandtechnology.eu. For more information, see http://www.ethicsandtechnology.eu. 
To my grandmother,

a natural liberal. 



\section{Contents}

I Prologue I

I Cloned sheep, clashing contestants 3

I.I Dolly's unholy heritage 3

I.2 The pains of purification 9

I.3 Technology as destabilizing morality I8

I.4 Problem definition 2I

$\begin{array}{ll}\text { Outline } & 23\end{array}$

II A liberal, technological culture 25

2 Politics as purification $\quad 27$

2.I An unstable pluralism 27

2.2 A pluralism of ideas of the good 28

2.3 The liberal problem: between public and private 37

2.4 We have never been liberal 55

3 Political technology 65

3.I We live in a technological culture $\quad 65$

3.2 Technology between tool and tyrant 66

3.3 Science and technology as networks 75

$\begin{array}{ll}3.4 & \text { Technoscience goes political } \\ & \end{array}$

$\begin{array}{ll}\text { Overview } & 97\end{array}$

III Political practices of technology IOI

4 Enhancement, eugenics and the designer baby I03

$\begin{array}{ll}\text { 4.I Medicine beyond disease } & \text { I03 }\end{array}$

$\begin{array}{ll}\text { 4.2 The battle on being better } & \text { IO7 }\end{array}$ 


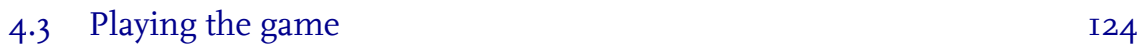

$\begin{array}{ll}\text { 4.4 Enhancement and modern culture } & \text { I37 }\end{array}$

5 Biobanks and the socio-technical body $\quad$ I49

5.I Base sequences in sequence bases $\quad$ I49

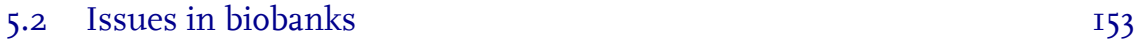

5.3 The hold of politics and genes I7I

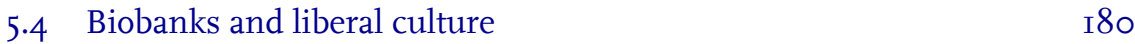

6 PGD: an episode in Dutch politics $\quad$ I93

$\begin{array}{ll}\text { 6.I Introduction } & \text { I93 }\end{array}$

6.2 What went before $\quad 194$

6.3 The embryo of discord 203

6.4 The aftermath 2II

$\begin{array}{ll}6.5 & \text { Reflection } \\ & 216\end{array}$

$\begin{array}{ll}\text { IV Epilogue } & \text { 2I9 }\end{array}$

7 Technological liberalism 22I

$\begin{array}{lll}\text { 7.I The problem of progress } & \text { 22I }\end{array}$

7.2 Liberal ideals $\quad 222$

$\begin{array}{lll}7 \cdot 3 & \text { Muddy debates } & 225\end{array}$

$\begin{array}{ll}7.4 & \text { What the quarrel is all about } \\ 227\end{array}$

$\begin{array}{ll}7 \cdot 5 & \text { Purification by all means } \\ 229\end{array}$

7.6 Liberalism or politics, technology or change? 234

$\begin{array}{lll}7.7 & \text { Liberal technology } & 236\end{array}$

Bibliography 24I

$\begin{array}{lr}\text { Summary } & 257\end{array}$

$\begin{array}{ll}\text { Samenvatting (Dutch summary) } & 273\end{array}$

$\begin{array}{ll}\text { Index } & 295\end{array}$ 


\section{Preface}

Doing a PhD formally means that one proves to have the abilities that a proper scientist or scholar has. What a complex world such a simple idea can hide. It was reading, it was writing, it was listening, it was misunderstanding, it was thinking you understand while you did not, and then thinking you would never understand while in fact you already did, it was writing again, it was trashing your own work, it was building again from scratch, better this time, it was reading again, reading more and more of your own mediocre work and less and less of the brilliant work of others, it was doubting whether you were getting at something, it was recognizing very slowly that you were getting at something original - and then you have a week left for the typos and the preface. Above all, it was great fun. It was being grateful for having the time and space to explore a world unknown. And for having the opportunity to build something that you can be proud of - while recognizing that you are standing on the shoulders of others and that you may be just a child of your time.

In the very first place, I am heavily indebted to Hans Achterhuis and Tsjalling Swierstra. Hans confided in my capacities after my Master's graduation and allowed me to start working on a PhD. He continued playing a role of great inspiration until the end. Tsjalling took up the challenge of guiding me through the swamps that writing a book is. The many o-so-critical talks, hints and literature suggestions, as well as the harsh words about my other career, were essential for developing the qualities that I now have: a sensitivity for how ideas compete with one another for our attention; how things help those ideas cheating on one another and on us; and how we think we are just fine with that. And then it turns out that it is all just about composing a proper text.

My colleagues in Twente have always provided me with a warm social context. We were so solitary and yet so together. In particular, I thank Sebo Uithol, Charlene Versluijs and Steven Dorrestijn. I have shared an office with them, and hence I have shared important parts of my life with them. The same holds for Rinke Klein-Entink, even though it was not the office but mainly the coffee corner that 
we shared. My friends of the STS Leesclub Universiteit Twente have offered an irreplaceable pastime during office hours. It is really too bad that attendance to the meetings has declined dramatically over the last few years. I hope the meetings will revive one day. Without me, unfortunately.

A cordial word of gratitude I wish to speak to my WTMC friends. Attending workshops, summer schools and dissertation days was always a warm and welcome change to the somewhat solitary work that doing a $\mathrm{PhD}$ often is. I do sometimes miss the late-night chats on the couch at Soeterbeeck. A special word of thanks is for those who actively commented on parts of my work on one of these occasions, in historical order: Roos Spanjers, Niki Vermeulen, Jeroen van den Hoven, Erik Aarden, Wiebe Bijker, Julia Quartz, and Harro van Lente. And of course, WTMC would simply not be what it is without those who kept this club going: Els Rommes, Sally Wyatt and Willem Halffman.

One world is essential to my life: music. I owe a lot to those who joined me in making music, enjoyed it with me, gave me chances, and helped me develop. A collective thank you goes to to my friends of the Musica Silvestra Orchestra, to my fellow students at the Enschede Conservatory, and to the many music teachers I learnt from, both inside and outside the conservatory. In particular, Annette Kleine, Marien van Nieukerken and Felix Schoonenboom have helped me finding my own way.

Finally, I thank my family for supporting me in all the way they did. My parents have always been there when I needed them. In particular I thank my two brothers Jochem and Wessel; first of all for being paranymphs at the defense of this thesis; and second for perpetually reminding me, mostly over Skype, that there is hope in life. Or actually more accurate, for bullying me with pictures of them on ski slopes out there that I can only hope of, while I was drudging in yet another cycle of editing. But then, that kind of hope is not so much different from most other hopes.

My dearest Claudia, you have made so many days with just a smile.

G.V. 
I Prologue 



\section{Cloned sheep, clashing contestants}

\subsection{Dolly's unholy heritage}

\subsubsection{Ambiguous animal}

In February, I997, the Roslin Institute, located near Edinburgh, announced the successful cloning of an adult sheep. Dolly, as the creature was named, was the protagonist of a vivid controversy that lasted for several years. Worldwide, an uncountable number of essays, ethical analysis and editorial comments were dedicated to it. Discussions were carried on in a disconcerting tone of voice: this would be the first step towards the final dehumanization of mankind, and a Brave New World of total manipulation would be within reach. The Vatican issued 'an urgent appeal to reason and to humanity', and in Germany the fear of the blue-eyed Aryan superhuman appeared immediately (see James: 1997). Any human imperfection would soon belong to the past - at the cost of losing the art of taking life the way it comes.

Besides being a source of nightmarish outlooks on the future, Dolly exemplified the typical way modern society seems to deal with issues in technological and scientific change. The controversy was exemplary in a number of ways. It was a vivid debate in which positions were explained and confronted. But in addition, the debate also displayed a number of difficulties. One of those was that it was not always a polite exchange of opinions, but also sometimes a difficult and even dirty dispute in which people were disqualified in difficult ways. Moreover, the arguments entered in the debate were much more 'ethically laden' than we are used to in modern politics. And it seemed to be exactly the repression of these arguments that caused the friction.

In addition to a herald of dystopia, Dolly was the icon of promised solutions to numerous difficulties. The cloning technology was at that time still to be perfected. But in a further stage of development, it promised to provide numerous opportunities to increase efficiency as compared to how things are achieved today. For example, laboratory test animals, whether created by traditional breeding or by genetic modification, will need to be produced only one time. Once conceived, they can be reproduced infinitely, thus providing labs with test animal populations 


\section{Politics by All Means}

that are even more homogeneous than they are today. Moreover, cloning will increase the efficiency of employing animals in the production of medicine: the medicine-producing specimen needs to be bred - or genetically engineered, for that matter - only one time. Also for agricultural purposes, it will be more efficient to produce highly standardized cattle. In addition, if the technology reaches a mature stage and according low costs, it may even be used to replace deceased pets. Or it may help us to keep perfect breeds of guide dogs for the blind, perfect race horses and perfect sniffer dogs to be employed by narcotics squads. ${ }^{\mathrm{I}}$

It seems however that the disadvantages outweigh the advantages. For example, extensive resources are needed for cloning and this raises the question of whether no cheaper solutions to these problems can be thought of. Possibly, breeding good guide or sniffer dogs takes only a fraction of the expenses of cloning them. And what counts as a good racing horse, might well change over time. Keeping up with the breeding standards may be a wiser strategy then, in both cases. In addition, the well-being of the animals may be disproportionately burdened. Dolly indeed showed some serious problems: diseases typically associated with aging occurred earlier than would normally be expected. These concerns might be overcome in time, but the bottom line is that the whole practice remains one of experimenting on animals - with good results and bad ones. In addition, animal populations may lose some of their diversity, which is believed to contribute to population robustness to disease. Closely related is the hazard of repressing traits today that tomorrow may prove of vital importance. And finally, it may mean that we will increasingly need laboratories to grow livestock, which may make things difficult should these labs no longer be available. Thus, technological change comes at a cost and it is not self explanatory that the advantages tip the balance in favor of it.

At face value, Dolly is an icon of the progressive impetus in science and technology. Science and technology aim for the largest efficiency, and the advantages of cloning appear in line with that. At closer look however, Dolly is more than just a high-tech product. We also feel that there is something wrong with her: at face value, she is just a sheep; but then again she is not just a sheep. She is a sheep in a way that sheep should not be; while just as soft to pet as any other sheep, there is a monstrous ring to her; not that she would do much evil, but she just is not natural. She is a mixture of the technical and the natural, categories that some may fear should not be mixed (see also Midgley: 2000, p. Io; Smits:

1 Some of these visions incur the fallacy of genetic determinism, see page rog. 
2002, p. 28). As much as she is the icon of progress, she can also be seen as the symbol of hubris: the human haughtiness of defining what was until today not up to humans to define. These are matters that we will generally have a host of different opinions on. Therefore, it is likely that the debate on it will be awkward. Yet while it is indeed difficult to devise how we should speak about Dolly, neither can we afford not to speak about her.

\subsubsection{Silenced voices speak up}

As early as June, I997, Leon Kass, then Chairman of the U.S. President's Council on Bioethics, in his essay The Wisdom of Repugnance voiced a number of objections against ever cloning a human being. The essay argues that most people will agree on those objections. This is shown by the disgust with which just the idea of reproducing a human individual is disapproved of. The central claim of the essay is that feelings of repugnance should be taken seriously, since they are the voice of moral wisdoms that we all have, yet are unable to articulate in the modern culture we live in. Rather than doing away with them as emotional and irrational, Kass elevates sensations of repugnance above the level of ordinary gut feelings by showing their true origins.

Clearest among those origins is a disgust regarding the intentions that underly the practice of cloning. 'Producing' human beings can only be seen as an instrumental and even despotic stance towards future human beings: manufacturing them according to our desires would be profoundly dehumanizing. No matter how close to a 'perfect child' the product gets, it will always be in the shadow of its maker. This would be to misunderstand the meaning of having children and the way parent-child relations are meant to be (see Kass: I997/ı998, pp. 39-40).

In addition, cloning would seriously burden our sense of identity and individuality. That is, the clone child will have to live up to the expectations raised by the one it has been cloned from, thus being less free to develop a life plan of its own - in other words, being less individual and unique than you and I are. After all, what other reason could be thought of than an appreciation of the original, to create the clone in the first place (see Kass: I997/I998, p. 33)? This, according to Kass, is incompatible with human dignity.

Still, the most intriguing observation is of a different nature. Kass (1997/1998,

p. 44) observes a slippery use of the idea of procreative liberty: the 'right to reproduce' can safely be asserted in defense against state interference with family 


\section{Politics by All Means}

planning; but it surely cannot justify the trespassing of natural borders, should technology eventually provide the means. This is remarkable: a right that is generally taken for granted, becomes less straightforward if technological change occurs. At least, appealing to this right in this new situation raises new questions. Kass is convinced that in such situations it is natural to react with disgust: when terms are used in ways so radically unprecedented.

In line with Kass, Mary Midgley (2000) argues that yucky feelings should be seen as serious beacons that guide our rational thought. Even though they are by themselves not infallible, they can often be explained as an implicit conception of human nature that we feel is being violated. We intuitively feel that manipulating or even just replicating the genome of a specimen transgresses the intrinsic nature of its species, especially when our own species is concerned. Allowing such a transgression would ultimately call on us to radically alter our whole conception of human nature. Revising this conception is something we are hesitant about, which is not simply an irrational revulsion. Therefore, Midgley pleads for paying better attention to emotions, as to reveal their strong rational components.

Martha C. Nussbaum (2004, pp. 79-82) has given an extensive overview of the roles that emotions play in our political life. She does observe that Kass argues that values essential to liberalism include dignity. Thus, liberalism has a duty in protecting it. However, Kass's specific implementation of dignity is strongly related to a 'given human nature', which is beyond the liberal understanding of dignity. Moreover, she observes that Kass faces a dilemma that he fails to address. Either, all instances of repugnance offer sound moral guidance, which incurs that Kass agree that repugnance against Jews and homosexuals is morally sound which most of us disagree with. Or, some forms of repugnance are morally sound, but this requires that Kass specify why some forms of repugnance are morally correct while others are not, an explanation that Kass fails to provide.

Alternatively, David Tracy (I998, pp. I94-I95) argues that today's appeal to reason in public discussions is to beg the question: sure, we should be ready to explain our arguments, but what public truth is, remains fundamentally a matter of consensus. The arguments we use are only one leg of the search for truth. The other should be an enquiry into various intuitions of the good, including those expressed in art and religion. The liberal debate tends to exclude those as private, whereas we do all 'share a repulsion, a moral outrage at such conduct as unacceptable for anyone claiming to be a human being' (p. I99). Finding out 
if and why we share basic values requires that we look into religions, which are in fact traditions of great and subtle complexity. Then Tracy continues to argue some specific insights that we can gain from religion. He concludes (p. 202) that those traditions are at our service, if we are just wise enough to employ them. The matter of cloning is a fine example where these contemplative sources could enlighten the 'shouting matches' that Tracy discerns today in the cloning debate.

Kass and others lament a loss of moral meaning in public debate. In politics and political debate, our moral vocabulary usually focuses mostly on assets and liabilities. This is a vocabulary much too narrow to do justice to considerations appropriate to cloning: considerations of what it means to be human. According to Kass and others, it is impossible to discuss the whole topic of cloning without taking account of what we believe to be the fundamentals of what it means to be human: we now face decisions that may radically alter our own human nature. They argue that this requires more than a shallow discussion in terms of costs and benefits. However, in the next subsection I will explain how this shallow discussion also has its upsides.

\subsubsection{Keeping the talk clear}

Opposing Kass and Midgley, a number of discussants argues that the appeals to emotions, repugnance or religious wisdom do not at all help the debate, but rather obscure it. For example, Ruth Macklin (2002) argues that much of the revulsion fed by the idea of cloning is to be traced back to false understandings of genetic causation: if two persons share the same genome, this is not at all to say that they are the same persons or have the same identity, nor should they share their life plans or anything else. Rather, since so much of our identity is determined by our personal history and our personal choices, chances are that rather different individuals will develop. Thus, seeing identities endangered by cloning is to misunderstand the whole phenomenon. By taking up a scientifically-valid argumentation, the whole problem vanishes for Macklin.

Similarly, in May 2008, Steven Pinker (2008) wrote an essay, illustratively called The Stupidity of Dignity, expressing his unease concerning the use of the concept of dignity. He argues that the usage of dignity seems only acceptable insofar as it conceals an appeal to autonomy: dignity is whatever we respect if we treat people in the way that they wish to be treated. He thus argues that dignity adds little to the much better defined concept of autonomy, which in its turn raises 


\section{Politics by All Means}

the question why all the efforts are taken to put up the smoke screen of the concept of dignity. He then argues that dignity seems to be used by Kass c.s. primarily as a vehicle to pervade the public discourse with Christian and Catholic values. While Pinker does not explicitly follow up on the cloning debate, he does rely on Ruth Macklin's (2003) essay Dignity is a useless concept, in which she argues the same point in opposition to Kass's report on cloning (see Kass: 2002a). She argues that dignity either amounts to vague restatement of more concrete principles like autonomy, or they are mere slogans that add nothing to the argument. The reason that the notion of dignity is so popular may be that it appears repeatedly in Roman Catholic writings. Macklin explicitly does not push this to the conclusion that it is a 'religious contamination' of a 'secular' debate, but she does suspect that the origin of its widespread use is likely to be found in religious realms.

In similar vein, John Harris (2004, pp. 2I-22) argues that fears for a decline of human dignity are generally short of a convincing elaboration of the concept of dignity, let alone an account of how this dignity is endangered by supplying someone with a chosen genome instead of a random one. Harris observes that most claims about the wickedness of cloning are either posited as if they were self-evident, or lacking any citations, presuming that the sources of evidence are widely known. He fears that much of the panic in Dolly's wake is to be ascribed to wild fantasies and imaginations, partly stemming from science fiction and horror stories, capturing the debate.

Finally, Dan Brock (I998) observes that the often proclaimed rights to a unique identity and to an open future obscure rather than clarify the debate: identity and the open future are not endangered in any way that matters. As a corollary, this also eliminates the objections of the despotic stance: if germ-line engineering leaves so much open in the development of the individual, possible hopes fostered by despotic parents will be in vein anyway. This is an important counterargument against the adduced problems of identity. Indeed, Buchanan, Brock, Daniels and Wikler (2000, ch. 8) conclude that cloning does generally not incur a despotic stance of the creators over the created any more than 'conventional' reproduction does. Hence, that alleged stance does not justify an impediment on the reproductive freedom of parents - which should thus be understood as including a justification for cloning.

The preceding paragraphs have exposed some more efficient visions on the debate: they boiled down to the idea that not so much is at stake, if we are smart 
enough to adopt the (believed-to-be) appropriate scientific vocabulary. This is however at odds with the import of the subsection before, in which the complexity of the matter was exposed to support the need for more 'philosophical' content. This conflict is a first answer to the question of why the discussion took so long and was so awkward. In Tsjalling Swierstra's (2000, p. II6) reconstruction of the debate, it is shown that all arguments pro and contra had been expressed in the first months of the controversy. That is to say, after a few months, nothing really new was put forward. Nevertheless, the discussion itself went on for two more years indeed, largely showing repetitions of arguments without coming to closure. In the next section I will explain that the reason for this is not just that there were some stubborn discussants ready to conduct never-ending discussions. Rather, behind the discussion we can discern a mechanism that is at the fundamentals of our modern culture: we tend to think of a large part of our ethics as private, while at the same time this part of ethics is sometimes unavoidable even in public. It was this mechanism that produced the deadlock.

\subsection{The pains of purification}

\subsubsection{Appropriate arguments}

A first important observation to be made regarding the discussion about Dolly is that not only arguments about Dolly were expressed, but also arguments about arguments: indeed, meta-arguments, that concerned the validity and appropriateness of arguments themselves. This is a common element in any discussion, since discussions always need rules and these rules need articulating every now and then. However, in the case of Dolly, a surprisingly large part of the debate was dedicated to the question of how the debate should be conducted. This section will explore these meta-arguments and rules of speech.

Before we can start however, it is necessary to first explicate the concept of politics I will use throughout this book. Politics or political affairs, I understand as the sphere in which we discuss those problems that are relevant to all of us. It is indeed where public affairs are discussed. Thus, I do not restrict politics to the actions of parliaments and governments, nor to the formalized activity of legislation. Essential to it is however that within politics, the aim is to produce normative claims that are supposed to pertain to all citizens. Thus, it sticks closely to the suggestion by Adam Swift (200I, p. 5), who takes the political to be the 


\section{Politics by All Means}

concern with how a state may or may not coercively act. This way, it is only a subset of the wider idea of public debate. The latter may discuss a whole lot more, but not necessarily with the pretention that it should apply to all.

As political affairs are defined as concerning all of us, it is no more than reasonable that we demand that we only use arguments that are acceptable or even obvious to all. For example, we may expect all reasonable persons to agree that against the background of current knowledge, cloning will be inhumane and close to a form of torture. Indeed, the present state of the art in cloning provides not a single reason to believe that it will produce healthy humans. Experiments in cloning mammals so far show serious diseases and malformations (see Kass: I997/I998, p. 3I; Plasterk: 200I). If such a premature technology were simply transferred to the use with humans, this would amount to grave torture. We may therefore presume that the conclusion is accepted by all relevant citizens, at least for the time being, that cloning in pursuit of human reproduction should be prohibited because it is seriously harmful. Indeed, it seemed that this argument and its conclusion were accepted throughout the entire debate, and it was the main reason for a moratorium on cloning to be accepted in most countries (see Center for Genetics and Society: 2006, p. I0). The argument of harm was a politically appropriate argument.

At the same time, we need not look far to find arguments in the same discussion that are not as easily accepted by all discussants. One example of a significantly less accepted argument, is the appeal to human dignity. Indeed, Kass holds the view that cloning - that is, today in sheep and tomorrow in humans poses a threat to dignity because it does away with one of the essentials of what makes us human: sexual reproduction and the reshuffling of genes it involves (see Kass: I997/I998, pp. 24-3I). However, dignity fails to convince many. Dignity cannot be conclusive here for two reasons: first, everybody embraces it and would not be caught arguing against it; and second, each discussant thinks something different of it. Indeed, whether an appeal to dignity is acceptable to discussants strongly depends upon further specification of the concept. And then, if speaker and receiver have a strongly different background, such specification is likely to raise controversy rather than consensus. The common ground needed is failing here. Moreover, the acceptance of the concept seems to depend upon the end to which it is put forward. Worst case, this leads discussants to see appeals to dignity as inappropriate to the debate, simply because it lacks clarity. 
This distinction between appropriate and inappropriate arguments, indeed on the meta-level of the debate, is a precarious one. The world would be well-ordered if we had clear a priori rules or procedures to establish whether arguments can be accepted or not. But the world is not well-ordered. On the contrary, the rules of acceptance and acceptability are fuzzy, inconsistent and changeable. They are continuously guarded, enacted and challenged. Of course, each discussant wants his or her arguments to be accepted by all: it is part of politics, that we try to win as many others as possible for our position. To this end, we generally support our claims with arguments why they are good claims, thus including why they are appropriate in the discourse.

Simultaneously, each discussant has an interest in disqualifying the arguments that his or her opponents adduce. This is typically reflected by the response that Kass meets: his arguments are disqualified as irrational, crypto-religious and so on. What is important here is that it is apparently not enough for discussants to just stage arguments and explain that they disagree with their opponents. In addition, they often argue why opponents' views should not be in the debate in the first place.

Thus, we recognize two levels in the debate: the level of arguments and claims that people may disagree upon, and the level of whether arguments are relevant, appropriate and valid in the public discourse. Apparently, besides discussing our collective decisions, there is the continuous activity of sorting out arguments as appropriate or inappropriate for this very discussion. I will henceforth refer to this underlying process as purification. ${ }^{2}$ This combination of arguments and meta-arguments, or of debate and purification, I call discourse. In the following paragraphs, I will explore how this discourse is shaped.

\subsubsection{Purification in action}

Dolly was not just a healthy sheep; she showed serious diseases. The current scientific background provides no reasons to expect that human clones will live a healthy life. Indeed, these troubles appeared to suffice as arguments in support of the moratorium. This is a common mechanism: arguments appealing to tangible harms run a good chance of surviving the purification that I just observed. We can

2 For some readers, this term will be associated with the work of Bruno Latour. The connection with his work will become clear in the course of chapter 2 on liberalism and chapter 3 on technology. 


\section{Politics by All Means}

safely assume that no decent person will challenge the duty to prevent physical harm if we can. In fact, we can assume that we will agree upon this principle, regardless of our private backgrounds. Indeed, the infliction of physical harm is immoral from any perspective - at least, the perspectives we feel compelled to take seriously. Thus, it is easy to see that the earlier argument that cloning will not (as yet) produce healthy individuals, is indeed accepted by all parties as a justification for a semi-permanent ban on cloning. In general, arguments connected to harm will be convincing if they are sufficiently serious. In somewhat more general terms, any argument appealing to something 'clearly grave' has a good chance of surviving.

However, graveness alone is not enough to make arguments acceptable. The prospect that cloned sheep will eventually colonize the earth and take away all the food available to humans today is certainly a grave one - yet it lacks all reality. Indeed, this is exactly why molecular biologist and publicist Ronald Plasterk (2000, p. 244) complains that people tend to exaggerate the dangers that scientific practices expose us to, and that especially those who are most remote from the research practice do so. Instead, people should have themselves informed by those who know best: the scientists in the lab. The discussion should then be restricted to issues that are indeed occurring or can be reasonably expected to occur in the near future. The physical harm incurred by present-day cloning is a fine example of such a realistic issue, and indeed it does survive purification. Apparently, in addition to being grave, arguments do also need to be real and present, and arguments that enjoy scientific support run a better chance of surviving than those that do not.

At this point, it could be suggested that in addition to obviously bad things, also things that are obviously good will have a good chance of being accepted. However, this is in fact what we saw with dignity. It is quite understandable that discussants appeal to dignity: who, after all, would disagree that dignity is an important value? What is more, every discussant has an interest in keeping away even the ghost of arguing against dignity. Even if one has a good reason to disqualify opponents' appeals to dignity, there is the immediate danger of being accused of disrespecting dignity. In the end, dignity turned out to be unable to conclude discussions, exactly because of its many different interpretations. The same holds for other values like liberty, justice and well-being. These are things that everyone values dearly, and no reasonable person would want to be caught 
endangering them. Despite the noblesse of such arguments, it is at the same time easy to remove appeals to them from the debate. In the case of dignity, it was argued that cloning is not detrimental to it, and that dignity is a concept too vague to convince anyway. By similar moves, appeals to liberty, justice and well-being are vulnerable to disqualification: their power depends on their detailed conceptualizations, and this is often where disagreement is sparked rather than settled. Because these values are simultaneously of the utmost importance and fairly vague, they are likely to raise a diffusion of tongues. Thus, sometimes arguments may seem likely to survive purification at first, while, later, they prove to only contribute to further confusion.

Throughout this book, a number of arguments will be seen that participants typically try to remove from the debate. Arguments are most likely to taste defeat, if they appeal to things that are not generally accepted. Religious beliefs are prominent among those. Indeed, we will see quite a few times that arguments are discarded as private or even downright backward if only a trace of religion is suspected. Similarly, accounts of human nature often fail to convince, indeed because so many interpretations of that human nature exist, let alone that it would be straightforward how political decisions can follow from it. This is generally not because religion or human nature are wrong or bad, but because they are not sufficiently unified and unambiguous in their advice.

The purification of arguments has an important consequence: if we impose criteria upon which kinds of expressions are appropriate, this co-defines the issues on which politics may make decisions. If we judge arguments based on the extent to which they contribute to preventing harm, it is clear that for example reproduction will hardly be a political matter: nobody, it is generally agreed upon, can be harmed by somebody else having children. (Of course, children can be harmed by the fact that those are their parents. In exceptional cases, this can be a justification to forbid couples to have children.)

Similarly, contemporary western society takes largely for granted that the expression of thoughts - within some degree of decency - can never harm someone else. Therefore, the freedom of speech is taken for granted. Only in fairly exceptional cases, what one may express becomes a political matter - indeed, whenever somebody wants to argue that he or she is really harmed by some expression. In general, both with respect to arguments and to what issues are discussed, contemporary politics has come to draw the line at harm to be publicly 


\section{Politics by All Means}

avoided. Anything beyond that line of clear harm is subject to private choice, taste, or religion, if one likes.

Moving issues to the realm of private choice is not a bad idea. Indeed, over recent history we have come to the insight that society works best in a situation where people have a large degree of private choice. This private choice is typically granted to us in order to allow us to lead the life that we think is best to live. This question of what life we want to live I will call private ethics, to be elaborated further in chapter 2. This distinction between on the one hand private ethics, and on the other hand harms that are publicly relevant and therefore co-define the opposing public ethics, forms the point from which to start the struggle over purification. That it is hard to divide all ideas between these two classes, is shown by Dolly's case. That is, some adduce arguments that others typically concern private considerations. Indeed, Gary Rosen (2003, p. 29) lists a number of arguments against Leon Kass, as if Kass were building only on nonrational explanations, demagoguery and sci-fi horror stories. Kass's opponents argue that these are his personal opinions, or in my terms: his private positions.

It is clear that the opponents of Kass do all they can to disqualify the arguments that Kass puts forward. In particular, they articulate its religious content - which they have a stake in removing from the debate. While this is not to say that all of them uncritically favor cloning, it is clear that their own points are more convincing if those opinions are rendered untenable that they disagree strongest with. This altogether provides an interesting instance of purification. Kass puts forward the argument of dignity, presuming that others will accept it. Indeed, at first glance, it seems convincing enough, as no reasonable person will argue against it. However, in this case it does not suffice, as the others make strong claims to the lack of realness and graveness. Pinker and Macklin argue that dignity does not offer much beyond what the much more usable concepts of autonomy and informed consent already offer, except for being a placeholder for Biblical dicta, Judeo-Christian doctrines, and an abhorrence of the shallowness of the life that biotechnologies are - mistakenly, thus Pinker - suspected to produce. Insofar as Pinker and Macklin agree on these values in the first place, they feel they are at most questionably violated by cloning. Hence, they refuse to see in dignity an appropriate argument.

This will prove an important mechanism throughout the study of this book: that arguments are moved in and out of the debate, and that the matter of seeing 
an argument as appropriate or not cannot be seen apart from its actual content, and from the way it is supported by other arguments. Indeed, discourse is one whole. That is to say, in the example above, the idea that cloning is in conflict with dignity, the support of this claim from allegedly religious arguments, and the fact that it argues against cloning, cannot be seen as separate dimensions, even though we pretend that we would ideally do so in politics. If it were not an argument against cloning, Harris, Pinker and Macklin would perhaps not have taken up the gauntlet of refuting it as crypto-religious nonsense. And if Kass's essay had argued in favor of dignity, but in a way that seemed less religious, the others might have taken less offence and viewed it as a valuable contribution to the debate. This book will articulate when and how arguments make it in the debate, and when they are excluded. And we may already suspect from the example that religious arguments will generally have a hard time.

\subsubsection{Efficiency or shallow debate?}

The purification of arguments has so far had an important consequence: some things are difficult to argue for in a universal vocabulary, and therefore run a small chance of surviving purification. More specifically, we saw that arguments are likely to be kicked out: there will always be someone who argues that those are unrealistic and even irrational concerns, or at least not more than personal concerns. As a consequence, those less-tangible concerns and less-universal moral values become less visible, and less prominent in mainstream normative discussions. Then they obviously cannot lead to conclusions - regardless of how true or false those arguments actually are. Thus, the objection should not come as a surprise that conclusions are drawn on only partial evidence. Indeed, some complain that fundamental objections are this way easily overlooked (see also Kass: I997/1998). And the other way round, it should not come as a surprise that some of the writers focusing on present and real arguments conclude that no fundamental objections against cloning exist (see also Brock: I998).

We might conclude from this, that we had better abolish purification and listen to all arguments, if it makes so many important things unspeakable. However, it is not difficult to see that we do need such a purification: by avoiding discussion over values that are likely to raise controversy, we can exactly avoid getting bogged down into talking about things that are hard to reach agreement on. Skipping over this grants that generally many different people will be able to join the discussion 


\section{Politics by All Means}

and subscribe to its outcomes: it provides a way to deal with a pluralism of many different life styles, because it evades talking about subjects that separate people. This is a central aim in the modern world: to achieve a society in which as many as possible different - yet reasonable - ideas of the good life can coexist peacefully. ${ }^{3}$ Between such different ideas, agreement is most easily obtained concerning issues that are somehow obvious for all. This is the core of political liberalism: to make collective decisions in a way that is acceptable to all. The clear arguments discussed in this section do a good job at that. In contemporary debate, liberal way purification is dominant, and appears as a de-facto privatization of some branches of ethics. This particularly concerns our ideas of the good life. However, its downside is that it produces a situation in which adherents of different life styles remain divided over exactly those difficult and unanswered questions - which may surface at times.

This mechanism is exactly the object of some critique - Leon Kass being its first spokesman. Indeed, the move by Kass is a remarkable one: to voice important arguments that we are supposed to leave in silence is one thing. But in addition, he explicitly justifies that those arguments are inevitable and should be heard, and are silenced unjustly. His explicit effort to address certain arguments confirms that those arguments would not earn proper attention otherwise. Apparently, just articulating the objections Kass has, is not enough. The very idea that these objections should be heard and that it would be a mistake to silence them needs to be articulated. Thus, Kass's argument is not just a contribution to the discussion about cloning, but also a critique of the nature of that discussion itself.

To Kass's discomfort, those branches of ethics are banished from public speech because we tend to disagree about them. Nevertheless, in Dolly's debate, such arguments appeared in public all the time - not only expressed by Kass, but also by a host of both related and opposing authors. Apparently, discussants felt the need to put forward ethical opinions that are usually kept private, because they felt that otherwise the debate would be too shallow for such an important issue. The discussants felt that in this case discussing the issues in-depth was more important than a consensus, if it would be only a consensus for its own sake. Kass starts The Wisdom of Repugnance from the observation that most present-day ethics have a rather limited vocabulary. It basically argues in terms of consequences, assessing them against the background of a limited number of values: freedom, autonomy,

3 Terms such as rational, irrational and emotional are used naively here. In chapter 2 a more refined use of them will be developed. 
the right to being safeguarded from harm. These are exactly the kind of arguments that we earlier saw as pertinent to the public debate. However, Kass argues that such a superficial approach cannot be expected to successfully solve the problems we face; for these broad, blunt terms render so many important things unarguable or even invisible. They 'ignore the deeper anthropological, social and, indeed, ontological meanings of bringing forth new life' (see Kass: I997/I998, p. 23).

Moreover, Kass observes that this limited vocabulary is a historical construct. He explains how these arguments have come to be regarded as emotional during the last centuries - for they have not always been so. Only a few decades ago, abortion was generally disapproved of, and this position was publicly speakable as well as enacted in public morality. Today however, disapproval of abortion is rather difficult to argue for in public - which is not to say that one may not a live a life disapproving of abortus and refusing to undergo it. One may hold the opinion privately, but in public, the idea is likely to be discredited indeed as 'backward private beliefs'. Kass (I997/1998, p. 7) complains that such opinions cannot convincingly be argued to belong to public policy making, even though this was much different only a few decades ago. Kass argues that the impossibility to express certain opinions in public speech is not a pre-given categorization, but rather something that has come into existence over the course of our enacted history. We tend to think of the classes of speakable and unspeakable things as fixed, a priori categories, which in fact they are not. 4

Kass (I997/1998, p. 22) and Swierstra (2000, pp. I22-124) share the observation that much of the discomfort experienced by discussants results from the barriers erected by the rules of public speech. In case arguments do not survive purification, they run a chance of being discarded as irrational or emotional. Either emotional or irrational, they lack decisive power in public debate. However, Kass argues that some things we disregard as merely emotional are not so at closer look. In support of their rehabilitation as publicly relevant, he provides two major lines of argument. The first line is to explicate the possible backgrounds of the emotions themselves. At closer look, their nature is more sophisticated than mere preference or taste. In the second line of argument, Kass questions the cultural habit of thinking of this class of arguments as irrational or emotional, which according to him is not universal, but historically local and shaped only over the course of the last few centuries. Some of what are now seen as private and personal

4 A similar point is made by Fukuyama (2002, p. IOI). 


\section{Politics by All Means}

considerations, once belonged to the realm of public and rational issues - and the change, says Kass, may not always have been for the better (see Kass: 1997/I998, p. $7-8)$.

There is more to say about how some arguments are accepted while others are not, beyond what I have already discussed. In general, politics and debates in public media are demanded to be rational debates. In modern Western societies, these rules have become widespread, and therefore largely accepted and implicit. Indeed, we experience a discomfort when we feel the need of publicly bringing forward arguments with an emotional ring, even when we see those arguments as inevitable. Instead, it is customary for us to stage our positions in terms of harms and assets and in terms of costs and benefits. As such terms are expected to be clear and rationally acceptable to all, they can be hoped to produce conclusive arguments - that is, much more conclusive than the ones appealing to humanness, the meaning of life, dignity or the intrinsic value of parental relations, and so on. We may still express such (allegedly) emotional arguments, but they will in general be seen as a private opinions.

In conclusion, it is remarkable that the shallowness that Kass discerns in the debate, is exactly what liberals have adopted as the solution to dealing with a pluralism of ideas of the good. For the latter, the avoidance of ideas of the good is a necessary measure in pursuit of a peaceful and stable society. They believe that such a society will enable persons to live a good life nonetheless, exactly because they believe this society grants the freedom necessary for that. The former however see in this avoidance the decay of morality at large. A society that fails to address the moral issues at depth, will ultimately fail to educate its citizens as moral beings. These are two hypothetical positions, however they will actually prove accurate poles between which the positions range that will be staged in this study.

\subsection{Technology as destabilizing morality}

Apparently, discussants sometimes feel the need to question the rules of discussion. The rules of discussion are typically something that we take for granted, that we are not aware of, and that remains implicit most of the time. They are routine. That is, until some change disturbs the normal operation of those routines. In such cases, friction emerges and we cannot take the routines for 
granted any longer, because our different opinions on private branches of ethics become publicly relevant. We will shift to a different mode of discussion, which results in a continuous effort of moving arguments in and out of the discussion. As we are likely to have different interests in getting arguments in and out, tension is likely to occur. This tension provides the starting point for this book.

It will be developed against the background of another observation from the Dolly case: that it is an example of progress in science and technology that brings this tension to a head and brings routines to a halt. We saw at the very beginning that Dolly would not let herself be discussed merely in terms of pros and cons, in terms of costs and benefits: the typical classes of arguments that liberal routines accept. Why is it exactly in the case of Dolly, that the gut feelings voiced by Kass don't let themselves be purified out of the discussion? Why is it in this case that Kass argues that the label 'gut feeling' requires reconsideration? And why do seemingly decisive arguments like the envisioned physical harm, which can be expected to enjoy broad support in democratic decision making, not suffice to conclude and silence this particular discussion? How is it, that different styles of reasoning seem to be incompatible, resulting in separate monologues rather than in a fruitful dialogue - thus not getting any closer to a consensus on this difficult matter?

A first answer has in fact already been given implicitly: Dolly forces us to rethink what we mean by harm, and similarly to rethink what we think dignity to be and how it can be compromised by cloning. While we do agree that harm is something to be discussed publicly, we do have fairly different answers to the question what harm is. As we will see later in chapter 2, such situations nearly always force us to use our more contemplative considerations in order to argue and explain how we see harm in this particular, unprecedented case. These contemplative considerations are often felt to be private. Put simply, harm is something different before and after Dolly. I will argue moreover in chapter 3 that there are some essentials in our technological culture that make that technological change will always force us to revise our language and meanings, and therefore is highly likely to spark controversies in which ideas of the good figure.

In addition, such a revision seems to have a prolific effect: if we are forced to rediscuss harm, this forces in its wake a reassessment of ideas of dignity; a reassessment of how dignity is actually harmed by cloning; a trial of whether this new idea of dignity can withstand purification; a rediscussion of the question of 


\section{Politics by All Means}

which arguments are public and which are private; a discussion of whether we should allow such a development to change our moral intuitions; a rediscussion of, given all these rediscussions, the question of whether to clone or not to clone can be a private question - and so on. Essential to this proliferation is that the more complex the problems grow, the more likely we are to be necessitated to draw on ideas of the good - indeed, our private ideas.

Kass recognizes that the alleged violations of moral wisdoms are often the result of technological progress: '[The world's] once-given natural boundaries are blurred by technological change and [its] moral boundaries are seemingly up for grabs' (see Kass: 1997/1998, p. 7). This forces society to invent new ways of living lives and to give new meanings to those lives, thus in effect to revise existing moralities. Apparently, neither technology nor morality consist of fixed and unequivocal elements, but rather of continually changing notions. Kass (I997/1998, p. I8) recognizes that many examples of revulsion in the past are calmly accepted today: 'Twenty-five years ago, abortion was still largely illegal and thought to be immoral, the sexual revolution (made possible by the extramarital use of the pill) was still in its infancy, and few had yet heard about the reproductive rights of single women, homosexual men and lesbians. [...] Today, one must even apologize for voicing opinions that twenty-five years ago were nearly universally regarded as the core of our culture's wisdom on these matters.' (see Kass: I997/1998, p. 7) Progress in science and technology apparently allows us to deal differently with things than we did in de past, also in a moral sense. In some cases, this provides moral progress - but Kass argues that by far it does not do so in all cases. Therefore, thus Kass argues, it would be too easy to say that moral stances that are critical of new developments are hopelessly old-fashioned and in need of updating. Instead, they may have a point worth listening to. ${ }^{5}$

This book will explore this intricate relation between scientific, technological and sociopolitical change. In particular, it will be articulated how technology plays a role in the purification of arguments. It does so mainly by imposing new meanings to concepts, in such a way that the moral import of technologies themselves remains largely invisible. Indeed, science and technology seem to fight on the side of liberalism and against the position defended by Kass. However,

5 Midgley (2000) makes a similar point, be it less elaborately. She argues that it is wrong to simply adjust morality imprudently to the ongoing pace of science and technology. Thus, she argues against the habituation argument (see Swierstra and Rip: 2007, p. I0), that holds that people will be willing to revise their morals once they get used to the new technology. 
at the same time, talking about science and technology forces us to draw on our private ideas of the good, even when talking in public. How this is so, will take quite a few pages to explain.

\subsection{Problem definition}

We saw an example of progress in science and technology that thwarts the project of purifying the arguments in public discourse. We observed that this purification is inherently connected with the liberal solution to the question of how to deal with a pluralism of ideas of the good life. This triad of technology, the good life and liberal pluralism will be the object matter of this book. The relation between them is condensed in the following three theses. First; considerations of the good life are private. That is the best way for public speech to avoid getting bogged down in its difficult matter. This is to say that it is not a matter of public discourse. Its arguments do not survive purification, and its decisions are not a matter of public concern. Second; technologies, especially life-science technologies, possibly produce impacts on the good life. And third; given the omnipresence of technologies, the second thesis produces a need to discuss the technological influence on the good life politically, that is in public, which is in contradiction with the first thesis. This altogether informs the following question, the central theme of this book:

How is it that the typical liberal way of dealing with a multitude of ideas of the good life, that is by dividing moral questions into public and private ones, becomes problematic in the face of progress in science and technology?

The aim of this book is to contribute a proper account of technology to political philosophy. This account will do justice to the inevitable interaction between technology, our ideas of the good, and our ability to deal with a pluralism of those ideas. It will explicate how technology challenges the distinction between public and private affairs, and how it challenges the vocabulary in which such problems are discussed. Thus, it will articulate how technology challenges liberalism at large. 


\section{Politics by All Means}




\section{Outline}

The narrative of this book will develop as follows. In part II, a vision will be developed on how we tend to do politics in our contemporary, technological culture. In particular, a conception will be presented of politics-as-purification and explain its dominant mode, political liberalism. In chapter 2 this will be done by developing a conception of politics in which the purification will be explained further. The chapter concludes with the typically liberal solution of privatizing questions of the good and restricting public talk to clear and reasonable terms. In chapter 3, this modern culture will be explored along the lines of its technological constitution. The chapter will offer a vision of technology that provides a handle for understanding how technology interferes with our political activities and especially with its purification.

In part III, three practices will be explored. Each of them will provide a particular nexus between science, technology and society, in which politics stands for the difficult task of finding answers to the problems posed by technological change. In chapter 4 , the somewhat futuristic theme of human enhancement will be discussed. Part of the debate on enhancement coincides with the cloning debate, but as it explicitly entails a revision of the concept of human nature, all that is interesting in purification comes to the fore there. Then, in chapter 5 , biobanks will be the object of investigation. Biobanks are large collections of biological material and information. In their regulation, they require some interesting revisions of concepts that we take for granted in politics. And finally, in chapter 6 an example of a real political debate will be explored: a controversy on preimplantation genetic diagnostics that flared up in the Netherlands, Spring 2008. This chapter will most of all show that the conception of politics as purification is not just a hypothetical reconstruction of an abstract debate, but that actual politics really turns into a dirty fight if technological progress urges politics to answer unprecedented questions.

Finally, in part IV the ideas of this book will be wrapped up. Chapter 7 will recapitulate how technology and politics are intimately intertwined, and how this relationship produces complex forms of debate. Moreover, it will give some strategic suggestions that should prevent us from being unpleasantly surprised by the radical debate that seems typical in the wake of technological progress. 


\section{Politics by All Means}

This book has been written within a program focussing on societal aspects of genomics research, the Societal Component of Genomics Research (MCG) of the Netherlands Organisation for Scientific Research (NWO). This is the main reason why the chapters in part III concern issues that are somehow related to genomics. On the one hand however, the theory as developed in part II is not strictly limited to genomic technologies. It offers in fact a more general picture of our technological modern culture. On the other hand, the theory cannot deny this background, and it must be open to the idea that different technologies would have required a slightly - indeed not radically - different theory. That genomic technologies are however a good starting point for this kind of theorizing is however granted by the fact that human technologies are clearly likely to spark controversies. 


\section{A liberal, technological culture}





\section{Politics as purification}

\subsection{An unstable pluralism}

Chapter I was concluded by two important observations. The first was that our society hosts a variety of irreconcilable opinions. Part of the solution to dealing with this variety is a privatization of ideas of the good. However, the fact that some parts of our normativity are private, leaves unaffected that people will often find those ideas important. Hence, silencing those ideas may sometimes be hard to accept. Making political decisions in a pluralist situation may therefore give rise to instability: at times, debate cannot escape issues that are otherwise private, and can no longer restrict itself to a neat exchange of pros and cons and terms that are acceptable to all. This inclusion of ideas of the good in the debate in its turn requires discussing which arguments are appropriate and which are not. This appropriateness of arguments is continually assessed and challenged, particularly if important changes force people to make reference to ideas that are not unanimously considered appropriate in the debate.

The second observation was that these changes appear as a result of progress in science and technology. In chapter I, this concerned the successful application of cloning technology to a higher animal. In part III, I will articulate the same phenomenon in other instances of technological change. In the case of Dolly, a first reason why these difficulties emerge was found in the recognition that cloning technologies open up new possible forms of harm. Or perhaps, opening up new forms of harm urges us to rediscuss what harm is, and this likely incurs reference to private ideas. As harm is an important reason for arguments to be appropriate in the debate, it is logical that changes in the idea of harm emanate on the appropriateness of those arguments.

In this chapter, I will articulate the principal questions that need to be answered when settling issues, including the appropriateness of arguments. I will develop problematization towards a conception of politics as purification: arguments are moved in and out of the debate, and it is not that obvious which arguments make it and which do not. The term purification is clearly inspired by the work of Bruno Latour, and the parallels to his work on modernity will become clear in due 


\section{Politics by All Means}

course. Moreover, I will pay particular attention to the liberal form of purification that is dominant in today's politics. For this liberal form, I will take the ideas of John Rawls as exemplary. And finally I will argue how this political structure of purification and the particular liberal implementation of it, is bound to remain imperfect. The next chapter will then describe how technological elements of our culture typically raise issues that complicate the problems that liberal purification is already facing.

This chapter will proceed as follows. In section 2.2, I will argue that we live in a pluralist society, and in addition I will argue why this pluralism is necessary and desirable. In section 2.3, I will provide a more elaborate outlook on some of the issues that such a pluralist society will have to deal with. In particular, I will pay attention to the solution that our history has produced to the difficulties of this pluralist society. Briefly, this solution has the form of a private and a public sphere, each being domains of ethics on their own. This is the typical liberal structure. And finally, in section 2.4, I will argue that liberalism remains intrinsically unstable, which is directly owed to the mechanism of purification. This will provide the onset to the next chapter, which will further elaborate on this instability by taking account of the technological character of contemporary culture.

\subsection{A pluralism of ideas of the good}

\subsubsection{The empirical datum of pluralism}

On September 24, 2007, Princess Máxima of the Netherlands ${ }^{\mathrm{I}}$ was invited to give an address on the occasion of the presentation of a report on engagement with the Dutch nationality. Her most remarkable observation, indeed reaching the front pages of several newspapers, was that there is no such thing as the Dutch identity. Dutch culture is essentially a heterogeneous set of values and symbols of which people appreciate different highlights in different situations. Moreover, to think of it as separate subgroups, each with their own homogeneous subculture, would be to mistake the Netherlands for a zoo - where indeed species are separated into their own cages. Instead, people are connected to various other people by the goals they share. A person may champion different goals in different situations, thus being member of a number of different groups (see Máxima: 2007).

1 Princess Máxima is married to the Crown Prince of the Netherlands, His Royal Highness Prince Willem-Alexander. Máxima is Argentinean by birth. 
A similar argument can be developed for any modern Western culture - as Máxima indeed did confirm for her own Argentinean background. Modern states are populated with many different individuals, all having different identities. These identities are linked to ethnic origin and descent, to religion, to different styles of life, to different political preferences, to sexual preferences, and sometimes even to adherence to specific soccer clubs. While some of these identities seem radically incompatible - take for example an orthodox Christian identity and an overtly homosexual one - it is remarkable that hard collisions between them are incidental rather than structural.

Apparently, the goals that at least a vast majority if not all of the members of this society share, must include the maintenance of a society which allows its citizens to live their own life peacefully, and respecting others as they wish to be respected themselves. Among the most important values to be respected is our freedom and the recognition of our ability to frame our own conception of the good. While it can be argued that Máxima has overlooked at least this essential part of the Dutch identity, it is also fair to say that it is a rather implicit part of that identity. It is usually taken for granted, and we are aware of it only in cases of failure. One typical case of such a failure was presented by the case of Dolly: discussants had different ideas of what this 'living peacefully together' must look like. That was what urged the discussion in terms that turned out to be problematic. Privatizing ideas of the good was no longer satisfactory.

One important element can already be extracted from what I have said so far. I will call it the condition of tolerance. One can adopt the stance that others may think differently, and that there is no reason to deny them the right to do so. However, one can only do so to the extent that one is convinced that the others' ways of doing are not inherently bad. I can accept that my neighbor dedicates her life to watching soccer games; I cannot accept that she educates her little boy to be a professional burglar. The first is not inherently bad while the latter is - at least to my eyes, of course. The condition of tolerance then states that intrinsic wrongs need not be tolerated. Or conversely, for something to be tolerated, it at least needs to be not intrinsically bad. This condition of tolerance is not a proper political-philosophical account, as the notion of 'intrinsically wrong' probably raises more questions than it answers. The condition of tolerance will however prove an important device in my empirical observations later, when people show discomfort with the idea of just leaving others be and doing what they think is right. 


\subsubsection{Pluralism as desirable}

In addition to its empirical existence, it can be argued that pluralism is desirable. In his essay On Liberty (see Mill: I859/I99I, p. 54), John Stuart Mill establishes a number of reasons why we should favor a variety of opinions to exist. First, it is simply unwise to silence a dissenting minority. To begin with, there is always the possibility that the minority is right and the majority is wrong. Moreover, even if the minority were wrong, the majority may need it as an intellectual 'sparring partner' to prevent itself from growing narrow-minded. Moral wisdom becomes empty, if we do not continually confront it with other opinions, for neither the ruling opinion nor the dissenting one can be assumed to contain the full truth.

Second, more narrowly related to politics and public debate, a variety of positions is needed to provide to the electorate a sufficiently broad range of options to choose from (see Mill: I859/I991, p. 53). ${ }^{2}$ After all, any good decision is most likely to be some balance between extremes: between progress and reactionism, between thriftiness and squandermania, and between keen competition and a level playing field. Fostering pluralism is a means to grant that a wide range of options is maintained. Only then will citizens and their aggregate be able to make good choices.

Finally, only if a sufficiently broad variety exists, will people see themselves as really free to guide their own lives and make their own choices. In a society housing dozens of religious faiths, humanism, agnosticism and atheism, rather than one accommodating just Roman Catholicism and Protestantism, people can make choices that are really choices. Only if a pluralism is sufficiently broad and varied will it be able to withstand the danger of becoming polarized or segregated. Thus, for pluralism to exist over a longer period of time in the first place, it is necessary that it actively fosters a broad range of visions or at least grants their existence. Otherwise, a small number of visions or even just one of them may become dominant, which would in effect be the end of pluralism.

2 Mill frames this as the need for both a progressive and a conservative party. However, for the argument of this book, there is no conclusive reason to stick to this rather specific implementation of the general idea. The most important characteristic omitted this way is that limiting our choices to two (or any small number) of parties allows (or even forces) the constituency to choose between 'package deals'. This might be preferable when politics is too complex to expect the citizen to have an opinion on every single issue; at the same time, it carries a certain paternalism, since it presumes that the citizen is not capable of such an opinion and needs helping by simplifying the choices. Yet the tenet remains that only a diversity of opinions allows a fair chance to all sides of the truth. 


\subsubsection{The burdens of judgment and private ethics}

The account so far took pluralism more or less at face value. Both normatively and empirically recognizing the need for a pluralism of ideas of the good organically raises the question of how to establish or warrant such a pluralism, what should belong to it and why. Apparently, there are issues on which we can (or must) be relativistic. But clearly, there are also issues on which we cannot: full relativism would lead to moral emptiness, anarchy, or self-defeat. To draw the line, starting from the hypothetical opposite will be clarifying. Arguing in favor of a unified and perfect way of life, we need to ask at least two questions. First, if such a perfect way were to be devised, we would need to articulate what it should be like. And second, if a perfect way of life were devised, we would still need to justify why it can be coerced onto people if they do not adopt it by themselves. After all, it is not straightforward that there is no such thing as the right to make oneself unhappy, or to just live an imperfect life, for that matter. There is a priority relation between these two questions: if the first question cannot be convincingly answered, there is no point in wasting time on the second. Indeed, we need not go far here: the impossibility of answering the first question, is exactly what follows from what John Rawls has articulated as the burdens of judgment (see Rawls: I993, pp. 54-56).

These burdens of judgment can be summarized as follows. If we recognize in ourselves the capacity and moral powers to rationally frame an idea of the good, we have ample reason to believe others possess similar powers. However, possessing the same moral and intellectual powers does not guarantee that we will always come to the same conclusions. This particularly holds for questions concerning the good life. Since an idea of the good life is essentially a diffuse, comprehensive, far-reaching, complex normative account, it is unlikely that people will agree on all issues that matter. In addition, the social world in which we have to practice our ideas of the good life, is so complex that it is impossible to take into account all values and relevant issues. Even in fairly similar situations, different persons may differently prioritize between consequences, principles and values. This is complicated by the fact that the number of relevant moral and even factual presuppositions is considerable, which makes it impossible for all of them to be explicit. Thus, any talk is necessarily incomplete. This will also hold for good-life judgments. Moreover, even if people agree about the presuppositions, they may still evaluate them differently and arrive at a different balance between values. These values may mean different things to each of us, anyway. Finding 


\section{Politics by All Means}

our way through this host of considerations is largely dependent on our personal background, how we were raised and educated. This eliminates any hope on a unified idea of the good.

Thus, these burdens of judgment explain that even similar situations may lead us to different moral judgments. However, it is important to note that these burdens no not disqualify the rational capacities of the persons involved, nor does a disagreement resulting from them. Rather, they signify the contingent difficulties that rationality is embedded in, thus allowing for many different yet rational conclusions to obtain in different situations. ${ }^{3}$ This implies that it will generally be difficult to decide between different yet rational positions. After all, if a convincing criterion were available to decide between them, this would in fact be an overarching and better rationality. Nevertheless, the same complexity that produces the burdens of judgment, is also an entry point for prejudice, bias, self and group interests, blindness and willfulness. These sources of disagreement are not to be defended under the guise of the burdens of judgment. What counts, says Rawls (I993, p. 58), is that 'many of our most important judgments are made under conditions where it is not to be expected that conscientious persons with full powers of reason, even after free discussion, will all arrive at the same conclusion. [...] These burdens of judgment are of first significance for a democratic idea of toleration.'

The differences at the basis of these burdens thus justify a tolerant pluralism. To identify the 'stuff' of the pluralism, concepts like the good life, conception of the good, comprehensive doctrine, religion, world view and private ethics will be used in very similar ways and often indeed interchangeably. I will briefly explicate them, here. A notion underlying the following definitions is that of normativity. In the broadest sense, I understand normativity as any expression of how the world should be, indeed anything with an 'ought' character as opposed to an 'is'. Typical examples of normativity are laws, etiquette, the Ten Commandments, but also a bit more far-fetched - the fact that a typical piano today is to be tuned at a' $=442$ $\mathrm{Hz}$ in an even temperament. An important body of normativity is the idea of a comprehensive doctrine. In line with John Rawls (I993, p. I3), I see a comprehensive doctrine as the complete set of normative positions that a person has. Such a broad definition is in itself not of much use, but the following refinements build upon it and they are useful. 
A first subset of these are the normative positions that we think are so important and clear that they should hold for all people. This importance may be related to the fact that the positions concern the fundamentals of our existence: those things that we need at least to respect ourselves and see ourselves respected by others as human beings. Both the universalizing stance and the concern with fundamental matters are also widely recognized as essentials to moral stances. (Ralws, i993, p. I3, calls positions that we think are eligible for universalization general positions, but for my argument this is not too important: it makes little sense to think of claims that are general and not at the same time moral, and then I think the word 'moral' does more justice to the weight we attach to it.)

A second subset of our comprehensive doctrine are those claims that we do not think of as eligible for universalization. Matters of taste are exemplary for this class. However, the lack of universal power does not say that they are unimportant to us individually. We may highly value teaching our children habits like good table manners, and appreciations for certain forms of culture, without thinking that this should be the same for all people. And similarly, some of us would find a life without sports not worth living, while they are also open to the idea that many people feel differently. As such values are important to us, I group them together as our idea of the good life or a conception of the good. Thus, briefly, our comprehensive doctrine is the sum of our moral positions and our conception of the good. That the boundary between our morality and the conception of the good is not a priori fixed, is essential to the difficulties discussed in this book.

Third, a world view is the set of answers to the question of what the world is like. Thus, a world view is primarily an ontological concept, and indeed not a normative one. However, its normative weight should not be underestimated, as persons strongly build on their ideas of what the world is like, when they seek answers to questions of what the world should be like. For example, whether abortion of the early embryo is morally permitted, strongly depends upon what one believes this embryo to be: a premature yet full human being, or just a small lump of cells. ${ }^{4}$ Clearly, the normative consequences of our world view are likely to end up as part of our comprehensive doctrine, either in the moral or the good-life subsection.

A fourth category is religion. I call something a religion if it gives a metaphysical, transcendental account of the world. Religions typically prescribe an ideal of the good life, they offer an account or explanation of what the world is like, and they

4 This is not to justify is-ought fallacies, but just to emphasize that normative accounts are meaningless without accompanying ontological accounts. 


\section{Politics by All Means}

prescribe a certain morality. Thus, if one adheres to a religion, this is likely to coincide largely with one's comprehensive doctrine. However, while everybody has a world view, an idea of the good and a comprehensive doctrine, not everybody needs to have a religion.

So far, I have only discerned between normative claims that we think are eligible for universalization and claims that we think are not. However, whether we think of moral claims as being eligible for universalization, does not really say anything as to whether they also have the political power or justification to be so. Think again of two possible positions towards the fetus and the embryo, and as a consequence of that position, how one relates to abortion. Many different opinions exist on this point, and we may assume that most people think their opinion is the right one and should be adopted by all. Some believe that the unborn child is a full human being and that therefore abortion is murder. Others believe that a fetus or an embryo is not as yet a full human being, or even just a lump of cells, and therefore abortion can be justified under specific circumstances. Against the former background, it is highly unlikely that somebody will say: 'for me, this is murder, but it is just fine if you happen to see it as just another medical intervention.' Rather, if it is murder, it should be forbidden, and we cannot be relativistic on that; indeed, these are moral positions. And this is not purely owing to the pro-life fundamentalism that one may discern behind the first position. The other way round, the story would be the same. If one thinks that abortion is just another medical intervention, he or she cannot accept that others call it murder. This is a moral position just as much. Moreover, they are different moral positions - despite the fact that moral positions typically claim universal validity.

Thus, there is a fifth category to be introduced here, namely the notion of private ethics. Despite the fact that moral claims have a universal pretention, some of them are for whatever reason not universalized. That is to say, their universalization empirically lacks acceptance. The burdens of judgment give an explanation for that. In solution of the dilemma on abortion, Dutch law has been arranged such that the mother is free to take this moral decision - despite the fact that some may nevertheless see it as murder. Indeed, it is constructed to be a private-ethical decision. In many other countries, the law is different and prohibits abortion. In those countries, abortion is not a private decision, let alone a private-ethical decision. This shows that whether something is private-ethical or public-ethical, is a contingent distinction. This fifth category gives rise to a sixth one, its complement 
of public ethics, but that one is obviously co-defined by private ethics and needs no separate discussion.

Intuitively, we could raise some explanations for parts of ethics to be seen as private. First, we ourselves may think of a position as being insufficiently important to generalize it to all, like matters of good taste. Second, one may lack justification for generalizing the claim, no matter how important one thinks it is - indeed like the value of life coinciding with sports. Or third, others may reject our claim because they think it is none of our business. We might think they are wrong, but that alone does not always convince. And fourth, others may reject our claims because they think we are plain wrong on the level of the claim itself. This would be the case if somebody argued that a life dedicated to sports is a wasted life while we believed that this was the only way to live a valued life. (In fact the second and third answer only differ on the question with whom the judgment of universality is located, but the effect is much the same.) These four reasons for seeing ethics as private are not intended to give a conclusive answer here. What matters for my argument is that there is a category of issues that are private, and that the reasons for something to be private can be manifold. Moreover, the fact that just from scratch we find four reasons why some parts of ethics would not be universal, signifies that there is plenty of room for disagreement.

This last concept, of private ethics, has a particular relation to the earlier concepts. Private ethics is that part of the comprehensive doctrine that will generally not convince in public. This has some resemblance with the conception of the good that I explained above, but it is not the same. The judgment of universalization is located differently: this time it is with the wider public, whereas in the conception of the good it was inherent to the conception itself and the person holding the conception. Thus, elements of a comprehensive doctrine seem to be eligible for public use, insofar as they are not regarded as private ethics by the broader audience. This does however not necessarily coincide with how we ourselves regard the claims. Private ethics is not always the same as the conception of the good. This may produce friction, and I will indeed retake this later when discussing the issue of justification in politics.

\subsubsection{Autonomy as a private sphere}

I have just explained how the burdens of judgment provided reasons to be tolerant with respect to certain claims. In particular, I developed how these burdens give 


\section{Politics by All Means}

rise to recognizing a realm of private ethics. In more general terms, we saw that modern society must recognize that individuals are entitled to a certain amount of autonomy. Indeed, at the basis of virtually all strands of liberalism and also most other flavors of political philosophy is an appreciation of this capacity of the human individual to 'rule oneself. The idea of autonomy thus comes in both an empirical and a normative flavor: the recognition that the human person is able to rule his or her own deeds in a reflexive way, and the recognition that the human person is therefore entitled to a freedom to do so. I will now develop a bit further how this autonomy may be shaped.

Today's typical implementation of autonomy has the form of a private sphere. I have already discussed that there is a realm of ethics that society leaves us to harbor our own decisions and justifications: the realm of private ethics. A tentative list of decisions that are today seen as typically private is not difficult to devise: religion, sexual preference, development of personhood and identity, choices of profession, education - of course within some limits set by educational laws - and leisure, aesthetical preferences, ways of family building, and a whole lot more. And for these decisions, one may largely choose a justification as one desires: religious sources, taste, traditions, habits, etc. In contrast, a tentative list of issues belonging to the opposing public sphere is not difficult to find either: tax rates, which side of the road to drive on, how much to spend on the military and on public health services, and for example the fact that murder, theft and kidnapping are illegal and deserve legal punishment. This complementary sphere also has its specific sources of justification: laws, ideas of justice, ideas of citizenship, and ideas of the limits of agency of the state. I understand the public and private sphere as both decision spaces and sources of justification, the meaning of which will become clear in section 2.3.

Just to clarify, this conception of the private sphere does, perhaps somewhat counter-intuitively, not coincide with the (nuclear) family or the locus of the private house. The difference between the two shows from examples such as child molestation and marital rape. These phenomena typically occur within the family and the private house. Yet today, most of us would not accept them as strictly private affairs or personal choices - recall the condition of tolerance here. Indeed, we believe that they are wrong and that the state has an obligation to prevent them. We do think that they need judicial sanctioning. Thus, something typically linked to the private house can be a public issue. Of course, the physical space of the 
private house or family and the private moral decision space do partly coincide. Moreover, they do facilitate one another's existence to some extent. Yet, they are not always the same.

It is important to note here, that the private sphere has two origins: it is empirically there, and it is normatively legitimated from the recognition of human autonomy. It is however not established a priori that these two reasons coincide. Indeed, the private sphere is a constructed phenomenon and contingent at that. The tradition of political liberalism has taken up the challenge of settling this intricate balance in a satisfying way, to be elaborated further in the next section

\subsection{The liberal problem: between public and private}

\subsubsection{The need for politics}

The previous section has developed a brief outlook on a pluralism of ideas of the good. We differ on those ideas, and therefore, keeping the burdens of judgment to the back of our minds, we should simply grant one another a large freedom to pursue our own ideals. Thus, accepting pluralism is a first solution to the empirically existing difficulty of a pluralism of ideas of the good. However, acceptance of such a moral pluralism is not just indifference towards any choice that others make. I already argued that this must at least satisfy the condition of tolerance, see also page 29. But in addition, we must be open to the idea that in our actions, we may - either intentionally or unintentionally - interfere with the lives of others, as well as they may with ours. Any freedom must thus be a freedom within limits, and there are some things that undeniably need settling at the societal level. In other words, as we live together in one society, we need politics.

In addition, we have also seen that the distinction between public and private has in fact two directions: there are issues that we may decide upon individually or collectively, and there are normative positions that we may or may not argue from in public. These are the dimensions of decision space and source of justification, respectively. And we have seen that on both of these dimensions, the distinction between the respective classes of public and private is likely to be subject to disagreement. This tension is the starting point of this section.

In this section, I will develop a methodological device that helps us articulate how politics proceeds, and where it is likely to run aground. In particular, it will develop three levels on which the disagreement can occur. The vocabulary I will 


\section{Politics by All Means}

develop here builds indeed on three questions. For every issue, politics should offer an answer to each of them. First, politics needs to answer whether the issue requires political decision, or rather that we should conclude that it is irrelevant or perhaps impossible for politics to discuss. Second, if politics decides that the matter needs political discussion, how will this discussion proceed? How do we draw conclusions, and what arguments can we adduce in support of them? And third, if we agree that we should make a decision collectively and how we are going to make it, what will then indeed be the conclusion? Each of these questions will be developed further here, together with some of the answers that political philosophy has given to them in general.

Much of what I will discuss now will be related to the tradition of political liberalism. It is largely associated with the work of John Rawls. It is dedicated to the question of 'how [it is] possible that there may exist over time a stable and just society of free and equal citizens profoundly divided by reasonable though incompatible religious, philosophical, and moral doctrines' (see Rawls: I993, p. xxvii). Political liberalism aims at producing a democratic regime that holds on to a general conception of justice, in which as many as possible reasonable conceptions of the good can find their way. Political liberalism is not to be confused with the many strands in politics that go under the name of 'liberal' and which attach to the banner of liberalism specific ideologies. These may be concerned with individual freedom, minimal statism and minimal wealth redistribution by means of taxes. However, political liberalism sees these only as possible political solutions, not the necessary or only ones. Neither does political liberalism necessarily amount to a defence of free-market economies or of progress as opposed to conservatism, while again these do belong to the possible outcomes of a political-liberal debate. Political liberalism rather tries to provide a vehicle, neutral towards these specific outcomes, that facilitates the fair discussion and neutral justification of these alternatives. And one final remark: political liberalism is not how we really do politics. Rather, I take it as the ideal of doing politics that receives most aspiration today. It is our collective aspirational fiction.

\subsubsection{Scope}

The first question to be answered on a political issue is whether the issue is actually political. Politics can only work if it successfully discerns between publicly relevant issues and publicly irrelevant issues. That is: we must make sure that issues 
belong to the scope of politics. Politics is not the place where we discuss all our ethical matters, but where we discuss the ethical matters that we find important as citizens.

A first answer to this question of scope is firmly rooted in history: we are likely to agree that the state has a responsibility in the prevention of harm. This has become known as the harm principle..$^{5}$ As argued by John Stuart Mill (I859/I99I, p. I4), '[...] the sole end for which mankind are warranted, individually or collectively, in interfering with the liberty of action of any of their number, is self-protection'. The most plausible way to justify the coerced limitation of freedom is by claiming the prevention of something that is worse than the coercion itself, and for physical harm this sounds plausible. We saw this in the discussion on cloning. Given that current cloning technologies are far from reliable, it is highly likely that the clone would develop serious diseases if these technologies were applied to human beings. The wrongs done to the future individual are so evident that no sensible person will question a moratorium on human reproductive cloning.

At first sight, this harm principle seems to put a proper limit on political decision making: limiting the freedom of citizens can only be justified by preventing harm, and otherwise the state should leave people free in whatever they want to do. However, it is not easy to see how all the actions of present-day states are restricted to the mere prevention of harm. For example, whether or not the 'higher cultures' of opera and museums deserve financial support from the state is hard to frame as a harm or its prevention, or it must be the loss of cultural heritage that only a small part of the people holds so dear. And then, it is still a more plausible account of harm that tax payers are burdened beyond what they believe is reasonable. Similarly, how a state takes its responsibility in education is also ambiguously connected to harm: on the one hand there are again the tax payers whose money is spent, but on the other hand the children would be harmed if they do not receive education - which is an uncertain harm anyway, because we have reason to believe that many parents would take up the duty of education if the state did not. These examples are not sufficiently explained by harm as the only explanatory device. The examples do not involve a clear limitation of freedom, let alone the prevention of physical harm. However, as the state is the subject here, it

5 The principle goes by both the names harm principle and no-harm principle. I choose however to reserve the latter for one of the maxims guiding medical ethics: 'before anything else, do no harm'. 


\section{Politics by All Means}

is clearly a political question. Thus, Mill leaves open at least some issues. ${ }^{6}$

A second answer can be found in Political Liberalism by John Rawls (1993). Fair enough, Rawls takes a somewhat different question central to his work. Instead of everyday politics, Rawls discusses the more abstract topic of political liberalism. Its central challenge, with Rawls, is 'how to set up a just constitution for a state' rather than 'how to do everyday politics'. Nevertheless, we can learn from his account some basics of the scope of politics. He postulates (p. II) that political liberalism concerns the basic structure ${ }^{7}$ of society, which he in its turn defines as 'society's main political, social, and economic institutions, and how they fit together into one unified system of social cooperation from one generation to the next'. He understands an institution as 'a public system of rules which defines offices and positions with their rights and duties, powers and immunities and the like.' (see Rawls: I97I/ı999, p. 47)

For the argument of this book, it is wise to generalize this idea of institutions somewhat towards 'anything that exercises formal power with a legitimation embedded in society', and then the adjective 'formal' may even deserve omission. I thus take them to include laws, government and its offices, codes of conduct, systems and regulations of education and science, welfare systems, law-enforcing powers such as police and to some extent the military, and the rules of democratic representation and election to offices of power. And last but not least, in my line of argument science and technology are important institutions: those exercise power along intricate lines that will become clear in chapter 3. Essential to institutions is that they have an influence stronger and more far-reaching than any individual person could ever achieve. Therefore, they need specific restrictions that protect citizens from being treated unjustly. This provides a link to the earlier definition of the scope of politics by means of the harm principle: as treating citizens unjustly

6 It has in addition been argued that the harm principle is unable to prevent classes of wrongs that we all agree need prevention. For example, Ripstein (2006) has developed the example of harmless trespass: even if I do not inflict damage of any sort, it still deserves prevention that I intrude your house without your permission. Therefore, Ripstein suggests alternatively that restrictions on conduct should be justified by the protection of mutual independence of free persons from each other: the sovereignty principle. However, such alternative definitions seem unable to satisfy the need that Mill's principle leaves unanswered here.

7 Rawls actually defines this as the subject of a political conception of justice. For my reasonings it seems justified, to equate this with the subject of political liberalism, witness also his introductory sentence to A Theory of Justice (see Rawls: I97I/I999, p. 3): 'Justice is the first virtue of social institutions, as truth is of systems of thought.' 
will generally be recognized as harm, institutions belong to the proper scope of politics. They do so even in an intuitive sense, simply because they concern all citizens of a state.

However, like the first, also the second answer is only a minimal one. Both Mill's harm principle and the institutional view extended from Rawls specify what politics should at least be about, not what the boundaries are that it should not go beyond. In fact, Rawls allows the state to favor museums and higher culture, if such is decided by a democratic principle (see Swift: 200I, p. 157). Anything beyond the minimal conceptions of scope can thus be a matter of politics, provided that it is arrived at along some democratic principle. Indeed, regardless of any analytic definition of the outer bound of the object of politics, we see in practice that there is no limit to what people at least try to get addressed in political discourse, and that indeed the question of what belongs to politics is itself a topic of political debate. And then the minimal conceptions just devised prove insufficiently conclusive.

For example, in the controversy following some caricatures of the prophet Muhammad, late 2005, it was claimed that those cartoons were a grave insult and hence a form of harm towards the Islamic community. However, many non-Islamic discussants argued that this could not possibly be seen as a harm sufficient to justify a limitation of the freedom of speech - which in itself would be a worse harm (see Troost: 2006). In fact they have Mill on their side: speaking out deviant opinions cannot possibly be as harmful as the failure to permanently question received opinions (see Mill: I859/I99I, p. 40). Similar cases in point are the offence that orthodox Christians took to billboard advertisements starring sparsely-dressed women (see Van Zanten: 2007), and the loss of contentment people claim when modern electricity producing windmills contribute to 'horizon pollution' (see Trouw: 2006). While especially the last claim does indeed enjoy some success, all three of these examples are strongly contestable; yet at the same time, they force politics at least to answer the question of whether such issues are a matter for politics in the first place. (This shows a vulnerability that I observe again on page I24, that debates can be dominated by just anybody putting just anything onto the agenda.)

Another hard case shows that the boundaries are not easily fixed. Current issues of alcohol abuse among adolescents in the Netherlands are challenging the limits. It is generally agreed upon that alcohol abuse among minors is a serious problem in need of prevention. It is moreover a problem that occurs at 


\section{Politics by All Means}

the societal level and scale (see Pijlman, Krul and Niesink: 2003). For these two reasons, it seems to call for public attention and governmental policy. It is a public problem. At the same time however, most people are convinced that it is the parents' responsibility to take care that their children behave well. It is felt as an unjust intrusion of the private sphere, if the state were to exercise too much control on this point. This incites the charge of paternalism: the present Minister of Health Care, Ab Klink, is indeed sarcastically referred to as the Minister of Petty-Bourgeois Affairs, when he issues governmental policy to fight this problem (see Weel: 2008). This shows that the question of scope receives answers in different directions. The resulting deadlock stands in the way of a quick and easy decision on governmental measures against juvenile alcohol abuse.

The fact that scope is hard to articulate, is not to say that there is no idea of it. However, this idea is usually implicit, and often experienced as part of the cultural background in which politics is conducted. It is often a matter of tradition and history, which things are on the political agenda and which are not. And if things are hard to put on the agenda, it is hardly thinkable that any radical conclusion can be obtained. Thus, the fact that a society has a culture is in itself a reason for political decision making to be not too radically different from how things actually are, and neither can politics decide from scratch what it will put on the agenda and what will be left out. Thus, scope is part of the routines that I already mentioned in section I.3: we only become aware that scope is not obvious when it fails.

While the picture so far is somewhat question-begging - politics is simply about the things that politics happens to be about - it will prove accurate in part III where the boundaries of political decision making are themselves the objects of political debate. For now, it suffices to conclude that the scope of politics is not $a$ priori and fixed, but constructed, enacted and historically contingent. In addition, from now on I will take the claim that an issue is private to be the same as to say that it is not part of the scope of political decision making. Conversely, a thing is public if and only if it does belong to the scope of politics.

\subsubsection{Justification}

Once an issue is found to belong to the scope of public decision making, politics needs a way to proceed. The clearest solution is provided by the strict rules of democratic decisions, today usually defining a system of representative democracy, sometimes extended by systems of direct democracy, that after many thinkable 
forms of debate settles the discussion on a numerical basis. But politics is hardly ever just a matter of raising hands or counting costs and benefits. On the contrary, it is a permanent muddle of adducing arguments and disqualifying other arguments, considering package deals and even horse trading at times. Especially this disqualification of arguments has already been exposed in chapter I. Moreover, how convincing arguments will be, largely depends on the cultural background to which politics is conducted: appeals to papal dicta are less convincing in the secular Netherlands than they are in strongly Roman-Catholic Poland. Similar to the contingency that we saw in the scope of politics, it is hard to tell in advance which arguments or ways of arguing will be successful, and which will not. This is what I call the issue of justification: how do we draw political conclusions, and justify that they can be considered valid for all citizens? Or alternatively: what are the conditions that an argument or statement must meet to be accepted and taken seriously in public speech?

In this case too, some answers can be found in history. Like the matter of scope, the harm principle does have some implications for justification. It suggests that politics should at least be open to arguments that refer to harms, as those are likely to suffice in justifying coercive power. Against this background, those arguments that most convincingly argue that harm is possibly involved, will best survive in the debate. In fact, we saw a nice example of this in the cloning debate. The moratorium on cloning was relatively easily arrived at: given the imperfections, harm to future human beings was obvious and therefore a sufficient justification, acceptable to all. More precisely, difficult and vague notions like the decline of human dignity and a deterioration of parenthood were not further needed in the discussion, for we are not going to do it, anyway. Among all thinkable arguments, the harm principle did the job and made all other arguments irrelevant - whether or not they argued towards the same conclusion. Thus, the harm principle is among the most powerful elements of justification.

With respect to justification, we can find an additional answer with Rawls. He argues that for any public decision to be justified, it is necessary that it can be presented as free-standing, that is defended without reference to any comprehensive doctrine. This is what Rawls calls political arguments (see Rawls: I993, p. I2). ${ }^{8}$ More specifically, Rawls (I993, p. li) suggests that our comprehensive

8 At this point, Rawls is particularly explaining the political conception of justice, not political conceptions in general. However, as I understand him, the general property of 'being political' can be derived from this 'ability to remain freestanding'. 


\section{Politics by All Means}

doctrines can be adduced in support of normative claims we make in public. However, we may only do so, if in due course we also provide support for the claim in political terms, that is terms acceptable for all without further reference to our comprehensive doctrines. Thus, part of our comprehensive doctrines can be made public, and more specifically, that part of our comprehensive doctrines that goes fine with publicly accepted normative claims. Thus, public ethics is continually redefined by admitting and expelling arguments from our respective private normativities.

It follows from Rawls's view that public ethics is essentially a constructed category within normativity. Then, private ethics remains as a residual category as opposed to public ethics. We are not allowed to adduce this realm of private ethics in pursuit of justification. Thus, this is once more a hint that the public-private dichotomy is primarily a socially constructed boundary. However, we also saw that the distinction between morality and the conception of the good was inherent to the normative positions themselves. Both distinctions - between public and private ethics, and between morality and the conception of the good - emanate onto the universality of claims. It is clear that friction may be felt if those interpretations of the boundary do not coincide. That is one source of difficulty that will occur in the debates in part III of this book.

One might wonder why debates cannot simply be settled by appealing to knowledge that is certain, or at least accepted as such by the majority. Why can factual claims not function as the ultimate justification? Why not just ask the scientists in the lab, what would be the best way to control biotechnology? Indeed, we could decide to accept the most rational option. However, the burdens of judgment are important for us to realize that indeed rationality is not a sufficient condition for agreement. For this to be clear, I must however first briefly explain the distinction between on the one hand a concept and on the other hand the many conceptions that such a concept can receive. I broadly understand a concept as a general term, word or idea that we can deploy in our speech. It is used in fairly similar ways at different places. It has a kind of 'grammar' around it that implicitly tells us how the term can be used or not. However, it does not specify what we exactly mean by the concept. This 'exact meaning' is what I refer to as our particular conception of the concept. A conception is a possible answer to a 'what is'-question. Often, many answers are possible, even different between times and places, and between the persons whom we ask (see also Swift: 200I, p. II). 
I suggest now that we define the concept of rationality as 'a set of rules or criteria that a statement must satisfy for it to be accepted as true, right or valid'. This makes sense, because usually, when we consider a claim irrational, this is to say that we think the claim is not sufficiently supported by 'rules of thought', like logic, or ideas of how to interpret perception, or how to value and assess sources of knowledge. And on the contrary, something rational can usually be further explained by explicating how we concluded to the claim: what perceptions, books and inferences contributed to it.

In real life however, people tend to hold a host of different ideas on how to assess the rationality of statements. For me, personally, it is perfectly rational that homoeopathy is nonsense. That is, the 'pure' version of homoeopathy that holds that disease can be cured by administering the source of disease (a germ, a poison or whatever) in an endless dilution. The reason is simple: I am quite sure that something endlessly diluted cannot have any effect. This is clear to me from all that I understand of physics, chemistry and biology, supported by practicals in secondary education, opinions from experts that I think are right, and so on. In addition, to the successes that homeopathy now and then boasts, I can devise explanations that I find more convincing: the placebo effect, the power of the human body to recover - not always, but enough to provide homoeopaths with some successes - and the fact that being cared for is usually beneficial to human health and well-being. Indeed, if I would believe otherwise, I would consequently have to give up a vast proportion of my knowledge of the natural sciences.

However, given the large support that homoeopaths find, we must conclude that there is a significant number of people that believe there is some truth in homoeopathy. They may do so based on its successes, or based on their perception of regular medicine as bungling even more than homoeopathy, or because they believe that knowledge of homoeopaths has a longer history and has therefore been corroborated better, or simply because they find the explanations that homoeopaths offer more convincing than the ones by conventional practitioners. Now, I could accuse them of being irrational. They are so indeed from my perspective, and I would probably enjoy support from the vast majority of medical scientists. However, that does not bridge the gap, but rather widens it: from their own perspective, they are perfectly rational, because they have good reasons in support of their conviction and see no inconsistency in it. For them, their belief in homoeopathy is backed by the rules of thought that they adhere to. My judgment of them being irrational 


\section{Politics by All Means}

does not change much about that. This is what I mean by saying that there are different conceptions of rationality. This entails that in disagreements, an appeal to rationality is not at all a warranty for a solution or closure.

For this reason, Rawls (I993, pp. 49-50) suggests that political speech must not be guided by any rules of rationality, but rather by the rules of reasonableness. The first element of reasonableness is that we should be 'ready to propose principles and standards as fair terms of cooperation and to abide by them willingly, given the assurance that others will likewise do so', and be ready to discuss similar proposals made by others. In addition, reasonable persons are 'not moved by the general good as such but desire for its own sake a social world in which they, as free and equal, can cooperate with others on terms all can accept'. Moreover, reasonableness includes a recognition of the burdens of judgment discussed earlier. Thus, reasonableness is a way to peace, whereas different rationalities may lead to war. Similarly, the reasonable is public in a way the rational is not (see Rawls: I993, p. 53). (I am aware that intuitively, one might indeed think of rationality to be the solution of disagreement: exactly because rational claims have the rules of rationality in their support, they would be the best to base our conclusions on. However, this fails to take seriously the disagreement we can have, and in practice do have, on these rules of rationality.)

The idea to take reasonableness (not rationality) as a criterion for political speech primarily says something about the attitude by which something may be adduced. It does however not say much as to the kind of arguments that may be put forward. Like with the scope of politics, it seems in practice that in justification, many people want to adduce more than strictly the prevention of harm. In the cloning debate we saw that some people estimated that arguments concerning the decline of parenthood were relevant. At the same time, these arguments were found irrelevant by others and discarded as mere private opinions. The failure of parenthood to convince seems to be in the fact that the harm done to parenthood is not straightforward, and even denied by some. Moreover, the fact that the moratorium was obtained on the basis of more obvious arguments, made the arguments of parenthood irrelevant. It would have been interesting to see how the argument had evolved if harm by cloning were less obvious: the role of arguments of parenthood might have been different.

This approach to justification is not convincing to all: for example, Jürgen Habermas argues that Rawls should make a stronger distinction between accept- 
ability and acceptance (see Habermas: I995, p. I22). As Rawls sees the acceptance by citizens of a political conception ${ }^{9}$ as a condition for it to successfully become part of an overlapping consensus, he leaves open the question of the epistemic foundation of it. Habermas argues that Rawls therefore also fails to argue why and how a political conception would be neutral between comprehensive doctrines. For my line of argument, this has the consequence that political conceptions will have little argumentative force in distinguishing between political and non-political (or in my terms: appropriate and inappropriate) arguments: if people disagree on the idea of political conceptions in the first place, they will not agree on the appropriateness of specific arguments either.

Habermas's own idea of the ideal discourse situation at least offers some inspiration to return to in the concluding chapter. Habermas suggests an ideal discourse situation in which principally all arguments are welcome, provided that they are open to discussion under conditions of freedom from power. He speaks here about public debate, not parliamentary activity. This unlimited communication allows for a more sensitive articulation of problems, a more critical stance towards things that are taken for granted, etc. A critique to Habermas's approach is however that in practice, discourses will never be completely free from power, nor will they allow for participation of all relevant parties. In particular, experts will be in an advantaged position in any discussion. This incurs a limitation of the kinds of justification that may be adduced - or alternatively, the idea would face the impossibility of a utopian democracy in which each citizen has a full say (see Swierstra: I998). Thus, Habermas' approach also does not escape the hazard that justification will always advance certain kinds of arguments over others.

In addition, part of this tension between speakable and unspeakable things is reflected by the communitarian critique of liberalism. Its most important content is a denial of the possibility to separate the right, that is the thin form of normativity that I denounced as public ethics, from the good, which is a more comprehensive account including parts of ethics that are believed to be private. As a foundation to this diagnosis, at least two presumptions are essential. The first is that it is rather difficult to see how one person can judge public normativity and private normativity along different lines of justification. Things that we deem good, are humanly speaking pretty much the same as the things that we deem right. This stands in the way of a pluralism of ideas of the good. This view is mainly associated

9 Again at this point, the dispute is in particular about a political conception of justice, but I see no reason why this should not hold for political conceptions in general. 


\section{Politics by All Means}

with Alasdair MacIntyre (I98I, ch. 6; see also Mulhall and Swift: I992, p. 95).

And second, the communitarian school sees our ideal of the good as strongly connected to our traditions and social groups (see Mulhall and Swift: I992, pp I62-I64). This means that the larger part of our conception of the good is also inherently connected to the public sphere, which renders pointless the drive for a thin public normativity. In addition, we are not ultimately free to choose our own ends, so it makes little sense to arrange society such that it maximizes exactly this freedom. While this diagnosis of the tension between public and private largely coincides with how I just developed it, there is some disagreement as to those two underlying presumptions: for my conception of liberalism, we need not deny persons' connectedness to social groups and the fact that the good and the right are fairly difficult to discuss in their own right, to normatively hold dear the idea that the state and public normativity are not the first institutions to (more or less formally) prescribe our conception of the good.

None of these approaches takes away that in the end a conclusion is nearly always enforced by means of majority vote. After all, the alternative would be to accept that no conclusion is drawn, which will probably be even less attractive to all discussants. Sometimes discussants do prefer reaching no conclusion over reaching a bad conclusion. However, I reckon this is continuing the problem rather than producing a solution. In general, voting will produce a minority that is unhappy with the outcome - for if the voting were unanimous, the problem was probably in effect settled in a preceding conversation leading to either seeing the issue as private, or eligible for a solution neutral enough for all. But central to the idea of democracy is that one can accept a majority opinion without actually agreeing with it, and that this moreover is not an inconsistent position.

Depending on how satisfying the preceding discussion has been for all discussants, the outcome will be somewhere between two extremes. The first possible extreme is a full endorsement of the outcome, both with respect to its content and to how it has been discussed and justified. This is not to say that everybody will cordially agree to the content. It is to say that they will at least agree to the content as being something publicly and justly decided, because they do truly believe that the procedure was sufficiently neutral and fair and thus did produce a justified outcome. The opposite extreme is a modus vivendi: an equilibrium that can persist only because of an unequal power distribution. That is, people dissentingly accept the outcome, because they fear somehow the power that supports it. They do not 
accept its justification, and thus experience the decision as something suppressing. Alternatively, Rawls (I993, pp. 39I-392) uses the term for an agreement that today furthers our self and group interests, but that we may abandon tomorrow if things are different then. The two forms of a modus vivendi are similar at least with respect to the fact that the justification of a decision is not completely subscribed to. ${ }^{\text {IO }}$

The full endorsement resembles what Rawls (1993, p. I34) refers to as the overlapping consensus of reasonable comprehensive doctrines: a consensus in which 'the reasonable doctrines endorse the political conception, each from its own point of view'. It is an agreement endorsed by all comprehensive doctrines involved, because the combination of their justifications produces a public justification, and therefore they accept the outcome (see Rawls: I993, pp. I34; 391-392). According to Rawls, this is a stable agreement because all recognize that its object is of a moral kind, and all recognize this from their own moral backgrounds. (Recall the difference that I suggested on page 34 between morality and public ethics: each have a different subject deciding on the universality of the claim. Translating this to Rawls's stance would be to say that public ethics is the greatest common subset of our different moralities. This puts an even stronger emphasis on the constructive nature of public ethics.)

The ideas discussed so far are merely normative ideas of how we should do politics. They do not really tell how things go in practice - which is usually a lot more muddy. I have however shown at least that justification is an essential element of politics, and that its criteria are far from straightforward. Indeed, none of them is really capable of reliably predicting which arguments are going to be successful in the debate and which are not. Justification knows different theoretical formulations. In practice however, it is largely contingent. It is in this actual muddle of getting arguments in and out, that the purifying moment in liberalism becomes most clear. Purification is in a way the enactment of justification: not just the presentation of arguments and why they hold, but an active affair of getting arguments accepted or not. This point will be corroborated empirically in part III.

In fact, Charles Taylor (I999) argues that it is impossible between different comprehensive views to come to an agreement on moral claims unless we allow for a disagreement on the justification of those moral claims. Thus, this is always a kind of modus vivendi. However, this seems to refer to the justification that we apply to it from our private perspective, and this need not lead to an experience of suppression. We may well disagree about our private justifications, while agreeing upon some public form of justification that supports the decision. 


\section{Politics by All Means}

However, for a convincing elaboration of liberal politics as purification, we need one more element. That is, in the next subsection, I will pay attention to the role played by the actual outcomes of political decision making.

\subsubsection{Content}

The actual outcome of political decision making is what I refer to as the content. This content consists of the actual claims that are supposed to enjoy support from the decision-making community, and are therefore justified for imposition onto society. Among such outcomes, a number of different styles can be discerned, which will be discussed here.

The first possible outcome of a debate is that the matter is still considered private. It is possible that the best regulation for a subject is no regulation, or alternatively, a regulation that is explicitly aimed at enabling individuals to make their own choices. A case in point is, again, the Dutch law on abortion. After thorough debate, a situation was obtained in which the choice whether to undergo abortion is located in the pregnant woman. The main purpose of this law is to grant individual choice, exactly because abortion has such a complex moral dimension that we must expect that in modern pluralist society a host of opinions will be held on it. This example shows that making something private does not mean that the debate has been in vain: if no regulation had been formulated, many people would perhaps have been unable to follow their own moral conscience. This shows once more that the private sphere is something that is actively shaped. Thus, both the scope and the sources of justification are once more contingent and themselves the result of politics. This circular causality will prove essential in subsection 2.4.4.

The second possible outcome is that something is settled in a way that is neutral between all debate participants. We need to discern here two forms of neutrality: neutrality in justification, and neutrality in effect. Neutrality in justification means that the decision is arrived at in a way that can be explained to all and accepted by them as a fair way. This is one of the fundamentals of democracy. Neutrality in effect means that the consequences of a decision burden and benefit all members of society equally. This is in practice impossible, because any decision is intended to make a difference in reality, and there are very few, if any, decisions that affect us equally. State-funded education burdens the tax payer and benefits the school child. This is non-neutral, but it is also not of much use to talk about neutrality this way. Against the background of my line of argument, it makes more sense to 
define neutrality in effect in terms of neutrality between comprehensive doctrines. That makes more sense: state-funded education burdens tax payers, yet it does so regardless of whether those are Jewish or Islamic. Thus, neutrality in justification seems feasible, and neutrality in effects seems feasible if we limit our view to different comprehensive doctrines. This way, a neutral outcome of a discussion can sometimes be achieved. ${ }^{\text {II }}$

The third possible outcome is then however that an issue is concluded along neutral lines of justification, while it is in its effect not neutral between different comprehensive doctrines. Think of the following example, from actual Dutch politics. Strongly embedded in any democratic tradition is the right to free speech and freedom of thought. This right reflects a truly impartial justification, that is the recognition that we are in our humanity equally entitled to devise an opinion, and express it to others. However, a number of public figures have felt the need to argue that the prophet Muhammad is a despicable person, for whatever reason. According to the right to free speech, they were perfectly legitimated in arguing so. However, public figures from an Islamic background took offence to such arguments. While the right to free speech knows a neutral justification, it leaves some religions unprotected against insult. That is: it leaves all comprehensive doctrines similarly unprotected, but some are more prone to experience this as harm than others. Thus, even if the justification itself is neutral, specific properties of comprehensive doctrines may still be insufficiently protected by it.

It is important to recognize that the content thus becomes itself part of our culture. More specifically, it is likely to become part of our normative routines on each of the three levels: content, justification, and scope. Normative routines are much like infrastructure: one does not notice them too much as long as they function properly. But when things fail, they become all the more apparent to us. Indeed, when moral routines fail, they become themselves the object of political discussion. This is what happens in the controversies central to this book.

Alternatively, Jonathan Seglow (2003, p. 84) distinguishes between empirical and moral neutrality. The former concerns the affirmation of conceptions of the good that are not controversial. The latter concerns claims that do not affirm or deny the validity of any conception of the good. This distinction seems not too useful here, but it does signify that whenever something has moral content, it easily draws the blame of non-neutrality. In solution to this dilemma between moral non-contestedness and moral emptiness, Seglow (2003, p. 95) suggests to take up at least the comprehensive ideal of deliberative democracy, not as a straightforward political principle, but as a generative mechanism for arriving at shared principles. 


\section{Politics by All Means}

\subsubsection{Justice and the limits of decision space}

The preceding subsections lead to the remarkable conclusion that politics decides itself upon its 'proper rules'. It would be quite a match, if the competitors discussed during the game of chess whether the bishop moves diagonally or laterally. This may have created the impression that in the end, just anything goes: anything that politics decides to along its own idea of proper political conduct, would be a legitimate outcome. Indeed, the constructivist momentum in my approach is vulnerable to the accusation that it would allow for practically anything to be decided: decisions are just a matter of playing a keen game of political martial art, not of whether they are essentially good or bad. And indeed, David Tracy (I998, p. I94) has argued that political truth is essentially a matter of consensus. However, the following arguments will mitigate this somewhat nihilist conclusion.

As I argued, the justification in politics does not stand on its own, but it is intimately connected to the content of earlier decisions. On its own terms, this mechanism provides some limits to what is possible: as the content bears on scope and justification, we may not expect that things will be accepted that are too radically at odds with how things are settled in practice. Thus, proposals that are far-off from today's political reality, have a very small chance of surviving the debate. They will not pass justification, or alternatively, require a justification that will not take root. Political debate condenses into content, and this makes politics slow.

In addition, some more theoretical limits have been established to what politics may decide. I present some of them here, not because they would exactly represent real life politics, but because they are ideas that at least enjoy some support: they are aspirational fictions like I took political liberalism to be. To begin with, not just anything goes, because in practice not just anything will be accepted. This seems a circular inference, but in fact it reflects that politics is contingent on history. Some things that are likely to remain stable over a longer period, at least in Western contemporary democracies, form underlying conceptions to the debate: that all persons are equal (at least in a number of relevant respects), ideas of democracy, and ideas of justice. This is to say that it is fairly difficult for politics to decide to things that are detrimental to democracy, that make inappropriate distinctions between different classes of citizens, and things that are somehow unjust. The first two are beyond the scope of this book, but justice will be a theme that recurs now and then. Therefore, I will elaborate on this theme here. 
Insofar as justice is relevant for my argument, I take it in the narrow sense of concerning the distribution of goods according to some distribution scheme - distributive justice, indeed. ${ }^{12}$ If A has more or less of a certain good than B, then such a distribution scheme will generally posit whether this difference is just or not, and whether and how it should be corrected or compensated for. Some believe that uneven distributions are unjust if they are the result of decisions beyond one's control. Others believe that uneven distributions are just as long as each one's wealth has been acquired in a legal or legitimate way. Generally, all distribution schemes offer a specific balance between a level playing field and complete freedom of pursuit, that is: between all-encompassing redistribution and no distribution at all. Or alternatively, all conceptions of justice represent a kind of level playing field, but disagree upon what should be subject to leveling and what should not. Or even a third way of staging it, most agree that unequal distributions need a justification, but disagree upon this justification.

As an example of such a scheme of distributive justice, I take Rawls's conception of justice as fairness. This conception essentially consists of two principles: the difference principle and the principle of equal opportunity. The difference principle holds that organized differences in society can only be justified by their being advantageous to society as a whole, or more specifically advantageous for the worst off. The principle of equal opportunity holds that offices of power should be open to all under equal conditions. These two principles are where some of the limits to content of Rawls's political liberalism are specified: society may democratically decide to the widest range of options, provided that they are not unjust in the light of this specific conception of justice. This content bears clearly on scope and justification as well.

Not everybody agrees to Rawls's conception of justice as fairness. An alternative version is the maximin principle, which comes close to justice as fairness, but it is not the same. It states that differences must be arranged such that they maximize the good of the worst off. This comes even closer to an overall redistribution of goods. (The difference between maximin and justice as fairness is that the former requires maximization of the goods of the poorest groups, while the latter only requires that those poorest groups enjoy any benefit, no matter how small, from the unequal distribution.) 


\section{Politics by All Means}

Yet another conception of justice is justice as entitlement. This is usually associated with Robert Nozick. It briefly holds that people may keep whatever they have acquired in a legitimate way: through transactions such as trading and receiving, through earning such as harvesting or producing, and through the correction of earlier unlawful acquisition like the correction of theft. It is thus not strictly that much of a distributive idea of justice, but rather an idea of respect for the right of people to own things, and thus an idea against redistribution. Is does not cast a strong condemnation of differences, but more importantly, it does not see in differences per se a justification for redistribution (see Swift: 200I, pp. 30-39).

It is not my intention here to conclusively decide between these conceptions of justice. It is however important to see that contemporary societies have something of redistribution implemented, primarily in their tax schemes. Obviously, the United States are much more organized towards the entitlement pole, whereas several 'welfare states' in northwestern Europe are arranged more towards the maximin extreme. And even within single states, it differs between spheres what form of justice one sees. Health care in the Netherlands is (at least theoretically) largely egalitarian: citizens pay principally the same through insurance premiums, while they receive the care they need. In fact, elite care for the wealthy, or premium care paid for by employers in order to have their employees back to the workplace quicker, are close to a taboo. But the broader outlook on the society of the Netherlands is not egalitarian: financial differences between persons can be huge, without these differences per se being a reason for redistribution.

In each of the chapters in part III we will encounter problems that are somehow in conflict with specific distribution schemes, and thus argued to be in conflict with justice. In such cases it will be interesting to ask what exactly the underlying idea of justice is, how it is compromised in the specific case, and what solutions are proposed. A related question will be what apparently is believed to be subject to the redistribution scheme. In addition, it will be interesting to see how justice is adduced as a limit on the design space that political decision making is confined to. For now, it is important to realize that different schemes exist, and that they, being part of the content of politics, bear on the justification and scope of politics. This thus explicates once more the contingency of any one political category. 


\subsection{We have never been liberal}

\subsubsection{The clear waters of tolerance}

Above anything else, liberal politics has brought peace in conclusion to church wars. Rawls (I993, pp. xxiv-xxvi) observes that a number of historical developments lead to the modern period. The most important of them for my line of argument is indeed the Reformation, which fragmented religious life, thus opening the door to pluralisms of many kinds. A liberty of conscience and a freedom of thought were achieved then. The pluralism of religions in its wake did not amount to the feared disastrous downfall of moral life. Rather, it proved to be the natural consequence of human enquiry under conditions of freedom. In addition, the development of modern science, reinforced by mathematical analysis, paved the road to a more skeptical stance towards dogmatic doctrines. Rawls develops his version of political liberalism as the answer to the question of how a society with a religious pluralism (and in a more general sense: a pluralism of comprehensive doctrines) can be stable. Indeed, it has enabled present-day Western civilization to foster a host of different religions, political movements and styles of life in a peaceful way unthinkable otherwise.

What kind of liberal society we actually live in, is however less straightforward. We could say that we pretend to live in a Rawlsian liberal society. This is what I meant by seeing political liberalism as our aspirational fiction. This raises the question of what is below this fiction. In other words, how does my vision of actual liberalism differ from Rawls's theoretical version of it? The most important difference is in the underlying idea of constructivism. By political constructivism Rawls (I993, pp. 97-98) refers to the principle that through fair rules of construction, citizens will come to rules of justification that they can endorse. My version of constructivism holds that such fair rules are themselves an illusion. That is to say, people may largely agree upon the rules of political conduct. They will however at times feel the need to challenge those rules. This is moreover not a process prior to political discussion, but an inherent part of it.

Nevertheless, some Rawlsian traces are clearly recognizable in how we do politics. We are allowed to adduce our private ethics and comprehensive doctrines as justification for our political positions, but final political decisions should be as much as possible acceptable to all citizens, regardless of their comprehensive doctrines. That is, indeed we may use our comprehensive doctrines insofar as 


\section{Politics by All Means}

others accept that the arguments produced are valid arguments. In addition, we certainly live in a generic liberal society, as any typical Western society somehow champions liberal values like liberty, freedom from harm and freedom of religion, and some kind of pluralism - however diverse the particular meanings individuals and different societies attach to these concepts. The following subsections will reveal what is hidden behind this Rawlsian pretension.

\subsubsection{The muddy undercurrents}

The earlier examples regarding the private sphere as a moral decision space have shown that the private sphere is historically contingent: intramarital rape and child molestation have not always been public problems, for at times they were hidden behind the front door and were not a matter of public concern. For sure, norms of decency were one day much more a public justification than they are now, witness the controversy on (semi)nudity in street advertisements. Sometimes, changing circumstances demand that we pull certain things out of the private sphere into the public sphere - or the other way round. This usually takes the shape of a crisis in politics: the demarcation between public and private fails and can no longer be taken for granted. And for things to change, societal consideration and consolidation seem a necessary path to take. Solving the problem will ultimately entail a redefinition of the private and public spheres. Rendering issues differently with respect to the public-private divide, both regarding scope and justification, usually takes the shape of a crisis in politics. The demarcation between public and private is no longer unproblematic. We are then confronted with existing moral routines that fail.

This historically contingent account of the boundaries entails that they are also constructed borders. This is to say that where exactly the boundaries lie, is permanently open to challenge - at least in theory, but also empirically observable in real life. For example, that the boundaries of justification are indeed the source of some resentment, is clearly reflected by Kass's position in the cloning debate. Part of his critique concerned the shallowness of the debate, as the received conception of harm does not do justice to all aspects that Kass considers relevant. Particularly the impediment of dignity, indeed another example of a concept engaged in justification, is unjustly left out of thoughts of harm, thus Kass. This reflects once again the problems that we saw the discussion on Dolly run into in chapter I: many of Kass's arguments were hard to grasp without taking into 
account his Roman Catholic background. Much to Kass's regret, his opponents do have their strongholds to keep it that way. It is not a matter of any eternal truth whether Kass's arguments must be left out. It is hard work for both camps.

A similar constructive moment can be recognized in challenges of the scope of politics. This will be seen in the debate on human enhancement. Among the many disputed objections to enhancement, the claim is heard that enhancement is simply not a private affair, because of the many dangers that we should not leave parents free to expose their children to (see for example Selgelid: 2003). If enhancement were clearly harmful, this would indeed be obvious. But it is not: it is particularly harmful against the background of specific comprehensive doctrines, that strongly appreciate life as a gift. However, it is not so for all comprehensive doctrines. This provides a fundamental conflict: if we decide to tolerate or privatize something, this implies the judgment that the thing is not so bad in itself that it should be forbidden. And this is what people disagree upon. Indeed, for some the condition of tolerance (see page 29) is not met.

The following pattern thus captures how private-ethical arguments typically appear in public. First, consider a non-crisis situation, where the boundaries of scope and justification enjoy general consensus. That is to say, the condition of tolerance is met for any issue, and scope and justification are routine. Second, consider a change of any sort with ethical relevance, at least felt to be so by some. This is likely to thwart routines. (If it had no great ethical relevance but just minor relevance, routines would probably just do their job.) This requires that the new situation is assessed with respect to the condition of tolerance. It is likely that in such a non-routine assessment, we need to find a new balance between public and private ethics. In fact, in non-routine matters we generally need recourse to our complete set of normative values: our comprehensive doctrine - including the part that was considered private.

This is the first entrance for private ethics into the public debate. Then, finding a new balance requires that the new situation is arranged such that the condition of tolerance is met for all involved. This is again something that relates to our comprehensive doctrine and hence offers a second entrance for private ethics into the public realm. That is, in rearranging the boundaries between public and private ethics, we necessarily assess this boundary against the background of our private ethics - which follows from the very definition of the condition of tolerance. This explains why private-ethical elements will occur in the public sphere. 


\section{Politics by All Means}

When boundaries become unstable, their construction and enactment may boil down to plain rhetoric. We have seen that religious arguments are sometimes easily swept away because they are religious, without a further assessment of whether their content is really so irrelevant. In other places, the right to free choice is claimed by appealing to the fact that nobody is forced to make the same choice, while at closer glance the choice may have strong societal implications, such that the freedom of choice is not that straightforward. And a nice example of rhetoric that is just powerful rhetoric, is what we could call neutralization by embracement: if human dignity is brought to the fore, all can argue that 'nobody would ever argue against human dignity'. Thus, those arguments - indeed, hidden behind the claims to dignity - are sometimes silenced without giving them the attention that some think they deserve. Arguments get a dynamics of their own, fairly independent of their content. Thoughts are thus sometimes pushed in and out of the public sphere, and it is not trivial what arguments make it or not, nor is it for what reason they are so. This is what I refer to as the mud fight that politics sometimes is. And particularly, we cannot easily avoid this mud fight. As the mechanism above predicts, private ethics will seep into the public sphere, while it is at the same time vulnerable to exclusion.

This observation that arguments are expelled from the debate raises an important question: which arguments are discarded, and which are accepted? Is it possible to frame any criteria of pertinence that can tell in advance whether arguments make it or not? The answer is that it is at least impossible to frame a simple answer to this question. At the same time, it is clear that the vaguer an argument is, the smaller its chances of survival will be. Thus, God fails to convince, while mathematics does. Reality is however a bit more complicated than this, and I will get back to this in chapter 7 .

\subsubsection{Technology is not a religion}

So far, I have said hardly anything about politics in its relation to technology. This chapter mainly discussed how politics may deal with a pluralism of ideas of the good. I have suggested a shape for this pluralism, as well as some of the difficulties this may produce. These difficulties were mostly about the problematic distinction between public and private forms of normativity, and the contestability of the universalization of normative claims. I also already mentioned that liberalism as we know it today, has largely been shaped as a solution to religious differences. 
However, the problems to be discussed in part III are mostly problems occurring against the background of our technological culture. I have argued elsewhere that technologies may play a role comparable to religions in that both provide us with meaning and both have an influence on the choices that we make (see Valkenburg: 2008). In addition, the blind optimism with which some people uncritically take all the promises that technologies offer is indeed sometimes hard to discern from the unconditional endorsement that religions sometimes enjoy.

But at the same time, the differences are immense. Religions are largely privatizable in that each can follow his or her own course without disturbing others. Religions are pretty much immune to effects of distributive justice. Clearly, human enhancement technologies and tomato harvesting machines may, at least theoretically, give some an unfair head start over others. The same is however hard to imagine about the differences between Calvinism and Catholicism. And the way that technologies possibly exercise power is much different from the way religions do: while the latter can certainly mainly exert social and authoritarian pressure, the former can do so by putting hard limits to what is possible or available to whom.

Important here is that therefore, we may expect that liberalism runs the risk of 'solving the wrong problem': even though discussants may remain polite and reasonable, technologies may produce difficulties that liberalism offers no clear-cut answers for. This may be so, even though liberalism was fairly capable of dealing with religious differences (or different comprehensive doctrines, for that matter). Indeed, in chapter 3, I will develop some difficulties that are owing to technology and that are not straightforwardly solved by liberalism.

\subsubsection{The dialectics of politics as purification}

So far, I have argued that the distinction between public and private issues is far from obvious. First, it is contestable: given the burdens of judgment, we will not only come to a variety of moral conclusions, but also to a variety of conclusions to the question of whether an issue does or does not belong to the scope of politics, and similarly, how justifications are assessed as appropriate or not. Just the fact that, given the earlier observations, the boundary differs over time and space, show that they are not likely to be eternal truths and that there rather is a contingent ring to it.

Second, regardless of the existence of any eternal truth underlying the distinction between the public and the private, this distinction will necessarily be fuzzy. 


\section{Politics by All Means}

Essentially, we are one and the same person, and as we constantly move in and out of public and private spheres, we take with us all kinds of objects: possessions, ideas, identities, rules of behavior, and so on. Thus, a lot of objects must have their place in both the public and the private sphere. Hence, it will sometimes be difficult to tell whether something is public or private; it might well be both.

This will prove to be a recurring phenomenon: that so many things Do not let themselves be classified between public and private. It is a typically human trait that we try to capture the world surrounding us in clearly categorized terms. However, the world is not that clear: many things do not neatly fit into the categories we want to put them in. And things that do not nicely fit in the categories of either public or private, are hard to discuss politically - or render private, for that matter. They do not fit comfortably with our strategies for private issues, nor do they line up with our political routines. Thus, they earn some immunity to our grip. I suggest to call such things hybrids. ${ }^{\mathrm{I3}}$

In addition to the difficulties deriving simply from our human condition of living in a world too complex to classify, there is a difficulty specifically linked to modern technological culture: some things are not possible to privatize technically spoken. As will be discussed in chapter 3, one of the many effects of technologies is their production of dependencies between persons, things, actions, locations and more, that would not exist otherwise. For example, in chapter 5 the problem will be developed that a biobank defines groups and dependencies that did not exist previously (see also Chadwick: I999a, p. 298). And with human enhancement in chapter 4 and preimplantation genetic diagnostics in chapter 6 , we will see that technologies play a tough game by making things urgent in the eyes of some citizens, who thereby are forced to adduce their private justifications in public debate - such to the dislike of many others. Decisions and justifications of the kinds that we would earlier associate with the private sphere, are now all of a sudden reshuffled over the public-private boundary.

Thus, justifications and decisions are continually rearranged between the public and private spheres. This allows for two possible explanations. One explanation would be that the categories of public and private are mouldable. That is, if different criteria are applied at different times, the same thing may fall into different categories. The alternative explanation is that the things themselves are changeable, and hence fall into different categories at different times. I suggest

This usage is in line with Bruno Latour (I993b, p. I3I), who will receive proper attention in chapter 3 . 
that we assume that in our political reality, it is a bit of both. This is partly owing to the somewhat circular definition and enactment of the public and private spheres. Those things are public that we consider part of the scope of political decision. This scope on its turn is before anything else understood by means of its exemplars: the elements that are part of it. For the private sphere, the same holds. The elements define the spheres; the spheres define the elements.

Three things are to be noticed at this point. First, this purely constructivist approach must be related to the positive definitions given in section 2.3, and the slowness in politics that was observed as a result of how content relates to scope and justification. It seems contradictory that something is at the same time constructed and theoretically established. This is however only a paradox. Those more theoretical definitions were rather open and formal. They were largely concepts. To concepts, it is not so strange to find more material definitions or conceptions that are the result of construction and that change or evolve over time. As the material definitions are what matter in daily life, the constructivist approach is appropriate there.

Second, this has important epistemological consequences. As the existence of the private sphere is the cause of the existence of good-life ethics as a separate, private branch of ethics, we cannot adduce good-life ethics and its private character as an explanation of the existence and nature of the private sphere. At the same time, the private sphere is mainly defined by its exemplary contents. Therefore, the private sphere cannot fully explain what its contents is. In other words, there is no reason to see either the private sphere or its contents as a priori definitive of the other. Rather, they co-evolve in a complex entanglement. In addition, exactly the same argument holds for the public sphere. And what is more, this picture of co-evolution entails that we can neither understand the public sphere as definitive of the private sphere, nor the other way round. This entails that indeed both spheres are open to continuous challenge and redefinition. And it also means that we need to pay equal attention to either sphere if we really want to understand modern technological and political culture. ${ }^{\mathrm{I}} 4$

And third, it can be argued that the work of purification gives rise to its own anomalies. Dividing normativities between public and private classes is itself a normative affair. Any conception of what public and private normativities should be like will thus have links to the contents of both public and private normativities. 


\section{Politics by All Means}

Therefore, hybrid forms of normativity that are half private and half public are a necessary consequence of the political purification. It is equally so for the liberal implementation of that purification. ${ }^{\mathrm{I5}}$

The property of hybridity inherent to normative issues offers a hint towards yet another important property of them: that in real speech, it suffices if we attach roughly the same meaning to the things we talk about. Just roughly the same thing, because the 'contamination' by private-ethical elements will be different for each of us. However, roughly is sometimes not enough. In some situations, the different conceptions we attach to concepts collide. That is, we attach meanings to words, that turn out to be so radically different that they cannot be seen as different yet compatible meanings. We saw this with harm as a demarcation of justified state coercion. We all agree that harm should be prevented, because we sufficiently agree to judge harm as something very wrong. However, at closer look this criterion was not all that clear. We saw indeed in chapter I that Kass understands harm differently than his opponents do. The (usually implicitly) different conceptions of harm are to blame for the controversy arising. (In this particular case, it boils down to the question of whether future beings sufficiently count as subjects who can suffer harm, and whether dignity is the kind of good that Kass thinks it to be, as to count as harm when impeded upon.) This produces a controversy, not only on the actual collective decisions, but also on the question of how to argue on them. That is, it produces a controversy on both the justification and the scope of collective decision. ${ }^{16}$

This property of meaning different things in different situations much resem-

15 Again, a touch of Latour (I993b, pp. 49-5I) may be recognized here. By purification he refers to separation of objects and subjects, humans and non-humans, and the social and the natural. However, these separations are intrinsically human activities. Thus, even if something ends up in a merely non-human category, it gets 'contaminated', through this action, with some of our humanity. Hence a hybrid is born.

16 A quite similar way of putting it is from Bert Musschenga (1992). The hybrid character of words and meanings shows that the conceptions we attach to concepts are strongly related to our world views and our comprehensive doctrines. In other words, the way we talk in public, cannot be seen apart from what we think privately. The relation between our private meanings and our public speech is thus precarious by definition. That our comprehensive doctrines seep into the public sphere, is most clearly seen in complex situations where prioritizing between values is needed. In those situations, we are necessitated to fall back onto our comprehensive doctrines and argue on their basis. Thus, the distinction between public and private elements - both decisions and justifications - is difficult, not only simply because they are so hard to tell from one another. It is also difficult, because they are intrinsically and inseparably linked to one another. 
bles the idea of a boundary object (see Bowker and Star: I999, p. I6): things that can function in different contexts and meet the different needs of those contexts, while they remain sufficiently rigid or stable as to be recognized within the different contexts. Harm means many different things in different situations, yet its meaning is sufficiently constant as to allow different people to agree in broad terms on what counts as harm and what does not. However, its ability to cross boundaries and the according mouldability make that harm is always open to a certain degree of modification. This is likely to give rise to controversy. This is what we saw in Dolly's aftermath: harm means so many things in so many places, while we pretend to speak of one and the same thing all the time.

This elaborates again the idea of (liberal) politics as a mode of purification. On the one hand, there are the criteria that tell us whether something is a public or a private element. Thus, those criteria specify what can be said and what cannot. On the other hand, whatever we think those criteria to be is at the same time a result of that very speech. Harm and other concepts receive their conceptions in our talking, and in their turn impose criteria onto that talking. This is not to say that our talking conclusively produces conceptions that all agree upon, but it is to say that dominant modes of speech will reinforce their dominance and make the dominated positions less audible. That is what purification does: keeping hard-won positions and trying to gain more territory. In this game, the weapons and the bounties are of the same kind.

Moreover, this elaborated idea of purification hints towards an explanation of how it fires back. Any sportsperson will disapprove of rules being changed in the course of a game. Yet this is what politics does all the time. A sportsperson is most likely to object if his or her chances to success are tainted. This is what we also see in politics, and will observe in the empirical chapters in part III: those arguments that are threatened with exclusion will gain support from those who have an interest in keeping those arguments in. This is what I mean by backfiring, and what I will henceforth refer to as the dialectics of purification. I call it that for two reasons. First, the effect has a momentum opposed to the momentum of purification. And second, the effect is intrinsic to the purification itself. One cannot have purification without inciting its countermovement. 


\section{Politics by All Means}

\section{Review}

This chapter has explored how politics can be conceptualized as a process of purification. After arguing that a pluralism of ideas of the good is both unavoidable and desirable, I started inferring what primary questions politics may have to answer in facilitating such a pluralism. I came to the three levels of scope, that is whether an issue needs a political decision; justification, that is how decisions are argued and concluded; and content, that is the actual normative position that is supposed to enjoy collective support. I have labeled this a process of purification: the debate is continually purified as to contain only appropriate arguments and not inappropriate ones, and only about things that politically matter as opposed to irrelevant issues. This structure entails that in defending a certain normative position, it can be strategic to fight the battle on one of the other levels. If we disagree on content, it might work in our favor if we discredit our opponents' positions on the other two levels, and so on. Thus purification is also sometimes a mud fight.

I also argued that politics does not take place in a vacuum, but rather against the background of historical circumstances. That is, the rules along which the debate today is purified, cannot be seen apart from the history that led to the point politics take place. The rules along which purification takes place, are themselves the results of earlier debates. Thus, purification is itself at the same time the result of earlier purification.

We had already observed in chapter I that it was progress in science and technology that caused the process of purification to run aporetic. Therefore, the next chapter will engage in establishing a conception of technology that can be incorporated into this conception of politics. This combined conception of politics and technology will serve to explain how the creation of Dolly, and each of the practices to be discussed in part III, acquires the ability to cause such panic. 


\section{Political technology}

\subsection{We live in a technological culture}

Our contemporary Western culture is technological to the bone. Technologies are omnipresent, at any time and place and for anyone. Our daily lives are unthinkable without technologies: we wake up by automatic alarm clocks, use artificial light in case the sun hasn't risen yet, travel to our work by bike, car or bus, do our work on a computer or with a mechanic drill, and in the evening we watch television, listen to electronically captured music, or read a mechanically printed newspaper or book. Also on a more macroscopic level, the world ${ }^{\mathrm{I}}$ cannot be appropriately described without reference to technologies. Society would not be organized the way it is, if it were not along the existing lines of mass communication, transport systems and power grids, the incredible power of institutes like universities, innovation platforms and research foundations, and the off-the-shelf availability of medical technologies. And even family bonds, perhaps in a way the most 'naturally induced' social elements of our life, would have a different meaning and character in the absence of telephones, instant messaging and email, and highways that enable efficient traveling.

In the previous chapter, some political aspects of our human condition have been explored. In the present chapter, technological aspects of that same condition will be articulated. It requires little imagination to understand that the two are intricately intertwined. Debates are conducted through the widest range of media, many sociopolitical issues are caused by progress in science and technology in the first place, and above all, technologies constitute a large part of our social lives. And on a less visible level, both play an important role in shaping our lives, our daily routines, in our understandings of what is right and wrong. Indeed, our technological constitution cannot be seen as separate from whether we think things are public or private. We have seen in the previous chapter that doing politics also contains the boundary work of purification: getting issues and

1 The preceding description limits the scope of this book to the modern Western world, hence this perspective must be assumed throughout the remainder of this book. This limit is justified by discussing liberalism, anyway. 


\section{Politics by All Means}

arguments in and out of the debate and the public sphere. In this chapter, I will explain how things get even more complicated if the technological and scientific part of our constitution fully plays out its role in the same game.

In section 3.2, I will propose an answer to the question to what extent we are left free in our choices by the technologies that surround us. In addition, I will explain how science and technology appear neutral, despite the fact that the influence of technologies on our choices is undeniable. In section 3.3, I will give a more theoretical account of science and technology. I will understand them in terms of actor-network theory (ANT), which opens up interesting perspectives on the relation between science, technology, and our life world in which politics and ethics are shaped. Finally, in section 3.4, I will develop the consequences of this conception of science and technology for the conception of politics that I developed in chapter 2 .

\subsection{Technology between tool and tyrant}

\subsubsection{Instrumentalism versus determinism}

As to the question of what technology is, the most straightforward answer is something like 'technology is the application of scientific knowledge, in pursuit of efficiently achieving goals that would otherwise be much harder or even impossible to achieve'. However, as usual, the most straightforward answer is too simple and too beautiful to be true. To begin with, it would be an idealization of the genesis of a specific technology, as if there were a fixed problem or goal, for which the designer went to sit at his or her workbench, and after reading the right books on physics and chemistry would produce a brilliant solution to. In addition, this vision presumes that the physics and chemistry are just ready to be picked off the shelf and applied straightforwardly in a technological design. And what is more, it presumes that the problem can be clearly and unambiguously defined, such that the designer is able to decide what physics and chemistry to use.

The many visions of technology that history has produced, principally range between two extremes: instrumentalism and determinism (see also Borgmann: I984, pp. 9-I2; Feenberg: I999, p. 9). ${ }^{2}$ The first extreme is the instrumental

2 There is a wide variety in the uses of these terms and the detailed meanings attributed to them. Moreover, I myself am not even completely consistent with the authors cited, as Borgmann uses the term 'substantivism' for what I call determinism. My aim is to sufficiently explain my use of the terms, and to use them consistently throughout the book. 
vision of technology. It sees technologies as mere means to ends. It presumes that the human user is able and free to devise the ends and to decide what means to deploy. It also presumes that there is a 'world out there', at our disposal to be used and manipulated. And finally, it presumes that technology is neutral and just an extension of human action: literally a tool or an instrument. The most important consequence of this view is that social change is indeed solely the result of social interactions - and that such is not a tautology will become clear shortly, in discussion of the determinist view.

This instrumentalist vision can sometimes be discerned when technical solutions are (too easily) called for in dealing with sociopolitical problems, the so-called technological fix. Typical is the proposal of the Dutch Member of Parliament, Sander de Rouwe, for an electronic black-box that should monitor anti-social driving style in notorious traffic offenders (see Van Keken: 2008). The box does not exist, and probably will never exist because the notion of anti-social behavior is not something that, today, a computer can assess. From a technological perspective, the proposal was downright naive. Another suggestion by the Dutch Minister of Environmental Affairs, Jacqueline Cramer, also clearly looks like a technological fix. She suggests to build 'clean' coal-powered power plants that store the produced $\mathrm{CO}_{2}$ in exhausted gas fields. Estimates as to when such technology can be available range from 2020 to 2050 , but the permit for the plant has already been issued (see Kallenberg: 2008). Apparently in both cases, seeking a technical solution is more attractive than changing the socio-political mechanisms that underly the problems.

In addition, the instrumentalist view can be discerned in a subtle form behind some well-articulated ideas. As an example, I take a brieflook at the ideas of Richard Sclove in his book Democracy and Technology (I995). The line of reasoning in this book is as follows: (I) citizens ought to be empowered to participate in shaping their society's basic circumstances and (2) technologies profoundly affect and partly constitute those circumstances; then it follows that (3) technological design and practice should be democratized. Thus, Sclove recognizes that technologies have immense effects and that they are rigid in that respect. Nevertheless, he seems to foster the hope that technology is apt for democratization, in the sense that we can mould it in any way that we - collectively, democratically approve of. Thus, he still cherishes the idea that, after the appropriate democratic changes (which has indeed been accused of being simplistically straightforward, 


\section{Politics by All Means}

see Mitcham: I997, p. I74), technology can be a tool at our collective disposal. While Sclove is not a downright instrumentalist, at least this instrumentalist trace is undeniable. However, as will be made clear throughout this section, neither the general instrumental vision nor Sclove's more sophisticated vision, with at least some traces of instrumentalism, are tenable.

To add some differentiation, Andrew Feenberg (2002, pp. 5-6) distinguishes four forms of instrumentalism that can be observed in thinking about technology. First, technology is assumed to be indifferent to the ends to which it can be deployed. This version attributes the ultimate cause in our histories to human agency. In the second form, technology is considered to be neutral between social forms, for example between capitalism and socialism. That is to say, a socialist society would not need (or produce) fundamentally different technologies than a capitalist one, and therefore technologies can be transported from one social system to another - unlike, say, laws and tax and education systems. The third form of instrumentalism attributes to technology a neutrality because of its rational character and the universal truths it incorporates. And fourth, technology is thought to be neutral because it is guided by universal norms of efficiency. As such norms are believed to be the same in any context and against any background, no partiality can be suspected. Throughout this book, particularly the second and third versions of instrumentalism will prove relevant: I will show that whenever neutral views of technology appear, this often cannot be seen apart from the liberal society they are embedded in. And moreover, technology appears to be neutral by appealing to a neutral rationality, which is in some respects not completely neutral.

The other extreme is the so-called determinist view of technology. Instead of seeing technology as a mere instrument for the human will, the determinist vision sees technology as something that has its own impetus and internal force, such that human intention and agency become irrelevant. The reasons for seeing technology as determinist can be multiple. It might be that there is a linear trajectory for natural-scientific facts to end up in ready-to-use machines. That is to say, natural laws can end up in machines in only one way. Alternatively, it might be the view that history of science and technology forms one linear path towards the present technological constitution, without a significant role for human agency. Or it might be that technologies are designed by an 'evil genius' that works towards the submission of human beings. Or it might be that technologies are compatible only 
with specific ways of life, thus overruling our ideas of the good and thus in effect making us slaves. The central element that these ideas share, is that determinism is a picture void of human agency, and therefore void of dignity and anything that makes life worthwhile. As a consequence, it makes all morality ironic and superfluous.

Technological determinism thus believes technology to be the actual source of action or societal change. Therefore, people can do nothing but await their fate as 'decided' by technology. Forms of technological determinism are usually associated with thinkers such as Jacques Ellul, Martin Heidegger and Max Weber (see Feenberg: I99I, p. 7), who tend to see technology as a project aimed at shaping the entire world into an object of control, including the social and its human inhabitants. This view can also be discerned in the position taken by Kass, as discussed in chapter I: his closing paragraph poses the question whether we should be 'slaves to unregulated progress' (see Kass: I997/1998, p. 58) or not. And Kass is not alone in this. Many disquieting comments on technological achievements, particularly in newspapers and background television reports, picture the enterprize of science and technology as a 'train rolling on', pursuing its own impetus without asking us humans for our consent.

An interesting version of this deterministic view is found with Albert Borgmann (1984, ch. 9), who discerns in modern technology a device paradigm. This paradigm holds that modern technology detaches us from the essence of the goods we consume. While preparing a meal traditionally took a lot of work and thus established a true engagement between us and the activity of eating, today we only push a few buttons to heat something in the microwave oven that we bought the day before in the supermarket and meanwhile stored in the fridge - it takes minutes, instead of hours. According to Borgmann, this 'commodification' results in a severe decline of the fullness of our lives. What is specifically deterministic in Borgmann's view is that the relation between our human agency and the production of the commodity seems irreversibly disturbed. First, machineries conceal their genesis: we do not know the context in which they emerged and what rationale guided their development. And even if we have sufficient knowledge of the natural sciences to analyze those machines, we can only do so in a decontextualized manner. And second, machineries conceal their inner workings. They just present themselves as devices with an input and an output. And as we are not involved in their making, we lose relatedness to them. 


\section{Politics by All Means}

Fairness demands to say that Borgmann pays a lot of attention to the distinction between instrumentalism and determinism, and it would be unfair to call him a plain determinist. But he is at least a determinist in that he sees no convincing solution with such technologies, but only in seeking the fullness of life outside these technologies. And for the argument of this book, it nevertheless provides a sophisticated alternative to Kass's (certainly deterministic) position. And, as Borgmann's view specifically pertains to questions of the good life, the overall idea of commodification will prove relevant a few times more throughout this book. (Indeed, to Borgmann's vision, Peter-Paul Verbeek (2005) has objected that it is empirically wrong that valued relations are no longer possible in our technological world. True enough, the characters of relations have changed and some have disappeared from our cultural repertoire, but numerous valuable new forms of engagement have appeared in their stead.)

Before affirming myself to a position on the determinism-instrumentalism axis, there are some loose ends to wrap up here. First, it needs explication that this axis is (at least theoretically) independent of the question regarding the good and the bad in technology. We may find both good and bad technologies that comply with a rather instrumental idea of them, and we may find both good and bad technologies that show some deterministic traits. Empirically, we will see that determinist views are more likely to go together with pessimistic evaluations. This is understandable from the fact that determinism is the counterpart of our human freedom, and losing that is hard to value as something positive. And contrarily, instrumentalist visions emphasize the choices that are left to us; thus, they are prone to a more optimistic view. However, this need not be so. Think of the airbag in the car: this object saves lives while leaving nothing to our choice, so it is in fact deterministic (be it on a very micro-political scale); and at the same time, it is hard to argue that this is bad. And in opposition, the personal computer is so versatile in its use, that it comes close to a universal tool that we can deploy for any goal we desire. This does however not justify the conclusion that a personal computer is something intrinsically good, because we can do so much with it. It opens up very bad possibilities as well.

And then there is a second loose end: the question of whether technologies are ethically neutral or not. ${ }^{3}$ If things are good or bad, they are not ethically neutral,

3 In common philosophical parlance, 'morally neutral' would be expected here instead of 'ethically neutral'. However, in chapter 2 I reserved the word 'moral' for claims with a universalizing stance, which is an irrelevant subdivision here. 'Ethical' captures the whole 
because good and bad are ethical categories (amongst others, that is). I will take this indeed for granted. But there might be a third option: that technologies are neither good nor bad. That is to say: the moral good or bad of a resultant situation is not to be attributed to the good or bad of the technology that contributed to the situation. Or alternatively, the deontological equivalent would state that the good or bad of an action is not related to the good or bad of the technological means through which the action was performed. This seems tenable only in combination with an instrumental evaluation of technology - which indeed was found untenable. Nevertheless, at least one specific form of neutrality is possible that does not require an instrumental vision of technology. Indeed, technologies might have an intrinsic ethical dimension, but do so equally for all comprehensive doctrines (see page 50 for the different forms of neutrality). Its ethical neutrality must then be understood as neutrality between ethical stances.

Thus, there are three dimensions: instrumentalism versus determinism, good versus bad, and ethically neutral versus ethically non-neutral. I will not take a position on these dimensions here, not in the last place because I think such a position can never be argued for conclusively. The importance of the dimensions is however, that we must recognize that these are different dimensions, and that they are in practice not completely independent or orthogonal if you like. ${ }^{4}$ And we must recognize, that this multitude of dimensions may lead to a multitude of evaluations of one and the same technology. Each of the three dimensions provides an entrance to disagreement, and in a technical, political society, these add to Rawls's burdens of judgment (see page 3I).

\subsubsection{The neutral image of science and technology}

In the previous subsection, I explained that the vision of technology as applied natural science is not tenable. However, many moves in the debate can only be understood if we suspect that speakers do implicitly hold such an applied-science vision of technology, or even actively maintain it. In this subsection, I will explain how this picture of technology as neutral can emerge and persist, and how this will collaterally lead to a picture of technology as being politically irrelevant. I will start from the separation between facts and values. Then I will look at some

of it.

4 I will suggest an idea of the difference between independent and orthogonal in subsection $4 \cdot 4 \cdot 2$. 


\section{Politics by All Means}

methodological aspects of science and technology that help to establish a neutral image. Finally I will explicate some properties of the institutional settings of science and technology, that cause them to appear neutral.

I take the separation between facts and values, emerging in the wake of Enlightenment, as one of the most important characteristics of modernity and modern culture. This separation is recognizable in everyday speech. Values and facts are intuitively taken to be two different categories. On the one hand, facts are what we must agree about. In case of disagreement, scientists are to be consulted as the exemplary arbiters of those facts. They are supposed to know best about the methods of empirical enquiry and the way to prove and disprove facts in ways convincing to all. Values, on the other hand, being judgments about what the world should be like, are of a different nature. We accept that they give more rise to disagreement, even though we are not completely relativistic concerning, say, the despicability of murder. Insofar as we feel the need to discuss values, they are a matter of politics, of religious belief and interpretation, of negotiation between husband and wife, or just a matter of observing 'what is considered appropriate by all members of society'. But values are certainly not a question of scientific investigation. They are not a matter of what is true, but rather a matter of what is good. With respect to the judgment that I plus I equals Io, it would make little sense to respond that 'ok, it's fine if that is your opinion; I just tell you that it is not mine'. If we were told about, say, the beauty of a picture or the desirability of a welfare state, such relativistic answers make a lot more sense. This is not to say that values can by definition only be faced with relativism or indifference, witness the murder example. Yet it is to say that we cherish a separation between things that we can disagree about and things that we cannot, and that science and its 'applied sibling' technology are most likely to end up in the latter category.

In this vein, David Hume (I740, book III, part I, section I) observed that many thinkers wrongly commence inference from a set of factual premises (that is, statements with an 'is'-character or claims about how the world actually is) and conclude to a set of normative statements (that is, statements with an 'ought'character or reference to how the world should really be). This kind of is-ought inference, according to Hume, is definitely invalid as empirical statements are of an entirely different nature than normative ones. Therefore, they cannot be reduced to one another, nor will there be an objective way to discern between morally good and morally wrong statements in a way similar to the differentiation 
between true and false factual statements. ${ }^{5}$ Given the intimate ties between technology and scientific knowledge, against this background it is unlikely that there is anything morally relevant in the application of those facts.

A second reason for post-Enlightenment science to appear neutral can be found in the mechanistic and reductionistic world view. This view tries to understand the material world in terms of its smallest constituents. If we understand those, we can also understand their aggregate. ${ }^{6}$ In addition, empirical investigation can be managed best by cutting it into fairly simple and small experiments. Thus, the desire for empirical investigation incites a strategy of splitting up larger and more complex phenomena into smaller and simpler ones. Similarly, technology as the application of science enjoys the image of being composed of small elements that engineers do neatly understand. And as there hardly is anything normative to basic principles and elements - who would question the moral irrelevance of Newton's and Ohm's laws or the principal working of cog wheels? - it is hard to believe that their aggregates will pose great moral problems. In a broader vein, Alan Petersen (2005, p. 204) has argued that 'the language of science is seen as providing a neutral description of a natural, [...], pre-social world'.

A third reason is recognized by Gerard de De Vries (I999, pp. 26-28) in the typical vocabulary of modern ethics. The question of 'how to live' is actually answered in laboratories, on the drawing table, in marketing departments, and more broadly speaking in practical situations. However, ethicists are concerned mostly with designing forms and regulations. Much like sociologists - as De Vries pointed out, in I999 - they fail to see the material infrastructure as an inherent element of our society. Rather, they argue from the Enlightenment tradition that sees our conscience as the free subject that rationally comes to conclusions

5 More specifically, Hume argues that the normative kind cannot in any way be arrived at by reason. Rather, they are the expressions of sentiments and desires. This latter statement makes Hume vulnerable to the accusation of emotivism, that is the inference from feelings to moral judgments which is today seen as problematic. Indeed, this is one of the reasons why Hume's view cannot be simply taken for granted. However, this does not disprove the empirical significance of the fact-value separation for modern culture, nor does it disprove that many people will conclude to the separation in a way much similar to Hume's.

6 This view can either be an ontological claim - the world is really not more than the aggregate of its smallest parts - or a methodological device - the best scientific methods are those that confront the world as if it were composed of smallest parts that contain all there is to know. However, the difference between the two does not really matter for my train of thought: regardless of what scientists actually have to in back of their minds, their sciences do generally try to explain wholes on the basis of parts, not the other way round. 


\section{Politics by All Means}

regarding desired actions. This way of thinking produces rules without a proper link to practice.

In addition to these epistemological factors, there are some institutional reasons for science and technology to appear neutral. Where the establishment of facts is concerned, the exemplary authority is the natural scientist: he or she is considered to have the widest repertoire of methods for either confirming or refuting factual claims. And as facts are fundamentally value neutral, we are inclined to think that anything a scientist creates or says is also value-neutral. If we then take into account the (naive yet widespread) belief that technology mainly consists of 'harnessed natural laws' or even just 'applied science', we see that technology is likely to appear as something that we can choose whether to deploy or not in achieving our valued ends. Indeed, Langdon Winner (I993, p. 365) observes that even many investigators of science and technology - mistakenly see technology as the lesser relative of science. In such a picture of technology as just 'applied-scientific means to ends', those ends again appear as independent of the technologies that serve them.

A second institutional reason why science and technology appear instrumental is more internally oriented. In order to stay out of political control, technologists and scientists have an interest in maintaining their image as being neutral. The more innocent and politically irrelevant they appear, the less they will have to fear interference in their business from others. Interesting enough, the norms and values that make science and technology into good science and technology, also contribute to its neutral appearance. For example, immanence is an important condition for neutrality. Immanent claims make no reference to metaphysical ideas and are principally completely understandable 'here-and-now'. As no references are made to things that are not accessible to all, the danger of non-neutrality is minimized. And indeed, this immanence is also an important corollary of the values of disinterestedness and organized scepticism which Robert K. Merton (I942) discerned among scientists. Those values grant that claims are open to further cleansing, should their conclusions be 'contaminated' with personal tastes and preferences. Technologists and scientists thus earn credibility regarding their neutrality by merit of their modesty.

In addition, De Vries (I987, p. I0) argues that these methodological outlooks are not just some rules of method for their own sake. Rather, they are strongly institutionalized and they are actively deployed to grant that science and politics 
be two strictly separate institutions that each have their own objects and mores. Science investigates what is objective; politics deals with what is subjective or normative. De Vries adds that the institutions of science pose formal requirements to admission, and deploy styles of reasoning that perpetually reestablish the niche that science has in society. Thus, these boundaries of scientific practices are not primarily logical, ontological or epistemological - which is what the account by Hume, described above, largely builds on - but rather constructed and enacted in the course of time. Similarly, Thomas F. Gieryn (I983) conceptualizes this very same boundary as indeed enacted and strategically defended, and argues that the scientific practice has an interest in keeping up the appearance of something descriptive and a-political. This altogether confirms that science, and hence its believed-to-be applied counterpart, technology, primarily go under an objective and value-free guise. This confirmation is independent of the more analytically oriented separation as just discussed.

\subsection{Science and technology as networks}

\subsubsection{Extra-human meaning}

In subsection 3.2.I, I discussed that visions of technology basically range between determinism and instrumentalism. That is, between no space for human agency, and ultimate freedom in service of human agency. However, our everyday experience is that there is always some degree of free choice, but that there can also be some limitations to that choice owing to our technological surroundings. Think for example of a gun. It does not kill by itself, since human intention is still a necessary precondition to commit murder: it takes a human to pull the trigger. (And even if the gun killed somebody by itself, we still do not put the gun to trial, but rather seek for a human actor we can blame of severe negligence or something of the like.) But obviously, the murderer can only pursue his or her evil plan - or at least this specific implementation of that plan - by merit of the existence of the gun. In absence of the gun, he or she might have taken another course, such that the victim might still have been alive. In the face of this peculiar balance between instrumentalism and determinism, I suggest to put aside the question to which side the balance tips. Rather, I propose to presume that we cannot tell in advance, and that we therefore devise an approach that is most open to all possibilities. This subsection and the following one will develop such a neutral approach. 


\section{Politics by All Means}

One elegant way of shaping how technologies, and more generally speaking things and artifacts surrounding us, bear upon our behavior, is through the concept of the script. Much like how the script of a play or a film prescribes what actions are to be taken at a certain moment, many things seem to demand that we act along certain patterns. The idea of inscription of user behavior into products comes from Madeleine Akrich (I992). Through scripts, technologies impose constraints on our actions. Plausible examples include cars that will not ignite unless seat belts are fastened, and key fobs that are simply too massive to accidentally smuggle them out of the hotel. Another textbook example was described by Bruno Latour in his book La clef de Berlin (see Latour: I993a, introduction): speed bumps, also known as sleeping policemen, force us to drive slower in the vicinity of schools and residences for the elderly. They do so at the threat of killing our car's shock absorbers. We do not really experience a free choice to drive on the street at a speed other than what has been established as appropriate; though we could, if we were willing to bear the costs. But above all, the speed is materially limited by the speed bump. Thus, the material configuration coerces us to behave morally, instead of running over innocent school kids. This account is a good onset for the unbiased approach I called for: it leaves undetermined a priori whether humans or non-humans are in charge, and does allow for both human choice and coercion by non-humans.

In a more abstract example, José van Dijck (I998, pp. I79-I85) captures the history of genetics in our culture in a number of stages. In the I950s, DNA was conceptualized in terms of 'language' and 'code', which served as metaphors for its working. In the following decades, focus shifted towards the individual gene, which eventually reached a status transcending the individual organism. In the I980s, the gene even became 'selfish' and was increasingly seen as able to 'reproduce' itself, using the body as its replicating machine. At the emergence of the Human Genome Project, this mechanistic approach to the individual gene lost its power in favor of the old metaphors of 'code' and 'language'. Peculiarly, this latter revival of earlier approaches cannot be seen apart from the emergence of the information society: the computers and computer programs surrounding us forced us in a way to look for metaphors that were more apt than the ones ruling at the time. And in addition, by opening up the possibility of detaching information from its material carriers, the same information society made it possible for us to think of genomic information as information. This imposed onto us the thought 
of wholly new conceptions of identity, which forced us to rethink all the possible scenarios that a genetic era may offer.

The effects that technologies have on our lives can be elaborated further. The work of Peter-Paul Verbeek offers a fruitful entry. Verbeek (2005, p. II9) distinguishes between existential and hermeneutic roles that artifacts can play. The former concept concerns how technologies co-shape our actions. The latter concerns how they influence our perceptions of the world, and how they thus in a broader sense co-shape our world view. Verbeek here argues largely in line with Don Ihde (I990, pp. 80 and onwards), who ascribes to technologies the ability to make us 'read' the world. For the argument of this book, both the hermeneutic and existential dimensions of artifacts are important.

To clarify the hermeneutic and existential dimensions of our living together with artifacts, medical screening programmes provide a fine example. First, there is the mere emergence of the screening technologies. Compare this with the previous situation, when there was no screening. In the earlier situation, patients simply were not confronted with screening opportunities. Then, at a certain point, they were sufficiently developed into a commodity for the medical doctor to use 'off the shelve'. Consequently, their existence produces a predetermination of action in the sense discussed above. This is the existential role, played by screening technologies: they are simply there, and thus make certain choices more logical than others. Second, the screening programs express - be it implicitly - the view that it is always best to know as much as possible. (Obviously, this view nicely coincides with the modern-scientific hunger for knowledge, which appears as morally neutral, simply because facts appear as morally neutral, see also subsection 3.2.2.) In a way, by their existence the screening technologies consolidate a vision of what a normal human being is like and how it should be monitored and interpreted. This is the hermeneutic role played by screening technologies: they co-constitute our world view.

This hermeneutic dimension is in fact played out on two levels of perception. Don Ihde (I990, p. 29) distinguishes a level of microperception and a level of macroperception. Microperception is the actual sensory act of perceiving. In contrast, macroperception is the kind of perception that we might call cultural, and which concerns in the broadest sense our view of the world. Macroperception is not only the addition of many microperceptions. Macroperception is also what microperceptions get their meaning from, as it puts them in perspective 


\section{Politics by All Means}

and context. Macroperception on the other hand, cannot exist without the microperceptions constituting it. This bidirectional dependency constitutes a hermeneutic circle, and explains how the influence of artifacts on our sensory perceptions pervades our view of the world at large.

Given how technologies clearly play roles in our microperception, it is inevitable that they also, if only indirectly, play roles in our macroperception. Technologies co-shape the way we see the world. This can be recognized in many contexts, including the one of medical technologies. For example, the very concept of brain death emerged first in the I96os, when heart-lung machines enabled the preservation of the bodies of comatose patients beyond the point at which all hope of recovery was in vein (see President's Commission: I98I). While earlier the diagnosis of death had depended on the cease of heartbeat, breath, or skin moisture, these criteria no longer sufficed once a machine had been invented that artificially keeps the body functioning. In particular, the heart, lungs and skin remaining functional were the major difficulties in redefining death. These were microperceptions that now collided with our macroperceptional idea of death. By reinterpreting the microperceptions involved, macroperception shifted. Thus, the cultural concept of death had undergone a radical change. This proves a fine example of the hermeneutic dimension of technology, having its effect on the level of both microperception and macroperception.

In a broader picture, this is how technologies co-shape our world and hence our perception of that world. Highways and telephone lines alter our perceptions of distance. Predictive medicine, to which the prospective contributions of genomics are large, alters our perception of illness and disease. By altering how we think of disease, it opens up new cultural visions of disease and thus it alters the very idea of disease. This impact on the meaning of concepts is not to be underestimated, as they 'populate' our everyday speech, which is practically the only thing we have to structure our world and our lives. Meanings of concepts are the building blocks of our world views. And if these change, this is likely to emanate onto our private normativity (see page 32 and onwards).

In addition indeed, given the intricate relation between public and private normativity discussed in chapter 2 , we may expect this to cause some friction. Through the mechanism of hermeneutic and existential roles played by technologies, the terms in which we perform politics are subject to change by technological and scientific influences. Indeed, part of this has been observed by Sclove (I995, p. I5), 
talking of symbolic meanings that predetermine some of our political thoughts. However, Sclove does not push this to the conclusion that this makes democratization of technology an inherently problematic enterprize. Instead, he works towards a further democratization of technology, still presuming that technology can be an object for democratic decision making. By drawing the moral consequences from the conception of technology I developed in this subsection, it follows however that we cannot see politics as prior to technological and scientific development, but as a co-evolving ensemble of the two closely knit together (see Bijker: I995, p. I5). And what is more, it will be fundamentally difficult to determine whether a certain ethics, either public or private, is the result of evolution in science and technology, or of human consideration.

\subsubsection{A network approach to science and technology}

The previous subsection gave an account of how technologies influence our life world, and did so from a perspective that was a priori symmetrical in respect to human and material agency. It has however not yet explained how these technologies come to be the way they are. This section will give more of such an ontological account, largely building on actor-network theory, henceforth referred to as $A N T$.

Truth to tell, ANT is an approach with some difficulties. That is, it gives a complete picture of the world, offering a place for every phenomenon. In this sense, ANT is an ontology. However, because of its wide stretch, it runs the risk of explaining too much and therefore actually explaining nothing. It also has little predictive power, and from its metaphysical character, it earns an immunity to falsification. Thus, we cannot take ANT as an actual theory - which is indeed recognized as one of its major flaws (see Latour: I998). However, at the cost of these difficulties, ANT offers a powerful vocabulary to describe the things we see. Thus, next to a modest ontology, it will also prove an important methodological device: it at least provides some terms in which we can discuss our observations. And most important, it does give a plausible account of how rigidity emerges, to be explained in due course. This rigidity will be shown to be the result of the networkedness and omnipresence of technology - exactly what I will need in part III. I will briefly give an account of ANT here, of which I take Bruno Latour to be the most important representative, even though he emphasizes that he is not the inventor or even a user of the term (see Latour: 1998). 


\section{Politics by All Means}

ANT understands the world in terms of actors that are related through networks. These networks give actors their identity: whatever an actor is can only be told if we know the network it is part of. The links between actors are links of power, of interest, of making other actors line up with one's strategies. It is their ties to networks and the influence that they can exert in them that makes actors successful - or the opposite, for that matter. The more other actors or 'allies' an actor gets enrolled, the larger the chances of success are (see Latour: 1987, pp. I03-I08). And consequently, the larger and more ramified the network supporting an actor is, the harder it will be to defeat, change or harness that actor.

One of the main methodological rules in ANT is a strict symmetry between humans and non-humans. In fact, such symmetry demands that you cannot even speak of humans and non-humans as separate identities or different sorts of actors (see Latour: I993a, p. 24). The artifacts surrounding us are what they are by merit of the connections and relations they have with other actors and the transformations they induce in them. And so are we, humans. Whatever we are, we can only be so by our connections to others, both humans and non-humans. We are like Siamese twins with all and everyone that surrounds us. Thus, for a story to be fully told, it is necessary that we take into account both humans and non-humans. Otherwise, we would get either a (human) sociology or a (non-human) history of technology which then misleadingly appear as separate entities. Therefore, I will henceforth silently presume that actors include both humans and non-humans, and refer to them as 'it'.

This approach to how humans and non-humans inhabit this world together has some important consequences. First, it entails that social and technical networks are one and the same. Relations between actors, both human and non-human, can be of a social nature or of a technological nature or both, but we cannot tell from the outside. The coincidence of social networks and technical networks and the fact that they together and equally have an influence on what happens in our world, makes that we cannot discern them separately. Neither should we try to. ANT entails that there cannot be an a priori idea of what or who has causal primacy over someone or something else.

The second consequence is that we cannot be too much interested in what causes things to happen, but all the more in those things themselves. All that we see are collisions between actors. In those collisions, actors induce changes in one another. They reposition them, break network connections and create 
new ones, and cause actors to change strategies. These collisions often appear as controversies, conspiracies or dirty fights. These will star abundantly throughout this book.

Third, while we cannot really see or assign causes or ultimate sources of power, we can see the collisions and interactions between actors and we can also see the result of those collisions and interactions. What counts is the final configuration that is obtained, in which humans and non-humans find their new place. Power will be distributed differently than before. Interests and alliances will be different. Once actors have acquired a new position in the network, the world will be different.

When a controversy is settled, it will fade away from our view and from the memories of the actors. It becomes invisible. What we are left with, is the new situation in which networks are arranged differently from how they were before. This means that powers are distributed differently, and that reality has been given a new face. This new face hides how the actors and their powers came to be distributed in that specific way. We see the new reality, but we do not see the genesis of this new reality. And we forget, therefore, that it is a new reality. This is when Latour says that a black box has been created: we see it, but we do not see how it came to be that way. Black boxes hide their history and genesis. Latour (I987, p. 2) borrows the term from cybernetics, when literally a black box is used to represent systems merely in terms of their inputs and outputs, abstracting from their internal working (see also Winner: I993, p. 365).

A settled network is a source of stability and solidity: the rigidity that I was looking for. Once a network is in place, it becomes harder to modify. The larger a network is, the more rigid it will generally be. If one wants to change a certain element, this will incur changing the whole network the element is part of. That is hard work. And conversely indeed, in absence of a network, an actor would be unable to stand up to even the smallest challenge. This again explains why we cannot understand an actor without the network surrounding it: actors cannot even exist - that is to say: maintain their identity - without their networks.

A network is not only a cause for reality to be one way and not another, it is also the consequence of that same reality. After all, the emergence of new networks and configurations will always be related to the background from which it takes its elements. For example, in the last decade, medicine has witnessed the emergence of evidence-based medicine. This new, formalized methodology 


\section{Politics by All Means}

aims at a rather impersonalized and reliable way of establishing medical-scientific knowledge. It does so by deploying strictly-controlled randomized clinical trials, that are supposed to meet statistically corroborated standards. The emergence of this approach cannot be seen apart from the 2oth-century liberal welfare state in which it evolved: they share a preference for impersonal and thus neutral ways of making decisions (see Dehue: 200I; Valkenburg, Achterhuis and Nijhof: 2003). Evidence-based medicine could in its present form never have emerged in a society that is not liberal in the way that brought forth this form of doing medical research.

The network as a source of rigidity in technology gives rise to a phenomenon known as the Collingridge dilemma. This dilemma is an immediate consequence of the observation that technologies become harder to modify as their maturity develops, while at the same time their final shape and possible downsides first emerge in the course of maturization. In the words of David Collingridge (I980, p. II): 'When change is easy, the need for it cannot be foreseen; when the need for change is apparent, change has become expensive, difficult and time consuming' It needs saying that in Collingridge's conceptualization, the emerging rigidity exists primarily owing to institutional aversion to change once decisions have been made. Accordingly, his solutions to problems of rigidity primarily aim at producing institutional flexibility. Nevertheless, the dilemma stands rather convincingly for ANT networks. It only demands generalizing Collingridge's account of organizations towards the networks of ANT, and then the networks prove themselves an account of the emerging rigidity.

The technical equivalent of the dilemma has indeed been observed and labeled emerging irreversibilities by Van Merkerk and Van Lente (2005). A similar notion is the collective agency described by Swierstra and Rip (2007, p. 8): given that technological solutions are difficult to change once they are in place, we must see agency as an affair distributed between human beings and those technological solutions, rather than a purely human affair. In each of these forms, the Collingridge dilemma will prove relevant later, as it produces a bias in favor of those who argue optimistically about technology.

I will now trade the notions of technology and science for one single notion of technoscience. In line with Latour (I987, pp. I74-I75), I keep to the following distinction. Technology, as well as science, are institutions that profile themselves as indeed clearly-bounded realms that each in their own ways earn their existence. However, following ANT, we must conclude that these boundaries can only be 
vague, as there is no reason to believe that networks keep to those boundaries. Moreover, the ANT view entails that science and technology are not so much of a different and autonomous thing. Rather, they are just 'accents' or highlights in endless networks that stretch way beyond the boundaries of the formal institutions, into the social, political and private world. This whole of relations will be referred to as technoscience. Science and technology on the other hand, are the black boxes that conceal the fuzzy networks of these relations, which appear once they are sufficiently corroborated. Whenever I speak of technoscience, I mean the whole of it that interacts with our life world and the meanings we attribute to it.

One of the problems with ANT is that today networks are omnipresent in the appearance of the internet, money transfer systems, telephone networks and so on. However, these are not anything like the networks that ANT was devised to describe. This has 'polluted' the original idea of networks (see Latour: I998). ANT is not about networks in terms of hard wires, but in terms of relations, collisions, transformations. A hard-wired network is supposed to transmit things at minimal distortion or minimal loss; they thus pursue transparency. ANT networks on the contrary do nothing but transforming and distorting and repressing elements. However, being aware of this huge source of confusion, there is still something to gain from more intuitive and everyday ideas of networks, and part of this even matches nicely with ANT networks. This primarily concerns the phenomenon of omnipresence, the enactment of power and agency, and the fact that hard-wired networks do embody relations between actors. (Insofar as confusion looms, I will speak of hard-wired networks to discern them from ANT networks, even though we may be speaking a bit more abstractly than strictly of copper-wire or glass-fibre connections.)

Outside ANT, a number of other thinkers indeed recognize that technology principally is made up of networks. Amongst others, Sclove (I995), Castells (I996) and Van Dijk (I99I) have articulated that networks are essential to understand contemporary technological culture. Contrary to ANT, these thinkers are talking about physical, hard-wired networks. What these hard-wired networks do however share with their ANT namesakes is that they show that it impossible to tell how situations are bounded, where influence stops, and who or what is in charge of what realm. By their spatial extendedness, both types of networks induce an omnipresence in technology: places will always be entrenched with some technology from some origin. And the hard-wired ones do so more tangibly. 


\section{Politics by All Means}

Many instances of these hard-wired networks are in fact quite comfortable: most of us would not trade electric lighting for candles and oil lamps. Nor would we like to live without the telephone or the television. However, sometimes these networks may transgress boundaries that we earlier took for granted: the telephone facilitates to some extent that others intrude our private houses in a subtle way. Needless to say, we tend to accept this as a cost of, for example, the valuable facilitation of family bonds. But the omnipresence of closed-circuit camera surveillance in virtually any modern city does raise discomfort in many. Indeed, hard-wired networks extend both inwards into the self 7 and outwards into the 'world out there'. Thus, technology and its specific instances become inevitable.

This technically-mediated social topology is often referred to as the Network Society (see also Van Dijk: I991; Castells: I996): not only are the consequences of our actions impossible to fully oversee, hard-wired networks also make that we feel related to children starving in Africa as we see them on our television. Networks are not only about acting, but also about defining whom we are related. This will prove a valuable recognition in discussing biobanks in chapter 5 .

We have now arrived at an account of technology that transgresses boundaries, has rigidity, shapes ourselves and our lifeworld, and consequently shapes the meaning we give to that world. Moreover, artifacts exact compliance by exerting influence through scripts. And they are rigid at that, which is directly owing to their networked character. At the same time, the constructed character of networks makes that networks implicitly reflect the background to which they emerged, even though the process of this genesis is usually hidden in a black box. We are largely determined by the networks we are part of, but at the same time, the ANT conception does justice to the fact that we have indeed plenty of opportunities to exert our own influence in that world. We are neither slaves nor masters, but inhabitants on an equal par with our nonhuman peers. Feeding this back to the account of how technologies give meaning, developed in the previous subsection, we now have an integral account of how both our meanings and our actions are connected to ourselves, actors surrounding us, and the networks by which we are connected to them.

7 I am aware that the notion of a self is in fact too much of an anthropocentric notion, which is incompatible with the symmetrical approach between humans and non-humans. However, despite the ontology expressed in ANT, our experience of the world is still one of an ' $\mathrm{I}$ ' that 'confronts' the world, and therefore it makes sense in this specific situation to speak of a self. 
Moreover, the presumptions that I started this chapter from have indeed been disproved. No, technology is not just there to serve the ends that we devised in full freedom; rather technologies are here with us, and help establishing the ends to which they are lined up. No, there is no world-out-there ready for us to manipulate, but rather do we and our technologies shape that world ourselves, thus implicitly defining our own entries for manipulating it. And no, technologies are not just tools and instruments, but rather interfere with our normativities along subtle lines. Thus, this already hints at how the boundary between public and private normativities may be technologically problematic, in addition to the political problematicity developed in chapter 2 . The next subsection will indeed discuss this political dimension to technology-as-networks.

\subsection{Technoscience goes political}

\subsubsection{Towards political technologies}

We have seen so far, that technoscience and human beings live together in networks that stretch far and invisibly into each others spheres. In fact, the ramifications of these networks are so refined that it is fairly difficult, if not impossible to tell what element belongs to what network, if we can discern separate networks in the first place. This idea of socio-technical networks, that is networks in the ANT conception in which humans, and non-humans 'live' together, has important political consequences.

I devised in chapter 2 that the first question that politics needs to answer is the question of scope. A first way for a network to exert influence on the scope is by its impact on what must be considered the relevant situation: since mobility and telecommunication are today proliferating, dependencies span increasing distances. And since all we have interacts in translation and combination with other actors, we cannot really tell where our influence stops or where our surroundings are bounded. Owing to our socio-technical networks, we are able to exert an influence on persons that we may never encounter in real life, in countries that we may never visit and at times that may be in the far future. Our relations are not limited to the geographically confined group in which we were born, but rather depend on the connections we manage to establish. This wide stretch of the influences of our action makes makes things falling inside the scope. Thus, this networking account has important consequences for the conception of the political 


\section{Politics by All Means}

landscape in terms of a public and a private sphere, as developed in section 2.3.

One particular consequence is that this unlimited influence also holds for movements within society: dominant styles have the largest influence in the public sphere (both as a moral decision style and as a physical or spatial implementation), and this may compromise the effective freedom of other styles. This cannot be seen apart from my ideas in subsection 2.4.4, where I explained that the boundaries between public and private spheres are always contested, trespassed and redefined. With the present conception of technology as being networked, the work of purification has received a material substrate, and a confusing one at that.

Health care provides a fine example of how the influence of networks easily trespasses the boundary between public and private. Health care in our society is largely a public institution: its main resources are public and its regulation is in public hands. Therefore, it is most likely that new medical technologies are also assessed in a public, political discourse. They are thus within the scope of politics. However, the use of such new technologies can be intimately connected to private lives and normativities. For example, screening technologies may find their implementation in population-wide screening programs. While this appears indeed as a public phenomenon, it is a highly private consideration how we exactly value this specific way of 'knowing thyself. Thus, because of the connectedness between public resources and policy, and private ethics, the phenomenon is ambiguously public and private.

One less straightforward way through which a technology can introduce something to this scope, is by enabling new forms of harm. Harm is a concept figuring in debates. And concepts are indeed among the non-human actors that star in our networks: even though we cannot touch them, they certainly have an influence on our speech and thought. We have indeed seen that something being harmful makes it likely that is part of the political scope. For example, with a contemporary car we can inflict harms on others that we could not do in times when horse and carriage were the means of transport. Thus, the introduction of the car has necessitated traffic laws that compensate for the new dangers. (This is not to say that traffic laws are discussed in parliament at length; it is just to say that traffic laws are public regulations that were needed for a public reason.) Less obvious constructions of harm that are unleashed by technoscientific change, can be found in the domain of human enhancement, which will be further discussed in chapter 4 . Enhancement may facilitate ways of manipulating our children in new 
ways. For some, these new ways will present new harms. This may then violate the condition of tolerance, which will urge them to bring part of our reproductive practice into the scope of politics. This will produce a controversy when not all agree that it should be there. And similarly, in the chapter on biobanks, we will see that the emergence of biobanks gives new meanings to some concepts, thus rearranging our possibilities to think of harm. As these forms of harm are new, they urge us to revise that public-private divide.

As a consequence, this bears upon the justification by which decisions are made. For if a technology pervades the private sphere as just exemplified, it is not more than logical that we allow private ethics to play an important role in its judgment. That we however do not always do so, is a likely consequence of political purification in the first place: we need to purify, and private ethics are not allowed in politics. This is problematic if in practice, a significant part of discussing technology takes place in the public sphere. In fact, it has been empirically observed that we have a tendency to deny in politics that technology has a link to private ethics, because we consider possible bad consequences to be side effects. In fact, in politics we tend to deny any link between technologies and ethical consequences; the latter are rather side effects and referred to as 'externalities' (see Jelsma: I992, p. 300). For example, the National Institute for Public Health and Environment (RIVM) in the Netherlands issued a report on the state of affairs in nano-technology. In a radio interview, Maaike van Zijverden, researcher at the Institute, added that the report just presents the facts, while it is up to politics to decide on further policy (see Van Zijverden and Sips: 2008; Desmet Live: 2008). This silently presumes that facts are indeed neutral and precede normative discussion. Which is in its turn remarkable, because the tone of voice was certainly one of caution.

However, the network conception of technology also has consequences in the other direction: technology is not only an object of politics-as-purification, it is also likely to play a role in that purification. As changes in the network are likely to induce changes elsewhere, and ideas, justifications and conceptions are part of our networks, it is indeed likely that technoscientific changes produce a change in ethics that builds on those conceptions. This sounds abstract, but it is clear if we recall the two dimensions that technologies play out in our life world: the hermeneutic and the existentialist dimension. Changes in our technological constitution are likely to change our world view and the choices we can make, 


\section{Politics by All Means}

and hence they will change how we assess arguments and ultimately co-shape our actions. Over the last centuries, many technologies have indeed opened up private choices. And a more concrete example, the fact that abortion can today be performed in a medically sound way, has strongly contributed to the (liberal) understanding that the woman should be able to 'rule her own belly', as it is represented in Dutch law. This seems to coincide with the hegemony of individual choice in ethics and politics today. Moreover, even opponents of abortion need to frame their arguments against a background hosting this technologically-mediated form of abortion. That makes abortion harder to argue against. This mechanism will recur in chapter 6 on preimplantation genetic diagnostics in Dutch politics.

The following is an even more concrete example of how the hermeneutic dimension will have an influence on justification in politics. Today, medical practice has at its disposal numerous different technologies for the visualization of the human body. Amongst others, this has provided us with vivid pictures of unborn fetuses. Even in stages in which the mother's abdomen hardly shows any sign of pregnancy, the person-to-be can be shown in a fairly human appearance (see Verbeek: $2008 \mathrm{~b}$, p. I4). As we tend to treat persons differently from the way we treat non-human entities when it comes to harming them, ${ }^{8}$ rendering a fetus more human-like will generally make us think of it more human-like in ethical terms as well. As we thus give new meanings to the unborn child, interventions like abortion and prenatal diagnostics will receive new meanings as well.

In addition, alongside the existential role, technology expresses a normativity by demanding our compliance. The way we act is not immediately the same as the way we politically justify our statements, but expressing ourselves is certainly a way of acting. Hence, our expressions may well be subject to compliance with technologies. In a general way, this is how a technocracy can emerge in the first place: he or she is most likely to get to power who is on the controlling end of technology; in particular, he or she who has the largest influence on public media, is most likely to get his or her arguments voiced. But it also works in a more implicit way. For example, regardless of how we regulate cars and the roads they drive on, it is hard to argue against individual mobility in a society like ours that is entrenched in these technologies.

8 This remark may appear at odds with the earlier methodological assumption of symmetry between humans and non-humans. However, it is not: saying that our method should not distinguish a priori between humans and non-humans is not the same as saying that in ordinary life, our judgments do not make any difference between humans and non-humans. 
Thus, by playing a role much like we do ourselves, technologies have an influence on both scope and justification. Fair enough, I have so far only exposed some basic lines of thought, without really giving a material account of these mechanisms. This will however follow in the empirical chapters in part III. The basic line of thought is that our behavior and thoughts cannot be seen apart from our relations, and these relations include ones with non-humans. Thus, these non-humans are likely to influence scope and justification. They co-shape what we see as politically relevant, and they co-shape how we discuss that.

So far, my conception of technoscience has largely been one with the character of a seamless web: the networks I devised are continuous, not discontinuous to use a metaphor from mathematics signifying that no boundaries are explicit. Therefore, it is hard to tell where technoscience enters or leaves the scope of politics, or how it renders justifications politically relevant or irrelevant. The examples just presented might feed the impression that technoscience clearly moves decisions and justifications to and from the private sphere. However, it is exactly the character of technoscience as a seamless web that makes these rearrangements hard to discern: as the networks do not clearly represent boundaries but rather deny them, rearranged elements can travel over the boundaries rather unnoticed. This was an important observation in subsection 3.2.2, where it was argued how technoscience can keep up its instrumental guise.

As a small excursion towards the end of this section, it is interesting to see how these mechanisms can be captured under the idea of monstrosity (see Smits: 2002, p. 28). In mythology, monsters are generally creatures that unite traits that should not be united. The minotaur is monstrous, not because either man or bull are monstrous, but because the male torso and the bull's corpus are not to be united. Both Dolly and Frankenstein's creature are monstrous in the same way: organic nature should not be united with human-made technology. Things belong to the category of human-made; animals and human beings belong to the category of naturally-growing. When these boundaries are violated, some people end up with a strong feeling of discomfort. Monsters arouse fear and anxiety, not by their being plainly evil but rather by their being vague, ambiguous and anomalous. At least, thus concludes Smits based on a cultural-anthropological approach.

Exactly because monsters do not fit into the categories that we use to organize our world, they are difficult to get our hands on. We cannot really get hold of them, because our repertoire of strategies is strongly correlated to our categories. We 


\section{Politics by All Means}

treat dirty things in a way that we think is appropriate for dirty things, and this way is different from how we treat clean things. But what if we encounter something that is neither clean nor dirty? Neither strategy will be completely appropriate: if things are anomalous to our categories, they are as a consequence anomalous to our repertoire of strategies. Thus, monsters are in this way immune to our hands. In a broad sense, anything that is difficult to place in classes, will be a monster. Against this background, practically every technology, because of its connection to other elements, will be a monster in the face of our various classifications. This is logical, as there is usually something new and unprecedented to technological changes.

However, this widespread opportunity for application of the concept of monstrosity urges us to be reluctant in doing so. Taking the idea of monstrosity too broadly makes it into a non-debunking explanation: it captures everything, and thereby explains nothing. Speaking in terms of monsters only makes sense in those situations in which we see that a strategy fails, while we would at first glance expect it to work. In such cases, it might be illuminating to observe that the problem at hand is in fact not a fine match for the strategy. Then the monster concept may prove valuable.

There is at least one way in which the monstrosity of technoscience will indeed prove valuable. It is at least monstrous, insofar as it refuses to be fitted into the public-private categorization. We have seen that this is so because it has the character of a seamless web and intrudes our private lives without us noticing it. And as I argued that purification between public and private spheres is an essential element to doing politics, it is clear that this technoscientific monstrosity provides a potential for difficulty. We will indeed see in part III that this monstrosity occurs prolifically: difficulty with the public-private classification is the rule rather than the exception.

There is one deeper mechanism through which technoscience shows quite a trace of monstrosity. I argued that technoscience contributes to the meaning we attribute to the world, through its hermeneutic dimension. In particular, this entails that technoscience is able to remould our categories: the public-private divide as well as any other judgment we make. As technoscience can change harms and the meaning of harms, it continually produces hard cases to existing political frameworks, and it makes problems into hard cases because of a perturbation of the framework. This is a mechanism that I have not found in existing monster 
theories, but I consider it monstrous nevertheless, because difficulty in classifying is at the core of both.

In addition to the public-private distinction, technoscience has the capacity to be monstrous in the face of at least two other classifications. First, they may frustrate the distinction between morally neutral and morally non-neutral things. They may appear on the outside as neutral, while below the surface they have strong normative impacts. Thus they appear to fit into the category of 'things that need no political consideration' or simply outside the political scope, while in fact they often at closer look seem to belong to the category of 'things that need political discussion', or things inside this scope.

And second, through the mechanisms described above they have an influence on our language. Besides failing to fit into our various classifications, this also makes that this language itself becomes monstrous: through the hermeneutic dimension, technoscience helps to attach new meanings to our concepts, which makes that the language itself is no longer clear nor unproblematic. This will raise a feeling of discomfort in many discussants. Categories need explicit reconsideration then, which will only add to experiencing monstrosity.

\subsubsection{Our political blind spots}

I argued in chapter 2 that politics, especially contemporary politics in a pluralistic situation, can be understood as a purification of arguments when we need to make collective decisions. A necessary consequence of purification is that certain aspects of normativity fall out of scope. As purification is often a muddy quarrel between discussants, we cannot clearly predict in advance what falls out of scope. Thus, if it renders invisible certain parts of our normativity, and if technologies happen to coincide with those categories, their normative import may be invisible accordingly. Moreover, I have argued in subsection 3.2.2 that technoscience often appears to be neutral. It is plausible that the neutral appearance may work side-by-side with the present silencing of normativity. Therefore, technoscience is even more likely to fall out of scope as being irrelevant. And if some disagree to it, controversy flares up easily.

We have also seen that contemporary politics puts an emphasis onto individual choice, which has produced some preferences in purification. This is largely inescapable because of the existing pluralism of ideas of the good, and it is indeed recognizable in how politics is conducted. This freedom of choice asks for a 


\section{Politics by All Means}

large leeway for individuals to make choices regarding technology: by rendering such choices private, many aspects of technology become even more invisible for politics. Indeed, this freedom legitimizes most choices in favor of the technology by an appeal to the fact that nobody will ever be forced to apply the technology. This adds to the previous observation, that politics is blind to some normative aspects as it tends to privatize a lot of normativity anyway.

Indeed, it has been observed by Richard Sclove (I995, p. 24) that technology often enjoys a neutral image. Similarly, Andrew Feenberg (2002, p. I68) argues that we (mistakenly) see rationality as inherently neutral and see its application in technology as open to any use. On the level of discourse, Jaap Jelsma (I992, p. 300) observes that social controversies on innovation typically concern the level of the effects, not the level of innovation itself. As the effects are thus understood as being on the level on which constraints are implemented and where politics is conducted, they seem to miss the inner structures of technology. These effects are often referred to as 'externalities'. While this is not strictly a neutral vision of technology, it does reveal some traces of an instrumental stance to technology: political disputes concern the acquisition and application of technology, not the ideas and backgrounds against which they were developed or the normativity that is embodied in them. It is at least an instrumental approach in that it believes that failing technology is a political problem, not a socio-technical problem. This is close enough to saying that the technology itself is instrumental. In the preceding sections, I have explained that this view is not tenable. Still, its appearance in controversies is widely observed.

It is interesting here to see that both politics as purification and modern technoscience are prominent heirs of Enlightenment and specifically its disentanglement of facts and values. This has important influences in both technoscience an politics. In technoscience, it contributes to the neutral image that it exports. In politics as purification, this separation has received the shape of focussing on clear terms acceptable to all. Claims must thus be immanent in the sense that they only build on elements that are accessible to all. Whether surprising or not, technologies show a similar immanence. Because of their tight connections to (indeed immanent) natural laws, the workings of technologies are accessible to all. Given this image, it is not so strange that politics as purification 'overlooks' technology: technology is a near kin of the public knowledge that is supposed to be equally valued by all, regardless of their comprehensive doctrines. 
Finally, there is something more about how technologies sometimes appear as politically irrelevant. The downsides of technologies are often vague, in the far future, and concerning vague victims. And contrarily, the upsides often appear as short-term benefits and with a clear appeal to who enjoys them. This is not always the case, but if it is, it is clear how this attributes to a moral irrelevance of technologies: insofar as the consequences of a technology are clear, they are often advertised as positive. And if one does not agree, there is no need to buy it. The slogan that Philips Electronics embraced until 2004 is exemplary: Let's make things better. Technology is just here to serve us in pursuit of whatever good we like. Moreover, you really do not have to buy it if you happen to dislike it. Closely related is the idea that technology often promises positive freedoms, while liberal purification prefers arguing about negative freedoms (see Berlin: I958). Thus, liberal politics has indeed a pitfall of overseeing the normative impact of technology.

\subsubsection{Unpredictability}

There is one important aspect to technoscience, that I just discuss here as to support analysis in later chapters: their inherent unpredictability. First, this unpredictability can be empirically concluded from the many false predictions in the past. From the fine overview by Sir John Meurig Thomas (2005), I repeat only two: in 1934, Sir Ernest Rutherford claimed that nobody would ever be able to extract energy from the transformation of atoms; and Lord Kelvin predicted long ago that heavier-than-air flying machines were impossible. Even the experts cannot look further than three years ahead, according to Thomas. Moreover, he shows that the major inventions throughout our history were either happy accidents, or very much related to urgent political needs. An example of a happy accident is provided by the invention of X rays by Wilhelm Röntgen. And political urgency and paranoia fed the development of radar as well as the internet as an information infrastructure that is robust in the face of partial damage. Clearly, these observations by Thomas are in line with my conception of technology as constructed in socio-technical networks: the context simply matters.

In addition to this empirical unpredictability, there is also an a priori reason for science and technology to be unpredictable. Whatever account one takes of valid knowledge or a working design, science and technology by definition pursue things that are not in the here-and-now yet, or are at best not known to be so. One 


\section{Politics by All Means}

of our technoscientific present-day dreams is the creation of cold nuclear fusion, as an attractive source of energy. ${ }^{9}$ That is, the broader idea of it exists, but the lack of exact knowledge as to how to achieve it makes it fundamentally difficult to predict when, if ever, we will reach it. If we could find out what knowledge we are missing today, this would in effect largely be the same as solving the puzzle itself. But we cannot, and therefore the achievement of cold fusion is fundamentally unpredictable. Similarly, predicting in a pre-historic era that there will eventually be something like the wheel, would in effect be the invention of the wheel itself. That is not prediction.

Closely related to this unpredictability is the phenomenon of transience. Owing to its unpredictability, scientific knowledge is always temporary: one never knows what facts of today may be falsified tomorrow. This temporariness has also been recognized methodologically in science. We do consider those facts scientifically proven that best resist falsification, yet every scientific fact should fear the trash bin in case a more convincing fact is found. This has an important consequence for the possible harms resulting from technoscientific progress. That is, harm is always harm as understood on the basis of current knowledge. Like scientific understanding, harm arguments need be taken to be true only temporarily, in expectation of either better proof or rebuttal. The harm argument against technoscientific progress can therefore often be downplayed with the concession of being careful today, and with the (vague) promise that the discussion will be reopened if insights change tomorrow. Under the condition of promising that it will not be employed in its present form, we need not stop technoscientific progress. That would be a waste of its beautiful opportunities. Thus, moral consideration is in effect likely to be postponed, which is remarkable against the insight of the Collingridge dilemma, see page 82 .

\section{Review}

In this chapter I have put forward several ideas about technology. First, I argued that the relation between us and our technologies is intricate: we are not completely free to devise the ends to which technologies are harnessed, nor are we (and for that matter, our free will) completely submerged by technology. That is, technology

9 Just to prevent confusion with a tragic hoax back in the I980s, by cold nuclear fusion I refer to fusion at a fraction of the solar temperature, where fusion occurs naturally. It is not really cold but still some hundreds of thousands of degrees above room temperature. 
is neither completely instrumental nor completely deterministic. I suggested to postpone the question of who is in charge, technologies or we, and to assume a symmetrical stance. Second, I suggested to frame the roles technologies play in our lives along two lines. On the one hand, by the hermeneutic role, they help us interpreting what the world is like. And on the other hand, by the existential role, they co shape what choices of action we make by rendering some options more likely than others. And third, I suggested to see ourselves, our technological artifacts and any other non-human element related through actor networks. In these networks power is exercised continuously, and thus reality is continuously redefined, constructed and enacted. As a corollary, the influence of elements and their transformations is not clearly bounded. Socio-technical networks are omnipresent.

By interfering with our interpretations and actions, technologies, or sociotechnical networks, interfere with our normativity and hence with our political discourse. In particular, given their omnipresence, their influence does not keep to the public-private divide, nor to the divide between our morality and our conception of the good. Thus, as they concern our complete comprehensive doctrine, it is likely that technoscientific change will bring about a change in our morality and our conception of the good and how these relate to one another. And it is also likely to bring about a change in our public and private ethics and the divide between them.

Thus, socio-technical networks are capable of moving things in and out of the scope of politics. In addition and partly as a consequence, they are a fine candidate for interfering with the purification that we fight over all the time. As things are moved in and out, discussants are being forced to rediscuss the boundaries, incurring reference to parts of our normativity that are private - either because we feel so ourselves, that is morality, or because it is collectively constructed to be so, that is private ethics.

It appeared that technoscience exports an image of neutrality much like the liberal claims to neutrality. Both of them have a preference for immanence. That they partly co-define what this immanence is like, usually remains concealed. Particularly in the case of technology this is remarkable: it interferes with both our normativity and our political discourses, it is also object of that discourse, while at the same time being in some respects immune to that discourse. 


\section{Politics by All Means}




\section{Overview}

Wrapping things up, the preceding chapters give our primary focus for the casestudy chapters to follow: how do technologies co-shape the concepts and the very language we use in discussing them, thus rendering the political debate inherently problematic? This question is in itself already a hypothetical answer to the main question in chapter I: How is it to be understood that the typical liberal way of dealing with the good life, that is of dividing moral questions into public and private ones, is made problematic by technology? What remains is an empirical corroboration, to be taken up now in part III.

In chapter I we saw that Dolly brought us some trouble. I diagnosed this to be the result of a technological achievement forcing us to revise our ethical conceptions, and that this cannot be seen apart from ethical notions that we are not used to discussing in public. An important issue in the debate was whether the exclusion of certain arguments was justified or not. In particular, it seemed that some arguments are excluded more radically than others, while no clear reason seemed to exist for that. That is to say: it seems that life-ethical arguments are excluded, but not in a completely clear way.

From this observation, I developed in chapter 2 the idea of politics as purification. Whatever way we agree to do politics, there will always be a distinction between things that belong to politics and things that do not. This concerns both the question of whether certain decisions should be made on the collective level (scope), and whether certain arguments are legitimate in the decision-making process (justification). Only if we agree on those, we can possibly come to a satisfactory conclusions (content). I also suggested that these boundaries of purification are not fixed a priori. Rather, they are contingent upon history, and moreover it is hard work to get arguments and issues in or out of the discussion. In particular, it is likely that if a change occurs in what is in and what is out, this change will incite its own counteraction because there might be others who have an interest in keeping it the old way. Thus, politics-as-purification is vulnerable to instability.

In chapter 3, I developed a conception of technology, closely related to actornetwork theory. In line with ANT, I suggest to understand ourselves and our 


\section{Politics by All Means}

technologies as intricately connected in networks, in which it is impossible to tell whether events are ultimately the result of either human decision or some material cause. ANT thus does not deny human agency, for we have the power to effect changes in the network. But neither does it grant that we are fully free, because our networks co-shape what we do and what we think. These two dimensions I suggested to label as respectively the existential and the hermeneutic dimension.

These two conceptions, of technology as networked and politics as purification, are in fact so akin that they can be combined well. Through the hermeneutic dimension and changes in it, technological networks may have an influence on our purification, as changes in our perception may emanate on our judgment of arguments. Similarly, political disputes have a hand in shaping our dominant public morality, and so indirectly co-shape our technologies. This may on its turn influence future politics and its purification through both the existential and hermeneutic relations, and it may influence technological development itself. Thus, public morality, private morality, human subjects and technological artefacts shape one another in the world that they inhabit together.

These ideas now relate to the subsequent chapters in the following way. Each of the chapters to come will discuss a field of application in genomics, in which the interaction between public and private morality and technoscientific change becomes tense. First, the chapters will show that both my conception of politics as purification and my conception of technoscience as networked provide accurate ways to describe everyday reality. Second, these chapters will show that the instability occurring is closely related to politics as purification and to changes induced by technoscientific networks. Third, it will show that the dominant forms in both realms, that is liberalism as a dominant form of purification and modern science as a dominant player in technoscientific networks, have a similar tendency: they have an interest in rendering the same kind of things invisible. And fourth, they invoke the same kind of counteraction. That is, both of them ultimately result in private ethics becoming public, even though they try to suppress it. This is again what we started from in chapter I with Dolly, and we have now a sufficient background to commence part III.

This book has been written against a strange heterogeneous background. In part, discussions and arguments are taken from the international scholarly debate. In part, it is the opinion pages of newspapers, which are mostly Dutch. And one chapter is really about the Dutch political culture. Part of the discussants are not 
really engaged in a discussion together. This however carries the upside that a rich collection of arguments can be obtained. In the PGD case, the lack of reality that some may discern in the first two debates is compensated for. This carries the downside that a locally and temporary bounded discussion is limited in its own right. I believe however that the strength of this book is in the whole of it, and less in the individual parts: together, the practical chapters give a rather complete view of what it means to do politics in a technological society. Chapters 2 and 3 have prepared it, and chapter 7 will conclude it. 


\section{Politics by All Means}




\section{Political practices of technology}





\section{Enhancement, eugenics and the designer baby}

\subsection{Medicine beyond disease}

The term human enhancement is today used for those medical interventions made for reasons beyond the mere cure of disease. Being unnecessary from a strictly medical point of view, such interventions are understood as aiming at making something 'better' in human life. One could think of improving sports performance, endurance, pain resistance, and an increased robustness with respect to disease. In the mental sphere, improvements may target abilities such as mathematical insight, artistic genius and emotional stability. In addition, we might go beyond reinforcing properties that we already have, and move to non-human properties like infrared vision and radiographic telepathy. Much of this however belongs, at least today, to the realm of science fiction.

However, the thought of enhancement does not only concern futuristic fantasies and their rejection. As early as I990, the first pregnancy was established in which the embryo was actively selected by human choice, not natural coincidence (see Silver: 1997, p. 237). This case concerned the prevention of a heritable disease that occurs only in daughters, not in sons. A more extreme example Jamie Whitaker was born in 2003. His genome had been selected such that Jamie would be a suitable bone-marrow donor to his sick older brother (see Dobson: 2003; BBC: 2003). Both of these events at their time triggered vivid reactions. While lauded for their achievements, the scientists involved also received the criticism of creating designer babies: human beings whose traits have been determined by human choice, rather than by natural coincidence or divine predestination. In particular, questions arose of whether Jamie was conceived for his own purpose, or just as a means to serve the interests of his older brother. If so, this would be a grave violation of Kant's imperative to respect the person as a person - at least, so argued the critics.

Lee Silver (I997, p. 278) envisions three stages in the future development of enhancement. First, we will eliminate congenital diseases and dispositions that 


\section{Politics by All Means}

have a severe impact on the quality of life: sickle cell anemia, cystic fibrosis and the like. In fact, the mechanism through which HIV infects the human body is believed to have a strong component within our own genome. Thus, it might prove apt for intervention through genetic engineering (see Campbell and Stock: 2000, pp. II-I3; Harris: 2007a, pp. 20-2I). It is hard to imagine who would argue against immunity for HIV and Alzheimer. Indeed, it could be questioned whether these are really examples of enhancement, not just therapy. This is in fact mitigation of serious suffering, rather than the introduction of futuristic features. Nevertheless, these interventions receive criticisms much like the ideas of genetic enhancement do. Indeed, many of its difficulties also hold for such germ-line therapies. Therefore, they deserve attention in this chapter. Moreover, it is often from down-to-earth promises of interventions like these, that the visions of more fancy ones earn credibility. Indeed, these examples inspire the thought and parlance of enhancement.

In the second phase as envisioned by Silver, genetic dispositions with less severe impacts will be the target of eradication. Once we understand the genetic background of obesity, diabetes, heart disease and a number of forms of cancer, we may be able to prevent them. The fact that these diseases can either be lived with quite well, or appear first at an age well beyond childhood, makes such interventions already more controversial to some. They argue that the diseases are not worth the interventions, and that therefore these interventions will be the onset to an age in which everything on our body becomes an object for technical manipulation. Thus, they fear that we will cease to be humanly dignified (see for example Dekker: 2007). Clearly, Silver does not share this opinion.

In the third stage of enhancement according to Silver, the mind and the senses will be improved. We might be able to eliminate alcohol addiction, as well as mental disease and antisocial behavior. And once we understand how the constitution of the brain is related to our genome well enough, we may provide parents with the opportunity of enhancing various cognitive talents in their children. Why not have a child with the talents of Mozart, without having his burdensome mental constitution? ${ }^{\mathrm{I}}$ Even though it is not explicitly mentioned by Silver, we may fancy

1 Neurological evidence suggests that both Mozart's prodigal status and the Tourette syndrome that burdened his entire life are the result of the same dopamine imbalance. While there may not be a causal relation between Tourette and Mozart's musical genius, it is not certain that the two could occur independently (see Simkin: 1992; Sacks: 1992). This renders the picture thus sketched unlikely, but it does not take away that enhancement offers such vague promises. 
that it will be in this stage that specific qualities for sports performance might benefit from some genetic boosting. While this employs an oversimplified idea of sports (see Sheridan, Pasveer and Van Hilvoorde: 2006), it is likely that there will be at least some entrances for genetic engineering to enter the playing field and tip the balance.

In addition to Silver's three stages, we may even think of a fourth stage. Indeed, if we understand our nature so well, why not extend our life span? We may mitigate the process of aging once we understand it (see De Grey: 2005). It will start with 'adding life to years': making that the burdensome period towards the end of our life will be compressed and thus start later, without actually extending our life. But eventually we may also increase longevity, thus 'adding years to life'. Some suggestions have been put forward that deterioration of the ends of chromosomes, so-called telomeres, is partly responsible for the process of ageing. If we could stop that, aging would be given a blow, too. However, it is not at all certain that it will work this way, and much research is indeed still to be performed concerning this topic (see Rodden Robinson: 2005, p. 334). Similarly, some single-gene mutations are expected to contribute to faster or slower aging, but again the mechanism through which they work remains unclear (see Kass: 2003, pp. I74-I8I). Nevertheless, extending life keeps tickling our fantasies.

These future scenarios are likely to raise questions. Should we take the path of human enhancement? Or rather the other way round: is there any hope for the human race if we refuse to do so? Indeed, some argue that we should never enhance a human being, while others argue that we have no choice. Some argue that enhancement will bring us a Brave New World in which we will be the slaves of technological suppression. Others argue that exactly because of its suppression through technology, Brave New World is not a tale of enhancement; the latter will rather liberate us and thus prevent the world from becoming anything like a brave new one. Some argue that enhancement will increase inequality and injustice, wile others argue that enhancement will rather help us to mitigate injustice, or at least not increase it. And some argue that enhancement cannot be reconcilable with human dignity, while again others argue that enhancement will liberate us from the undignified life we live today - and so on.

Two motivations justify a discussion of enhancement in this book. First, despite the questionable realism in many of the envisioned applications, genomics is often associated with enhancement - be it as a dream, as fear, or as vague 


\section{Politics by All Means}

promise. As genomics and its applications are believed to reveal the fundamentals of our human nature, it is not difficult to see a link to manipulation of that very nature. Today, some years after the heights of the hype that genomics once was, many of the promises of genomics have been tempered - certainly the ones of bold improvements of human nature. But not all of them: the examples of believed-to-be designer babies that I just mentioned, are still present and real

This indeed leads to the second reason for me to discuss enhancement: that many of the questions triggered by enhancement are somehow politically delicate. Our phantasies are apparently capable of sparking debates in which we seem no longer comfortable with the public-private distinction in normativity. Indeed, we seem to be unable to discuss the matter without reference to our conceptions of the good: what it means to be human, what an elegant way of living a life would be, and what we think we are obliged to do for future generations. The questions are often difficult to discuss, especially because they are not likely to survive political purification. First, the questions themselves are ambiguous as to whether they are public or not, that is whether or not they belong to the scope of politics. And second, so are the justifications we adduce while discussing them. The question of what it means to be human is today typically a private one. However, it is not straightforward that any answer to this question can also be legitimately pursued privately. For example, I already mentioned that child molestation is not a private issue. This explains why it is not straightforward to see enhancement as private, even if we see in it the answers to questions of the good life: some of its forms may by some be understood to be child molestation. Thus, we are forced to discuss the matter in public, calling on us all the problematic references to comprehensive doctrines. Indeed, such discussions reveal the intricate interference of technology with how we deal with the public-private divide. These matters are at the core of this book - whether or not we agree Jamie was a designer baby.

The argument of this chapter will proceed as follows. First, in section 4.2, I will discuss some moral issues on enhancement on the normative level itself. I will discuss the pro and cons there, without carrying this to normative conclusions. Second, in section 4.3 I will discuss how these arguments actually figure in the debates, and how discussants try to move their arguments into the debate and exclude the arguments of opponents. This is where the purification between appropriate and inappropriate arguments will be staged as hard work. And finally, in section 4.4 , I will reconnect the observations to the broader modern-cultural 
perspective I developed in part II. I will conclude there that the enhancement debate shows some typical features of a modernist purification, and a reinforcement of the form of rationality dominant in it.

\subsection{The battle on being better}

\subsubsection{For better or for worse?}

Arguing for making life better raises the question of what we can possibly mean by 'better'. Is life so miserable in the first place, that we need to improve it? Or the other way round, is 'improving' life not something that we have been doing since the earliest days, by means of all that we today call 'culture'? And has not this process led gradually to the task we face now: taking in hand the human body more explicitly? Indeed, a significant part of the dispute turns on these questions. Against the background of part II, these are likely to give their own twist to the purification that we saw is essential to politics.

An example of the contestedness of what 'better' means is found in innate deafness. This can be seen as either a trait or a disease, or perhaps as something in between. When understood as a disease, its eradication is consequently just another medical intervention. Contrarily, if it is seen as a trait, eradicating innate deafness is consequentially something beyond medical treatment. The Health Council of the Netherlands has argued that there sufficient evidence that deafness is an obstacle to normal social interaction. Even though this may not justify the conclusion that it is unequivocally a disease, it does urge some reluctance to accept deafness as just another human variant. Nevertheless, eradicating it might be interpreted as hiding a 'eugenic' or 'enhancing' stance. But if innate deafness is not a disease, does this then mean that its eradication is despicable? It would have important consequences, for sure. If applied on a large scale, it would eradicate the specific cultural forms that the deaf community has developed. And as it thus undermines this 'deaf culture', cases of complete deafness that occur nevertheless will face a larger social isolation than they do today. Does this then render the eradication at large a despicable venture?

Along similar lines of reasoning, it is contestable whether Down's syndrome should be conceived of as a disease. If we do so and see it as sufficiently serious, abortion of down-syndrome fetuses may be seen as a medical intervention. If we don't, abortion will consequently be seen as an act of enhancement, or even 


\section{Politics by All Means}

eugenic in the sense of eradicating undesirable life forms. This may reflect the cultural appreciation of Down children, and in fact even in part constitute this appreciation. Indeed, already today, people having a child with Down's syndrome receive disapproving reactions: why let the child live such a burdensome life, if prevention was an option (see Tijmstra, Bosboom and Bouman: 2000, pp. 49-51; Raad voor Maatschappelijke Ontwikkeling: 2004)? Indeed, this example is often adduced as a warning against enhancement: we would be creating a world in which no imperfection is tolerated. Taking life the way it comes is then no longer an option.

The ambiguity of what 'better' means is even more striking in the following case (from Sandel: 2007, pp. I-2). A deaf lesbian couple sought donor seed from a man with a family history of deafness. They explicitly wanted a deaf child, because they believed that a hearing child would not be able to develop well having two deaf parents, and they moreover believed that their deaf way of life was a life perfectly worth living. They succeeded and had a child that was practically deaf. Most of the reactions they earned were of despise; they had willfully inflicted a serious handicap onto their child. But they themselves argued that what they had achieved, was not much different from what a straight deaf couple would have gone through. What to other people meant the infliction of a handicap, was to them just the continuation of their everyday life. This shows that the idea of a valuable life first differs widely among persons, and that indeed these ideas of a valuable life become explicit in the public sphere in such controversies.

\subsubsection{Acting in uncertainty}

One of the difficulties in discussing enhancement is that it is largely in the future - notwithstanding the current examples I just gave. The potentials of genetic intervention are largely unknown, as are its consequences. What will happen socially, economically, human-biologically - if we manage to create a child with the exact features we desire? Science fiction literature may be an inspiration to imagine the pearls and perils of an age of enhancement. But as this can only reveal part of these consequences, experimentation seems unavoidable: the first 'genetically designed child' will by definition be an experiment. What is more, no test animal will be able to represent some fairly relevant aspects of the human organism. Especially in the mental sphere, it will be hard to assess the gain in the first place: how is emotional stability tested in a pig? How can we test the increased 
artistic ingenuity of a bonobo? And even if we manage to find the appropriate animals and the appropriate tests, we still face the difficulty of transferring this knowledge to humans, and it does not take away the fact that the first will be an experiment. And contrary to animal experiments, we will probably agree that an 'experimental human' cannot be put out painlessly if things go wrong. At the same time, the experimentation may not be that radical if we take in mind the trajectory that Silver depicted: the next step will always be a small one. However, as we are nevertheless speaking about the manipulation of human nature, even the slightest step into the realm of the unknown might pose difficulties that will be unacceptable to some.

However, we really aren't there yet. A first problem is that we may expect too much. It is to be suspected that the extremely optimistic visions hide a naive belief in what is genetically feasible. Particularly, they hold a mistaken assumption of genetic determinism, also referred to as biological determinism (see Rodden Robinson: 2005, p. 299; Dennett: 2003). This is the belief that the expression of genes is unequivocal and repeatable. That is, a particular genome would always develop into the same individual. However, it does not, witness the fact that identical twins are never exactly the same individuals. ${ }^{2}$ In fact, the genomics paradigm cherishes the idea that the expression of the genome is significantly connected to its environment: gene expression depends upon other genes, but also upon nutrition and other life-style factors. Thus, genomics brings not only promises, but also some tempering of those promises. Nevertheless, Henk Jochemsen (I999, p. II6) observes that we at least have a determinist way of talking: we speak of genes for this-and-that all the time.

Moreover, the whole idea of enhancement seems to presume that any combination of genes is compatible with life - which is unlikely, given that the majority of (naturally) fertilized eggs is rejected in an early stage. It is suspected that this often relates to the constitution of the embryo's genome. What if our present lives are simply the best we can possibly get? Similarly, promises of enhancement tend to ignore the fact that only some genes codify for singular properties like hair and eye color, while the vast majority of them is more complexly related to traits and in combination with many other genes. Thus, figuratively speaking, a genome may be optimized for the criterion of artistic genius, but be so at the cost of a decreased

2 The epistemological problem here is, however, that the twins themselves tend to overemphasize the differences. For the outside spectator, the likeness usually justifies the belief in a significant degree of genetic determinism. 


\section{Politics by All Means}

resistance to disease. That is to say: the phenotype space of our genome may be much smaller than the fantasies of enhancement seem to presume. ${ }^{3}$

Another question concerns enhancement's impact on the gene pool, that is the collection of genes that all human beings together possess. If a genetic enhancement is introduced in the genome, which is the case in so-called germ-line engineering, it will in principle also be present in the person's gametes. This means that the modification will be replicated in the person's progeny. Thus, the modification runs a chance of becoming just a common part of the human gene pool within a few generations. It seems to be for this very reason that John Campbell and Gregory Stock (2000) argue that the first genetic modifications should not become permanent parts of the human gene pool: experiments should somehow be contained. In similar vein, Françoise Baylis and Jason Scott Robert (2004, p. 3) argue that at least some enhancements are likely to fail. Therefore they conclude (p. I4) to a gradual introduction of enhancements. These authors raise the questionable impression that they do indeed accept that the earliest attempts will really be experiments that have a chance of failing.

This gene-pool impact may stretch more widely than it seems to do at first glance. For example, the gene coding for sickle-cell anemia also produces immunity to malaria. Persons carrying two copies of the recessive gene are both immune to malaria and prone to develop sickle-cell anemia; persons carrying only one copy are just immune to malaria. Thus, on the one hand, eradicating the severe disease of sickle-cell anemia may come at the cost of also eradicating immunity against malaria. It could however on the other hand be argued, that malaria is largely treatable and immunity does not by any chance outweigh the burden of sickle-cell anemia (see for example Harris: 2008). Nevertheless, the idea of eradicating sickle-cell anemia does run counter to the general evolutionary understanding that a broad genetic variation is contributive of survival: we cannot really tell in advance what we may need this gene for in the future.

In addition to these biological questions, there are uncertainties of a more general nature. What will be the consequences, both psychologically and physiologically, if we assemble genomes from multiple parents (see also Silver: I997,

3 This notion I derive from Dennett: I995, ch. 6, who speaks of the design space of all possible creatures that genetic evolution may produce. The phenomenon is also discussed by Baylis and Robert (2004, p. 8). They recognize pleiotropy as the underlying mechanism: one gene may code for different properties, which has the effect that we can only choose between 'package deals', rather than fine tuning every single trait. 
part 4), rather than nature's way of blindly taking half of a single father's and half of a single mother's? And what will be the consequences if at one day the differences between enhanced and non-enhanced humans are so great that they will have difficulty recognizing one another as human? Or perhaps at an earlier stage: what if the differences between them one day will be so big that the non-enhanced will be in effect underdeveloped, such that they are unable to ever catch up? These are important questions to ask, if only because it is felt by some that medical-technological developments today present the first steps in that direction. Again, these are empirically politically relevant questions.

Taking these aspects into account, acting in uncertainty poses a fundamental problem to discussing enhancement. We learned in chapter 2 that harm is an important demarcation device in distinguishing between appropriate and inappropriate arguments. But in each of the examples just given, it is unclear what harm consists of in the first place - recall also the phenomena of transience and postponement, discussed on page 94. This will be discussed further in section 4.3 , where it will also be articulated how this uncertainty is actually used to protect enhancement from moral judgment, rather than taking precautions and not considering it at all: uncertainty inspires the motive of incrementalism.

\subsubsection{Dignity and identity}

It is interesting to take a closer look at the controversies of embryo selection that were mentioned in section 4.I. Jamie Whitaker was not created a radically non-human being. Jamie was a fully-human boy that could have been born just by chance. It was only this chance that had been skewed a bit. It can thus be argued that he was not in any way an example of enhancement. It seems that the sting was in the embryo selection being aimed at obtaining a child with a genome apt for specific purposes. It was not Jamie himself that feeds the disgust, or even his genome. It was that parents wanted something that some believed they should not want at all - not even if it were for the noble purpose of serving as a donor for his diseased sibling. To them, it is a stance of hubris, and it thus appears clearly as an example of enhancement: the embryo was brought into existence by conscious choice with certain expectations. Such expectations pertain to something made rather than to something begotten. In other words, the whole intervention reflects a despotic stance in the parents. This was believed by some to be detrimental to Jamie's human dignity, and the dignity of our human race at large. 


\section{Politics by All Means}

Part of these arguments depend on the idea that children who are not begotten, will be less free in some way: it might be an impediment upon the liberty of those very children to develop a life plan of their own. For Michael Sandel (2007, p. 24), this is a reason to forbid enhancement. He is clearly aware of the low conclusiveness of dignity, witness the fact that he uses the word only in his problem definition, after which only few explicit references are made to it. The threat posed to dignity by human enhancement that he in the end concludes to, is to be found in the need for an appreciation of giftedness: 'eugenic parenting is objectionable because it expresses and entrenches a certain stance toward the world - a stance of mastery and dominion that fails to appreciate the gifted character of human powers and achievements, and misses the part of freedom that consists in a persisting negotiation with the given' (see Sandel: 2007, p. 83). Sandel claims that this freedom cannot exist in a designed child, subordinate to another person, i.c. the designing parent.

In a slightly different vein, Leon Kass (2002 b, p. I0I; I997/I998, p. 24) argues that our true origin is in the natural recombination of the genomes of our parents. By this origin we are all equally human, and yet at the same time unique and unrepeatable. Thus for Kass, any departure from this ideal means a decline of dignity. Drawing reproduction into the realm of technical creation would deprive it of its personal aspect and its connection to the love that is still today its basis. It could be objected here that today, the large number of single-parent families reveals that this praised 'love' is something of a myth, as it might well have been in the past too. And moreover, it could be objected that Kass fails to argue how exactly this connection between natural recombination and love and dignity is shaped why would I fail to love both my child and my partner if our child had received a non-accidental genome? Or even if I got the child without first loving a partner?

These positions seem to presume that we can only be really free, if our origins are natural, divine, or at least essentially beyond human choice. The question is therefore pressing whether this is the only conception of dignity. Indeed, human culture has always imposed certain expectations upon individuals. The difference between, for example, social class as a ground for one's expected course of life, and one's genetic constitution as a ground for similar expectations, might not be as radical as Sandel seems to presume. Indeed, it is argued by Allen Buchanan et al. (2000, p. I60) that such an account would build on an oversimplified picture, as if genetic interventions would make us into a different person, whereas educational, 
mainstream-medical, and nutritional interventions would only induce superficial changes in essentially the same person. This would be to run into the pitfall of, again, genetic determinism while failing to see the import of those other factors to their full extent.

In similar vein, Kass argues that it is strange that the fact that 'a clone of Mel Gibson would not be Mel Gibson' is being used to downplay objections against cloning: if the clone is not the same, what objections can Mel Gibson have against it? Kass argues that this is twisting the truth, as the expectation that the clone will at least be somewhat like Mel Gibson is the only reason to clone him. 'Truth to tell, the only powerful justification for objecting is that genotype really does have something to do with identity, and everybody knows it.' (see Kass: 1997/1998, p. 35) Thus, Kass's position is indifferent to the question to what extent genetic determinism is true. If it is true, then the objections of identity against cloning are true as well. If it is false, then what reason can we possibly have to pursue cloning? Thus, there can be no consistent reason to pursue cloning and hence it cannot be legitimated. While primarily concerning cloning, this line of reasoning can be extended to enhancement: if a trait is engineered in to alter one's character, how can we deny then that this makes him or her a different person?

Nicholas Agar takes a different stance. He does indeed compare enhancement (which he advertises as liberal eugenics) to the other measures that parents take to benefit their children. He argues that parents generally should want the greatest freedom for their children (see Agar: 2004, pp. I2I-I24). He gives a counterexample of 'hothousing': extreme forms of home education. He describes a girl who is educated to go to University at age I3. The narrow life plan that her father educated her to, comes close to abuse and torture. Agar condemns this example. Indeed, genetic modifications that have a similar effect of narrowing the child's possible life plans, should therefore be prohibited. In fact, Agar attributes a different meaning to dignity, which builds on possible paths of life rather than on origin, and which is at least not categorically incompatible with human enhancement.

Along similar lines, Agar argues that it is not acceptable to engineer children in such a way that they cease to be moral beings, or cease to be recognizable as moral beings (see Agar: 2004, p. I42): our social life would be heavily burdened, even if the 'genetically immoralized' ones themselves do not seem to care much about it. While Agar does not explicitly appeal to this as a problem of dignity, I do interpret it as coinciding with the matter. However, it is an important difference 


\section{Politics by All Means}

that Agar seems to develop and articulate more specific problems, rather than concealing them in vaguer notions such as dignity.

For John Harris (2008), one's freedom does not at all depend upon how one is genetically shaped or what the origin of one's genome is. For example, since some people are born with a sixth digit on each hand, there cannot be something immoral to engineering this trait into someone, for the purpose of pursuing a career as a pianist. More in general, as throughout our entire history, children have been conceived for the widest variety of purposes, conceiving them along the lines of enhancement cannot entail much novelty. For Harris, dignity is a category that is immune to such interventions.

What is more, it can be argued in opposition that some of these features can be rather conducive to human dignity. After all, what is so dignified about alcohol addiction (see Harris: 2008)? Sure, it suits those fine who manage to resist such seduction without further help. But the real addicts will take little dignity from their problems. Enhancing us towards a better resistance against alcohol addiction does not in any way express a depreciation of life as a gift; it just recognizes that life's gifts are sometimes not to be appreciated (see also Verbeek: 2008a; Ter Meulen: 2006, p. II).

This could be carried to an even more radical conclusion. Indeed, it has been argued that we have a moral duty to enhance our children. For example, John Harris $(2007 a$, ch. 2) argues that under the condition that enhancements are obviously good for us and can be obtained with safety, we should grant full access to them and even provide it to all. Alternatively, Julian Savulescu (200I) argues that maintaining or even increasing social inequality cannot conclude against selection on sex and intelligence. Rather, the duty of parents to give their children the best possible life prevails over social inequality. Doctors even have a duty to persuade parents if they refuse to make the wisest choices by themselves, although coercion is of course one step too far. It seems to be exactly these lines of inference that bring Dov Fox (2007) to the conclusion that liberal eugenics cannot really be as liberal as its proponents claim. Eugenics will be much like the practices that even liberals want to regulate a lot in: education, health care and so on. Fox argues that these precedents provide ample reason for us to believe that in the end, parents will not be left completely free to decide upon their children's enhancements. 


\subsubsection{The meaning of life}

Related to this class of arguments of dignity are the arguments that appeal to the meaning of life, which is believed to be taken away by enhancement. Such claims often depend on a conception of meaning of life as the struggle, effort and discipline it takes to make something out of our lives. If enhancements enable us to achieve our ends without any substantial effort, we fail to see that this effort is essential to our appreciation of the ends. For example, Michael Sandel (2007, p. IOO) argues that such an approach to human flourishing is a flawed vision of our liberation out of misery. Rather, 'it threatens to banish our appreciation of life as a gift, and to leave us with nothing to affirm or behold outside of our own will'.

This critique is similar to Albert Borgmann's critique of our technological culture at large. Borgmann (I984) characterizes modern technology as a device paradigm, which fulfills our needs without actually requiring us to engage in fulfilling those needs - we just buy them in the supermarket. This does not give the same meaning to life that 'focal practices' do. Borgmann uses this term to indicate those situations in which we really needed to pay attention to achieving our goals. These include the basic ones like caring for one another and even preparing food. Borgmann laments the loss of these focal practices. Extending this line of reasoning to the human body, the developments sketched above could be seen as producing a disengagement between us and our bodies: ${ }^{4}$ life would lose depth if athletic, intellectual and social excellence no longer demanded the effort that they do demand today. That this loss is really a loss, is witnessed by our valuation of those achievements: they strongly build on that very effort. ${ }^{5}$

Pro-enhancers partly downplay such arguments by claiming that even after enhancement, still enough meaning remains. In particular, Agar (2004, pp. 6I-63) argues that humans have the capacity to invest things with meaning. Thus, also an enhanced life is open to such investments. Indeed, according to Agar, enhancement advocates see more rather than less opportunities to find meaning in

4 I wish to step over the problem that the Cartesianism required to distinguish between ' $u$ s' and 'our bodies' is obsolete.

5 A similar reasoning is found with Carl Mitcham (1987, p. 24), be it from a more religious perspective. He argues that technology is in conflict with many religious doctrines, because it separates the fulfilment of (material) needs from the transformation of the human self that is needed as well. The difference between technology and religion is that the former is concerned with transforming the world, whereas the latter is concerned with transforming the self. In solution, Mitcham suggests that amidst our technological culture, some should renounce the promises that technologies offer. 


\section{Politics by All Means}

life. He attacks Kass's view that enhancement would separate performance from effort, or, in other cases, pleasure from activity, while these would ordinarily be their foundations. According to Agar, even in a society that endorses enhancement, people will take care of one another and derive joy from the relationships they have. And moreover, (p. 99) he argues that 'those whose genomes have been constructed by genetic engineers or selected by cloners will find winning medals and avoiding drug addiction no easier than those to whom nature has given the same performance-boosting genes.' In fact, he pushes this to a concrete conclusion: if something can occur naturally and we do not find ourselves necessitated to prevent that, this implies that we are also allowed to introduce it. Moreover, he argues that even while interventions may provide some with a head start over others, they do not eliminate the effort that even the enhanced ones will have to put into their achievements. Competitions, of whatever kind, have always been competitions between persons with different initial positions - that is, if we agree to Agar's wide conception of 'initial position' (p. II5). Consequently, competitions will always also be a competition between efforts, and genetic boosting does not take that away.

These different approaches show that enhancement does not unambiguously take away the meaning of life. In line with Peter-Paul Verbeek's critique of Borgmann's ideas (see Verbeek: 2005, pp. 186-I9I) that technology does not eliminate but rather changes practices, it can be argued that enhancement does not (only) take away some of the meaning of life, but that it may also add alternative meaning. But most important to observe for the argument of this book is that the many different ideas of the meaning of life are an important foundation of the positions in the debate. They explain why discussants disagree. And moreover, they offer little hope that the discussants will come much closer together.

\subsubsection{Playing God}

The argument is often heard that we should abstain from playing god. This might refer to an actually existing (Christian) God, like in the appeal of the Vatican (2002, lemma 91). It states that it would be radically immoral if man ${ }^{6}$ assumed a co-creatorship next to God. The way to improve oneself is by recognizing the superior image of God in oneself, and by trying to imitate Christ. Not by 
genetic engineering (see also: Bosman: 2008; Sullivan and Salladay: 2007). A secular version of the argument exists in the recognition that consequences of genetic engineering cannot be fully overseen - something that only a god, if only hypothetically existing, would be capable of. In this form, the argument is also known as the motive of the sorcerer's apprentice or the allegation of hubris.

The argument that we should not be playing God is often heard, and it is just as often discarded with rigor. Most of the rebuttals of the argument build on the argument from precedent: as far as our history can tell, we have always been playing God: we have always tried to thwart nature if its course was bad for us. Simon Blackburn (200I, pp. 57-58) argues that the charge of playing God has no independent force, but only appears when there is something at stake that some people feel is uncomfortable. And to Blackburns confidence, most of the discomfort is mistaken. The playing-God argument usually hides rather intangible notions, much like the dignity and meaning-of-life arguments. At least, according to its opponents. I will not repeat the discussions given for those arguments here, as it would be only more of the same.

\subsubsection{Justice}

In chapter 2, I developed a general notion of justice, and in particular restricted it to distributive justice. One way of staging the differences between conceptions of justice was to assume that most conceptions of justice deploy a kind of levelplaying-field conception, but they hold different opinions on what should be subject to leveling (see also subsection 2.3.5). In the context of enhancement, this raises the following question. If our genetic assets become subject to our manipulation as opposed to natural chance, does this imply that it will also be an object of justice, and if so, how? I think that the answer to the first half is necessarily affirmative, and that it is so because its denial can only be consistent with a general denial of distributive justice. For if there is a sense of distributive justice, and if we recognize that enhancements may bring a benefit of any sort, it cannot be precluded that this benefit is in conflict with the sense of distributive justice. What remains then, is the question of how enhancement may interfere with justice, and how the somewhat intangible content of enhancement translates to the more or less financial goods that are the typical object of justice.

In their book From Chance to Choice, Buchanan et al. (2000, ch. 3) stage it thus: once our natural assets become the object of manipulation, will they become the 


\section{Politics by All Means}

object of justice as well, and how? Redistributive tax systems are generally designed to compensate for inequalities that are beyond responsibility and control of the ones burdened. But does consistency demand that we start offering compensation to people who have 'poor genes', if we are able to manipulate their genomes at some point in the germ line? Or to use Buchanan's phrase: will the natural be colonized by the just?

Michael J. Selgelid (2003) argues that unequal access to enhancements my provide the financially fortunate with competitive advantages. Moreover, it would take away medical resources that could possibly have been applied for therapeutic purposes in a much more efficient and fruitful way. As Selgelid finds himself unable to tell how likely or severe those consequences may be, he abstains from condemning enhancement in general. He does however stress the need for further research, and for creating social and political awareness for these possible consequences and the difficulty of balancing freedom against equality.

One motive often draws attention in discussions of enhancement and justice: that enhancement may produce positional goods. These are goods that earn their goodness from the advantage they produce over others, particularly if we have more of them than others (see also Swift: 200I, pp. II5-II8). Body length in a basket-ball team is a positional good, since it is valuable only if others are shorter. A typical non-positional good would be health: the value of health is clearly independent of the amount of health others possess. Clearly, if enhancements produce positional goods and are available only to the financially best-off, these enhancements are likely to increase inequality rather than mitigate it, and for this reason they may not be justified for some. But there is more to say about this in a genetic context.

Positional goods have the peculiar property that they tend to incite their own proliferation. As it is always desirable to be one step ahead of others, one has to keep acquiring them. Thus, social pressure may result and force people to engage in this proliferation, even if they think the good itself is not intrinsically appreciable. What is more, after the race we may end up in a distribution of goods that is not much different from the distribution of today - thus, the effort will to some extent have been in vain. This is what has been called self-defeat of positional goods: once we have all acquired the particular good, the net effect is again zero (see Buchanan et al.: 2000, p. I85; Wenz: 2005). This runs the risk of absorbing resources while not producing benefits, which is hard to reconcile with most ideas of distributive justice. 
However, what Peter Wenz seems to oversee in this inference is that many positional goods have an intrinsic component to them as well. Think of today's vaccination programmes, glasses, and even general prosperity in a welfare state. These are positional goods, as someone vaccinated has better economic opportunities than someone whose risk of disease is substantially larger. But these goods do clearly have strong intrinsic components to them as well. Thus, simply prohibiting all of them because they may increase inequality runs the risk of throwing the child away with the bath water. They may indeed be appreciable if all have them, even if this requires the pain of a proliferation typically linked to positional goods. Indeed, Buchanan et al. (2000, p. I86) confirm that many envisioned enhancements in fact provide a complex blend of intrinsic, instrumental and positional goods. In addition, Agar (2004, pp I29-I3I) argues that enhancements producing positional goods should be allowed if they also have an intrinsic component to them. As he is aware of dangers in positional goods per se, he also argues that such enhancements should not be allowed if they are primarily aimed at what he calls winner-takes-all competitions. That is, a proliferation of such enhancements is immoral if only one or very few persons can enjoy the benefits of it. We should not breed genetically-boosted athletes if the majority of them will suffer the burdens of the enhancement while only the champion gets the bounties.

And then, this is not only stupid in view of the fact that we would all need to join in the proliferation while not all value it. It is also liberally stupid in that the proliferation may incur a social pressure onto all to use it, even to those who do not value the good based on their personal convictions or ideas of the good. It may thus undermine the liberal appreciation of a pluralism of ideas of the good, because some see their idea of the good less protected than others. This is stupid-for-all at least in the sense that it is at odds with the liberty of the pluralist society that we all enjoy the fruits from as described in chapter 2 . This mechanism will prove important later, as it will be observed that, in general, technologies typically promise such positional goods, and do indeed in a way that hides the burdening of the common good. So, even if people are not fully egoistic in the sense that they would disregard any common good, they may in effect be egoistic by using technologies that, first, inconspicuously force others to use them even against their beliefs, and second, that may thus undermine a liberal pluralism. It may seem that in these considerations I have departed a bit from the original question of how enhancements may impede upon the distribution of goods, and 


\section{Politics by All Means}

got bogged down a bit into matters of liberal pluralism. Nevertheless, this was a direct consequence of how such distributions can be influenced by enhancement. For if we want to grant that a broad range of ideas of the good can be pursued in a liberal pluralism, it is necessary that the distribution of goods does not impede this.

Perhaps the most important mechanism through which enhancement influences justice is reflected by the remark by Buchanan et al. (2000): that the just may colonize the natural. A question relevant for something to be object of justice, at least the Rawlsian and related liberal implementations of it, is the criterion of whether something is under one's control or not. For if one freely chooses to be poor, there is little reason to say that this is unjust or that it needs compensating for. And contrarily, the social class in which one is born is clearly beyond control; hence many conceptions of justice are open to the idea that lower classes are entitled to more support than the higher ones. One example of something beyond our control is the genome we are born with. This means that indeed according to some distribution schemes, differences resulting from different 'genetic talents' need to be compensated for. The question then is: how to settle this balance? From our different conceptions of justice, we could carry this to a number of conclusions. We could conclude that genetically-poor persons are entitled to compensation, for example by means of better education of simply financial support, to mitigate their unfair start. We could also argue that it is just bad luck for them, and argue that there is nothing to do about it.

But now, in the envisioned era of enhancement, genetic differences may in part become the result of conscious choice. That is: the unblamable diagnosis of 'bad luck' may shift towards the blamable diagnosis of 'your parents were stupid; blame them!'. We may feel less pity for the latter, and may see therefore less justification for compensation. It then depends on the reasons why parents chose not to apply enhancement. If the parents were in an economically poor position that did not allow enhancement, we may see in this a form of societal injustice. If they chose not to do it because they preferred to spend their money on a winter holiday, it's a different tale already. And if they chose not to use enhancement because their conception of the good would not allow it, then what? In opposition to these arguments, Andy Miah (2008) concludes that any difference in personal assets potentially amounts to social injustice, and that the injustice resulting from enhancement will not be much different from that. 
Here we see again the link to the problem of liberal pluralism. First, can something be wrong or unjust if not all can have it? And second, can something be wrong if not all will have it because some do not want to have it? The intuitive answer to the first question will generally be negative: we do not tend to think that owning a luxury car is wrong because others can afford only a middle-class version or even less. However, this bears heavily on the (capitalist-liberalist) idea that it is theoretically possible for all to achieve the big car, or that the system is at least not arranged such that for some it is fundamentally impossible to do so. With enhancements this may be different. If the dreams of Silver and Bostrom come true, the differences between enhanced and non-enhanced persons may be so large that it is fundamentally impossible for the non-enhanced to ever reach the status of the enhanced. Then, there may be really something unfair or unjust to the fact that not all have the enhancements. And then, the second question cannot be done away with by a simple 'it was your parents' own choice'. The vision of one's children being stuck in the lower strata of society will for many parents be compelling enough to apply enhancements, even if they disapprove of it from their - otherwise perfectly reasonable - comprehensive doctrines. This might be interpreted as being at odds with core liberal values: some will at least experience an impediment of freedom to live their own good life. Whether they are entitled to such claims is an object for debate, itself.

So far, the impression may have been fed that all that enhancement does poses threats to justice. However, when goods are produced, there is always also a chance that they can be deployed in support of justice. Why not argue that enhancements are just, at least insofar as they are being used in support of those who have drawn the shortest straws? Why not support poor families, such that their children will have better chances in the socio-economic rat race? Indeed, this would comply with the maximin principle: the idea that we have a duty to support those who are worst off. One small step away from such radical redistribution would be Rawls's difference principle, that holds that differences must be organized such that they benefit the worst-off. This may be interpreted as if the rich may enhance themselves freely, under the condition that the poor are better off than when the rich had no enhancement. For example, if by their enhancement the rich generate more gross national product, they can deliver more taxes which will benefit schools and hospitals for the poor. This benefit might serve as a justification for enhancement for the rich. 


\section{Politics by All Means}

However, the accompanying principle of equal opportunity requires a bit more: positions of official power must be accessible to all under equal conditions. This may be hard to attain under the condition that half of the population is enhanced while the other half is not. Much like today, despite sexism being fought against in recent decades, some of the differences between men and women are relevant to some kinds of jobs, we may in the future envision some positions that all things considered can only be held by enhanced people.

In fact, a regulation of enhancement that meets Rawls's conception of justice is feasible (see Rawls: I97I/I999, pp. 9I-92, also referred to by Sandel: 2007, p. 77). Briefly, it holds that it is not in the interest of lower strata to propose policies that reduce the abilities of others. Rather, they should recognize that according to the difference principle, the abilities of others will be used to the common benefit, which enables all to pursue a valuable course of life.

The connections between enhancement and justice are not difficult to generalize to a global perspective. If some countries can offer their population genetic boosts, while others cannot, this may increase global inequality. This raises the same questions. Should we refrain from the path of enhancement, if poor countries do not have the resources to follow? Or alternatively, may we spend our resources on enhancement technologies, while a fraction of the cost would suffice to save the poorest countries from starvation? Should rich countries be obliged to provide the enhancement technologies to poor countries, much like today's pharmaceutical companies are being forced to supply HIV medication at a low cost in Africa? And then what if countries decide that enhancement technologies do not align with their cultures? I take these issues of global justice to be beyond the scope of this book, but much of them can be answered along similar lines as the matters of intranational justice.

\subsubsection{Dystopia debunked}

It seems that enhancement cannot be discussed without the motive of eugenics popping up. Indeed, evil practices like the eradication of inferior races by the Nazis, forced sterilization in at least a handful of countries throughout the world, and marriage counselors connecting 'fit couples' even decades after World War II are engraved in our collective memories. Anything feeding the suspicion of aiming for better humans calls on the curses of these evils. However, as Buchanan et al. (2000, pp. 9-I0) point out, these allegations are often more rhetorical 
than substantial: if the ethical rationales behind 'old-school eugenics' and modern ideas on enhancement are explicated sufficiently, considerable differences are to be discerned. Probably the most important is that in the earlier, despicable forms of eugenics the ones on whom eugenics was practiced, were being forced so by a dominating class. In today's thoughts on enhancement, practically all discussants stress that in the forms of enhancement they champion nobody will ever be forced to undergo treatment that he or she does not approve of (see Agar: 2004, p. 5). Thus, the good pursued in the act of enhancement, is the good envisioned by those whom it actually concerns, rather than the good very much external to him or her that played its part in historical eugenics.

In addition, against the warning that enhancement would bring us some leaps closer to a Brave New World, it is argued that enhancement helps avoiding rather than achieving a such a world. Indeed, Nick Bostrom (2005, p. 4) argues that Brave New World is 'not a tale of human enhancement gone amok but a tragedy of technology and social engineering being used to deliberately cripple moral and intellectual capacities - the exact antithesis of the transhumanist proposal'. In similar vein yet a bit more prudent, Peter-Paul Verbeek (2008a) argues that the fiction of Brave New World should indeed be a signpost to caution, but that it would be a mistake to conclude from this to a categorical rejection of enhancement. We have always been entwined with technology, and these technologies targeting human nature offer new possibilities to live a human and humane life.

Both the arguments against the Brave-New-World argument and against the resemblances between new enhancement and old eugenics are in fact arguments from precedent: we have been there before, and we shouldn't go there again. However, it is interesting that they can be rebutted in part by appeal to similar precedents. Indeed, it has been argued that we may to the eyes of a cave dweller already look like post-humans today (see also Plasterk: 2000, p. I3; Bijker: I995, p. 4). While we may think intuitively that a certain argument will always be adduced in the same direction - that is: either in favor of enhancement or against it - we see at closer look that most arguments are adduced in both directions. This section showed that Brave New World justifies and forbids enhancement. Justice does the same ambiguous trick. So do the meaning of life, dignity, and uncertainty. Thus, once more, things are not easily settled. This informs two questions to be kept in mind in the remainder of this chapter. First, if the arguments themselves fail to convince, then how do they operate in the debate to tip the balance? And second, 


\section{Politics by All Means}

if the arguments themselves do not give proper justification, then what does? The first question will be discussed in the next section where the political debate is portrayed as a dynamic game of purification, rather than the static collection of arguments just presented. The second question will provide the background to the concluding section, in which the enhancement debate is discussed as exemplary for our modern culture.

\subsection{Playing the game}

\subsubsection{One issue, three publics}

From the perspective of the conception of politics that I developed in chapter 2 , it is clear that the first thing to ask is whether we can leave a question to private choice or not; that is, whether it falls within the scope of politics. At first glance, enhancement apparently belongs to our political scope, because some feel the need to discuss it in public. Admitted, this leaves unresolved the theoretical vulnerability of liberal debate to being dominated by just anyone putting just anything onto the agenda because they think it is publicly relevant. However, in the more descriptive stance I take in this chapter, this is not a big problem.

One thing that is traditionally in the public sphere is medical ethics. It seems that the 'public eye' tends to intuitively reckon enhancement belongs in this realm. That is, it tends to discuss enhancement in much the same way as new medical technologies would be discussed. It does not, for example, capture enhancement as just another form of procreation. Thus, it inherits the forms of purification and privatization that are characteristic for medical ethics, rather than for procreative freedom. Theoretically, in the alternative case enhancement would have been treated as a private affair.

An example, the case of Jamie Whitaker proved to be exactly on the boundary between illegal and legal, and therefore at the boundary of public and private: his conception would have been illegal in the UK. Therefore it could not possibly be a private affair. It does not just violate the condition of tolerance, it violates the limits that public ethics in the form of laws puts to private action. For this reason, his parents went to the US, where the treatment was permitted (see Dobson: 2003). There was a lot of debate about it, and supporters expressed the hope that in a few years, the treatment would be available routinely for similar situations. But it remains an unprecedented debate over the boundaries of public and private. 
In addition, from the difficulties exposed in section 4.2, some additional a priori reasons for enhancement to fall within scope can be devised. First, principally anything that comes close to experimenting with humans, is unlikely to pass any legal conditions. Thus, if such suspicions are raised of that, it will be a public issue. Moreover, even if it is not exactly human experimenting, based on its novelty alone, the suggestion of such experimentation is attached; this is likely to cause a failure in the application of our moral routines (see also page 5I), and in such cases the controversy is likely to fall within the scope of politics. This is clearly at issue with, for example, the gene-pool impact of enhancement. This is literally so unprecedented, that existing regulations cannot offer an answer to the problems that it might produce. We see here that the technoscientific outlook on enhancement has a direct impact upon the debate.

Thus, we find sufficient intuitive reasons to expect that enhancement will call for discussion in the public sphere. This leaves the question how this discussion will be shaped open. An overview of arguments pro and contra enhancement has been given in section 4.2, primarily to create an overview of the normative issues that may become pressing in the face of enhancement. Because of those difficulties, and because of the fact that they are novel, it is likely that our moral routines will no longer be satisfactory, at least for some of the discussants. Indeed, we saw that the issues raised on enhancement pose some moral perplexities: even though arguments look fairly similar, they may in fact be adduced in support of mutually contradictory conclusions. In such cases, private-ethical concerns will typically find their way into the public realm.

As to facilitate articulating the tensions on the public-private divide, I will use three model positions as a methodological device. I have labeled them genetic transhumanism, genetic liberalism, and genetic protectionism. Each of them will receive attention in their own subsection. These positions are hypothetical in that practically no discussant will fit perfectly in one of the boxes, and some of the discussants indeed belong thought in more than one box. Nevertheless, the boxes will serve well to structure the arguments and the styles of purification that accompany them. 


\subsubsection{Private procreation}

The position with the strongest drive towards purification is genetic transhumanism..$^{7}$ It lauds the exploration of technological opportunities and moreover sees no fundamental reason to regard the status quo as something to be preserved. On the contrary, it holds that there is ample room for improvement. In fact, genetic enhancement will in the end enable us to explore and implement capacities that today we cannot even think of. While transhumanists recognize that there are some important technical difficulties with possibly painful consequences, they cherish the hope that the final outcome will be worth the burden. Moreover, they support their position with a tantamount appreciation of private choice. All in all, the transhumanist position concludes to a categorical 'yes'.

Typically, transhumanism tries to gain leeway by claiming that the actual interventions will first remain concealed in the lab, and that an assessment can first take place after developments have crystalized sufficiently. And indeed, as long as enhancements remain in the lab, nobody can be harmed, and therefore, no ethical consideration is due as yet. In the afterword to the paperback edition of Remaking Eden, Lee Silver (I997, p. 294) concludes the very first paragraph thus: 'My goal has been to present both the scientific and the political realities of reprogenetic technologies as I see them, along with the ethical dilemmas their use will raise. I leave it to philosophers and bioethicists to figure out how these ethical dilemmas might be resolved.' Thus, Silver tries to postpone moral judgment by suggesting that today, a moral argument cannot be convincingly made, simply because the factual premises are lacking. This coincides with the transience that I observed in subsection 3.4.3: it builds on the fact that science only produces temporary knowledge, and that therefore ethical judgment always comes too early. It is much like how Dan W. Brock (I998) argues that cloning cannot be conclusively argued for or against, given the infancy of the very techniques; thus, the path cannot be excluded from at least exploring. This also hides a stance of incrementalism: the next step is believed to be always a small one, and there will be plenty of opportunity to halt if it turns out unfortunate.

In addition, in the statement just quoted, Silver seems to presume a separation between his own technoscientific sphere, and the sphere of ethics and politics. He seems to presume that in the end, politics and ethics will be able to decide

7 Here, I take transhumanism to be the same as posthumanism. For a possible interpretation of the difference, see Bostrom (2003), but I think the difference is irrelevant here. 
upon a 'go/no go' regarding the interventions. This view is only tenable if we accept that within technoscientific practices no morally decisive actions take place: whatever technoscientists can do may have a moral impact, but it need not work out that way. This hides a conception of technology much different from the one I developed in chapter 3 .

Alternatively, Baylis and Robert (2004, pp. 3-4) argue that it is simply a given that some daredevils will try enhancements and then the rest has no choice but to follow. Therefore, whether we appreciate enhancement or not, all moral consideration is irrelevant or at least futile. In addition, it does not really matter whether we think arguments are appropriate or not. This is a fatalist diagnosis of technology, which renders any objection irrelevant. Baylis and Robert seem to try to mitigate this by proposing a gradual introduction of enhancements, and a postponement of ethical analysis until the enhancements have developed far enough. So they suggest trying to actively shape incrementalism. (It remains unclear to me how they want to implement the ethical assessment without burdening it with exactly the same futility, and how they want to achieve a gradual introduction if enhancements are unavoidable anyway.)

In addition, transhumanists typically argue that there is nothing new about enhancements: we have always aimed to make life easier to live. Indeed, Baylis and Robert (2004, pp. 23-24) argue that the future is ours to shape, because we have always been shaping it: humans essentially strive for their self-actualization. Examples are widespread: education, agriculture, consolidation of social structures, cooperation in general, and even religious and magic practices insofar as these were believed to improve the human condition. The argument then roughly runs that calling enhancement immoral would require that we also think of education, nutrition and medicine as despicable practices. Enhancement is just doing the same by other means. This is clearly an argument from precedent. This style of reasoning has been observed by Swierstra and Rip (2007, p. 9). By pointing out similarities with accepted preceding or existing practices, the novelty of a new technology is downplayed. It suggests that we can rely on existing moral routines. Against this background, it can even be argued that genetic enhancements do more to free us from the constraints that nature has so far put on our development. (Indeed, Baylis and Robert: 2004 leave the question open why we should believe that enhancement 'sufficiently resembles' earlier practices and why we should value anything that comes close to it.) 


\section{Politics by All Means}

Moreover, transhumanists will generally disagree that the natural order has any intrinsic value or that it would for that reason be vulnerable. Indeed, Nick Bostrom (2005, p. 3) argues: 'Our own species-specified natures are a rich source of much of the thoroughly unrespectable and unacceptable - susceptibility to disease, murder, rape, genocide, cheating, torture, racism. The horrors of nature in general and of our own nature in particular are so well documented that it is astonishing that somebody as distinguished as Leon Kass should still in this day and age be tempted to rely on the natural as a guide to what is desirable or normatively right.' What Bostrom does here, is simply denying that there is any truth in the moral stance of Kass, as it builds upon an inference from is to ought. That is, regardless of how Bostrom estimates he is politically related to Kass, he clearly disapproves of his moral position. While this is not clearly an act of purification, it is so at closer inspection: it denies the rationality of Kass's position (be it however by adducing some half-truths, because Kass does explain more than Bostrom is willing to admit at this point).

Another, related accusation of irrationality is found with bio-gerontologist Aubrey De Grey (2005, p. 659). He argues that already today, irrational arguments are standing in the way for our longevity to reach its potential. He refutes this irrationality by an appeal to consistency. Today, we agree that there is nothing immoral to homosexuality, and we do so by recognizing that treating homosexuals differently cannot be consistent with our other moral beliefs that we should treat persons equally. Therefore, thus De Grey, our understanding is presently more consistent than in the recent past, when we did see in homosexuality a proper ground for discrimination. Similarly, we should follow the same path of consistence, and conclude from it that arguing against ageing is irrational, because it is inconsistent with the belief that saving one's life is a noble deed. Peculiarly, De Grey's vision seems to imply that present morality is in general more consistent than prior morality. Thus, it favors a progressive stance over a conservative attitude.

The objection that enhancement might be at odds with human dignity, finds its direct counterpart in the transhumanist rhetoric: Bostrom (2005) simply argues that enhancement will enable us to live a more dignified life than we do today. This is an interesting manoeuvre: by embracing the same fundamental value as one's opponents, the rhetoric of the latter is rendered forceless. I call this the strategy of neutralization by embracement. Or in fact, it shifts the disagreement from the 
life-ethical or even political content to the technical content. We can still disagree about that, but at least it is denied that this will necessarily lead to wrongs. This thus presumes a more instrumental and morally-neutral vision of technology, which indeed allows for it to be placed outside politics.

In conclusion, we can capture the repertoire of transhumanists into two major strands of arguments. The first group of arguments argues that the opponents are plainly wrong in their moral beliefs. To begin with, they hold that enhancement is just the next step in what we have always been doing, or just represents new means of achieving ends we have always pursued: arguments from precedent. In addition, they hold that enhancement is more rather than less consistent with morality, dignity and the like: an argument of embracement of important values. And finally, they argue that protecting the natural order would be immoral or irrational, rather than noble. To this end, they may sometimes argue against the is-ought fallacy.

The second group of arguments expresses reasons why we needn't discuss the matter with our opponents, largely regardless of what they may morally believe. First, it is argued that enhancement is something that is not apt for moral discussion now but must be discussed when it is ready to leave the lab, or alternatively that the lab is something separate from moral discussion: arguments of postponement and a suggestion of separatism. Moreover, this stance suggests instrumentalism in that there is hardly anything morally relevant in the development of technology. They may also argue that enhancement is unavoidable and therefore futile to morally discuss: an argument of determinism. In addition, they may argue that enhancement technologies are so flexible that they need no moral discussion apart from the moral discussion of our lives at large: again an argument of instrumentalism. Or they may argue that enhancements will develop so slowly that moral discussion need not look further than one step ahead: this, I call the argument of incrementalism.

\subsubsection{Prudence and progress}

One step more restrictive is the stance of genetic liberalism. Within this style, we discern the hope that a lot of humankind's suffering may be alleviated if we do decide to take the path of genetic modification of human beings. It does not restrict the interventions to curing disease, because the boundary is hard to establish in the first place. Nevertheless, genetic liberals recognize that there are 


\section{Politics by All Means}

certain borders that urge us to some caution. Much like child molestation and intra-marital rape are public issues, genetic liberals hold that not all choices can be left to the parents or scientists. Some things should simply be precluded because they are plainly wrong: the prevention of harm and the protection of liberty are at the core of genetic liberalism. From these justifications, it concludes to a position of 'yes, provided that...'.

The most articulate representative of genetic liberalism is Nicholas Agar (2004). He legitimizes the genetic-liberal position by an appeal to the claim that no human being will ever be forced to undergo enhancement. In fact, genetic liberalism sees private decision as the only way to implement enhancement, for otherwise the shadows of earlier eugenic practices loom. Indeed, Agar (2004, p. 5) adduces free choice as a justification. This presumes that an issue such as enhancement can be privatized. This has some implications. First, it seems to presume that the condition of tolerance is met. That is, it is believed to be met for all people or at least for all people that we want to account for. This is open to the stance of denying accountability towards some who we then accuse of unreasonableness. More concretely: it would be Kass's own problem if he thinks enhancement is not a private affair. And second it has implications for an underlying conception of technology. In particular, it presumes that technology can be kept private, thus making it subject only to private choice. This is significantly different from the conception of technology I developed in chapter 3. It is however a clear form of purification: it privatizes moral appeals, as it advertises a neutral vision of technology. Moreover, it is in line with technology promising positive freedoms while liberalism protects negative freedoms, see subsection 3.4.2. This bears here on purification.

Moreover, this appeal to free choice does not only serve its own right, but additionally serves to justify the genetic-liberal position at large. Agar does not only seek reasons why the state would not have any right to interfere with our private choices regarding enhancement, but also articulates that enhancement can only exist privately. Thus, a decent form of genetic liberalism is by definition not a matter of politics.

Nevertheless, Agar is open to the idea that the prevention of indecent forms is a matter of political concern: against the transhumanists, Agar argues that we should not unconditionally endorse the technological means they propose (p. ı6). To explain this, he recognizes two primary forms of harm. First, we 
may not engineer-in traits that come with a significant genetic burden, even if the combination of the trait and the burden occurs naturally in existing human beings. And second, we may engineer children such that they are less free to choose a life plan (pp. IOI-IO2). Of course, Agar recognizes that the exact nature of the freedom to pursue a life plan is something open to debate. In an alternative account of the limits we should put onto enhancement, Agar (2004, p. I42) argues that the conditions for justice must be respected: we must for example be able to recognize one another as moral beings, both as a capacity in the recognizer and a possibility to discern the capacity in the recognisee.

Agar (2004, p. 23) demands that arguments introduced in the debate be transparent. That is, they must make clear how patients are affected and how their life style may be interfered with. Enhancement advocates must furnish descriptions of the enhancements that allow for a moral assessment, and critics must argue how their objections are realistically directed at the technologies. Consequently, he argues (p. 56) that the arguments of dignity and the meaning of life that Kass adduces, fail exactly on this demand of transparency: with Kass, part of morality itself is nontransparent (see also the protectionist vision, to be discussed in 4.3.4). This is an interesting argument: that those arguments are nontransparent, cannot be seen apart from the arguments themselves, nor from the way we are used to doing politics. So, Agar discredits arguments indirectly because of their content, rather than that they would be politically irrelevant $a$ priori. He wants to allow as many arguments in the debate as possible - as long as these are accessible in a liberal vein. Otherwise, they should remain private. Thus, his appeal will only convince against the background of a society that already has a preference for privatizing important parts of its normativity and for discussing public issues in typically liberal terms.

In the genetic-liberal stance, we find comparisons with earlier practices like we saw earlier with the transhumanist stance. For example, Agar (2004, p. II3) investigates whether our being allowed to induce certain traits by modifying our children's environment, also allows us to produce them by modifying their genomes. He thus questions whether achievements through genetic means are not too radically quantitative in their effects: we may increase the IQ of our children by a few points by giving them the right nutrition at an early age. However, this is not the several tens of points that the enhancement enthusiasts predict. Hence, we should wonder whether we can transfer the legitimacy from the former to 


\section{Politics by All Means}

the latter. What he concludes is that what impresses us about achievements is that they are beyond our expectation, not the fact that we are genetically or otherwise predetermined to accomplish them. This will remain intact even in the case of genetic engineering, no matter how great the genetic boost. While Agar's conclusion is not too explicit on this point, he seems sympathetic to the idea.

Again, in conclusion the arguments can be captured into two strands here. First, we recognize arguments on the normative level. To begin with, genetic liberals believe that earlier practices and beliefs pave the road for a liberal approach to enhancement: again the argument from precedent. In addition, they argue that private choice is necessary and can moreover be shaped as a sufficient warrant for enhancement to take place properly. This implicitly attributes moral neutrality to it, at least in the sense that it would satisfy the condition of tolerance.

The second class concerns the need to regulate enhancement on the collective level. Genetic liberals believe that enhancement can partly remain outside the scope of politics because of the free choice demanded for its implementation. Only some limits can be placed because some envisioned forms of enhancement are plainly wrong; this renders further discussion superfluous. It also demands that these wrongs are framed in transparent terms, thus disqualifying a host of less tangible arguments. This suggests that while genetic liberals are ready to listen what their opponents have to say, they also demand that the arguments show some degree of liberal reasonableness. (Indeed, I observed that this has consequences not only on the level of political attitude, but also on the normative level of the arguments themselves.)

\subsubsection{Better will be worse}

The most conservative position is what I will call genetic protectionism. It holds that there is no justification for enhancing human beings by genetic means ever. Several grounds are adduced for that. The problem may be in the natural order being violated. It may be in the role of God being unjustly assumed by man. It may be in human dignity becoming impossible if our creation is in human hands while it first was beyond our reach. Alternatively, the problem may be in the consequences of enhancement, mostly of social and psychological nature. For example, preventing genetic diseases may be the first step towards a lesser social acceptance of sufferers of those diseases. In short, protectionism holds that enhancement is a stance of hubris. The protectionist stance answers a resolute 'no' 
against enhancement, and may in some cases see present genetic interventions as steps in the wrong direction.

An important spokesman of this position is Michael Sandel. He argues that if we leave parents free to create the children they want, they will typically do so with a certain vision of an ideal path of life in the back of their minds. This suffices for a despotic stance to be suspected. They do not even explicitly need to engineer those children such that their lives will be predisposed towards a certain path of life. As discussed in subsection 4.2.4, Sandel argues that the wrong we do to our children is in the very stance of mastery and dominion. If we fail to appreciate the giftedness of life, nothing will be left but the shallow idea of life as a commodity (see Sandel: 2002). Moreover, it could simply mean a first step to making better humans, which would express a grave disrespect for the human race as it is now, especially those who are 'imperfect' against the envisioned perfect human being (see Bosman: 2008).

A similar critique concerning the stance hidden in enhancement, Leon Kass (I999, p. 38) argues that cloning and enhancement reflect a scientific approach, which undermines human freedom and excellence, exactly because it approaches the human being as just another animal. If we trade our traditional submission to nature for a new submission to the crafts of scientists, Kass fosters little hope that we will really be better off. This is an implicit yet clear appreciation of the natural order, however shaped as a general warning against a cold stance in scientists. This is in fact an alternative claim, directed at those who do not share his complete moral framework: even if we do not quite share Kass's valuation of a natural order, we may agree with his claim that it is humiliating to treat ourselves and our children as just another animal. Indeed, Kass argues that liberalism cannot live up to its own promise, if it refuses to go beyond the prevention of bodily harm (see Kass: 1997/1998, p. 21): it ignores harms that are less tangible and yet so real. This could be seen as an act of counter-purification by stretching the meaning of harm: Kass argues that the received conception of harm is too narrow, and thus does not do justice to the grave difficulties that enhancement will incur.

Sandel (2007) argues that the hazard of failing to appreciate the giftedness of life is even greater given the widespread occurrence of what he calls hyperparenting: the extreme effort that parents take to make sure their kids will be prodigies. We better give up all hope that this fear is in vain: today, parents are spending fortunes to get their children good scores on admission tests to University, have 


\section{Politics by All Means}

them educated at expensive schools and by expensive private trainers. ${ }^{8}$ Strangely enough, while we do discredit the use of steroids in sports, we seem to have little difficulty on a society level with the use of similar boosters for mental powers: a poll in Nature (see Maher: 2008) shows that their use is widespread under academics. Imagine, with Sandel, what this would be like, if genetic interventions were ready to use.

It is interesting to see how Sandel founds his arguments: he builds upon a diagnosis of what we, $2 \mathrm{I}^{\text {st }}$-century citizens, are typically like. While it is laudable that parents want the best for their kids, Sandel observes that we often push them a bridge too far. He thus takes existing practices as a tell tale of what is likely to happen. He then extrapolates the consequences in case genetics are involved. But in fact, we need not even introduce genetics to buy Sandel's arguments. This is a clever strategy: even though we cannot really tell what genetic enhancement will be like in the future, we can already diagnose from our present social and psychological constitution, that it is likely to bring us nothing but trouble. Thus, as Sandel's position rests only marginally on a technical analysis of enhancement, it is robust with respect to possible errors in that respect. For example, his approach is immune to the pitfall of genetic determinism: it is the stance in parents that is wrong, and thus the feasibility of genetic interventions does not matter that much. We could call this a strategy against social perfectionism: what Sandel disapproves of is a socio-psychological phenomenon, which renders talk about technical pros and cons irrelevant.

An alternative version of this argument, Henk Jochemsen (I999, p. II9) observes that contemporary medical practices reflect an instrumental view. Jochemsen argues that in the vision of Lee Silver (1997), the value of a human being depends upon what he or she is capable of. He thus fails to see the unconditional value of human beings. This would not only be in conflict with the Christian and Judaic creeds, but also with the principles of humanism. In contrast, if we were to pursue Silvers vision, Jochemsen is convinced that we end up in a society where people are judged on their genes, even a priori, before their life actually starts. And this danger is already among us, as the instrumentalist stance is clearly recognizable in our widespread pursuit of health and mastery.

8 Sandel is discussing the U.S. situation. The Netherlands and most other Western-European countries have a more egalitarian educational system where test scores simply matter less. But also in the Netherlands, I have seen not-so-brilliant children of wealthy parents receiving expensive additional education and parental drudgery just to get them somewhere. 
On one point, Jochemsen and Kass share a way of reasoning. They do observe some premises in science that are claimed to give science a neutral character. Kass (2002b, pp. 42-46) observes that modern science precludes the assumption of a teleology or 'meaning of life'. And Jochemsen (I999, p. II3) observes that science forbids any reference to transcendent elements, in particular to God: the methodological atheism of science. This is not to say that science avows the non-existence of God, but that in its explanation no role can be attributed to the existence nor the non-existence of God. Along these two lines, the authors argue that it is not surprising that technoscience does not show any trace of the meaning of life or the existence of God. This helps indeed for science to keep up the front of neutrality, but both argue that this is exactly the reason why science does not provide the kind of vocabulary to discuss difficult matters such as enhancement exactly the kind of vocabulary that transhumanists and genetic liberals do adopt in discussing it.

The disapproval of the stance behind enhancement does however not necessarily lead to the protectionist stance of a categorical rejection of genetic intervention as such. Kass (I999, p. 38) explicitly states that he is not against genetic engineering. Yet we should take control of it, for otherwise genetic engineering itself may take control and make us into its creatures and slaves. In addition, Sandel's arguments only stand up against enhancement, while they would be irrelevant or even collapse in face of the idea of, for example, germ-line engineering to prevent cystic fibrosis. That leaves unexplained why Sandel discusses the idea of genetic medicine - that is genetic interventions to restore or achieve "normal body functioning' without the suggestion of enhancement - with little enthusiasm.

In addition, Mary Midgley (2000, p. I3) observes that a number of irrational strains are recognizable in proponents of enhancement, just as much as they allege the protectionists to be irrational. She argues that the ideology of modern biotechnology is one of actively obscuring the ethical content: 'This proposed new way of looking at nature is not scientific: it is not something that biology has shown to be necessary. Far from that, it is scientifically muddled. It rests on bad genetics and dubious evolutionary biology. [... It is] a powerful myth expressing a determination to put ourselves in a relation of control to the nonhuman world around us.' She moreover explicitly observes (p. Io) that ' $t$ the problem is not that we must somehow catch up our ethics to our technology. The problem is that technology is rapidly gutting our ethics.' What she thus shows, is that what 


\section{Politics by All Means}

in my terms would be described as purification, in fact unjustly discards some arguments as inappropriate. It is not just about a right to be irrational, that Leon Kass is now and then accused of advocating. It is about showing that the dominant idea of rationality is just one out of many, that it is polluted with ideology just as much as the suppressed (and hence seemingly irrational) ones. This all amounts to an argument of symmetry: it argues that proponents and opponents should be assessed by the same criteria.

In conclusion, the arguments in support of the protectionist stance are as follows. It might be argued on the normative level that genetic enhancement is a violation of the natural order, or alternatively expresses a reifying, humiliating, cold stance. In addition, it builds on the precedents of our greed to mend our lives. This all boils down to the idea that enhancement is plainly wrong, and that it therefore cannot find any legitimation, whether public or private. It argues thus that enhancement should be prevented politically because it violates the condition of tolerance. Moreover, exactly the liberal boundaries of this condition of tolerance are target of critique. Importantly, Midgley argues that these boundaries hide a deeper, ideological content.

From this, it becomes clear that the second class of arguments that we saw in the other stances, that rendered the views of certain opponents irrelevant, is less visible here: as the condition of tolerance is not met, the problem is seen as completely public, and therefore all visions are relevant. In other words, as the condition of tolerance is not met, the moral appreciation and the relevance appreciation of the arguments coincide. Interestingly, the stance does not put arguments beyond discussion, but it puts enhancement itself beyond discussion. As it will only be able to produce plain wrongs, there is no further need to discuss enhancement politically. Thus, enhancement is irrelevant at large because it cannot possibly be good. Therefore, it is also politically irrelevant, and all its spokesmen consequentially deserve little attention. For the same reason, the technical assessment of hopes and fears needs little discussion.

This confirms the observation in section 2.4, that Kass's strategy resembles counter-purification rather than offering an alternative purification: he has no stake in keeping certain arguments out of politics, but only in keeping things in. Similarly, the protectionist stance does so by exposing the plain wrongs it sees in enhancement. The only way in which protectionism can be seen as an alternative purification, is in its interest in putting enhancement itself beyond discussion. 


\subsection{Enhancement and modern culture}

\subsubsection{Public prohibition or private permission?}

Roughly, two tendencies can be discerned in the debate: one towards a public prohibition of enhancement and the inclusion of less-tangible arguments, and one towards the private permission of enhancement and the exclusion of lesstangible arguments. These two tendencies coincide with purification and counterpurification, respectively. The battle over whether enhancement should be allowed or not, is partly fought over the question of what arguments are appropriate and what are not. Some arguments are felt to be inappropriate by discussants because they think those are just private opinions that cannot serve collective decision making. However, others may feel that those very arguments are appropriate and even necessary in the debate, as they see in them a violation of the condition of tolerance that I explained in subsection 2.2.I: one can only accept that others act and think differently, insofar as we are convinced that those other ways are in themselves not bad enough as to legitimize our interference. We generally judge others' ways along the lines of our own morality, and perturbation produced by technoscientific change will generally enforce a revision of the lines of tolerance. This may urge people to bring forward arguments, even if others do not accept them.

The first tendency, towards public prohibition of enhancement, builds on a rather inclusive conception of harm. This leaning argues for incorporating a wider and more abstract set of values. First we find the arguments of hubris and the adjacent motive of the sorcerer's apprentice, which argue that enhancement is bad because we mistakenly think that things are in our hands, in a deontological and consequentialist vein, respectively. But those things are not in our hands, and tinkering with the unknown may call misfortune down upon us. But even if things were in our hands, we would be immoral in that, because the stance of mastery and dominion and the failure to appreciate life as a gift can produce nothing but an undignified life. The same will result from the approach of the human being as if it were just another animal, a mechanistic entity or even just a plain instrument that we may modify as we desire. From such considerations, it is argued that the typical scientific vocabulary that largely serves as a model for the liberal vocabulary, can only produce a shallow assessment of the moral import of enhancement. And at large, each of these arguments can be understood as a claim suggesting that 


\section{Politics by All Means}

the liberal vocabulary deployed a notion of harm that is way too shallow - and therefore requires inclusion of more substantial notions. Below the surface, these arguments incorporate a conception of human nature and human psychology, human dignity, a valuation of the natural order or even an appeal to God's will.

The other tendency, towards a private permission of enhancement, works in the direction of a minimal conception of harm. It limits the conception to physical injury and the impediment of a general sense of liberty. Importantly, this sense of liberty is somewhat shallow, as it seems compatible with a host of interventions that according to the tendency towards prohibition does does interfere with liberty. Or more precisely: it has a preference for negative liberties, that just protect persons from unjust interference. This is largely in line with the liberal way of purification. It thus serves both the genetic liberals and the transhumanists.

I recognized some rhetorical figures in section 4.3. These can be related to these tendencies in conceptions of harm. For example, the motive of postponement of moral judgment holds that there is no convincing indication of harm, and therefore no judgment can be made. This presumes that the conception of harm is at least not in line with what I just explained under the tendency towards a public prohibition of enhancement. Similarly, the motive of separation of technoscience and morality, closely related to boundary work, can be interpreted as a drive to detach technoscience from any politically-relevant harm. We have also seen that the severity of harm is indeed downplayed by the argument from precedent. It argues that we will be doing nothing new, and as old practices require no political interference, neither will new ones, because neither of them is harmful. Then there is the rebuttal of the is-ought fallacy: we cannot derive an is from an ought, if only because some elements of nature are downright evil. In other words, changing how things are is not a priori a form of harm. And the argument of irrationality mainly excludes forms of harm because they build upon values and conceptions that do not meet the specifically scientific rules of thought.

One more example of how the respective tendencies to prohibition and privatization counteract one another intricately is provided by dignity. At first sight, such a laudable value appears as an opportunity for seeking common ground. Indeed, all are likely to believe that dignity is something that is universally laudable and worthy of protection. Both the transhumanist position and the protectionist position embrace dignity - and so does the genetic-liberal position, but I leave that one out for this example. However, in the debate, the transhumanists use this 
value to 'pacify' the protectionist stance: they agree upon dignity at large, but they use it here to refute the protectionists' diagnosis of technology. They deny that technology will work out to any detriment of dignity. They support this claim by stating that there will be plenty of opportunities for us to control the technology on our way there, and that it in fact opens up a host of possibilities for enlarging our dignity. This is a strategy of neutralization by embracement. Thus, at closer inspection, dignity is just one more apple of discord. It serves both positions, as it can be argued both in support of enhancement and against it. In fact, it serves none.

\subsubsection{Rhetoric and below}

The disagreements just discussed can be divided into at least four different dimensions. First, discussants may disagree about factual claims. That is, they may agree or disagree that a specific technological scenario is plausible or not. As actual enhancement is largely in the future, it is not surprising if disagreements occur on this point. I suggest to call this the level of diagnosis of technology. ${ }^{9}$ Below this level, we may discern a second level of disagreement, which I propose to call the level of conception of technology. This is what people think technology in general to be. This may concern a wide range of properties that we can attribute to technology and technologies, but of particular interest here is the instrumentalismdeterminism dimension. A third level of disagreement concerns the normative position against which a situation (whether hypothetical or empirical) is to be judged. We can disagree about what is right and what is wrong. Then, in addition on a fourth level, we can disagree whether the particular normative stance should hold for all or not, and consequently whether we can accept the disagreement or not. I call this the dimension of universalization.

Important to note now is that our agreement on each of these dimensions is orthogonal: a position on one of the dimensions can, theoretically, be combined with any position on the other dimension. Just to make sure: the word orthogonal refers to things that we can logically think of as unconnected. Henceforth, I will use independent as referring to things that are in real life thought of as unconnected.

9 Taking into account that enhancement is largely in the future, 'prognosis' would perhaps be a better choice of words, but outside of enhancement, the same level of disagreement could also occur regarding present and past technologies. Hence I prefer 'diagnosis' as an overarching term, thus including 'prognosis' as the 'diagnosis of the future'. 


\section{Politics by All Means}

Let me clarify this further with a - hypothetical - example. One typical diagnosis of technology would be that in a number of years, all children will be given a specific genetic constitution that makes them less vulnerable to air pollution. One typical underlying conception of technology would be that indeed present technological practices will probably or even necessarily lead to such a genetic-enhancement technology. When the air-pollution enhancement obtains, parents will simply have no choice than to use it. Alternatively, one may contend that the future scenario is likely, yet not because technology forces us that way, but for example because it is simply the wisest choice, much like how today practically all parents send their kids to the dentist twice a year. These two positions share the diagnosis that a certain technological configuration will come about. They do however not share the conception of technology, as one leaves leeway to human choice while the other does not. A third position could be framed: one may agree with the first position that present practices of technology will inescapably lead to certain situations, but not to the genetic 'vaccination' against air pollution. Thus, the first and third position share their determinist conception of technology, yet not their diagnosis.

The same example can be extended to the third and fourth dimension of disagreement. People may think it is right to design their children such that they will be able to follow the best education with moderate effort. Others may think this is wrong. This entails a disagreement on the normative position. That is quite a different question from the question whether others should hold the same. Again, disagreement on these third and fourth levels is orthogonal. One may think it is wrong to design your children in such-and-such a way, while not seeing the need to demand that others think the same. Or any other combination of the two.

The sting now seems to be in the combination of these four dimensions. I posited that theoretically, they are orthogonal, that is the position an issue takes on a certain axes need in no way be related to its position on each of the other axis. But in reality, our positions on each of the dimensions are not independent. That is, if somebody estimates the situation to be grave on one of the first three dimensions, he or she is likely to have a universalistic stance on the fourth dimension. In fact, it is quite likely that someone would be of the opinion that certain enhancements are wrong while one can still allow others to do. (Remarkably, Mulhall and Swift: I992, p. I60, do seem to presume independence between different dimensions of disagreement, in particular between the substantive content and the scope 
of a theory. In my terms, they are mistaken in the independence, although orthogonality might still be feasible.) Similarly, people with a determinist view of technology, are likely to hold a more pessimistic diagnosis of it too. I suggest to use the term crosstalk here, borrowed from communication engineering, where it is used for leakage between signals that should remain separated. This insight will help us articulate the disagreement on enhancement in a sharper way.

The disagreements that I articulated in subsection 4.4.I can now be analyzed along these dimensions. For example, the threat that enhancement was believed to pose to dignity, was primarily cast on the normative and universalization levels. Those appreciations of dignity were then accepted on those levels by adherents of enhancement, yet they were rebutted on the levels of the conception and diagnosis of technology. And then the rebuttal was not even that strong on the diagnosis, but especially on the conception of technology. Even if it is conceded that technology may turn out to work the way the opponents fear, the adherents will nevertheless say that this is not a consequence of the technology (thus a determinist stance), but rather of our choices (thus an instrumentalist stance). Do not worry, we will pull the break whenever necessary - this seems to be the message of the proponents. The strategy of neutralization by embracement is thus to be explained as a shift between levels. This view can be extended to harm in general.

\subsubsection{The coincidence of liberal and technoscientific purification}

The reconstruction of the enhancement debate so far has shown that it is difficult to tell what the exact nature of the purification is: various levels of disagreement run through one another, and disagreement on one level might be concluded on another level. In addition, the disagreements on each of these levels raise another question: whether they relate to a dominant liberal style, and how this style relates to a vision of technologies as morally neutral. Indeed, counter-purification often produces critiques of both the dominant liberal style, and of the view of technoscience as instrumental. Much like how liberalism tries to silence, neutralize or disguise its impact in the realm in which our private ethics should be our guide, so do the advocates of technoscience seem to conceal the good-life impact of technology. And conversely, the opponents need to work hard to get their arguments in.

The following example shows even closer how a specific conception of technology coincides with liberal ideas. By providing a certain interpretation to how 


\section{Politics by All Means}

technology works, genetic liberals render technology as nicely matching the liberal privatization of a significant part of ethics. By promising that plain wrongs will be successfully prohibited, genetic liberals implicitly advertise an instrumentalist view of technology so as to render difficult moral talk superfluous. This will be acceptable against a liberal background.

Another correlation between liberalism and technoscience can be recognized in the positional goods discussed in subsection 4.2.6 and the liberal style of purifying we generally subscribe to in the politics. In acquiring positional goods, we do not really coerce others to take them. Thus, we are not doing anything wrong in the view of liberal ethics: we leave it to individual decision, each to be made with reference to whatever idea of the good we value. As no enhancement is enforced, the potential downsides of proliferation seem escapable, too: one may simply decide not to engage. Thus, the downsides do not appear as an individual responsibility. Positional goods may not be just 'smart for one, stupid for all'. Rather, they can be 'obviously smart for one, and at the same time stealthily stupid for all'. This is however fairly difficult to argue for in a liberal vein, as the liberal has a preference for private choice over a vocabulary of responsibilities.

We can even recognize this coincidence in the fact that the antipositions coincide similarly. In (some advocates of) the protectionist position, we see that a presumed deterministic character of technology renders moral talk publicly inevitable. Moreover, it renders enhancement so bad that in fact it deserves no attention. A number of examples more, showing the entwinement of technological and political ideas, can be devised from the arguments in 4.3 quite easily.

Thus, advocates of enhancement largely line up with liberals, while the critics also seem to combine a critique of liberalism with a critique of enhancement. Indeed, enhancement, as an appearance of technoscience including human advocates, appears to export a notion of technology as morally irrelevant. That this irrelevance derives for example from both a determinist vision and an instrumental vision, two opposing views that both serve the transhumanist position, does not refute the rhetorical use of the two. However, we must learn from this for later conclusions, that part of what technoscience 'does', is indeed just what happens with it in the hands of people. 


\subsubsection{Dialectics of purification in enhancement}

This all confirms once more that the process of moving things out of the debate meets some resistance. The arguments rendered private by some do not let themselves be excluded from the public sphere: some authors feel the need to reintroduce them and stress that it is a (typically liberal and technoscientific) mistake not to take them seriously. By stressing the importance and disproving the irrationality of exactly the meaning of life, human dignity and the natural order, they perpetually argue that technology is not just instrumental. They contend that therefore, the dominant technoscientific and liberal rationality represents a shallow picture of the lifeworld, and technological purification would be a mistake in the first place. And whether one agrees with these positions or not, we can at least empirically observe that we are principally unable to discuss enhancement without making reference to our private ethics, that is to our ideas of the good life.

A first example of this counter-purification is given by Michael Sandel (2007, pp. 75-83). He shows that the liberal-eugenic vocabulary puts a number of threats beyond discussion, which in effect brings those threats back in, only in a different guise. The liberal-eugenic stance is largely justified by claiming that it does not in any way corrupt the autonomy of the future child. However, thus Sandel argues, we do allow the state to demand that parents send their children to school, indeed because this ensures that children can pursue a wide variety of life plans. Along exactly the same line of reasoning, we may in the end demand that parents give their children the right enhancements. Thus, Sandel argues that the premises of liberal eugenics on their own terms do not safeguard people against compulsory enhancement. Sandel then continues that the typically liberal ethic of autonomy and equality cannot on its own terms conclude pro or contra enhancement. What is needed in addition is the understanding that a designer child is at least compromised in the sense that the origin of its life is less contingent than the life of others. This reflects the stance of mastery and dominion again, something that the liberal vocabulary is incapable of dealing with. He adds that this indeed cannot be argued convincingly in consequentialist terms, because it is not a matter of individual or collective benefits, it is about a state of mind (see Sandel: 2007, p. 96).

Similarly, Leon Kass (2002 b, p. 6I) argues that the dominant mode of ethics is a hyper-rationalist analytic exercise. Being just a conceptual analysis of justifications that seems to amount only to clarity, consistency and coherence, it overlooks what 


\section{Politics by All Means}

really moves persons: their motives and passions, loves and hates, in short those matters that are sometimes dismissed as nonethical or irrational. Thus, ethical discourse focuses only on matters conceptual and logic, and oversees the full extent of personhood. Kass therefore suggests broadening the subject of morality: not the rational mind without flesh and blood, but the institutions and customs in which the moral health of our entire community is embodied (see Kass: 2002b, p. 73). This critique clearly mimics the communitarian critique that liberalism received in general (see also page 47). This is clearly an instance of counter-purification as it

pleads for acceptance of certain arguments into the debate that are now discarded unjustly.

One last example comes from Henk Jochemsen (2003, p. 6I). He argues that the preference for individual choice may lead to a bottom-up evolution of eugenics. While choices on genetically-enhanced reproduction appear to be free, they are of course only choices because the medical profession offers those choices. However, offering those choices hides a normative position on what a good society is. Moreover, this position may be reinforced by means of social and institutional pressure. This will lead to a societal prevalence of the idea of a makable child. These are considerations that are overlooked when discussed in a free-choice vocabulary, and Jochemsen thus proposes to include them in the political debate. Indeed, this is explicit counter-purification that tries to stretch the boundaries.

I already suggested this in chapter 2: the failure of purification is inherent to purification itself (see also Latour: I993b, pp. 49-5I). In the first place, both liberal and technoscientific purification have a hard time because some things are too much ambiguous for any classification in terms of public and private to be uncontested. Things are not just either harm or not harm, but they are always harm in a complex way, under a specific perspective of both morality and the nature of technoscience, and in specific situations. Thus, arguments are hardly ever plainly irrelevant, but complexly relevant or irrelevant at the same time. And in the second place, purification is doomed to fail because it will incite its own countermovement: if elements are being artificially defined out of scope, they will collect support from those who have an interest in keeping them in scope. That such potential support exists, is reflected by the fact that each of the three positions at least enjoys some support.

Indeed, what some of the critics of enhancement do, could be described as counter-purifying: they try to rehabilitate arguments that others think are 
inappropriate. They do so by showing that there is a core of - appropriate and valuable - rationality in them (see Midgley: 2000), or that their exclusion from the public sphere is unjust (see Kass: I997/I998). Perhaps they would be done more justice if we described their activity as 'enacting an alternative purification', because this would present a more symmetrical and less prejudiced approach. After all, the counter-purifiers do not have a categorical interest in getting just anything back into the public sphere. Rather, they have an interest in putting the boundary in a different place. However, as they fight the dominant way of purification, that is the political-liberal variant of it, they are in effect only moving things in, and hardly anything out. The asymmetry results from contingency, not from my approach. Whether symmetric or asymmetric, it can still be empirically observed that purification, counter-purification or offering an alternative purification, is hard work for whomever happens to be engaged in any of these. This chapter has clearly illustrated the dialectical mechanism that was devised hypothetically in chapter 2.

\subsubsection{Technoscience's double bind}

I discussed in the previous subsections that technoscience and liberalism produce similar ways of purification, and that these purifications together produce their dialectical countermovements. However, at closer look, it seems that at least the purification of technoscientific origin kind of burns its own fingers: not only does it contribute to a successful purification. It also presents itself as a hard case to that very purification. I call this the double bind of technology.

That is, as technologies are often malleable in an early stage, numerous interpretations of them appear. We see disagreements then on the four levels devised in subsection 4.4.2. And given the phenomenon of crosstalk, it is at least empirically difficult to see enhancement as a private affair. At least part of the people will be reluctant to see it as private. Insofar as the possibility exists that the technology cannot be privatized, it is by definition a public issue. Technoscience thus often earns some aspect of monstrosity (see also Smits: 2002; Midgley: 2000) from its initial flexibility: it stands in the way of an unambiguous classification.

This is clearly found in the rhetoric of enhancement: while it is advertised as something that everybody should be able to decide about for themselves, it is also unclear what we should exactly expect. Enhancement is thus empirically in the public sphere, at least as long as it is under ballot for privatization. The 


\section{Politics by All Means}

tension concerns those things that advocates see as private opinions, while they are adduced by the critics as important things and necessary to discuss in public. Moreover, both parties use partly the same arguments. The boundaries between public and private are thus continually challenged. Even though we may discern in technoscience a tendency towards privatization, it also presents a hard case to this privatization. In fact, enhancement itself has made the natural order into a public issue.

As a consequence, our private ethics is pulled into the public sphere and into politics as well: even though it is banished from the public sphere in normal situations, private ethics for each person is constitutive of the subtleties of how he or she uses public concepts in public. In the case of enhancement, this is to say that private ethics becomes public, because the talk of enhancement forces us to revise our conceptions of concepts that are indeed essential to liberal speech: liberty, harm and justice, among others. It is no wonder thus, that controversies seem interminable and moreover cannot but concern good-life issues. The counterpurification is thus successful at least in the sense that it forces discussants to explicitly argue over the good-life aspects of the matter.

\subsubsection{Rationality revisited}

It is remarkable that critics of enhancement are accused of irrationality, or need to explicitly defend their arguments as rational, while the advocates of enhancement seem to get away much easier with not providing rational explanations. Those who want to argue that enhancement is at odds with the good life, human dignity or the natural order, have to work much harder to have their arguments heard than those who argue in favor of enhancement and argue about seemingly clear benefits, and seem to deploy arguments that have a similar irrational ring to them. But what if the counter-purifiers argue that their arguments are just as rational? Or even stronger, that the arguments of enhancement advocates are just as much irrational?

Mary Midgley (2000) observes that emotional judgments often have a large cognitive component to them, while judgments that are claimed to be rational often cannot be seen apart from the emotional background to which they emerge. Therefore, Midgley argues that we should at least pay equal attention to both sides under the same conditions: without prior judgment of rationality, that is. She suggests that we see emotions and rational judgment in a juxtaposition, for a 
rational judgment that is not supported by an emotional counterpart is an empty one, and vice versa (see Midgley: 2000, p. 9): 'Heart and mind are not enemies or alternative tools. They are complementary aspects of a single process.' But then, how can the balance in the debate be this uneven? Or more specifically, why are some irrationalities tolerated, while others are banned mercilessly?

An answer might be found in Andrew Feenberg's Transforming technology: a critical theory revisited (see Feenberg: 2002, ch. 7). He argues that dominant forms of rationality have the tendency to reinforce and expand themselves. This would be unproblematic if the rationality were strictly neutral: then it could be applied to all ends, and we would only have to discuss the ends. Or alternatively, if we think that a technology does not serve a certain moral good, we can try to argue so by saying that it is not in accordance with rationality. But any attempt to criticize or revise the dominant form of rationality itself, will appear fundamentally irrational. This is why alternative rationalities like Kass's indeed seem irrational. They question the whole ideology behind technological progress, not just its applications. In opposition, this is why advocates of enhancements find a good ally in the capitalist rationality in terms of efficiency towards external goals, and hence in liberalism. It helps them repress the vaguer objections against enhancement.

\section{Review}

This chapter has shown some of the mechanisms developed in part II. It has shown that purification is hard work: some things are harder to discuss or argue than others, and it is hard work to get arguments in or out. The chapter has shown that this purification partly runs through giving new meanings to concepts, which on their turn build upon underlying ideas of technology, and upon comprehensive doctrines. It has shown that some battles on justification are in fact fought out on the field of scope, and the other way round. Arguing that enhancement is a private business, seems to correlate with the refusal of certain, in effect de-privatizing, arguments in the debate. The levels of political debate run through one another.

What this chapter has not shown, is a solid role played by technological artefacts. So far, I have not really needed the conception of technology as networks, nor any account of the interactions between persons and things. Nevertheless, technology has played some role here: its hermeneutic dimension is played out by the technological-cultural background against which the debates were conducted. Brave-new world arguments can only occur in a situation that gives sufficient 


\section{Politics by All Means}

reason to suspect such a world. Indeed, many of today's technologies do raise such suspicions in some. Similarly, the idea of manipulating our human nature can only become so pressing as to discuss it at length, if actual technologies offer sufficient promises that such manipulation will be possible, soon. (Biomedical experts will generally argue that these promises are not that probable, but this does not take away the impression of such promises in a sufficiently large number of discussants.)

To this chapter, the next one will add exactly this more concrete role played by technical artefacts. In the next chapter, the hermeneutic and existential dimensions of biobanks and the genes contained in them will be elaborated. Technology will become technologies there: tangible artifacts, rather than the abstract cultural idea they were in the present chapter. 


\section{Biobanks and the socio-technical body}

\subsection{Base sequences in sequence bases}

Genomics is literally the pursuit of knowledge about the whole genome - as opposed to genetics, a name that does not emphasize such a holistic focus. As the human genome consists of 3 billion base pairs, forming sequences divided over some 25-30 thousand genes and a lot of non-coding or junk DNA (see Rodden Robinson: 2005 , pp. I63-163), it is clear that this requires a lot of storage and computing capacity. Indeed, the rise of genomics is deeply linked to the proliferation of another sector: information and communication technologies. Genomics largely builds on the existence of advanced computing systems, and the newly-evolved field of bio-informatics. By means of large-scale correlation analysis, a host of so far unknown correlations between genotype and phenotype are open to discovery. The exemplary locus of such investigation has thus become the biobank, sometimes also referred to as tissue bank or gene bank. Its basic idea is that a large collection of materials connected to a data base allows for the discovery of even weak correlations. If a large quantity of genetic, anamnestic and possibly life-style information is available, a computer can literally do the math.

Biobanks promise to be gold mines of genomic knowledge. With a deepened understanding of correlations between the genome and our lives, we will be able to manage our health in a more efficient and better informed way. Medicines can be prescribed to better fit our specific properties. Diets will be better informed and fine-tuned to our individual genetic properties. Diseases can be foreseen and recognized at an early stage and therefore be treated better. Problematic genomes can be recognized earlier, possibly even before conception. Biobanks are believed to be a necessary step in delivering these promises, and thus have become the icon of all that genomics stands for: a deepened understanding of the genetic nature of our person.

The German National Ethics Council defines biobanks as 'collections of samples of human bodily substances that are or can be associated with personal data and information on their donors. Examples of bodily substances are cells, tissue and blood, as well as DNA as the physical medium of genetic information. Depending 


\section{Politics by All Means}

on the purpose of a given biobank, both genetic information on persons and information related to their health and lifestyle may be associated with the samples. It is this association that makes the sample collections important' (see German National Ethics Council: 2004, p. 2I). The Canadian Biotechnology Advisory Council similarly defines biobanks as 'a collection of physical specimens from which DNA can be derived, the data derived from the DNA samples, or both' (see Yeo: 2004, p. I2). Tansey and Burgess (2004, pp. 7-8) emphasize the three common elements in what are mostly understood as biobanks: first, they contain biological source material. Tissue may or may not be collected for the purpose of extracting DNA, but what counts is that DNA extraction is performed in the end. Second, they build on genetic information systems. The information is usually stored in an electronic database. And finally, they contain phenotypic information. This information stems from physical examination, questionnaires and individual health records. In addition, some definitions emphasize the aim of research (as opposed to for example population screening) as a necessary condition. Also, some definitions demand that samples are physically stored, rather than just extracting and keeping data while discarding the samples (see Einsiedel: 2003, p. 2). However, for the line of argument of this chapter, I consider these differences irrelevant.

Indeed, a number of biobanks have been established over the last decade. The widest-known example is the Icelandic Health Sector Database. The project was commenced based on the belief that the Icelandic population is genetically more homogeneous than other populations. In addition, the Icelanders have a long tradition of genealogy as a pastime effort. This means that family relations can be charted easily and reliably. Moreover, Iceland has a reliable record of medical information of many individuals, which will serve the analysis of genetic information (see Tansey and Burgess: 2004, p. 13). Thus, it was believed that the Icelandic biobank would outperform all others, and the collective effort would mean a boost to national unity. This altogether was believed to be a gold mine to which all citizens would subscribe as enthusiastic participants.

The exploitation of the biobank was governed by deCODE, a private research investor based in the United States. This lead to controversy because it incurred the commercialization of goods that were hitherto common goods. Additional controversy has flared over the Health Sector Database Act, passed December I99 8 by Iceland's Parliament (see Einsiedel: 2003, p. 3). Particularly controversial 
was its decision to an opt-out system: consent in the Icelandic population was presumed, and in case one did not wish to participate in the project, one needed to explicitly opt out. This has sparked a movement of resistance, culminating in the Mannvernd Association of Icelanders for Ethics in Science and Medicine, boasting $5 \%$ of the whole Icelandic population opting out in 2003 (see Busby and Martin: 2006, p. 239). In 2004, the HSD Act was declared unconstitutional. This clearly was a deception compared with the original promises. In the end, this somewhat clumsy approach has led the Icelandic biobank to failure (see Rose: 2006).

A more socially-sophisticated initiative is the UK Biobank project. By working at a prudently slow pace it seeks public support through all means. It aims to establish several cohorts, the largest of which serves a 500,000 member trial of middle-aged persons. It aims at investigation into endocrine, cardiovascular, and respiratory diseases. The biobank will be managed from a hub, hosted in Manchester, where the general control of the project will take place. Attached to it, six spokes all over the country are envisioned, where the actual recruitment and data collection is to take place (see Barbour: 2003, p. I735). As the project aims at the widest range of investigations, up to seven samples are to be collected from each donor. Characteristic of the project is its industrial scale. Its material facilities are not hosted in academic laboratories, but in dedicated buildings. These are designed with over-compacted floors to withstand the weights of the fridges, and an ambient temperature of $-20{ }^{\circ} \mathrm{C}$ as to keep samples frozen even when fridges need opening (see Harris: 2007 b). It seems that in the UK case, things are going more smoothly, not in the last place because more attention was paid to acquiring the trust of the public. Indeed, as of October 2008, over I90.000 participants have been enrolled (see UK Biobank: 2008).

In the Netherlands, the Parelsnoer ('String-of-pearls') Initiative is the flagship of biobanking initiatives. It is a collection of biobanks dedicated to specific diseases, each called a 'pearl', operating under uniform conditions in one of the Academic Medical Centers in the Netherlands. Each of these hospitals provides the coordination for one of the diseases. The official documents of the initiative breathe a technical approach: the main concern seems to be a streamlined implementation of facilities that can be deployed universally across the Academic Medical Centers. It is remarkable that the project is not mentioned a single time in Dutch media, ${ }^{\mathrm{I}}$

1 As of October I7, 2008, Google News produces no hits when searching for the proper name 'Parelsnoer'. While Google News dates back only two months, LexisNexis goes back up to twelve years, but only indexes the leading five national newspapers. It does not produce any 


\section{Politics by All Means}

though some professional publications are available and partly published on the web. We may thus suspect that the initiative either has a poor public-relations department, or more likely, that it profiles itself as business-as-usual within the walls of academic hospitals. This is indeed reflected by the fact that the initiative tries to keep up with existing regulations as much as possible, and largely delegates legal and ethical concerns to medical-ethical hospital committees (see Parelsnoer Initiatief: 2008, p. 8).

While promising a lot, biobanks also in their novelty raise suspicion. As biobanks may store a lot of intimate things about us, the roaming shadows of Orwell's Big Brother and Bentham's Panopticon are only a step away. Therefore, anonymization and protection of data are at the core of the regulations of biobank initiatives. This aims at making them legally feasible, and at acquiring trust in the participating citizens. Biobanks face the challenge of taking away the impression of threats to our privacy. Even when we know that researchers cannot actually link their browsing to our persons, the feeling of their browsing through our anonymized records can raise discomfort (see Naser: I999, p. II3; Ripstein: 2006, p. 218). On the other hand, influential institutes such as the German National Ethics Council (2004, p. I7) argue that anonymization of samples and data suffices for privacy to be safeguarded. These divergent opinions signify that there are at least some tensions that are not straightforwardly solved. Thus, already from the normative disagreement, we may expect that biobanks will provide an interesting source of difficulties that politics will typically run into when confronted with new technologies.

In chapter 2, I argued that public speech inherently contains a purification of arguments. This purification both enacts and maintains the existence of a public and a private sphere. However, I also argued that this purification remains both hard work and a muddy issue at that. Thus, the distinction between public and private itself remains fuzzy. Moreover, I argued that technologies add to this confusion, as they often bear upon the divide between public and private. That is, sometimes technologies become publicly inescapable, or publicly relevant in any way. As consequence, a discussion is urged in which we feel the need to appeal to our comprehensive doctrines. Thus, private ethics may become publicly inescapable. In the course of this chapter, biobanks will be proven guilty as charged of producing such difficulties.

hits, either. 
This chapter will proceed as follows. In section 5.2 a number of ethical questions will be discussed that can be linked to the introduction of biobanks. The section will principally discuss the pros and cons of biobanks on the normative level, however without carrying this to conclusive judgments. Then, in section 5.3 I will articulate part of the debate as a meta-debate. It can be seen as an implicit critique of how existing notions no longer suffice, and how our routines of discussion need revising. Finally, in section 5.4 I will provide an analysis of this whole phenomenon against the background of the ideas developed in part II.

\subsection{Issues in biobanks}

\subsubsection{Should we want biobanks?}

As explained before, biobanks boast great promises. The knowledge they intend to produce should serve our health, the predictability of our medical records, our life styles and our diets. However, countering these promises, biobanks raise numerous difficulties. As with all large-scale storage of data, it raises the question of whether this information will be used to the benefit or to the detriment of citizens. Besides a gold mine for medical-scientific purposes, biobanks are also gold mines for insurance companies: if they can somehow get hold of the genetic profile of a potential customer, they may even find in this a good reason for excluding him or her from the insurance plan. As Curtis Naser (I999, p. Io9) argues, insurers have an interest in minimizing risk. And given the huge capitals at issue, we do better not expect that the scientists involved will wait until we have the ethics straight (p. II8). However, he also recognizes that the customer's interest is opposed. Building on Annas' coded future diary (see Annas: I993), Naser surmises that potential customers who learn that their profile suggests that they are statistically at risk, will recognize that negotiating an insurance will be even more important to them. This renders the general demand by insurance companies delicate, that customers reveal anything that they can be reasonably expected to recognize as relevant.

In addition, it is being questioned whether promises of biobanks are that realistic, and whether the expectations are worth all the trouble. It is unclear in the first place whether the biobank will reveal much, as many diseases can be expected to be too complex to be traced in even larger populations. In the UK-Biobank case, the consulted experts are hardly united in their opinions on this matter. Also, it 


\section{Politics by All Means}

has been suggested that tissue-specific samples would be of much more use (see Barbour: 2003, p. 1738). Moreover, biobanks strongly build upon the polygenetic paradigm ruling genomics. What grants that this paradigm will remain fit in place for a longer period of time, to recover the costs made to establish the biobanks? Can we rule out the scenario in which, ten years from now, biobanks are simply no longer considered the way to go in investigating human nature?

\subsubsection{Medical ethics: autonomy as informed consent}

Intuitively, as biobanks are primarily an enterprize for medical-scientific research, medical (research) ethics is the first place to look for answers to questions of regulation. Moreover, present-day medical ethics strongly reflects a politicalliberal origin that stresses individual choice and responsibility. As medical ethics is in a way paradigmatic for how we do politics, we may expect that it will also be applied to biobanks. Values that medical ethics pursues in protection of the individual most prominently include autonomy, non-maleficence, benevolence, and justice (see Beauchamp and Childress: 2003), or alternatively dignity, integrity and vulnerability (see Rendtorff: 200I). Biobanks can be assessed by asking the question to what extent they respect or even promote these values. These values will be discussed in this section, except justice which will be paid attention to separately in subsection 5.2.4.

Among these values, non-maleficence, benevolence and vulnerability seem to be either respected by or irrelevant to biobanks. First, taking a sample is hardly or not invasive, so the value of non-maleficence is respected. One might object that operations on the sample can still harm the donor. Indeed, the violation of privacy is a maleficent thing; however, this is not the physical harm referred to by non-maleficence. Nevertheless, privacy will be discussed in due course.

Second, the value of benevolence seems granted too: all that biobanks stand for, is a proliferation of medical-genetic knowledge for the benefit of humankind's health. There is little question about that, or it must be of the kind that in general criticizes the modern stance of hunger for knowledge. However, it may be unclear who enjoys this benefit: in most cases, the benefit will be abstract and not concern the donor. Thus, it is not the benevolence exemplary in medical ethics that specifies that the research subject should benefit from the act, but it is at least $a$ benevolence that may add to the legitimacy of biobanks. This does however raise some questions of justice, which will be discussed later. 
And third, a similar inference holds for the respect for vulnerability. This is the recognition that human life can be hurt or damaged. Indeed, hurting human life by taking and analyzing a sample seems far-fetched, but damaging autonomy or dignity can still be envisioned. These will be discussed in their own right.

With some other values, it is not that obvious that biobanks serve or respect them. For example, the value of autonomy raises the question what autonomy might mean in the context of biobanks. In general, autonomy comes in many forms. Self-determination in terms of informed consent is its most prominent guise in medical-ethical contexts. The principle of informed consent has grown into a kind of golden standard of medical ethics. In its 2000 version, the Helsinki Declaration of the World Medical Association captures its meaning as follows:

'In any research on human beings, each potential subject must be adequately informed of the aims, methods, sources of funding, any possible conflicts of interest, institutional affiliations of the researcher, the anticipated benefits and potential risks of the study and the discomfort it may entail. The subject should be informed of the right to abstain from participation in the study or to withdraw consent to participate at any time without reprisal. After ensuring that the subject has understood the information, the physician should then obtain the subject's freely-given informed consent, preferably in writing. If the consent cannot be obtained in writing, the non-written consent must be formally documented and witnessed.' (World Medical Association: 2000, art. 22)

In short, it holds that medical professionals should educate patients or research subjects to the fullest extent and in a neutral way, after which the subject can decide for himself or herself. Underneath this guideline is the belief that the best decision is well-informed and free of coercion, and that coercion, abuse or disrespect of the patient are to be continuously watched for.

While this definition of informed consent gives sufficient guidance for research that is performed on the living patient, it is not so clear in the context of the typical biobank situation, where research is performed on abstract samples of the patient. Indeed, several authors have argued that such informed consent is fundamentally problematic concerning of biobanks. For example, Winickoff (200I, pp. I3-I4) argues that informed consent is impossible. Referring to official guidelines, Winickoff shows that these build heavily on the need to explain all future uses 


\section{Politics by All Means}

of the samples. However, the fundamental unpredictability of scientific research makes this impossible (see section 3.4.3). Similarly, it is questioned whether it is possible for even an educated person to be genuinely informed of all the risks and benefits in genetic research (see Chadwick and Berg: 200I, p. 3I8), and whether a physician will be in the position to explain all relevant facts (see Chadwick: I999b, p. 443).

The peculiar nature of genomes relates in a peculiar way to the possibilities for autonomy. Suppose I would like to undergo a genetic test, to check whether I have an inclination to develop a certain disease. There will be little disagreement that I have a right to do so. Equally likely, just as I have right to know anything relevant to my health, I could alternatively claim a similar right not to know, to preserve my idea of an open future (see Andorno: 2004). However, my siblings could claim exactly the same. And as such a test reveals to some extent their inclinations as well, my siblings could claim that my taking a test is a violation of their right not to know. The compromise could be suggested that I have a right to undergo the test under the condition that I agree not to reveal the results to my relatives. However, this would in effect also prohibit me from acting in any way according to the outcome. If, say, my condition would be strongly mitigated if I kept to a strict diet (which is the case with some cardiovascular diseases, see Castle and DeBusk: 2008) or took preventive medication, this would be very difficult to conceal from my relatives.

Thus, the effectuation of my fundamental right to know can be in conflict with my relatives' equally fundamental right not to know. Similar difficulties can be discerned in the right to donate my genome to a biobank, or for example in the question of whether genomes can be framed as a common-good kind of knowledge that does not require my consent before it can be demanded from me. So, my genome is both mine and not-mine in two very similar ways (see Annas: 2004, p. 4; Everett: 2003 , p. 54). This paradox is real. On the one hand it is conceivable that someone really does not want to know his or her genetic predispositions nor those of siblings. A similar inference holds for mankind at large. On the other hand however, it makes little sense to say that I have the right to conceal knowledge that concerns 'all men', or perhaps 'all Caucasian people' or perhaps even 'all humans' (see also Ossorio: 2002, p. 4I4). This will prove an exemplary difficulty, to be taken up again in subsection 5.2.4 and developed further in a more general way in section 5.3. 
In addition, several authors (see Yeo: 2004, p. I4; Busby and Martin: 2006, p. 24I) argue that scientific rationality encourages gerrymandering with procedures of informed consent: it seems that informed consent is a downright barrier to all the things a biobank may promise. Any scientific hunger will thus incur the seduction of acting less conscientious about informed consent. Moreover, informed consent will suffer if scientists actually have an interest in finding new ways of research (see Shickle: 2006, pp. 510-5II). And at least in a more abstract sense, it has been observed that the commercial incentives lead (both corporate and academic) researchers to taking an asymmetrical stance towards their research objects (see Hayden: 2007). This is also reflected by the strategy of the Dutch Parelsnoer Initiative: it is stated explicitly that future use of a sample, unknown and unforeseen at the time the sample was collected, cannot by definition fall under the protocols under which the sample was collected. Collecting the sample will strictly speaking not even be part of the research and its protocols, because it takes place at a detached point in place and time. This means that collecting the sample escapes judgment of the medical-ethical committees that usually assess such research. The Parelsnoer initiative recognizes this, and therefore states that any decision on the use of the sample is ultimately up to legal bodies at the moment the research is conducted (see Parelsnoer Initiatief: 2008, p. 8).

Beneath all these concerns on informed consent, a peculiar tension can be discerned: whether or not informed consent in the first place pertains to collecting genetic material. The first question to be asked then is to what extent our genome coincides with us as a subject: we decide upon our bodies and lives, but are genes really part of that? Indeed, this question receives multiple answers. It makes sense that the choice should be mine whether or not to have revealed my dispositions for certain diseases. However, as we certainly share our genes with our relatives, the question arises whether we also have the right to reveal or conceal knowledge derived from our siblings' genomes. So, the subject that consents does not really coincide with the genome that the consent is about.

These difficulties have inspired some to suggest alternative approaches. For example, as Swierstra (2004, p. 39) suggests, perhaps we had for all these reasons better consider the possibility of a 'knowingly and deliberately uninformed consent': once we recognize the benefits of a biobank, and our moral obligation to contribute to it, why can we not fulfill our civic duties without going through the trouble of having ourselves informed so thoroughly? Perhaps, having oneself 


\section{Politics by All Means}

informed is a burden rather than a pleasure; and indeed one need not study economics to understand that taxes must be paid. In addition to the mere burden, more information may even make the decision harder (see also Chadwick: r999a, p. 297). What is more, a similar reasoning is deployed by the German National Ethics Council (2004, pp. I2-I3), which suggests the possibility to consent to a generalized package of research, because the samples would be of too little use if their applications need detailed specification in advance.

\subsubsection{Autonomy as privacy}

The second important guise in which the value of autonomy appears is the deep liberal respect for privacy. Indeed, a fear for the loss of privacy is one of the primary concerns that often appears in both public media and scholarly journals when biobanks are discussed. To the question of what privacy is, a host of answers has been produced in scholarly literature. I will confine myself to a discussion of privacy concerning the human body.

Regarding the human body, privacy has been considered to mean at least three things: a protection of the individual against physical invasion of his or her body; a protection of the control individuals have over intrusive actions such as medical treatments; and a protection of individuals against unwanted publication of intimate body parts (see Dubbeld: 2004, p. 58). The latter should perhaps be seen even in a wider sense, for publication of pictures of persons or knowledge about their whereabouts can be invasive and illegitimate even if no private parts are displayed. Indeed many countries know at least a portrait right, stating that no pictures of private persons may be published without proper reason or permission. This is in fact the exemplary problem against which the original formulation of privacy as the 'right to be let alone' was devised: journalists and photographers who revealed all that we thought belonged to private and domestic life (see Warren and Brandeis: 1890$)$.

The genetic context demands that we at least consider one extension of this conception of privacy: the right to concealment of genetic information and correlated medical records. This extension of the conception of privacy is not difficult to argue for. Presuming that the genome conceals information about our future (see Annas: 2004, p. 4); and that this informationregarding our bodily health, is considered private; it is an obvious concern that others be kept from browsing through it as they please. But in addition to knowledge about the future, 
knowledge about the present and even about the past becomes precarious too: our genome is unique in the sense that absolutely nobody in this world will have the same genome as I do, ${ }^{2}$ and it does reveal my formal identity, descent and whether my father is genetically my father or not.

The relation between biobanks and privacy builds in part on the relation between our genome and our identity. On the one hand, our genomes are unique. Thus, they are uniquely related to our identities - whatever that may mean. On the other hand, they are loosely connected to what we really are. Indeed, genetic determinism (see page Io9) is obsolete. If I know your genome, I cannot by far tell what and who you are. Of course, sensitive information on certain traits is in our genome as I just explicated. Even though those are in a way related to our identities, they do not completely constitute our identity. ${ }^{3}$

In pursuit of a safeguard for privacy, anonymization is the first solution one might come up with. Indeed, many efforts have been made to find appropriate forms of it. Even though many more definitions exist, for my argument it only makes sense to discern between systems in which samples and records are retraceable to human individuals, and those systems in which the samples and records are not (see also Cambon-Thomsen, Rial-Sebbag and Knoppers: 2007, p. 376; Tansey and Burgess: 2004, pp. 6-7). In the first class, two subsets can be discerned. On the one hand, there are those systems that work with anonymization, which is to say 'they irreversibly cut all links between persons and the samples and information they are related to.' On the other hand, there are systems that work with pseudonymization, which is to say 'encrypting all links and subjecting the possibility of decryption to strict rules' (see Parelsnoer Initiatief: 2008, p. 9). These forms of anonymization and pseudonymization will indeed provide a sufficient warrant of privacy for many. However, they are not convincing to all. For example, Naser (I999, p. II3) argues that simply anonymizing the data may not be enough, as just the thought of disclosure of this information and the idea of scientists browsing through it can be felt as a violation of our privacy.

Underneath these disputes, a more fundamental problem can be discerned. Even though it is principally possible to cut all links between individual persons and

2 I step over the issue of identical twins here.

3 An important class of concerns of identity considers ethnic identity. It has been argued that the Western way of enquiry may be in conflict with the values that indigenous people attach to body materials and the like, while the same way of enquiry may undermine those beliefs (see Einsiedel: 2003, p. 32). 


\section{Politics by All Means}

whatever is derived from them, it must be kept in mind that, given the uniqueness of our genomes, a sample is always conclusively linkable to an individual. That is, it may require disproportionate effort and cost of mapping an individual genome and comparing it to the samples, but it is possible. And what is more, this cost is likely to decline in the future, since developments in DNA sequencing are making rapid progress. Thus, the scenario in which privacy becomes fundamentally problematic in the face of biobanks will be viable in the future. It can be questioned how bad this retraceability really is, and what the likelihood is that somebody will really try to trace a sample back to a person. However, that does not take away the fact that we do not have an answer to the intrinsic traceability of the genome today.

This links back to the difficulty raised in subsection 5.2.I, that it is not exactly clear what the genome should mean in relation to what we are. Depending on what we think of the link between our genome and our identity, we arrive at different conclusions regarding the question how bad it is that information on our genes becomes public. What damage can I suffer from it? People may see that I am a male Caucasian with blue eyes - but probably not even that I have a hearing impairment, let alone what my body length will be or for what sports I do or do not have a talent. And it can certainly not reveal all those intimate details of my life that brought me to the point of writing a dissertation in philosophy of technology. While the genome is strictly spoken unique, it is also not that straightforward to explain how it can possibly be 'personal' or 'individual'. And yet, debunking an underlying - allegedly false - idea of genetic determinism will not suffice to tip the balance. This would mix up levels of discourse: genetic determinism being obsolete from a biomedical-scientific point of view, is not to say that in political discourse the non-privateness of genetic information is to be taken for granted.

\subsubsection{Justice}

Biobanks demand investments and give profits in return. The question of how these returns and investments should be distributed, is typically a matter of distributive justice as I explained in subsection 2.3.5. In its broadest sense, distributive justice concerns our entitlements: what is ours and why, and what must we give to others or receive from them? It is not difficult to see how biobanks challenge ideas of justice. Where the investment should come from and where the return should go to is far from obvious. The investment itself is difficult enough: besides substantial financial resources, biobanks require donations of samples and 
information from average citizens. Will those receive remuneration? And how will this be quantified, then? Or, alternatively, is the investment by donors regarded too small to make any claims anyway, particularly when compared to the financial investments needed? The distribution is even more complex as the results of biobanks are likely to serve abstract individuals in the future, rather than the donors living today (see Chadwick: I999b, p. 442). Indeed, Genewatch, a not-forprofit public-interest group that monitors developments in genetic technologies in the UK, has expressed its concern that the benefits for the public are unclear. This might undermine public support (see Barbour: 2003, p. 1738).

This controversy on the distribution of benefits leads some to disapprove of biobanks. As mentioned earlier, the Mannvernd organization in Iceland has succeeded to unite $5 \%$ of the population to stand up against the whole project. The main motivation for people to opt out was the fact that the Icelandic government has commercialized things that were seen as common goods: the records of both medical and genealogical data. These were felt to belong to everyone, while all of a sudden they became sources of profit for only some people. This undermined the appeals that the project explicitly made to a nationalistic genetic identity (see Rose: 200I). The project was mistaken in the presumption that this would lead people to subscribe to this distribution of profits.

In a more general vein yet certainly related to justice, Nikolas Rose and Carlos Novas (2003) argue that the notion of citizenship does not straightforwardly fit with biobanks. In the past, citizenship was largely a nationalistic category. This could have served the acceptance of redistributive ideas of justice, as people are generally more charitable to people they feel related to. This has already changed over recent times, as the state and the nation tend to coincide less. This change must be expected to continue in the new era of biobanks. They argue that appeals to biological lines, like the appeal to membership of the human race that we see in biobanks, are likely to change ideas of citizenship. In the end, this reconsideration of citizenship may be needed to align biobanks and justice.

Alternatively, Richard Tutton (2007, p. I77) argues that citizenship in case of biobanks relates to donating in favor of the common good, rather than relating to having a relevant say in the courses of biobanking - a notion of citizenship that complies with political theory. The downside observed by Tutton is that these appeals to citizenship are twisted such that it suits the scientists fine, rather than really amounting to serving the interests of citizens. 


\section{Politics by All Means}

However, there is another side to the story as well: empirical studies have shown that, different from the Icelandic situation, a large majority of citizens would be willing to donate to a biobank, if they are convinced that this will improve health care. The willingness is mainly driven by altruism, and depends on the public being well-informed and having trust in experts and institutions (see KettisLindblad, Ring, Viberth and Hansson: 2005; see also Swierstra: 2004, p. 38). In addition, we may suspect that we cannot entirely rule out the possibility of plain opportunism: people may just realize that they or their children will in the end benefit from the act. Nevertheless, enough precedents exist of altruistic practices involving 'bodily sacrifices'. Indeed, Busby and Martin (2006, p. 239) argue that UK Biobank owes part of its success to explicit appeals to existing traditions of blood donation. In the UK case this is inspired by chauvinism, advertising the country as great and united does not deny that people actually do something without getting paid for it. Remarkably, this appeal is theoretically not that much different from the Icelandic chauvinist appeal to a genetic nationalism, where it did not work out the way people wanted. We can however conclude from this, that by the treatment of blood as a common good, a precedent has been shaped that paved the road for genes to become a similar common good.

The difficulties in gaining support for biobanks have been recognized in the socalled communitarian turn. Its most elaborate advocate is Ruth Chadwick (I999a). She argues that communal benefits are generally underrated in the political and medical-ethical discourses, which on the contrary primarily focus on protecting individual interests. She argues that it is equally conceivable that one has a duty to facilitate research progress and to provide knowledge if it is expected to be crucial to the health of others (see Chadwick and Berg: 200I; Su and Macer: 2004).

Alternatively, Jacob Dahl Rendtorff (200I) argues that we must look for a different logic, instead of the logic currently deployed in thoughts on justice, for instance the logic of the gift. As Rendtorff suggests to conceive of the body as something between thing and person, it provides for both a respect for ethical principles including autonomy, and for an economy in which body materials can be distributed. It is a kind of 'informed consent to commodification' that we might look for as a solution to the problem of justice in biobanks. However, as Hub Zwart (I998, pp. 46-47) argues in the context of blood donation, the modern perspective has abandoned the idea of the gift in favor of the liberal ideas of consent and autonomy. Even though Zwart argues in conclusion that a rehabilitation of the 
vocabulary of the gift would be an enrichment of moral pluralism, he is also aware that it would be considered an a-modern and little convincing move. Zwart's view can directly be transferred to donation of DNA samples, tempering the hopes that Rendtorff offers.

The communitarian turn thus pursues a political transformation. That is to say, it looks for new political and ethical points of view, that better match the idea of biobanks. It argues that genes should somehow be regarded as a kind of common heritage. We find this in open-commons and similar communityoriented initiatives, and in arguments that try to frame genes as a kind of common good. Chadwick and Wilson (2004, p. I25) argue that the genome and the information it holds should be seen as a common good, and even as a global public good. Seeing the databases as public goods would recognize their being non-rivalrous in that one person's use of it does not diminish the supply of that good for others. Moreover, it would recognize that they are non-excludable in that there is no justification to exclude others from using it. And as genomics knowledge is not bound to a specific geographical area, they are also global goods. Thus the argument reaches another level. First, the stakes for the common good may well outweigh the individual assets, and second, it is hard to argue that my genes are strictly mine, anyway.

It is interesting to observe that this is in fact an attempt to articulate a political structure that matches the nature of our genome well. However, these approaches pay little attention to the idea that there might be something technically special about genes and owning and redistributing them. This will be discussed in section5.3.

\subsubsection{Ownership}

Generally, a workable idea of redistributive justice requires a stable and accepted idea of ownership. In the context of biobanks, justice raises unprecedented questions about the ownership of the body and its derivatives such as samples, and information such as medical and genealogical data. Indeed, it has been argued that commodification of genealogical information has not primarily raised ethical questions, but questions of ownership. Public debate has addressed the question whether medical information can and should be commercialized. Indeed, the Icelandic Ministry of Health has declared that it is both illegal and unethical for individuals to demand an allowance for their share (see Pálsson and Rabinow: 


\section{Politics by All Means}

200I, p. I68). This is a delicate issue, given that the ministry itself has important interests in making the biobank project into a success.

To find a tentative conception of ownership, we need not look far. One figuring abundantly, also in biobank debates, is based on the thoughts of John Locke (I690, ch. 5, sec. 45). Its core idea is that those things become our property to which we apply our labor. This idea was devised as an answer to the question of the ownership of farmland. The one who is most entitled to its ownership, is the one who makes the effort to bring the soil to production. Locke's thesis is founded on the idea that one's ultimate possessions are his or her life, and his or her body. ${ }^{4}$ Alienation of the fruits of the labor performed by that body, would be the alienation of all that makes life respectable.

Transforming this view to the domain of biobanks, it could be argued that biological material and even medical records are more or less worthless until the contained data can be efficiently mined by new information technologies. The economic value of genes is primarily due to the hard work of the scientists; it is not because the donor did anything for it, nor can the donor reasonably claim that he or she loses much if a gene or even the whole genome is collected from them (see also Rose: 200I, p. 29; Cassier: 2002, p. 86; Berg: 200I, p. 242). Moreover, donating a sample to a biobank can hardly be seen as a serious effort, if any at all (see also Shickle: 2006, p. 509). This would justify the conclusion that profits made by biobanks primarily belong to medical professionals, technicians and scientists who do the hard work. This renders it hard to argue that the earnings of a biobank should flow back to the donors.

However, at closer look, Locke's account fails to settle the question. Interestingly enough, we could push the 'ownership of the body' into a different direction. If the body is our ultimate possession, then why not attach dear value to the derivatives of that very body, i.c. the sample taken for research? Clearly, this is not the entitlement to the 'fruits of our labours' that Locke argued for. But it certainly follows from the same premise that Locke built the fruits-of-labor vision upon, that is the ultimate ownership of the body as what gives value to life. A donated sample could paraphrastically be called the 'fruits of the body' (see also Swierstra: 2004, p. 39). Thus, in its singleness, Locke's thesis seems to produce two contradictory

4 Interestingly, Donna Dickenson (2004, p. I58) argues that Locke does not make explicit that we own our bodies or can sell parts of it, but that we own our labor which is an essential human faculty. This is reflected in (UK) customary law, that derivatives of our bodies are considered either 'unownable' or 'left behind'. 
conclusions. This paradox will prove an essential symptom of the difficulties that technological change produce for politics, to be discussed in section 5.3.

In a similar line of thought, Gísli Pálsson and Paul Rabinow (200I, p. I68) investigate the parallel between fishery and genomics. They do so based on Locke's conception of property as 'the rights to the fruits of labor', and show that the regime of ownership in fishery is immensely complex and contingent upon history. They investigate (p. I69) whether genes should be treated like fishing rights. This entails that their commercialization should be arranged such that it promotes equity and fairness, much like Icelandic fishery rights do. Since a patient does not really 'do' anything for his or her body material, he or she is not straightforwardly entitled to its ownership. Remarkably, this argument is reflected in legislation: the Ministry of Health has decided that it would be unethical and illegal for citizens to withdraw from the biobank and offer reentrance in exchange for a share of the profit. Pálsson and Rabinow (200I) argue that this is in line with the communitarian perspective that the Icelandic project reflects. Fair enough, they also recognize various difficulties in transferring fishery rights to genomics. One of them is that fishing stocks tend to be overused, thus compromising the stakes of all, while the exclusion of potential users from databases does not seem related to overuse in any way that matters. This is one of the things that stand in the way of an easy translation of fishery rights to biobanks.

In addition, Stephanie Turner (2005) argues that producing data from samples involves two essential transformations: first, there is the transformation of characteristics of the donor and the donated sample into computationally accessible data, and second, there is the transformation of this data into intellectually interesting material. She concludes from this that the ethical assessment of genetic data is strongly detached from the subject. Additionally, this means that what a possible contribution by a donor may consist of, is increasingly abstract.

I have already hinted at the idea that ownership shows a certain ambiguity when it comes to our genome: it is both mine and not-mine at the same time. I share 50\% of my genome with each of my parents, siblings and first-degree progeny. Hence, if I sell (whatever that may mean) my genome, I effectively sell half of theirs as well. The paradox just raised in conclusion to Locke's conception of ownership adds to the confusion, as it renders ambiguous who is to be remunerated for what. We might conclude from this that ownership of genes cannot be asserted, for example because such would have the immoral consequence of claiming ownership of the 


\section{Politics by All Means}

genes of my relatives as well. Then, if I cannot claim ownership of my own genes, I cannot transfer this ownership to, say, scientists running a biobank. Nor can anyone claim that I have a duty to donate those genes, for whatever their grounds are, they cannot possibly be stronger than my own claims - which were untenable. Of course, one could for all practical purposes simply donate a sample and allow biobank scientists to do with it whatever they think is scientifically valuable. But that is to define the problem away; it does not resolve the paradoxes articulated above.

Thus, the matter of ownership over a genome remains ambiguous, despite all the attempts to find new frameworks. The sting seems to be in the given that calling my genome 'mine' and calling it 'ours' have equally convincing justifications, both economically and morally. Thus, in pursuit of a conception workable for biobanks, we could look even further for examples of practices in which goods are both collective and individual at the same time. One example of such a mixture is the Norwegian allemannsretten or 'every man's right': if a plot of land is owned privately but not used in an economically or culturally relevant way, trespassing the land and even recreating and camping on it cannot be prohibited. ${ }^{5}$ Another example is that we can have peculiar sentiments about family property. I happen to have a fine collection of gramophone records, once belonging to my now-deceased grandfather. In today's digital era they are of little value and use, and honesty demands to say that the bulk of them is of poor quality (mostly recordings of unknown orchestras that are unknown for a very clear reason). Even while I do not expect anyone in my family to be interested in them, it is difficult for me to just get rid of the poor ones: I feel it is not up to me to decide over their further existence since they are family property. (There are some treasures among them as well - they are a different story.)

Yet even the examples of allemannsretten and family property do not suffice. Mimicking allemannsretten, it would be a bit of a caricature to say: 'you are not doing anything with your genome, so let me have it, and I will take care that nothing bad happens to it'. Such reasoning commits a categoric mistake in that it treats genes and land equally. It fails to articulate 'doing nothing bad', which

5 In fact, the system is somewhat more complex: it only holds for those pieces of ground on which the owner cannot reasonably claim disturbance by the trespassers, for example in forestal and uncultivated areas. It obviously does not pertain to private gardens, agricultural land and farmyards. Moreover, it is not just a right, but also entails the duty to treat the land in a preserving way. 
is exactly at the core of the whole problem: by 'using' a genome, people can get harmed at least in particular (perhaps even just private) senses, while the allemannsretten can largely be justified by the recognition that nobody is really harmed by (decent) camping and trespassing. Similarly, to call my genome family property leaves too many questions open. In fact, it is a strictly economic manner of division, building on emotional bonds. However, selling my grandfather's records would at worst be merely a form of theft, while selling my genome would, again a worst-case scenario, be a violation of my family's autonomy and dignity.

The importance of ownership as a concept underlying the considerations of justice finds its correlate in a similar importance of ownership to the earlier problems of privacy and autonomy. That is, privacy can be understood as the ownership of information at least in the sense that the one owning it is the one to decide upon its use and disclosure. With autonomy, the link is a bit more far-fetched, because explaining autonomy as the 'ownership of the freedom to govern oneself rather begs the question. However, exactly in the context of genetic samples, my freedom to govern myself all of a sudden depends upon the question to what extent the genetic sample is 'mine' or even 'me'. Depending on the answer given to this question of ownership, it may or may not be a violation of autonomy when a scientist performs operations on that sample. This section will not further concern ownership in relation to autonomy and privacy, but the relation will prove of importance in section $5 \cdot 3$, where meta-aspects of the controversies will be discussed.

We can conclude from this, that ownership of genes poses questions that are so unprecedented that no earlier practice of ownership can serve as an example. We have seen that each of the attempts fails to see that in the case of genes, property is no longer just a category of economics and justice, but also one of identity. The fact that it is not simply about finding a balance of distribution but about opening up entirely new categories, justifies the claim that ownership of genes is radically unprecedented. However, before proceeding, we should first look at perhaps the most sophisticated idea of ownership, relevant to science and technology: patents.

\subsubsection{Patents}

Patenting is one of the many solutions that modern culture has produced to a specific problem of ownership. In short, a patent grants that the inventor of a novelty is granted the fruits of the invention. A patent thus protects an invention 


\section{Politics by All Means}

from unjust exploitation. It expresses that an inventor should at least be able to earn back the time and effort he or she invested in it. At the same time, a patent entails revealing the invention to others, such that they can indirectly benefit from it as well and add their own creativity to it. Thus, patents seek balance between different kinds of rights and values: commercial stakes are weighed against the value of free enquiry, keen competition is weighed against the availability of technoscientific knowledge, and technoscientific progress is intricately connected to the acknowledgement of some kind of ownership of that very progress. And what is more, this system of patenting is believed to be beneficial for society at large, as it encourages innovation and entrepreneurship. In fact, this is usually how patents are justified.

Biobanks combine scientific curiosity, commercial interests and medical benefits. Thus, the link with patents is not difficult to see. This suggests that patents may indeed be an appropriate regulatory system for matters of genomics. After all, patents are not just any conception of ownership. They are a very specific conception, fine-tuned towards a specific problem. Patents posit an idea of ownership of 'stuff' that is otherwise intangible and amorphous. In this sense, intellectual property is much like our genome: even though the latter is materially condensed in sequence bases, it is not at all straightforward what owning it means. In addition, the connection might not just be one of analogy, as one of the discussions on gene ownership concerns the applicability of patents. However, a closer look at the debate on patenting and its applicability for genetics shows exactly the same inability of dealing with the ambiguities as developed above for ownership in general.

At least three questions arise when applying the idea of patenting to genes. First, articulation of the exact conditions that justify filing a patent in general is necessary. Second, we will have to question whether these conditions can somehow be framed to apply to genes and genomes. And third, we will have to question what the implications of patents in genomics are against the background of the liberal technological culture as I portrayed it in part II.

The first question concerns the conditions for patens. Principally, patents are believed to be justified because inventions entail hard work. More specifically, the work must be characterized by novelty, non-obviousness and usefulness. Thus, things that are made, designed, or somehow made up can possibly be patented. Patents cannot be filed for things that are just found or for things that one happens 
to possess. Indeed, a bicycle design can be patented if you made it up, but a bicycle itself cannot if the only reason is that you just happen to have it (see Ossorio: 2002, p. 4II). By this structure, technoscientists are given an incentive to their work by being granted the consumption of its fruits. Moreover, patents thus work as a device that imposes the Mertonian scientific ideal of openness onto the commercial stance of the market that is much like the peer-review system in science (see Angrist and Cook-Deegan: 2006, pp. 88-89). This way, it is believed that society as a whole benefits from the existence of a patent system.

Asking the second question of whether genes sufficiently resemble other patentable things offers some interesting observations. Indeed, Pilar Ossorio (2002, p. 4I2) argues that the patentability of DNA depends on the question of whether it can be characterized as having been 'made by man'. She concludes that patenting a particular DNA sequence entails specifying how this DNA sequence can be acquired and used. Thus, technologies for isolating and purifying the DNA and inserting it into the right place, in bacteria for example, are essential elements of the patent. Her argument is based on the exemplary precedent of a patent for (naturally occurring) human adrenaline, which could only be granted because isolating it demanded a very specific procedure. This of course raises the question of whether it is actually the adrenaline that is patented, or rather the process of isolating it. This example could form be a precedent for a certain gene that might be isolated with a similarly significant effort. However, like with the adrenaline in our bodies, this patent would have no relevance at all to those people who happen to have the gene in their bodies. And indeed, it would inherit rather than solve the question of whether the gene is patented, or the method of isolating the gene.

Adding to the difficulty of patenting genes is that genes represent importantly information rather than design or novelty. And patent claims to information form a radical departure from the traditional patent concept. It would come close to patenting natural laws, which in its turn would be paralyzing to science (see Andrews: 2002, p. 804; Andrews: 2006). In addition, as it is novel that the genes come from people, the question is new and unanswered of how people should be rewarded for the genes they have donated. Nevertheless, many argue that patenting genes is close enough to patenting other inventions to see them as similarly justified, and that there is no reason to believe that patenting of genes is any more immoral than the idea of patenting as such (see also Lever: 200I; Ossorio: 2002). 


\section{Politics by All Means}

Finally we must ask the third question: whether gene patents can, will or are likely to be employed in desirable ways. After all, observing that genes are much like other things that can be patented does not yet justify the conclusion that patenting them will automatically be similarly desirable. And even though we just saw one cannot straightforwardly apply ideas on patenting to genes, it earns the benefit of the doubt simply from the fact that some people argue for it. The easiest way to proceed is to ask whether patenting genes would compromise important values. Would I be less autonomous, suffer more harm or have less dignity? My autonomy could be compromised if the patentee of some of my genes prevented me from using my genes. The most important thing I can 'do' as an ordinary citizen with my genes is procreating, and understanding this as being inhibited by a patent would require a cartoon version of patenting. Of course doing more sophisticated scientific research on my genes might run into the restrictions imposed by a patent, but that does not concern my autonomy as an ordinary citizen, and is hard to relate to the fact that the genes are 'mine'. Thus, it is hard so see how I can be harmed if one or more genes, part of my genome, are patented, when all I do with my genes boils down to living my life as an ordinary person.

Furthermore, it is sometimes argued that patenting (human) genes is contradictory to human dignity. However we saw in chapter I that dignity is an inherently problematic concept. Indeed, it can be argued that a patent does not confer ownership in any sense that matters to the actual instances of the thing patented, and hence patenting genes does not involve any violation of dignity. It is not in any way like instrumentalizing or even owning other persons, as for example in the case of slavery (see Ossorio: 2002, p. 4I3).

In addition, Angrist and Cook-Deegan (2006, p. 92) show that in practice some open-access initiatives have proven to speed up the processes. By rapid disclosure of sequenced data, an implicit coordination system has emerged that prevents duplication of research. This has increased efficiency in research, and it thus seems that the practice of patenting genes has produced some of the same benefits that patenting in general produces. This, however, does not say much about the moral assessment of patenting genes: that something produces an economical situation, is not to say that it is morally just. But it does at least take away part of the fear for what has been called the tragedy of the anticommons: the existence of a patent system may incite some to file patents on just any gene, in order to exclude others from making a profit on them (see also Heller and 
Eisenberg: I998). Remarkably, Gary Stix (2006) has argued that the fear for this tragedy is unnecessary, as in practice hardly any scientist is impeded by the patents of others.

We can conclude from the answers to the second and third question that there is little hope for an unambiguous answer to the patentability of genes, which would in its turn provide a starting point from which an answer to the question of ownership might be developed. Rather, the answers add to the confusion. In answer to the second question, of the likeness of genes to other patentable things, some remarkable differences appear. Genes themselves are not really invented. They are more like information or natural laws, things that are today not really patentable. And genes come from people, which opens up unprecedented questions of remuneration, which are certainly not answered by existing regulations of patents. In answer to the third question, we see that the most difficult issues still depend upon the question of what our genes mean for our identity, including what it means to own or not to own them. Discussing the issue in terms of dignity does not solve it, but rather serves to emphasize that there are some unresolved ambiguities - which might be an important purpose, nonetheless. Even though we have seen that there are some observations of positive and negative results of patenting, we also saw that these are divergent rather than convergent, and moreover they define away rather than genuinely resolve the underlying difficulty of what it means to own genes or what genes mean to our identity.

\subsection{The hold of politics and genes}

\subsubsection{Public biobanks}

At face value, the relation between biobanks and politics is clearly visible: biobanks are a technological novelty that spark controversy on political and otherwise normative issues. This section will discuss the intricate relation between biobanks and how we do politics. More specifically, I will describe biobanks as examples of technologies in relation to the conception of politics as purification. Biobanks are quintessentially technoscientific: they are machine, organization, knowledge production, manipulation and storage of samples, methods in chemistry and information science and so on, all at the same time. They are also quintessentially political: they operate on a societal level, they are intuitively subject to medical 


\section{Politics by All Means}

ethics, to economy, to long-term strategy, and to public funding. It is in the connection between on the one hand technoscientific progress, and on the other hand those societal ramifications that biobanks enforce a political discussion.

We need not look far to find whether biobanks belong to the scope of today's politics, and it is hard to think of them as irrelevant for politics. The political relevance of biobanks is indeed provided at first sight by the fact that they are large nation-wide institutions. Nevertheless, we could at least try to frame biobanks as a private phenomenon. After all, many of the features I just mentioned also pertain to large railway networks, and those are largely private, at least with respect to how they are ethically judged. Insofar as railway networks are not private, this basically concerns governmental interference with their economy, but not the ethical matters of living a good life. However, trying to frame the public relevance of biobanks in economic terms and depicting the remainder as private is problematic. It is so, exactly because of the tensions that I discussed in section 5.2, which do not let themselves be resolved as 'let anyone decide for themselves whether they can be part of the good life' (or whether they think it is economically worthwhile, for that matter).

Indeed, biobanks are also publicly relevant for less obvious reasons. We saw that biobanks force us to discuss concepts that are central to our culture. For example, they demand that we revise the fundamentals of medical ethics. This is a political matter by definition, as medical ethics plays an important role in regulating important parts of society, and is moreover one of the conditions that society has put on medical practice for having so much self-regulation. Similarly, ideas of ownership and justice have not reached the stability needed for the whole issue of biobanks to be publicly unproblematic, hence it is politically relevant. Thus the reasons for biobanks to be public issues are both in their practical and organizational features, and in the ethical content they force us to discuss.

This calls for further enquiry into the exact nature of the relation between biobanks and political conversation. Each of the following subsections will discuss a specific dimension in this relation. The following subsection will discuss how biobanks conflict with existing moral and political routines. And the last subsection will discuss how most of the developments fit in the long history of Western science, technology and modern culture. In contrast to section 4.3 on enhancement, we will recognize a much more explicit role for the technoscientific constitution of biobanks. 


\subsubsection{Political changes}

Perhaps the most radical incompatibility between biobanks and our received conceptions seems to concern our conception of ownership. In our culture, the Lockean conception of the 'fruits of labor' is a dominant vision. However, biobanks carry a radically new conception of ownership. I already showed that it is not at all straightforward to what conclusions this new conception could be carried, let alone that such a new conception is supportable. In particular, we saw that in the face of biobanks, the Lockean conception of ownership offers two opposing answers to the problem of who owns the genome. That this conception remains aporetic in the face of biobanks clearly has to do with the fact that in his time Locke was discussing questions of an entirely different nature than the ones concerning the ownership of the genome or the fruits of genomic research (see Pálsson and Rabinow: 200I, p. I68). However, this explanation does not resolve the problem.

The paradox produced by Locke's conception shows that existing political content can be rendered obsolete by technological progress. This has been observed by Angrist and Cook-Deegan (2006, p. 95): 'Perhaps we have moved beyond the impassioned rhetoric of public versus private; perhaps we no longer regard the human genome as either 'the common heritage of all mankind' immune from IP rights, or as a Wild West for speculative patents and endless court fights.' Indeed, Swierstra (2004, p. 40) suggests to trade existing notions for others. He argues that we should not think of body material as something that is materially relevant, but as something that is informationally relevant. If society manages to succeed in protecting citizens against the dangers that collection of information may carry, it will suffice to grant donors a lesser say in control of biobanks. In short, these are suggestions as to revising what is owned.

In addition, we saw that Pálsson and Rabinow (200I) investigate alternative schemes of ownership based on fishery rights. Much like how fishery rights reflect the insight that the existence of fish is not the merit of the fishers, it could be suggested that the ownership of genes should resemble those fishery rights. Despite the difficulties they see in transferring fishery rights to genes, they do derive arguments that counter political stances on the protective-liberal end of the spectrum. Approaches that build on common goods theory will be more fruitful than visions that build on the Lockean conception. Even though the Lockean concept of ownership is not completely refuted, this further destabilizes it, by revising how things are owned. 


\section{Politics by All Means}

Interestingly, these two kinds of revisions - one regarding what is owned and one regarding how it is owned - are inspired by the technoscientific reality as materialized in biobanks. In effect, it is the actual nature of genes that, at least in this case, makes it harder to argue for a protectivist stance. This is an instance of purification that is owing to the material substrate on which politics is to be conducted, rather than to our political differences and the need to discredit those. However, even though we may expect that such a material embodiment of normativity may have some rigidity to it, it does not take away that old political content still has an important influence on the way we talk today.

Despite the instability inflicted on them by this instance of technoscience, many of our intuitive and everyday notions of ownership still have a Lockean ring to them. We have talked about ownership in this way for centuries, and it would be naive to think that this can be changed over one night's sleep. Thus, the dominant cultural ideas make that some alternatives are more difficult to argue for than others. So this is a purification by dominant cultural ideas.

Informed consent is another example of such a cultural idea that is dominant in a way similar to Lockean ownership. We saw that it is the dominant paradigm in medical ethics, while at the same time it is fundamentally difficult to achieve in the context of biobanks. What is more, biobanks even carry a temptation to be less conscientious about informed consent protocols (see subsection 5.2.2). In addition, we must also recognize that it is technically hard or even impossible to shape biobanks in any other way. Alternatively, we could suggest that research should indeed be cut down into slices so that each can be subject to informed consent. This means that long-term storage is not that useful, because if we have to obtain consent in the future, we might as well obtain fresh samples at low invasiveness, rather than going through the trouble of storing them. Moreover the workload will drastically increase because of the recurring consent procedures. As a consequence, the populations available for study will be smaller. In fact, all of this runs counter to the whole idea of genomics being dedicated to a holistic approach to genomes. It is difficult to devise a different way of doing science per se, let alone a way that would be less vulnerable to the difficulties surrounding informed consent. Indeed, to present understanding, this is how we study genes.

Nonetheless, is has been recognized that informed consent might not be the most appropriate way do deal with biobanks. And indeed, different options such as 'blanket consent' or 'willingly uninformed consent' have been suggested. 
However, both Swierstra (2004) and the German National Ethics Council (2004) recognize that our culture is not yet ripe for the alternative forms of consent they propose. This is again owing to the cultural robustness and support that informed consent has acquired over recent decades. Indeed, the principle of informed consent is rigid because of its embedment in modern society and the history through which it came into existence. It is firmly rooted in the manifests of the World Medical Association, it is central to all current handbooks in medical ethics, and also in our everyday lives we can recognize that paternalism is the last thing many of us are willing to accept from our doctors. Moreover, it implements the free choice that is also essential to our culture at large, not just to the medical and medical-scientific practices in it. Indeed, contemporary medical ethics is in line with today's political-liberal understanding that individuals will generally be the weaker party when in conflict with an institution; therefore, medical ethics, perhaps even more than political liberalism, features a protective stance towards the individual.

This all stands in the way of the biobanks' chances to change our appreciation of informed consent. Thus, here we see two instances of purification, each working in a different direction. Biobanks contribute to purifying informed consent out of the debate. They are backed by the network of technoscience that they are part of. They do so by trading political notions for attractive scientific benefits. And in the other direction, we see that informed consent stands in the way for biobanks to offer this benefit. It is culturally embedded and part of networks, just as biobanks are. It earns a certain robustness from that.

The issue of privacy is a similar dominant cultural idea that causes difficulties. Obeying ideas of privacy, it could be demanded that only fully anonymized information be obtained. This would grant that no test results may accidentally be revealed between siblings. However, at the same time this would carry the cost of eliminating the potential benefit of feeding back information to the donor. And what is more, these modifications would face the resistance of the whole idea of biobanks: the gold mine of knowledge is devastated to quite some extent, this way. Therefore, the network around them is likely to resist. We would have to convince scientists that they should engage in a different style of science. This would incur a reformation of bioinformatics. We should abandon the idea that the whole genome should be the object of investigation, etcetera. Scientists are not likely to accept this, given the ties of the present form of biobanks with its 


\section{Politics by All Means}

history, predominantly filled with reductionist approaches. Moreover, biobanks derive much of their legitimization from the benefits they promise, which will be rather modest if only smaller populations are investigated. It is again fairly problematic to reconcile biobanks with the culturally dominant idea of privacy and the latter is not that likely to give in.

Throughout the preceding chapters, it has become clear that dignity is anything but a useful and unambiguous concept to argue about. The same is confirmed once more in the biobank discussion. It could for example be argued that biobanks work to the detriment of our dignity, because they commercialize part of our identity and make it into an object of ruthless scrutiny. Despite the limited convincing power that this argument can be suspected to have in public, it is still a legitimate position. However, it has been argued that our genome only constitutes a small part of our identity, and arguing otherwise would incur the fallacy of genetic determinism (see Ossorio: 2002, p. 4I6). What makes us the way we are, is only to a minor extent the genome; far more significant is our physiological and social history. Therefore, whatever we do with a genome, can hardly be detrimental to dignity, identity and so on. This claim is based on current scientific understanding and in line with the configuration of biobanks. It renders certain claims untenable, and in particular some claims that are already hard to argue for anyway within that modern culture. That is, claims of dignity and loss of identity were already discarded as too vague to convince; they are even more so against the scientific background that biobanks line up with. ${ }^{6}$ What we see here, is that the scientific stance, through some detours, makes it difficult to argue about dignity. Dignity is purified out - materially.

A last example of biobanks causing aporia was found in anonymization and traceability of identity. On the one hand, a genome can always be linked to a person. But on the other hand, anonymization is part of the legitimation of biobanks. Even though expensive forensic lab facilities are introduced, complete

6 This line of inference seems prone to mistake the level of the gene for the level of the genome; that the individual gene says little about what we are or will be, does not justify the same conclusion about the genome as a whole. And while even the genome cannot by far predict our entire life, it would be a bridge too far to say that it is not in any way related to our identity. And then, the causal relation that a gene in the context of the genome has to individual identity, is exactly what Ossorio seems to overlook: she claims that a gene is not causally related to one's identity, and that therefore no violation of human dignity is at stake if a sequenced copy of my gene is exploited elsewhere (see also Resnik: 2007). However, the one thing that makes my specific genes interesting for scientists is exactly its situation in my genome and the connection to my identity, or at least some parts of it. 
anonymization is fundamentally impossible. As anonymization is questionable, it is also questionable whether biobanks can sufficiently protect data, including data about siblings of the donor. In addition, the scientific interest behind biobanks also concerns some personal information, like life-style and anamnesis. Thus, by their technical nature and the nature of genes, biobanks render invalid their own legitimation insofar as it depends upon anonymization. We may value the benefits more than the loss of anonymity or even just waive our rights to anonymity, or estimate that the costs of retracing the genome to the donor will never be outweighed by whatever gain one may expect from it. But this does not refute the fact that anonymity and the value of personal data in the genomic era is different than it was before, and that part of the arguments that we are familiar with lose their convincing power. Purification here exists in the fact that anonymity can no longer really be adduced as a justification or safeguard for storage of data. Or the other way round, anonymization as a safeguard is no longer valid in face of the problems that biobanks and genomes (at least theoretically) pose.

These paradoxes thus show that technological change emanates onto what concepts can be used and how. Both the Lockean conception of ownership and the informed-consent conception of autonomy provide no unambiguous advice. And the danger that biobanks pose to identity and privacy seems unstable because they depend on scientific facts and technological inventions that have not reached maturity. Each of these three conflicts represents a value or principle that is rooted in our culture, and that seems to be in conflict with what biobanks stand for. Still, those biobanks may not be as bad as we would be likely to believe, if those principles were the only criteria. Indeed, that other criteria are involved as well, is reflected by the fact that so many people argue in favor of biobanks, and by the empirically existing willingness to donate. We might eventually be willing to trade some notions, even on a societal level, but it is not straightforward.

\subsubsection{Cultural compliance}

The previous subsection has displayed some challenges that modern, liberal culture and biobanks pose for one another. However, there is not only animosity between them. For example, Swierstra (2004, p. 38) considers a different outlook on the cultural background against which biobanks are to be implemented: he observes that in reality, the majority of citizens will be ready to donate to a biobank. They will simply recognize the benefits, and will recognize that it will not cost 


\section{Politics by All Means}

them so dearly. Moreover, citizens are not that eager to have their say in the most democratic way, when complex issues are concerned like these, that are not really 'their cup of tea'. In addition, there is still something like altruism, and we do not necessarily see a threat to our individuality in a lack of choice. Similarly, empirical studies have shown that a majority of citizens would be willing to donate to a biobank, if they are convinced that this improves health care (see Kettis-Lindblad, Ring, Viberth and Hansson: 2005). And Busby (2006) shows that UK Biobank successfully appeals to existing traditions of blood donation, which was already considered a common good. In a way, by treating blood as a common good, the cultural background was prepared so as to be ready to accept a similar stance by biobanks. Thus, common-good parlance is not that distant from the general liberal reality as it sometimes appears. While it may require some further argument, it is at the same time not something that is impossible to argue for.

A similar feature of this cultural background is the omnipresence of information and communication technologies. Computers and databases are everywhere. In a way, we are already used to the idea that information is stored about us in any thinkable way. Thus, our sociotechnical history has shaped us to think of this as normal. That is not to say that we think it is desirable in all forms, but at least we have a vocabulary for talking about it. Regarding privacy, to say that I own the information on my whereabouts only makes sense if this is possible. Moreover, it only makes sense in light of the fact that others can make money from it while I do not want them to. So why the first reactions to the emergence of biobanks include demands for privacy, anonymization, and remuneration of profits still require an explanation. Our sociotechnical background enables us to first recognize the problem and talk about it, and to think of genetic information as something to be owned'. It also makes this problem less radical than if no information society had existed. Thus, the background has enabled our speaking about it, but it has also prepared us not to be too much struck when this happens.

In addition, Pálsson and Rabinow (200I, p. I67) suggest that the focus on commercial aspects in genomics is fairly characteristic for modern society with its individualist and materialist tendencies. While this doesn't seem directly linked to technology, the very possibility of accumulating capital (in the modern way) cannot be seen apart from technically-induced processes such as the rationalization and differentiation of production processes. Also, the modern way of investing capital is built on the idea that only joint ventures can provide the capital needed to start 
up the big facilities that factories usually are. This is to say that such a large enterprize is at least not a priori suspect. Thus, our culture at least allows for some possibility of arguing in favor of the enterprize of a biobank. This would be a whole lot more difficult in an agrarian culture. This renders unspeakable a specific class of arguments, that are however indeed not often spoken out loud that much. I haven't run into the argument that biobanks would be wrong because it is immoral to set up commercial research facilities, or that such big facilities cannot possibly yield valid knowledge on human life. I surmise that this is owing to the fact that simply nobody thought that these objections would make any sense; it would have been interesting if it had been otherwise.

Interestingly, the whole drive for anonymization and the protection of privacy must be seen as a reflection of liberal preferences for such values. Liberalism champions the protection of individual citizens. Biobanks potentially compromise those citizens. Therefore, the technical constitution of biobanks has been shaped such that it is most compatible with the protection of individuals. Thus, some characteristics of the biobank clearly derive from the cultural background against which they are implemented. Moreover, implemented this way, biobanks can certainly be argued for in the consequentialist style exemplary for liberal speech: the burdens for the individual are largely eliminated, and the benefit for others can be immense. That satisfies the consequentialist condition. This approach differs from the communitarian turn in that the latter argues for a revision of central principles or at least of the scope of application of those principles, while the present vision, justified by anonymization, remains in purely liberal terms, without actually challenging any of its concepts.

One final entrance for biobanks to comply with culture is observed by Swierstra (2004). In his last chapter, Swierstra concludes that the no-harm paradigm best fits monogenetic thinking. In particular, the right not to know pertains to monogenetic diseases that exhibit more of an all-or-nothing character, about which not much can be done. It could be a real harm if such knowledge accidentally leaked back to the donor, even if he or she did not want to know about this. But as of the last decade, the science of genomics has shifted its focus towards multifactorial diseases. First, predisposition to such diseases turns out to be much more vague and distributed than monogenetic ones. Moreover, they have a less determinate character, since often fruitful measures like diets and life styles can be taken. This mitigates the violation of the right not to know. Interestingly, by this shift 


\section{Politics by All Means}

of focus, genomics science and its champions, the biobanks, grow automatically towards compliance with liberal culture, in which the no-harm paradigm rules. The paradigm remains in place, only the appearance that biobanks violate the paradigm is removed.

The ANT approach offers us a mechanism to explain why technoscience reflects some of its genesis and the background to which it emerges. Thus, on the one hand, we saw in the previous subsection that the technoscientific constitution of biobanks collides with modern culture on a number of points. Yet remarkably, on the other hand, it also has some features that seem to go together well with that culture. We may assume that these 'elements of compliance' depend on the fact that biobanks emerged within our modern culture, and were not, say, imposed onto it from the outside.

\subsection{Biobanks and liberal culture}

\subsubsection{Progressive technology and conservative ethics}

The issues discussed so far can largely be captured as technoscientific developments calling for a revision of ethics and politics that ethics and politics are not willing to yield. Ethics is not by definition and entirely conservative, and technology is not by definition and entirely progressive. Nevertheless, they both are conservative and progressive in very specific senses. Given the fundamental unpredictability of technoscientific development as described in subsection 3.4.3, technoscience will always produce surprises that ethics and politics have not as yet thought about. And because knowledge of the past is always more convincing than knowledge of the future, this knowledge of the past will have the strongest influence on ethics. This is not to say that ethics cannot look forward, nor that technoscience cannot look for ways to optimize its alignment with existing mores. Nevertheless, the tension between old ideas and new technologies will always exist. This subsection will show that this uncertainty regarding the future is not just a matter for disagreement, but rather something related to the deepest characteristics of our liberal style of purification.

In the case of enhancement, I observed a drive to align both ethics and the idea of enhancement. However, contrary to enhancement, the concrete 'industrial-size labs' of biobanks are less malleable than the abstract ideas of improving human nature. Thus, more than enhancement, biobanks display the rigidity or hardness 
that characterizes technoscience. That is, technologies require effort, if we want to align them with our normative and moral stances. In addition, they put effort themselves into urging us to revise our normativity.

All things considered, we see that introducing biobanks is not simply a matter of 'getting the ethics straight' nor of 'making technology ethically sound'. The ambiguities of ownership and what genes mean to our identity emanate onto issues of privacy and autonomy, and as such, they are radically unprecedented. The issue of privacy is no longer a matter of articulating what information I am entitled to conceal as mine, but also a matter of articulating what information and entitlement are in the first place. And for autonomy as self-rule in terms of informed consent, things are similarly complicated. After all, whatever I commit to research, is still peculiarly mine and ours. Instability in the idea that my genes are mine destabilizes the whole possibility of consenting to study them. At large, both the problems and the solutions suggested to them are ambiguous. Or alternatively, solutions may be incompatible with received opinions (rather than being internally ambiguous). Even suggested alternative visions of ownership and autonomy lead us to divergent conclusions, and so does the technoscientific reality itself.

This tension between progress and conservation is linked to liberal purification in the following way. Liberalism has a preference for immanent and clear knowledge. The less certain the knowledge of the future, the less acceptance it will gain in the liberal debate. Moreover, liberalism has a preference for consequentialist rather than deontologist ethics, exactly because the former is more concrete and less dependent upon comprehensive doctrines than the latter. This entails the difficulty that consequentialist knowledge is more susceptible to uncertainty regarding the future than deontology would be. And then there is in addition the fact that liberalism has a preference for protecting negative freedoms over positive ones, as observed in subsection 3.4.2. Negative freedoms exist in the prevention of harms - which are in this case not that clear or unambiguous. The positive freedom of scientific enquiry that biobanks demand for themselves is likely to escape political view anyway. Thus, in addition to challenging existing normativities, biobanks run a good chance of being granted the benefit of the doubt. 


\section{Politics by All Means}

\subsubsection{The exemplary situation}

In understanding the emerging deadlock between old mores and new technologies, the idea of the exemplary situation from Lolle Nauta (1984, pp. 365-367), is clarifying. Ideas, whether philosophical, political or even scientific, are usually solutions to problems or answers to questions that belong to specific situations. Without a notion of the situation in which a solution obtained, its value and meaning cannot be properly understood. Recognizing the notion of the exemplary situation is not just cultural or historical relativism in the sense that anything would be simply a child of its time and place. But we need to be aware of the underlying time and place to understand why this problem was solved rather than any other and why this solution was sought while others might have availed as well. The problems solved are nonetheless real problems and the ingenuity required is still real ingenuity.

Thus, we can understand that the principles of privacy, autonomy and informed consent have obtained their central place in medical ethics, as an answer to problems that seem not too urgent in the case of biobanks. That is to say: medical ethics, today largely shaped as a protection paradigm, must primarily be understood as a safeguard against the horrific practices of Nazi doctor Mengele and the Tuskegee syphilis experiment (see Pinker: 2008), against forced sterilization of lower social classes, and in favor of abortion being decided upon by individual conscience instead of by an imposed religious doctrine. However, these problems are not much like the problems to be expected in the case of biobanks. This explains why these solutions appear to be less then ideal in this case. Nevertheless, they were real solutions to real problems in their own times, which explains the weight and rigidity they have, even in today's debate.

It was already mentioned that Locke, when devising his idea of ownership, indeed faced difficulties of an entirely different nature than we are facing today. And we also saw that informed consent emerged as an answer to the horrors of medical practices in the twentieth century, and to medical paternalism at large. Indeed, Cambon-Thomsen, Rial-Sebbag and Knoppers (2007, p. 376), Swierstra (2004, p. 38) and Chadwick (2003, p. 216) explain that informed consent emerged in the face of difficulties that were not much like biobanks, and more particularly as a safeguard to inhumane medical research treatments in the past. These do not really resemble the difficulties that 'biobanking ethics' has to deal with. In addition, Chadwick (I999a, p. 298) even argues that the higher principle of autonomy 
needs be placed under revision: originally, it was the anti-position of paternalism; but with advances in genetics and in an age in which 'individual choice' becomes the rule, it is no longer straightforward what the content of choice is. Similarly, we saw that Warren and Brandeis (I890) argued against the emerging press. All this does not render privacy obsolete as a cultural idea - on the contrary, it shows that it is firmly rooted in our liberal modern society and the history that produced it. But it does explain why new technologies may not be adopted easily.

While these observations may reveal an 'outdated justification' for today's values, principles and practices, it does not take away the fact that they are justifications that today have a strong influence, and that those justifications were in their own times convincing justifications. This historical mass attached to principles and concepts makes some things harder to argue for than others. In effect, the dominant culture thus purifies away some of the biobanks' bounties, and biobanks try alternatively to purify away some of the principles that liberal culture will not accept being purified. In fact, we have no reason to revise the principles other than for the promised benefits of biobanks. As argued above, in many respects this boils down to consequentialism against deontology, which is a precarious balance in its own right. There is nothing wrong with those principles per se, yet the good of biobanks makes them less tenable and hence less convincing. I would call this purification by induced obsoleteness: a core value that can not any longer be taken for granted, because of the evolution of the technoscientific constitution which shapes its context.

Two observations are interesting here. The first is that the horrors against which the protection paradigm is believed to protect us, while they appear to be primarily political or moral failures, at closer look reveal a certain technological character: they reduce human beings to material for manipulation and research, rather than individuals and ends in themselves. And what is more, none of these horrors would have been thinkable without the technical means that allowed for such elaborate, systematic operation: it took railways and large-scale administration systems to get Mengele's victims in the camps. Indeed, the protection paradigm largely coincides with seeing technology as massive, and hides a critical stance to technology. Even at closer look it is not that surprising that biobanks elicit concern within medical ethics.

The second observation is that these horrors are the opposites of the most important value in liberalism: individual flourishing and the protection this 


\section{Politics by All Means}

requires. From this perspective, it is not surprising that the protection paradigm can hold a prominent position in a culture that indeed champions individual freedom. (Admittedly, this is still begging the chicken-or-the-egg problem, but against the background of my evolutionary vision of society, this is not really a problem.) These two mechanisms present barriers to each attempt to adjust the protection paradigm. Indeed, they are part of the liberal interpretation of purification.

\subsubsection{Kinds of disagreement}

The previous subsection explained why biobanks are likely to produce friction with existing normative frameworks. But understanding the nature of this conflict requires further investigation. For there is something peculiar to it: it seems a transgression between discourses. Technology and ethics each have their own practices, and saying that biobanks and medical ethics are in conflict is like saying that the time tables at the railway station are poor on poetry. Clearly, that technoscientific progress and moral change are related has become one of the central assumptions of this book. More particularly, it raises the question of why apparently the domain of ethics does have the authority to say that a certain technology is immoral, while it would be rather surprising if advocates of technoscientific progress said that ethics simply consists of a backward discourse. (In fact, we can faintly recognize this stance in the alternative approaches that are adduced. Nevertheless, they are expressed only modestly; politics and ethics never allow for radical revisions, and the proponents know that.)

When classifying normative disagreements, Steven Lukes (I989, p. I29) provides a useful inventory of all the levels on which we can be in dissensus. The first class he would call conflicting purposes: some may value privacy higher than the common good of health care, others may not. This will lead them to different conclusions on a topic in which these two values collide. This seems to be the best diagnosis of the dissensus produced by the ambiguities of ownership. It is an unfortunate diagnosis nonetheless. Ownership can be understood as a concept instrumental to values such as justice, welfare and autonomy. Indeed, whether justice or autonomy prevails will probably make a difference concerning what we think of ownership. But this does not capture the ambiguity observed in subsection 5.2.4: it still presumes that autonomy and justice in this case are fixed so they can be weighed and tip the balance on ownership. But we saw that they 
are not,nor can we expect them to produce a conception of ownership that fits the new ideas emerging in the genetic era.

A second possibility is provided by conflicting obligations, which are due to values that are among themselves compatible but that incite contradicting forms of action. Respect for the patient and the drive for medical scientific knowledge are in themselves not incompatible or mutually exclusive, but the drive for knowledge will stimulate a different treatment of samples than respect for the patient will. However, balancing the two would require that we see the questions of which technology to develop and of how we should do ethics on a par. However, this just begs our original question: we are not used to balancing technological and ethical questions, or even to discussing them as if they were of the same nature. This appears to us not really a conflict of obligations, but rather as a category mistake. In the following section, some insights will be offered that conceptualize the relation between them, as well as the fact that they are in some respects indeed of the same nature. This helps moving beyond the straightforward notions of technology and ethics.

Third, Lukes speaks of conflicting conceptions of the good, between which no common ground is available in order to decide between them. Seeing the human body as divine and transferring this qualification to all human material deriving from it, or seeing it as 'just matter' especially insofar as the matter is no longer attached to the living human is an example of such conflicting conceptions. And there is little hope of finding a compromise or common ground between the two views. One might suggest here that indeed the two examples of ownership, and respect for the patient versus the drive for knowledge, can be framed as conflicts between conceptions of the good, each championing their own ideas about respectively medical ethics, laudable technological progress and ownership. However, this presumes that each conception of the good is able to frame for itself workable ideas on each of the other elements that can be weighed against the elements that are championed. This leads to the same difficulties of categorical mistakes. What is more, this does not articulate the very instability that genes and all the technoscience we need for them emanate the language that the conception of the good deploys to stage its stance. Even within any single conception of the good, the issues are fundamentally unstable.

And finally, Lukes discerns conflicts between different kinds of moral claim. For example, deontology and consequentialism may produce different outcomes 


\section{Politics by All Means}

to certain questions. Taking a sample from a patient without permission may produce the good result of contributing to science while not really harming the patient, but at the same time it is wrong from the deontological vision that acting in this way disrespects the patient's autonomy and his or her value as a human being. In fact, this problem is recognizable in the whole biobank controversy. Insofar as the benefits offered by biobanks can serve as a legitimation for their existence, it needs to build upon a consequentialist style of ethical reasoning. In contrast, informed consent largely builds on a deontological foundation, because it puts respect for the individual and his or her autonomy are considered paramount. While these two styles of ethics do not necessarily lead to opposing conclusions, balancing between them is generally a complex task, and it is indeed so in the case of biobanks. Admitted, this explains part of the deadlock, but not the fundamental difficulty of unstable concepts.

Just for the sake completeness, we must revisit the explanations that were offered in chapter 4 on enhancement. However, the four dimensions of disagreement that articulated in the analysis of enhancement (see subsection 4.4.2) seem not to add much depth to the four kinds of disagreement that I just discussed from Lukes (1989, p. I29). That is, it seems that people do not really disagree about the diagnosis of the technology, nor about the underlying conception of technology - which may be either deterministic or instrumental. That is not surprising: biobanks are present and real, or at least theoretically developed to the extent that little room is left for disagreement. The remaining disagreement now seems to focus on the dimension of normative background and possibly on whether normative claims can be universalized, but exactly this kind of disagreement seems particularly vulnerable to the destabilization of concepts that we saw throughout this chapter: ownership and autonomy are concepts central to political speech, and their destabilization largely explains that we have difficulty assessing our normative claims and the possibility to universalize them.

Thus, the instability that technological progress induces regarding ethical and political concepts as we saw in section 5.3, seems to be an anomaly in face of Lukes's classification of normative disagreements. It is so, even while at face value the disagreements seem just due to value pluralism. But the classification seems to miss exactly this point of destabilization. The concept of ownership all of a sudden acquires a host of different faces. The concept of privacy is perceived differently by opponents and advocates of biobanks. And the value of autonomy 
receives some new (but contested) interpretations as something that we might as well trade for a notion of citizenship: the common good becomes part of our selves more than it was before. It is this destabilization of concepts that provides the nexus between technology, normative questions and politics at large. It may not be the only nexus, but it is surely important enough to take a closer look at it in the next subsection.

\subsubsection{Destabilization of concepts}

I argued in subsection 5.4.I that technology continually produces new challenges to existing frameworks. In subsection 5.4.2 I argued how cultural ideas gain some of their hardness. And finally, I described in subsection 5.4.3 at which levels disagreement can occur. This subsection will combine these insights, and argue how biobanks as instances of technoscience destabilize the very language in which we conduct politics. Technoscience creates new situations all the time. Every once in a while, this newness will become radical enough to produce the aporia we see here. If concepts can mean new things, this sets us back to discussing the fundamentals. In fact, this may boil down to a complete revision of identity, groups and citizenship. This is indeed what we saw the proponents of biobanks argue for. This issue captures the way in which the problems posed by biobanks are unprecedented. This subsection will confront this novelty with my notion of purification.

The destabilization of concepts has important consequences. At least two scenarios can be devised at this point. First, it is possible that new language or usage occurs that does not survive purification, because it is too far-off the accepted political vocabulary. This is in fact what we saw with the approaches that suggested to see biobanks as important contributions to common goods that justify giving up some of the protection paradigm. For example, we saw that new notions of ownership were suggested, but they were still unapt to deal with the difficulties that biobanks and the peculiarities of our genome create. As Chadwick (I999a, p. 296) recognized, arguing for community runs the risk of not being accepted: present purification almost fetishizes individual choice, and arguing for community is easily discarded as being against that individual choice. This very remark of hers is exemplary for present purification posing a barrier for her to express such ideas. Here the problem might not be in the destabilization itself - for Chadwick actively proposes a new conception to the concept - but in the 


\section{Politics by All Means}

fact that this new conception does not enjoy sufficient stability when argued for in public. The same must be feared for Swierstra's 'knowingly and deliberately uninformed consent' (2004, p. 39): it is in radical conflict with all that present medical ethics stands for. Indeed, Swierstra recognizes that the way the principles of no-harm and autonomy are shaped today, are not their necessary appearances but rather contingent ones that emerged to specific backgrounds. His suggested conceptions are a departure of these appearances, and he realizes that it will take quite some effort for them to convince against the protection paradigm. The success of both Swierstra's and Chadwick's approaches is not primarily a matter of whether the proposals are good or bad, but rather of how radical they depart from received conceptions. Their parlance is hard to maintain against the background of liberal politics. The accepted vocabulary of the protection paradigm is rigid, because it embodies the result of earlier debate and history at large.

The second scenario is that we stick to existing language that survives purification. But then we may find ourselves unable to discuss the new technologies, because our old words do not suffice. Indeed, this last form is what we see with more conservative stances such as Naser's (I999, p. I09) approach. He depicts the dangers of high-speed genetic testing. As such testing would make genetic information available at a low cost, the question of ownership becomes relevant. He argues that 'detailed knowledge of genetics impacts on our self understanding', and therefore on how we ethically deal with issues concerning life and health. He moreover argues that scientists are not likely to wait until ethical approaches have caught up with technical development. The determinist vision of technology that can be discerned in the concluding lines of his paper does not undermine his diagnosis: he observes that ethics is obsolete in the face of new technologies. New technologies cannot always be aligned with received ethics.

A similar recognition of destabilization is found in the legal context by Angrist and Cook-Deegan (2006, p. 94): court decisions seem to contradict one another, and the questions of whether patents apply to genes seem to depend more on the aim for which the patent is filed, rather than on any clarity as to whether a gene is patentable or not. The authors argue that 'the patent system vis-à-vis genes seems broken', which apparently confirms my suggestion that ownership is far from evident in the case of genomic information.

The destabilization of concepts is not just a matter of a single concept getting a new meaning that we better just learn to live with. We saw with the example of 
the influence of genetic knowledge on autonomy that the effects of such a change infects a significant part of the symbolic order surrounding that concept. We cannot see autonomy apart from family relations (at least in the context of our genes), and the fundamental rights affected by these relations (see also Andorno: 2004). Changing autonomy changes everything related to it. Thus, not only is the concept unprecedented, but in addition the whole situation is somehow new. This makes that even new metaphors, suggested in pursuit of a better social embedment of biobanks, will face radical difficulties in gaining acceptance: metaphors build on accepted and consolidated situations, but here both the metaphors and the situations are too fresh. The same can be argued for ownership, identity and so on. Even though they try to align well, they are vulnerable to destabilization by the very technologies they are supposed to support. In fact, they are attempts to new forms of purification that themselves experience difficulties surviving purification.

\subsubsection{Ultra-wicked problems}

The preceding sections paint a fascinating picture: technological change induces change in how we perceive and interpret the world. As this shapes the conceptions used in politics, the latter is likely to run wild. In the general conception of politics in chapter 2 , this mostly concerned the distinction between public and private. In the context of biobanks, this tension gets the shape of discussions about harm, which are framed in terms that have gained strong cultural support: no-harm, autonomy, privacy, ownership. Destabilizing these concepts incurs the risk that this consensus is at any moment vulnerable to destabilization by technoscientific progress, even if an issue or justification enjoys consensus. This is moreover complicated by the fact that the same discourse of politics is supposed to govern that very technology.

Indeed, there is a peculiar circularity to the whole phenomenon of ownership of genes. It is assessed in the light of the broader conceptions of ownership that our cultural repertoire offers. But at the same time, those conceptions are subject to change because of the emerging questions concerning pertinence of ownership to genes. The whole development brings part of the natural into the technical sphere. Similarly, it brings things from the public into the private sphere and the other way round. That is, changing conceptions of harm underly which things are considered public or not - which thus changes in its turn. By these changes, biobanks change the space in which they receive their own political assessment. 


\section{Politics by All Means}

This insight informs the further diagnosis. Political problems can usually be divided along two dimensions: from normative agreement to disagreement, and from factual agreement to disagreement. Normative disagreement calls for a political or ethical debate to decide which values or principles are to prevail. Factual disagreement calls for further enquiry, mainly scientific or otherwise building on expertise. Obviously, the most difficult problems are those in which both the facts and the normative appreciation of those facts are subject to dissensus. In line with Swierstra (2009), I call these wicked problems. The earlier example of cloning can be seen as such a wicked problem. Discussants largely disagree about what cloning will be like, that is the facts are uncertain; and they also disagree about how to judge this practice morally, even if they had a sufficiently accepted idea of what cloning would probably be like. With biobanks, the problem is even more complex: in addition to both moral and factual disagreement, we see that the very language in which those disagreements are to be discussed is subject to change. This we could call an ultra-wicked problem (again in line with Swierstra: 2009).

As a consequence of the instability in conceptions, genes themselves will show many different faces while figuring in our debates. That is to say, because of the ambiguities in ownership, autonomy and so on, genes are at the same time private and public items. They do not let themselves be classified as either 'mine' or 'ours'. Thus, today's typical liberal form of purification, is here confronted with a hard case that does not let itself be classified easily, if at all. Genes are in fact hybrids in face of this classification: they unite properties of either class, thus failing to be an unambiguous part of any class. I already mentioned this phenomenon in chapter 3. Genes are monstrous because of their ability to destabilize the very language we use. They cannot be captured in our language $a$ priori because they do not match the categories the language consists of. And what's more, they are monstrous a posteriori because they twist those very categories. This illustrates once more the circularity observed above when arguing that biobanks and genes pose ultra-wicked problems. Presenting themselves through all the technical influences given, they force us to rediscuss those categories. Not only are genes themselves hard to manage, they configure our thinking somehow. Particularly by guiding our thinking on ownership, informed consent and privacy which are such central concepts to liberal thinking, they manages to create quite a mess. 


\section{Review}

This chapter has shown many more of the mechanisms developed in part II. It has shown that some things are harder to argue for than others. This is the result of purification. It appears as some moral routines, for example the emphasis on autonomy, that are fixed in their places. And it appears as meanings that we give to things, and that tend to resist change - even though those meanings change below the surface, as a result of technological change.

The chapter has moreover shown that technology offers new meanings to concepts. This included the concept of ownership. This is the hermeneutic dimension of technology. Moreover this chapter has shown that biobanks offer a host of questions that somehow need an answer. We have no choice but at least discussing them. This is the existential dimension of biobanks, which in this particular case offers an answer to the issue of scope. Another existential element is the seduction that biobanks offer us to give up some of our fundamental rights - for a noble cause, that is of course.

This chapter has added to the chapter on enhancement the dimension of real technologies playing their roles in controversies. It is however still a scholarly debate, and a constructed one at that. The discussions that I have staged here, have never been conducted in the real life. Rather they are collections of arguments that I composed out of positions that were not really confronting one another all the time - however real those positions may be. This is what the next chapter will add to the analysis: a reconstruction of an actual, real-life controversy. 


\section{Politics by All Means}




\section{PGD: an episode in Dutch politics}

\subsection{Introduction}

\subsubsection{Method: a chronicle}

Spring 2008, Dutch politics witnessed a vivid controversy on preimplantation genetic diagnostics or PGD. This chapter will retell this controversy as an episode in modern, liberal, technoscientific culture. The story is enacted by politicians, technoscientists and not in the last place technologies. It will show that technological progress forces us to revise political categories, and that this calls for extensive debate. This chapter will differ from the previous two descriptions of practices in that it is not organized along different analytical lines, but rather as a narrative that at the same time tells the history, and comments on it from a more analytic perspective.

This approach requires that the reader is comfortable with the concepts that were introduced in chapters 2 and 3 , and that were corroborated in chapters 4 and 5. It also requires that the reader has a certain sensitivity for the mechanisms that typically occur whenever chances are induced by technologies. It is for this reason that the chapter is presented as the last of three case studies.

\subsubsection{PGD: a brief explanation}

PGD is a medical intervention that allows for the selection of embryos based upon their genetic profile. When the embryo consists of six or eight cells, a biopsy is performed. The embryos with the desired genome are then to be implanted in the womb, which is part of an IVF (in vitro fertilization) procedure. In particular, this includes a diagnosis of the genome of the embryo. PGD allows for a wide range of possible applications. It can serve sex selection in order to prevent X-linked diseases. But it can also, theoretically, serve sex selection just because parents have a certain preference for whatever reason. Practically any trait the genetic background of which is known can be used as a criterion to select embryos. One controversial application was indeed the example of Jamie Whitaker, also discussed in chapter 4 , where the criterion was 'donor matching'. Within Europe, approximately 2500 PGD treatments per annum are performed. In the 


\section{Politics by All Means}

Netherlands, about 150 treatments are conducted every year, and it is expected that this may increase to 300 treatments if facilities are extended (see also Niermeijer, De Die-Smulders, Page-Christiaens and De Wert: 2008; De Die-Smulders, Land, Dreesen, Coonen, Evers and Geraedts: 2004).

Many diseases are suspected to have a genetic background. Indeed, it has been speculated that within only a few years the genetic backgrounds to diabetes, heart disease, cancer, mental illness, Parkinson Disease and asthma will be known, as promised in 2002 before the President's Commission chaired by Leon Kass (see Kass: 2004, p. 9I). Today, these promises have materialized a bit more. Some of the expectations have been tempered, and some have been delivered. However, regardless of their truth, those promises have to some extent paved the road for us to think of PGD in the way we do. Or rather: the many ways we do today.

In the Netherlands, prior to the controversy that I will discuss, PGD was already allowed in prevention of diseases to which no cure exists, and which are nearly certain to develop during the lifetime of the child-to-be. (This certainty is referred to as full penetrance, as opposed to incomplete penetrance of diseases that may occur only in part of the carriers.) The Academic Hospital Maastricht has so far been the only institution with a permit to perform the treatment. Between I994 and 2004, a total of 691 couples were found eligible for PGD, 260 of which actually underwent the treatment. This was mostly in cases with a familial history of sex-related chromosomal abnormalities, Huntington's disease, cystic fibrosis, and structural chromosomal defects (see De Die-Smulders, Land, Dreesen, Coonen, Evers and Geraedts: 2004). Within the Dutch context, I am not aware of any cases of PGD that were performed with the intent of creating donor matches, like the ones described by Kass (2004, p. 90) and Dobson (2003). In fact, this forbidden by law, but as it is permitted in neighboring countries, parents could theoretically have sought recourse to elsewhere (see Health Council: 2006, p. 46).

\subsection{What went before}

\subsubsection{A sociology of medicine}

To understand the background to which the PGD debate emerged, it is important to know something about the recent decades in Dutch socio-medical history. The Netherlands is both famous and notorious for how it deals with a number of medical-ethical difficulties. Abortion is legal, and euthanasia is allowed under 
strict conditions of caution and transparency - things that sometimes create an image of the Netherlands as a place where 'anything goes'. However, this somewhat shallow picture deserves a small exploration to provide it with depth.

Indeed, abortion is legal up to 24 weeks after conception. On the one hand, the passage of the law that permitted abortion was rather slow. Abortion became legal first in I984, which is late compared to for example the UK, where a similar law was passed as early as i968. The Dutch law did not leave abortion unconstrained: it placed a burden of proof with the practitioner, who was demanded to declare that an 'inescapable emergency' justifies the abortion. On the other hand, there was a strong social movement among women in favor of free choice, in advance of acceptance of the law. What is more, practice had been ahead of the law: many clinics and institutions had already emerged that provided a more or less stable and regulated opportunity for abortion. Moreover, the committees that took up the task of assessing the burden of proof usually came to the conclusion that indeed the woman is herself most capable of making the decision (see Treffers: 2006). Thus, while abortion was not left completely unbounded by law, it had over a longer period of time been enacted as a free-choice practice.

Importantly, there are today no official guidelines of what reasons possibly justify an abortion. Indeed, cases have been reported in which the prospective mother decided to have an abortion because the pregnancy interfered with winter holiday plans, or because it would interfere with the scheduled purchase of a new sofa (see Goslinga: I995). While there is no reason to question the truth of these stories, we must also realize that they surface exactly because they are absurd, and are also found absurd within the Dutch context. The vast majority of aborted pregnancies seem to be the result of improper use of contraceptives. This is particularly a problem within social strata in which sexual education is not straightforward (see Trouw: 2008a). Of particular relevance for the PGD controversy is that indeed the right to abortion - insofar as it is not completely a formal right, it is at least an enacted right - includes abortion because of suspected innate defects. Thus for all practical purposes, a prospective mother can decide to abort her pregnancy if she happens to know that the future child will carry familial breast cancer - one of the diseases at the basis of the controversy discussed in this chapter.

A second element in the Dutch context is the regulation of euthanasia. Again, informed, free choice is the guiding principle. After years of shaping a cautious 


\section{Politics by All Means}

practice, a euthanasia law was passed in 2002. This is again fairly late when compared to the evolution of the practice itself. Euthanasia is legally permitted on a number of strict conditions. The most important are that the physician thoroughly assesses the situation, including the question of whether the decision of the subject might be influenced by others, and that he includes the consultation of a second professional. The physician has to report the case afterwards to a review committee. This committee forwards the case to the judicial authorities, only when the suspicion of malpractice exists. This has happened in only $0.2 \mathrm{I} \%$ of all reported cases in the first four years of existence of the law. Thus, the procedure reflects a stance of transparency, which is believed to justify the indemnification (see Smets, Bilsen, Cohen, Rurup, Keyser and Deliens: 2008).

A third element co-constituting the situation is found in the practice of assisted reproduction by means of in vitro fertilization or IVF. With IVF, egg cells are harvested from the ovaries of the mother. This requires a heavy hormonal treatment in advance, in order to have a sufficient number of egg cells maturing at the same time. Egg cells are then fertilized with the father's sperm. After successful conception, a number of embryos are bred until they are six to eight cells in size. A small number of them are then implanted in the womb. Often, some of them have to be aborted in order to give offer one or two of the other embryos the chance to survive. As Van Teeseling (200I) discusses, treatments can take several years and are usually burdensome, because of both the hormonal treatment and the many things that can and do go wrong. Moreover, the treatment has a success rate of only 20\% (see also Steures, Van der Steeg, Hompes, Van der Veen and Mol: 2006; Scholtens: 2008). Although this figure is consistent with the success rate of natural pregnancies, the former presents a much heavier burden because it requires major treatment and will mercilessly reveal each failure, while in the 'natural way' the 'failures' usually go by unnoticed.

The history of IVF in the Netherlands is not much like the history of most other medical technologies. IVF started as a truly experimental technology, that women were enrolled into under vague conditions and promises. In particular, it was suggested that they contribute to the promise of IVF as a remedy for undesired childlessness. This way of recruiting would today not at all be accepted as proper informed consent. Apparently, the women involved were willing to support the development of a solution to involuntary childlessness. As childlessness is neither life-threatening nor poses a medical necessity of any other sort, one might 
expect that experimenting with it would be even more strictly regulated than experimenting with curative medicine. However, reality worked the other way round: exactly the fact the IVF is not a drug nor a curative technology, sufficed in the early ig8os to exempt it from the strict regulations that medical technology is subject to (see Kirejczyk, Van Berkel and Swierstra: 200I, p. 59).

One important role that IVF played on the societal level was breaching the taboo of infertility. Before IVF, infertility was perhaps a personal drama, but certainly not a societal issue, nor an issue that the physician was supposed to take care of. However, with the growing acceptance of IVF, this changed. After the birth, in I983, of the first IVF child in the Netherlands, public media increasingly paid attention to solutions to infertility, thus helping to lift the taboo. The desire for children among infertile couples was paid extensive attention to, and in effect served the emergence of an implicit 'right to have children'. Both IVF practitioners and involuntarily childless couples had a huge interest in staging IVF this way (see Kirejczyk et al.: 200I, pp. 60-63).

Especially the examples of abortion and euthanasia seem far-off from the PGD debate. IVF is less so, because it is actually an essential part of PGD. However, these practices share that they reflect a societal attitude that is not frenetic in protecting human life at any cost, but rather holds that it is more important to leave individuals free. Indeed, individuals are themselves the most appropriate parties to decide upon these delicate matters. And in very specific cases, termination of a life may be a better option. Good information and education are demanded, much in compliance with the model of informed consent that we saw earlier. Together with the transparency pursued, these are largely accepted as justification for these practices. In addition, witnessing how the practice of IVF got its shape, based on its own terms, free choice seems to justify invasive interventions. Moreover, each of these practices provides precedents of medical professionals taking the lead in finding new forms for practices, instead of awaiting new laws. And because so many actors have played roles in the genesis of the present situation, both legitimacy and rigidity are the result.

\subsubsection{PGD off-the-shelf}

By the time the controversy emerged in 2008, PGD had to a great extent become an off-the-shelf technology: it had been developed and tested and been used successfully in real-life situations. The PGD procedures had been conducted 


\section{Politics by All Means}

successfully and reliably, at least living up to the figures of in-vitro fertilization and intracytoplasmic sperm injection (see De Die-Smulders et al.: 2004). Its particular use in prevention of partial-penetrance diseases was already commonplace in neighboring countries. The question was not how it could possibly be developed further, but rather simply whether or not its use should be extended to incompletepenetrance diseases. On the one hand, telling the story this way suggests an externalist view: the enterprize of developing the technology is finished, and now we are facing the detached moral issue of whether certain uses are right or wrong. On the other hand, this externalism is just a varnish: now that its use was ready to be extended the urge to allow this was clearly felt. In fact, medical scientists and ethicists (see for example De Wert and De Beaufort: 2008) stress that it would be immoral not to allow PGD.

The image that PGD expresses in general is one of human nature being eligible for manipulation. It expresses a particular vision of the human embryo, namely one of disposability, and not in particular need of protection. In short it expresses a reductionist and materialist approach to human nature. On the one hand this need not coincide with the moral stance of the persons involved. That would be close to arguing that somebody owning a gun cannot be a moral, noble person simply because the gun expresses the idea that human life can be terminated at command. But on the other hand, PGD does make any position harder to argue for that sees the embryo as anything different from a disposable lump of cells. In part, this is owing to the pressure from the persons and institutions supporting PGD that. And in part, it comes in a more subtle way from the cultural habituation: PGD seems indeed just a small step in a culture in which IVF and (even selective) abortion are common practices.

What is more, PGD appears to be a meliorist technology: a technology that only offers good opportunities and solutions to bad problems. And if you happen to dislike the technology, there is no reason why you should fear it, for it will never be coerced onto anyone. This leads proponents of PGD to assuming that it is largely privatizable: that it can be applied depending only on the decision of individual parents, without having any influence on others. Thus, PGD appears to satisfy the condition of tolerance.

Importantly, the proponents must implicitly accept the view expressed by PGD, of the human embryo as something disposable. Disagreeing with this idea and instead holding on to the view of the embryo as fully entitled to protection entails 
seeing PGD as violating the condition of tolerance. It would then follow that this technology is not purely meliorist, and that it hides important downsides instead.

PGD and IVF procedures are burdensome. As I explained in subsection 6.2.I, IVF is a necessary part of the PGD treatment. It requires heavy hormonal treatment, and will in general be successful in only $20 \%$ of the attempts. Given all these hurdles, it is not that likely that parents will go through this trouble for just the color of their kids' eyes. Nevertheless, in the discussions on PGD, the fear is expressed that PGD in prevention of incomplete-penetrance diseases would open up a slippery slope towards making a perfect society (see Bosman: 2008) whatever one may hold that to be. Parents would select embryos for seemingly futile reasons, or based on abject ideas about the lives their children should live. However, these considerations seem to fail to take into account that PGD is not so funny at all (see Niermeijer, De Die-Smulders, Page-Christiaens and De Wert: 2008). Thus, while we may observe on the one hand the urge to use the technology now that it is there, at the same time it poses sufficient barriers as a fun treatment. This is interesting: it urges its use, but by remaining difficult, it unintendedly and implicitly contributes to its own legitimation by ruling out frivolous use. (This argument is indeed adduced by deputy minister of Health, mrs. Bussemaker in her second letter, see Tweede Kamer: $2008 d$, p. 5.)

One more thing needs saying here. One of the important things that I put forward in chapter 3, was the suspicion that the hermeneutic and existential roles played by technology are important yet underestimated. However, what I have shown so far in the case of PGD is mainly a lot of debate and quarreling, and fairly little about what the material things really do. True enough, it is not entirely straightforward that the situation is to be understood as a technology enforcing its own use. Nevertheless, I explained in the same chapter that what matters are primarily the connections between human and non-human actors. These are indeed clearly visible here, in a way that can only be understood if we include the technologies. The positions of discussants only make sense against the background of a culture that has developed a practice of PGD. This practice consists of the hospitals and laboratories in which PGD is conducted, as well as the Petri dishes, the PCR-processes and the mothers-to-be injecting themselves with hormones in their bathrooms. These elements are essential contributions to the picture that I just sketched. 


\subsubsection{Polders and politics}

Ever since the igth century, the Netherlands has been a parliamentary democracy. It has a bicameral system, of which only the lower house (Tweede Kamer der Staten Generaal) played a role in the controversy discussed here. In general, this lower house is where the actual political debate takes place, and I will now further refer to it simply as 'parliament'. Today, the Dutch parliament is populated by about a dozen of parties. Parties may take their identity from various sources. These sources may be mainstream political doctrines such as socialism, liberalism ${ }^{\mathrm{I}}$ and conservatism. In addition, confessional parties exist that explicitly relate their identity to a Christian background (or, theoretically, any other religious background, but so far no non-Christian confessional parties have been established). And finally, so-called 'one-issue' parties are founded now and then, that draw attention to a narrow range of themes. In practice, the identity of parties is a mixture of such sources of inspiration.

Against this background of a pluralism of many parties, none of the parties has ever acquired an absolute majority. This has always necessitated parties to form coalitions. As a consequence, governmental policy generally is a compromise between various election programs of parties taking part in the coalition. The compromise is formalized in the form of a coalition agreement. Of course, issues can be raised that are not conclusively settled in the coalition agreement, and therefore in practice, there is ample room for debate and disagreement between coalition partners.

Another element in the background is relevant here: the so-called polder model that characterizes Dutch politics. In its strict sense, this refers to the Dutch habit that structural economical decisions are not simply made by the government, but in close consultation between the triangle of government, labor unions, and associations of employers. In a broader sense, it refers to the Dutch habit of discussing everything and trying to find compromises, rather than just imposing majority opinions. The model owes its name to the typical Dutch 'polder', which refers to any area of land in which the water levels are strictly controlled, or in more common usage to any plot of land that has been won from the water. Either way, the tenet is that conquering water requires close cooperation and consent of all participants. While not directly related to the medical practices discussed in the previous subsection, it does reveal important aspects of the deliberative character

1 Not the Rawlsian version, this time! 
of Dutch politics, and it does explain how it can be that the law relatively often follows practices that were hitherto strictly spoken illegal. The polder model thus offers a solution to the phenomenon that politics will generally be slow when compared to technoscientific changes.

It is against this political background that one small protestant party, the Christian Union (ChristenUnie, CU henceforth), came to power. Through the years, it has never been an influential party. It formed only a small fraction, and especially its medical-ethical ideas differed to much from the ideas of the bigger parties to make it an attractive coalition partner. That is, until the elections of November 22, 2006. The outcome of the elections prohibited any two-party coalition, and negotiations started to form a three-party coalition. The negotiations were awkward, and it took until February 6, 2007 for the coalition agreement to be settled. The CU contributed two ministers to the cabinet, to which the much larger Christian Democratic Appeal (Christen Democratisch Appèl, CDA henceforth) and the Labor Party (Partij van de Arbeid, PvdA henceforth) delivered eight and six ministers, respectively.

Importantly, the CU fosters conservative opinions, especially on the medicalethical issues discussed in the previous paragraph. The CU disapproves of the current status of abortion and euthanasia as legally permitted interventions (see ChristenUnie: 2008). Owing to its small size, the CU did not succeed in getting these positions adopted literally in the coalition agreement. However, they can be recognized implicitly. The agreement states that permissions for euthanasia and abortion will not be extended during this term of office. Moreover, the coalition agreement emphasizes alternatives to abortion: prevention of undesired pregnancies and support for teenage parents. Similarly, additional attention will be paid to better palliative care (see Regeerakkoord: 2007). This captures an interesting tension between accepted policy and the disapproval of this policy by a minority. This situation strongly hinges upon the specific way by which this minority party gained influence. Remarkably, this minority seems incapable enforcing its opinions, despite the power it has gained. This is not in the last place so because of the embedment of PGD in society and medical institutions, as I will argue further in subsection 6.3.3.

In 2006, the Health Council of the Netherlands had issued an advice to the government to allow PGD in prevention of diseases of which development in the carrier of the mutation is not completely certain, so-called incomplete-penetrance 


\section{Politics by All Means}

diseases. The advice was not followed at that time by the Deputy Minister of Health, mrs. Ross-van Dorp, affiliated to the CDA. She argued that allowing PGD in prevention of partial-penetrance diseases would be taking a step down on a slippery slope towards the prevention of diseases that are not impossible to live with (see Niermeijer et al.: 2008). Between 2006 and early 2008, the Academic Hospital of Maastricht had respected this position and not performed PGD in prevention of heritable breast cancer. Thus, it left parents only the options of undergoing the treatment abroad, and of prenatal diagnostics, which incurs the possible abortion of an affected embryo (see Niermeijer et al.: 2008). Especially the latter can be significantly more burdensome than PGD, since it entails the termination of an embryo or fetus that is already implanted in the womb.

\section{Time line}

The following time line is provided only for orientation. The reader may as well skip over it, and just return to it if needed.

- November 20, 2007: A special committee of parliament discusses the state of affairs in PGD with the deputy minister, mrs. Bussemaker. She promises to issue a statement soon, which will be based on a respect for both autonomy and the protectworthiness of human life. (see Tweede Kamer: 2007, p. 2)

- May 26, 2008: Bussemaker announces an extension of the permission for PGD in her first letter to the parliament. (see Tweede Kamer: 2008a)

- May 27: The disapproving reception of the letter reaches the media, and several members of parliament from Christian parties demand an emergency debate. (see Trouw: 2008c)

- May 30: The cabinet decides that the letter will be withdrawn. Bussemaker promises to send a new letter, based on new discussion in the cabinet.

- June 3: Mr. Bos, vice premier on behalf of the Labor party, argues that the matter is of utmost moral importance to his party as well, and not just a topic for Christian parties.

- June 5: The parliament conducts a debate on the unfortunate procedure by which Bussemaker's first letter had been established and presented to the parliament. Despite this formal focus, much of the normative positions of discussants seeps through. (see Tweede Kamer: 2008c)

- June 27: Bussemaker issues the second letter that she promised, this time with consent of the full cabinet.

- July 2: The parliament conducts a debate on the second letter. It is endorsed and considered a much better compromise, even though on the technical level it differs hardly from the first version. Differences are mainly procedural. (see Tweede Kamer: $2008 b)$ 


\subsection{The embryo of discord}

\subsubsection{Parliament in panic}

Then, late May 2008, an exceptionally vivid controversy was sparked. Deputy Minister of Health, mrs. Bussemaker (affiliated with the PvdA), decided to allow PGD in prevention of certain forms of cancer that exhibit incomplete penetrance, that is a less-than-Ioo\% chance of developing in carriers of certain mutated genes. In particular, her position concerned the prevention of familial breast cancer that has a chance of development of 60-90\% and for which some treatments exist. She assumed that breast cancer is just as serious as Huntington's and Duchenne's, so a permission for the latter would also be applicable to the former. Moreover, she apparently concluded that the risk of $60-90 \%$ of developing the disease is great enough to outweigh the chance that embryos are discarded that would have lived a healthy life. She found no convincing argument in the fact that these forms of cancer can be mitigated or can be expected to become treatable in the near future. Rather, she seems to have assumed that a life with such diseases, or possibly just the knowledge of carrying the mutation, is significantly burdensome. (Indeed, in a correspondence in the national daily newspaper NRC Handelsblad, gynaecologist Evers (2008) argues that carrying the mutated gene can be 'Io०\% burdensome', even if the penetrance of the disease is not I००\%.) It is not quite clear how Bussemaker related her decision to her predecessor's ruling not to allow PGD in prevention of incomplete-penetrance diseases.

Mrs. Bussemaker announced the extension of the permission to perform PGD without first discussing it at large within the council of ministers. This is in itself not exceptional: even though Deputy Ministers are second in rank to Ministers, they have their own portfolio and make decisions independently all the time. The reason for her to do so without further discussion was mainly based on her estimation that the extension would only amount to a marginal practicality: given all the similarities between the diseases, she concluded that heritable afflictions such as breast cancer belonged on the list. She thus acted as if the extension of the permission for PGD was just a minor affair that fully resided under her authority.

However, Bussemaker turned out to be mistaken in her estimation of the decision being unproblematic. The loudest protest against this extension came from the CU, initially in the person of CU vice-premier Rouvoet. ${ }^{2}$ He contended

2 In the Dutch political system, the largest coalition partner provides the prime minister. Other partners provide one vice premier, which is a status auxiliary to a regular position as 


\section{Politics by All Means}

that the decision was so fundamental that Bussemaker should never have made it without proper prior discussion in the council of ministers. In addition, he argued that the extension would be a step unto a slippery slope towards a world of perfection, in which disease and diseased persons no longer earn respect (see Het Parool: $2008 b$ ). The CU feared the emergence of a society in which imperfection and disease become less and less acceptable - if only because many individual parents taking such decisions in effect produce a social pressure favoring embryo selection, even for those who disapprove of it. An additional argument brought forward by the CU was that the less-than-Ioo\% chance of developing the disease entails the risk of disposing embryos that would have lived a healthy life (see Herderschee and Sitalsing: 2008). As the CU holds embryos to be fully human persons and therefore worthy of protection, it cannot accept this as a cost of preventing the disease. For the CU, the issue was fundamental one: if we disallow human beings to live who have only a possibility of developing a disease, we are increasingly playing God. Moreover, they argued that the burden of making such decisions would be one that should not be imposed onto prospective parents.

Opponents of the CU argued that the view that the early embryo deserves full protection is only a personal opinion with which they disagree. On the contrary, they argued that the disposal of just a lump of cells can be justified by the prevention of the immense burden of breast cancer. Indeed, some argued that it would even be immoral to refuse to give people such treatment, if the refusal is merely justified by principles that only a small part of the electorate subscribes to. After all, the CU has 6 seats in parliament, which equals no more than $4 \%$ of the electorate. What is more, the opponents argue that the decision of whether or not to engage in PGD should be left to the parents, not to the state or anyone else (see Tweede Kamer: 2008c). In addition, it would be strongly inconsistent if we withhold sufferers of familial breast cancer what we do grant to sufferers of Huntington's. Moreover, the fear for the slippery slope would be a non-argument, as PGD-IVF is a highly intrusive treatment. It is unlikely to be abused for allegedly eugenic purposes like the selection of eye color or sex, or anything else close to the creation of whatever perfect society.

Mr. Bos, vice premier and leader of the PvdA, stressed that for his party, the matter is equally fundamental: we have an obligation to relieve suffering from

minister. At the time of the controversy, mr. Balkenende (CDA) was the prime minister of the Netherlands. He was accompanied by two vice premiers, namely Bos (PvdA) and Rouvoet (CU). 
cancer whenever we can, even if this involves the disposal of embryos. This has an interesting relation to the condition of tolerance: for Bos, it is not acceptable that people prohibit others to do what is good, i.c. the prevention of heritable breast cancer. (This is strictly not something that we allow others to practice in their private sphere or not, which is the question that I framed the condition of tolerance for. But it is about a private opinion that one disapproves of, mostly because of its public consequences.) Moreover, it proves that all parties are forced to be open about their life-ethical content, even if they profile themselves as 'secular', 'liberal' or otherwise not inspired by a 'life-ethical' doctrine. (I have put the words between quotes, to stress that it is a matter of profiling, not a matter of really being void of life ethics.) At the same time, the supporters of the CU and its position see the same condition violated, yet in a different way: they believe PGD is so bad that others cannot be allowed to practice it, even in their private realms.

In addition to these moral concerns, a prohibition was argued to be practically unfeasible for two reasons. First, similar treatments are legally allowed in Belgium, Spain and the UK (see Trouw: 2008b). And second, parents can already decide to have the pregnancy aborted if a genetic test of the foetus gives rise to questioning its genetic health. This is for many parents an even more traumatic experience than PGD, as it involves the abortion of an embryo that is already in the womb. Prohibiting only the latter would be an inconsistency in the law.

\subsubsection{Purification in practice}

Purification is by definition the process of accepting some arguments and discarding others as inappropriate. Thus, purification for example occurs whenever a CU member brings forward biblical arguments, and those arguments are disqualified as inappropriate by others - not because they are unconvincing, but because they are believed not to belong to political talk. We need not look far for that. As Bert Wagendorp (2008) argues in his column in De Volkskrant, one of the national daily newspapers, the CU position can only be seen as a dirty piece of religious populism: it stresses the aspects of PGD that it thinks are immoral, and hides the upside of preventing cancer. Moreover, Wagendorp contends that the CU houses some protestant fundamentalists that have tasted power (see subsection 6.2.3) and now want to use it to enforce their ideas onto the majority. Similarly, Sylvain Ephimenco (2008) argues in his column in Trouw, another national daily, that a small minority seems to be able to impose their obsolete visions onto a 


\section{Politics by All Means}

majority that does not care much for such backward Christian ideas. According to Ephimenco, the whole situation boils down to a punishment of women with a breast-cancer gene, even though those women are not in any way related to Christian visions.

Also inside the parliament, disqualifying voices towards the $\mathrm{CU}$ position are heard. Mr. Rutte, leader of the libertarian-oriented People's Party for Freedom and Democracy (Volkspartij voor Vrijheid en Democratie, VVD henceforth), uttered his disgust over the CU's stance that quality of life should not be equated solely with health (see Herderschee: 2008). Rutte wonders how the CU can possibly justify the imposition of this stance on society at large. This would be a grave impertinence towards all those women suffering from breast cancer: they are condemned to live under this sword of Damocles, against their will, even though a solution for it exists (see Tweede Kamer: 2008c, p. 6573). It is interesting here that the rhetoric can be interpreted along two lines: either, Rutte thinks the CU position should not be universalized because moral positions about the value of life should in general not be universalized, or because this specific moral position is too backward to be universalized. Either way, from Rutte's perspective the CU position deserves at most a private place, not a public one.

Something similar holds for the words of mrs. Kant of the Socialist Party (Socialistische Partij, SP henceforth). She argues that a small minority may not impose its moral doctrines onto the whole population (see Tweede Kamer: $2008 c$, p. 6576). Again it would be interesting to see how the SP would have argued in case the content of the moral doctrine had been more acceptable to them. Indeed, it is interesting that both Kant and Rutte argue against the CU on a mixture of the procedural and the normative level, even though the debate referred to was primarily intended to discuss the procedure through which mrs. Bussemaker came to write the letter that she sent to parliament. This debate was explicitly focused on purification. The fact that there was so much confusion and in fact a lot of 'contamination' of the debate by political content shows that indeed purification involves hard work as I argued in chapter 2.

The strategy of the CU was interpreted as halfhearted by some. On the one hand, in the parliament the CU pretended to argue only about the procedure by which the original decision of mrs. Bussemaker reached parliament. This was indeed the official agenda of the debate. In the first debate, on June $5^{\text {th, the }} \mathrm{CU}$ refused voice an explicit opinion with respect to PGD (although it can be clearly 
read between the lines that the $\mathrm{CU}$ is against it) and suggested to await the new statement of the cabinet. In the second debate, the CU did nothing but praise the new compromise. And yet on the technical and normative level, it differs very little from the first version - on the technical and normative level that is. It does include some important differences in the institutional setting of PGD, to be explained in subsection 6.4.I, which helped the CU to promote the image of conducting politics for its own purpose and thus accepting the outcome, as opposed to conducting politics only in favor of the CU's own interests (see Tweede Kamer: 2008c, p. 6586). Indeed, in the second debate they applauded the fact that politics, now, had followed a neat path, even though the outcome was fairly close to the outcome of the first debate (see Tweede Kamer: 2008b, p. 7425).

On the other hand, various CU politicians exposed their normative views in public media, including the complaint that they were not taken seriously. During the controversy, this complaint mainly concerned the fact that their normative position, that PGD would be an undesirable technology, was disregarded too easily. And some time after the controversy, the complaint concerned the level of purification: they argued that their visions were disregarded because they were Christian in origin. For example, vice-premier Rouvoet argued that there is something unfair about the idea that the CU should not be allowed to introduce biblical views into the debate, while views based on the books of Locke are commonly accepted. As both can be adhered to in equally dogmatic ways, why accept one and not the other? Rouvoet experienced that his party's views were unwelcome because they stem from a biblical background. The boundary between libertarianism and anti-religious sentiments proved quite fuzzy, thus Rouvoet. Moreover, he argued that religious belief is not irrational, but supra-rational in the sense that it cannot be disproved by rational methods. Thus, religious knowledge cannot be excluded from politics a priori (see Heerma van Voss and Reerink: $2008 a)$

Similarly, mr. Slob, leader of the CU fraction in parliament, felt insulted by the arguments that suggested that the CU consists of a collection of insensitive fanatics. Slob could not recognize the identity of his party in the caricatures he read in the papers: that the $\mathrm{CU}$ aimed to get its ways at the cost of women suffering from cancer; that CU politicians were fanatics, fundamentalists and tyrants; or that the CU showed quite some arrogance and self-satisfaction, now that it had reached power. On the contrary, Slob believes that politicians have by definition 


\section{Politics by All Means}

a certain mission. The unfairness was in the fact that particularly the Christian mission is disregarded (see Heerma van Voss and Stokmans: 2008).

Interestingly enough, in the same interview, Slob made an implicit reference to the condition of tolerance. He was reminded by the reporter that the $\mathrm{CU}$, representing only a small minority in Dutch society, has always argued for autonomy, especially in difficult ethical matters. For example, participation in vaccination programmes may be refused on religious grounds. Slob agreed that this is indeed a way of letting people live the life they want to live. However, he added that unborn life cannot defend itself. It is therefore our duty to take up this responsibility. Indeed, Slob agreed that politicians should not assume the roles that belong to physicians. But they do have a duty to establish the boundaries within which citizens may make decisions. In other words, treating embryos the way PGD does, is too immoral to be tolerated (see Heerma van Voss and Stokmans: 2008).

The position of the $\mathrm{CU}$ is just one opinion among many others, and parliamentary democracy demands that it should at least be possible to argue for any of these positions. This was indeed largely respected by other parties. However, because the CU took part in the coalition, it was feared by some that the CU would be able to enforce this position beyond the support that it would (strictly numerically speaking) get otherwise. Mrs. Kant of the SP persistently asked what would tip the balance: the importance of keeping the coalition together, even if this requires adopting the $\mathrm{CU}$ position collectively, or the weight of a vast majority in parliament who has a different opinion than the CU? The CU refuses to answer this question, while awaiting the official resolution of the cabinet (see Tweede Kamer: $2008 c$, pp. 6586-6587). This is interesting, as both options are in principle possible, and both options hide a stance towards the priority of different sources of legitimate power.

Towards the end of this subsection, the question becomes pressing what positions can be argued for and what not. That is to say: for some positions it will be accepted that someone defends them, and for other positions it will not. Where is the line drawn, empirically? It is interesting to see that Rouvoet and Slob argue that they feel a kind of categorical resistance towards their Christian ideas, while it is hard to find explicit examples of such resistance inside parliament. The blunt disqualifications of Christian ideas were mainly found in the opinion sections of newspapers (see Evers: 2008; Het Parool: 2008a; Etty: 2008). Perhaps the only 
interesting moves within parliament in this respect were made by $\mathrm{mr}$. Pechtold (Democrats '66, D66 henceforth) (see Tweede Kamer: 2008c, pp. 6569-6570) and mr. Rutte (see Tweede Kamer: 2008c, p. 6573). Pechtold argued that politics should abstain from entering the examination room. And Rutte argued that it would be quite something if the $\mathrm{CU}$ wished to condemn women to live under Damocles' sword. In other words: they argued that such moral decisions should be private. This is, strictly on its own terms, not a disqualification of Christian ideas. However, it is a purification that only allows liberal conceptions of the condition of tolerance.

Thus, while it is pretended that all visions can have their say in parliament, a Christian minority must indeed fear being silenced by the liberal majority. However, at the same time, the CU cannot deny that the visions of the CU reach the front pages of newspapers, partly because there is so much ado about the question of what is politically appropriate and what is not. Thus, attempts to silence certain views can amount to the opposite.

\subsubsection{The network outdoors}

So far, I have mainly discussed the verbal debates, which mainly occurred in parliament and on the opinion pages of newspapers. I have so far not really discussed the role that technology played in this controversy. Besides a clash of different ideologies, the controversy revealed some interesting roles that the hospital, being the material and institutional substrate on which the technology of PGD was effectuated, did play. The official position of the hospital was initially one of compliance with the position of the administration, and of awaiting official policy before acting. This was so, even despite the fact that it was not doing anything illegal (see Heerma van Voss and Reerink: 2008b). Between 2006 and 2008 it had not performed PGD in prevention of incomplete-penetrance forms of cancer, because it recognized the potential moral difficulties.

Interestingly enough, mrs. Bussemaker argued in second instance (see Tweede Kamer: $2008 d$, p. 3) that the 2006 regulation, explicated in mrs. Ross-van Dorp's letter, had not been discussed in parliament. Therefore, it lacked formal power. As a consequence, earlier policy was still in effect. This stated that PGD was allowed in case of an increased risk of a child with a burdensome heritable disease or lesion. Incomplete penetrance was not believed to be a convincing reason to see the disease as anything less burdensome. This renewed interpretation of the 


\section{Politics by All Means}

old policy seems to have been a major support for the hospital to start practicing PGD again after the first letter of mrs. Bussemaker. In addition to the fact that it was found indecent to deny to parents something that had been promised to them only a few weeks earlier, the hospital concluded that it was also strictly doing nothing illegal. This move was important. Even though it appears to be trivial because it enacts the old policy (be it in a new interpretation) instead of the 2006 version, the situation after the first letter was very different from the situation before. By enacting the practice, it became established and fortified, and made the $\mathrm{CU}$ position harder to argue for. PGD in prevention of heritable breast cancer thus acquired one more stronghold in society. And indeed, this shows that PGD is at least technically privatizable: one can have a PGD treatment without interfering in any way with the lives of others, especially those who disapprove of PGD. Enacting PGD this way provides a precedent for it also to be politically privatized: the claim that PGD is 'one's own business' is now easier to argue than if it had also been technically difficult to practice it without bothering others.

The hospital denied the moral difference between using PGD to prevent Huntington and using PGD to prevent familial breast cancer. It did not as such deny the ethical import of extending the use of PGD towards incompletepenetrance forms of cancer. This position implies a denial of the slippery-slope argument, which was an important boundary for the CU discussants. The moral irrelevance that the hospital attaches to this technical, small extension of the use of PGD gives it a somewhat externalist ring: it does not claim complete moral emptiness, but at least an ethical stance building on the slippery-slope argument cannot be part of the medical professional practice. This in its turn contributes to a privatizable conception of the PGD technology: if a significant part of normativity is not intrinsically connected to the PGD technology, there is little reason to make it politically relevant at all.

The hermeneutic and existential dimensions as developed in chapter 3 can be recognized here, even though they do not surface too explicitly. That is, PGD does not quite overtly influence our understanding of the world, nor does it force us to take certain actions and not others. But on an implicit level it does play a role on both dimensions: by existing, it expresses a vision of the embryo as something - not: 'somebody' - open to manipulation. In the presence of PGD, it is harder to argue for the embryo as being fully worthy of protection, than if no technology were present for manipulation of embryos. And even though PGD does not in any 
way coerce us into making certain decisions, it does at least open up some choices that we have to take a position on. And what is more, those choices are presented as quite attractive: who would turn down the offer of a life without cancer? Today, we can make decisions about embryos that we could not make before, and thus it has become necessary to make those choices (of course, only under some specific additional conditions, but that is not much relevant here).

\subsection{The aftermath}

\subsubsection{Political settlement: restricted privatization}

The second proposal is issued by Bussemaker late June 2008. It differs from the first letter primarily in a more explicit demand for assessment of the whole practice. Two bodies are assigned responsibility in decisions and evaluations. First, a multidisciplinary committee is responsible for issuing guidelines for practicing PGD. (The resemblance to the polder model, see page 200, is striking.) Second, the hospital will have to facilitate a multidisciplinary committee that assesses individual cases when PGD is considered. Moreover the hospital is required to consult the guideline committee if it considers treatments that are not covered by existing guidelines; and it has to report annually to the Ministry of Health, about the figures and kind of PGD treatments, as well as about the (novel) applications for which it has consulted the guideline committee (see Tweede Kamer: 2008d, pp. II-I2). This new statement is endorsed by the full cabinet and accepted by the parliament, and is believed to be a sufficient safeguard that no undesirable paths are taken

Some observations are appropriate here. The first observation is that the proposed structure is virtually equal to how things already are. In the hospital, a medical-ethical commission already discusses individual cases of PGD, thus delivering the duties of the second commission just mentioned. And even though the guideline commission dedicated to PGD has so far not been a formal body, it is largely how the medical profession is regulated. Both resemblances are explicitly mentioned in the proposal by mrs. Bussemaker(see Tweede Kamer: 2008d, pp. IO-II).

The second observation is that this in effect allows for just the same as the first proposal. The new proposal contains a number of broad criteria to which PGD should be subject, and which are open to further filling-in by the 


\section{Politics by All Means}

guideline committee. The original apple of discord, PGD in prevention of incomplete-penetrance heritable breast cancer, is unambiguously covered by the new proposal.

The third observation is that, again in effect, this proposal amounts to the ultimate decision being located with the parents. This is a de facto privatization of the decision to apply PGD. That is, parents will be allowed to take the decision on their own, after intensive counseling in which all aspects will be discussed, also the moral ones. In the end however, couples may decide to apply PGD according to their own moral insight. It could be argued that this is not a complete privatization as it involves accountability to institutional bodies. But alternatively, it could be argued that this accountability is a condition for the matter to be private, which is further reflected by the rather wide limits set by the ministry being.

This privatization is restricted in one additional sense: it does not overrule the professional ethics of the medical professionals involved. They still need to approve of the specific application. In general, they will be reluctant to do so, if they see a serious imbalance between the burdens and the assets. This can be the case with diseases that have a late onset or that can be treated sufficiently. This however approaches situations in which a physician may refuse any treatment if it is not in line with his or her conception of the profession. It thus closely resembles the way in which most medical decisions are private.

\subsubsection{Some metapolitical convulsions}

In an interview, published in the national daily NRC Handelsblad (see Heerma van Voss and Reerink: 2008a), Rouvoet explains his disappointment about the tone of voice in which the debate was largely conducted. He suspects that some of his political opponents disqualify his views because they are rooted in a biblical background. Rouvoet objects that appeals to Locke or the Universal Declaration of Human Rights are similarly unacceptable, if the one appealing refuses to discuss those appeals. He moreover argues that religious belief is just another source of knowledge, not much different from science or what one reads in the newspapers. Rouvoet contends that biblical knowledge should be part of public debate just as much.

In a commentary on July 29th, philosopher Herman Philipse explains in the same newspaper (see Philipse: 2008) that the idea of public reason works against all that Rouvoet argues for. Anything that is adduced into the debate, should be 
open to discussion. That is the very first condition to be fulfilled for any debate to be conducted. This forces a choice onto any participant in the debate: either adduce something and accept its being attacked, or leave it out. We have seen at several points in this book that some arguments are more likely to be attacked than others. The scientific fact can be taken as a paradigm for an undisputable claim, while religious and metaphysical claims populate the opposite extreme of most disputable facts. In Rawlsian terms, religious claims are unlikely to be political, freestanding claims (see also page 43).

Philipse carries this to the following irony for politicians from a Christian background. On the one horn of the dilemma, they adduce transcendental appeals. They must then fear that these appeals can be discarded by opponents without further justification. They are not convincing and not relevant for those who do not share the same religious background, and even found immoral at times. Specifically in the case of PGD, this is mainly owing to the fact that PGD is not addressed by the Bible, and to the fact that the authority of the Bible is questionable to many people and certainly not more convincing than other books. (Fair enough, this does in theory not only hold for religious backgrounds, but for any background. Secular backgrounds however are way less prone to use transcendental claims, and are hence less vulnerable in this respect.)

On the other horn, Christian politicians abstain from adducing transcendental appeals. This incurs however two other risks. They may be unable to make their points, as justification of those points is outside politics. Or, if they find sufficient alternative arguments in support of those points, people may suspect that the actual underlying motives are different from the explicit arguments. This will feed the impression of hypocrisy, making Christian politicians again vulnerable to being taken less serious in the debate.

This sheds different light on Rouvoet's argument that dogmatism based on Locke is fairly equal to dogmatism based on the Bible. From Philipse's vision, an important difference between the two can be distilled: Locke's thoughts themselves are open to discussion, whereas the divine origin of biblical thoughts puts those thoughts beyond discussion. In Rouvoet's terms: they are supra-rational. In other words, Locke can be argued to be completely mistaken - be it convincingly or not. Arguing that the Bible is mistaken however, usually meets a rejection of arguing on it in the first place. This confirms the observation that arguing on basis of the Bible is a fundamentally difficult affair within liberal politics. 


\section{Politics by All Means}

This has important consequences for the conception of politics that I developed throughout this book. On the one hand, liberalism aims at producing a platform on which as many reasonable doctrines can have their say as possible. At the same time however, the liberal way of conducting discussions renders Christian visions, and in a broader sense all visions that appeal to transcendental claims, fundamentally difficult to argue for. Moreover, there is again an element of irony towards Christian positions. On the one hand, they are necessitated to live in the society about which the decisions are to be made. This inescapability would justify that they are given a full say. At the same time however, they are not completely enabled to stage their views on it.

At this point, it could be argued that Christian politicians are being unreasonable here. After all, they do not restrict themselves to political terms. On the contrary, they are adducing peculiar forms of rationality. In chapter 2 I argued however with Rawls that rationality is private in a way that reasonableness is not, and that therefore rationality is a source for dispute rather than for agreement (see also page 2.3.3). This is certainly the case with Rouvoet's claim that religion is a supra-rational form of knowledge. Nevertheless, concluding the discussion by saying that the Christian position is unreasonable, would be too easy. In fact, the position of the $\mathrm{CU}$ in this debate is quite reasonable: the $\mathrm{CU}$ wishes to cooperate with people of other backgrounds and openly discuss the terms of cooperation. Its goal is a society that is good and just for its own purpose, and that is in principle open to many other ideas of the good. It does so through legitimate politics. And it extensively explains the justifications that underly its positions. Indeed, these justifications lead them to the position that an open, pluralist, and just society should not dispose of embryos. Thus, the problem seems to be rather that the forms of rationality dominant in liberal speech are incompatible with the rationality of some of its members. Or in this case, the rationality of Dutch liberal society and Dutch liberal politics is incompatible with the form of rationality that the $\mathrm{CU}$ holds on to. Or put even more radically: the typical liberal claims to reasonableness hide an implicit vision on rationality, even though it pretends to be a politically-wise alternative to rationality. Thus, while Philipse may have the noblest intentions of fortifying a truly liberal society, he also explicitly concludes that Rouvoet's positions are far from tenable in it. 


\subsubsection{Sociotechnical settlement: private again}

From a technical perspective, there is not much difference between the situation before the controversy and after. The technology has not really changed, and its use shifted only slightly. Not a single Petri dish, consent form or PCR reactor has been changed. The controversy thus seems to have been a merely political quarrel, not a rearrangement of the technological configuration. True enough, from a purist ANT perspective, it would be suggested that the change of use in fact entails the conclusion that a new technology has emerged. That doesn't seem too convincing here. The role that technology played in this controversy was that a slight change in its use, being itself a small next step rooting in a long history of development, was the immediate cause of the controversy. But the controversy itself seems to have changed little about the technology.

Nevertheless, the change is not completely unimportant for the technological configuration. The whole controversy contributed to PGD becoming a proper means for preventing heritable breast cancer. Now that the legal and ethical conditions for its use have been articulated better, it has gained a stronger embedment, which is conducive to its unproblematic use. Moreover, this particular embedment has contributed to the private character of important decisions. It has contributed to the embryo being something that can in specific cases be 'sacrificed' in favor of a less burdensome life. In short, the new technoscientific configuration contributes to everything that the CU position argued against. On the one hand, this seems contingent and things could have developed otherwise. On the other hand, it is not so much surprising, as it seems to be the configuration that finds support in the largest majority of the population. And moreover, it is the configuration that matches best with the configuration as it had already materially matured just a short while before the controversy flared up.

Although the changes are rather subtle, we must not underestimate them: exactly these subtle changes are what pertains to the dominant forms of rationality in political debate. That is to say, after this controversy, it will be one step more difficult to argue for the embryo being something divine and fundamentally entitled to protection. Thus, in fact, the CU position suffered a double defeat: on the surface, it just did not get its view on PGD accepted; and below the surface, things changed in such a way that this view will in the future be even more difficult to argue for. 


\section{Politics by All Means}

\subsection{Reflection}

At first sight, it might seem that the whole debate was conducted in vain: in the end, the technology is eligible for use pretty much independent of what the opposing voices contributed. The hospital took the path that it already saw as the most logical a priori. Politics took the course that was the opinion of the majority, also a priori.

However, as I just articulated, the changes below the surface cannot be denied. Those are more subtle than I might have suggested in earlier chapters. The embryo was not radically redefined: it was already to some extent disposable, at it is only a little bit more so, now. Neither was autonomy before the debate much different than after the debate. And neither was the vision of technology in general much changed, as the debate was mainly about new uses, not about intrinsic properties of the technology.

Nevertheless, this is exactly what makes the issue so interesting: because the changes remain rather subtle and implicit, their revelation becomes interesting. Probably, those changes can even better do their work because they do so unnoticed. Moreover, the radical changes that some predicted from. Similarly, the suspected eugenic stance that some feared in PGD turned out to be not much more than a bad dream: PGD is simply too burdensome to be toyed with. Because PGD offers no big steps forward - whatever direction, only small and marginal ones. Exactly for this reason, changes can proceed with relative ease. This is not to say that the debate was not a real and difficult debate, but it is to say that its outcome was again not much different from the situation before.

This offers an answer to the question of why the CU position cannot be argued for successfully. After all, the CU proposes decisions that are not that radically different from present reality, either. It is still quite surprising that a position that is so little counterfactual meets so much resistance. Thus, we need further explanation. This explanation can be found in the fact that, despite their near-factuality, the CU proposals are not compatible with the dominant forms of rationality. Saying that 99 plus I equals Ior is not far off the factual truth; yet it is very irrational. Whether or not we extend the use to heritable breast disease is only a small step from how things go today; however, not doing it seems irrational in the eyes of dominant forms of rationality. (This runs counter the difference between reasonable and rational that I introduced in section 2.3.5. However, even though all debate participants may adhere to the stance of reasonableness and 
accept that rationality is something more private, this is not the same as saying that the kind of 'public rationality' that underlies public speech is not being skewed by majority influences.)

Thus, positions of Christian origin are not too much repressed per se. Rather, they experience some repression because they are rendered irrational by the dominant forms of rationality - in this case, dominant styles of liberalism. Rather than explicitly silencing Christian voices - they are widely heard, after all - the concepts populating public speech receive their meanings from dominant forms of rationality, such that they poorly meet the meanings that the CU wants to attach to them. In this case, the meaning of heritable breast cancer is such that refusing to prevent it appears fairly irrational to most eyes - indeed not all eyes. This is in effect a suppression of Christian interpretations. The success of this dominance explains that explicit and contentious disqualifications of Christian visions are the exception rather than the rule.

This observation can first be extended to any religious vision, for the reasons given in subsection 6.4.2. And then Hinduism or Buddhism would have an even harder time in Dutch culture, in which Christianity in general is still main stream. (See also subsections I.2.2, 2.2.3 and 2.3.5 for reasons why religions have a hard time convincing in public.) And moreover, it can be extended to any minority vision: perhaps differences in conceptions of rationality are strongest between religious and secular positions, but certainly not limited to them. Between any two positions, differences may exist at the level of the most fundamental premises. This may concern for example our vision of human perception, or our vision of logical inference. These are indeed differences in our conceptions of rationality, see also page 2.3.3 for my idea of rationality. Clashes between them will generally amount to calling one another irrational. And then the majority draws the longest straws, as it has the best chances of enacting its forms of rationality and thus most influencing public speech and the concepts figuring in it.

\section{Review}

In this chapter, I have discussed a real political debate that had everything to it that we could expect. A controversy was sparked by a technological development. The debate became vivid as discussants felt the need to introduce private-ethical concerns. Those concerns were disqualified and purified away by others. Moreover, those concerns were hard to maintain against the background of earlier 


\section{Politics by All Means}

technological developments, that thus played their role in the purification. By giving meaning to embryos and diseases, PGD and IVF induced certain preferences in the debate. And by being there, they elicit certain choices rather than other ones. In short, this controversy showed how technology had an influence on scope, justification and content, and that it did so through both the hermeneutic and existential dimensions. And it showed that a specific technology is different before and after the controversy, and that this difference can only be understood from the wider picture that includes all relevant social and technical networks.

Two final remarks need to be made here. First, I have spoken unproblematically about technology and politics as if they were separate spheres, which is not in line with the ANT-oriented approach that I suggested in chapter 3. However, this seems to reflect the reality against which the controversy emerged, and it describes how the controversy itself was distributed over this background. The connections between technology and politics could be recognized, but only by the attentive eye that has been sharpened in the preceding chapters. Much remained below the surface. The second remark that I feel is important is the fact that I have spoken relatively little in terms of the hermeneutic and existential dimensions that I placed so central in the same chapter. That is again because the interactions with technology remained on a rather implicit level. And even though I may not have mentioned them too explicitly, they can be recognized: the hermeneutic dimension can be found specifically in the redefinition of the concepts I just discussed. And the existential direction is in the fact that from now on, every prospective parent carrying the genetic mutation for heritable breast cancer will in theory - have to wonder whether he or she will undergo PGD. 
IV Epilogue 



\section{Technological liberalism}

\subsection{The problem of progress}

This book has discussed the difficulties that modern liberal culture and technoscientific progress pose to one another. The central problem was identified as technoscientific progress sparking controversies which require a kind of talk that feels awkward in contemporary liberal politics. In particular, such progress requires us to discuss ethical topics in public that we are used to seeing as private. The present chapter will wrap up the answers I have found to the central problem, that is: how can we understand that the typical liberal way of dealing with pluralism of ideas of the good life, namely by splitting up ethics into public and private parts, becomes problematic in the face of progress in science and technology?

This problem is discussed here against a particular technological background. The technologies discussed in this book all relate directly to our human nature. Referring to enhancement, these technologies concern the manipulation of our nature, however abstract and futuristic their implementations may be at times. In the case of biobanks, these technologies concern the ultimate analysis of our nature, however idealistic and overpromising this may perhaps sound. And with preimplantation genetic diagnostics, both the manipulation and analysis are at issue, emanating the question of what society we want to shape and how it should relate to that human nature. My intent has not been to produce a normative critique of these technologies. I do not unconditionally want to stop them, nor have I tried to argue for their uncritical endorsement - though fairness demands to say that I am optimistic about most technologies and relatively unworried about the dangers they may carry. In fact, I think they offer many real promises towards

prosperity. My intent has however been to show how these technologies, by interfering with our nature and our conceptions of that nature, present difficulties that liberal democracy seems poorly prepared for.

The debates that I discussed are stylized. That is, in particular the discussions on enhancement and biobanks were only in part real discussions. What I presented was in fact an inventory of arguments from people that were only marginally arguing with one another. Moreover, those arguments were eclectically harvested 


\section{Politics by All Means}

from different contexts: different European countries were discussed, as well as the Canadian and US situation, without really differentiating between them. Thus, the discussions represent some 'generic liberal discourse', and therefore they produce conclusions that also pertain only to such a discourse. Nevertheless, I think the resulting overview is of philosophical value. And of course, the discussion of PGD adds a lot in this respect: this was an actual, situated, historical discussion in real politics against a liberal background.

I argued in chapter 2 that a pluralism of ideas of the good is necessary and desirable: the burdens of judgment justify that we abstain from pursuing a monist society, and only if a pluralism is sufficiently broad, will it be able to foster all reasonable comprehensive doctrines. In the same chapter, I showed that the actual implementation of this pluralism exhibits some ragged edges, and that it will be impossible to keep all citizens satisfied. In chapter 3 I argued that technoscientific progress offers a host of additional challenges to this structure. These challenges were observed and articulated drawing from various practices in part III. Indeed, it seemed that liberalism is poorly capable of dealing with difficulties produced by technoscientific progress. In this chapter, I will try to offer alternatives to the received form of liberalism, that do justice both to the laudability of liberal pluralism and to the complexity that a technoscientific culture offers.

\subsection{Liberal ideals}

I explained in chapter 2 that liberalism should be understood as an answer to the problem of how to achieve stability in a situation of a pluralism of mutually incompatible ideas of the good. In the early days of liberalism, the pluralism was predominantly a pluralism of religions. Today, liberalism concerns more than just that. It practically captures all that it takes to live an individually-shaped life. This liberalism is endorsed by most of us, as it promises to ensure a peaceful and stable society. This is more beneficial than a frenetic drive for a monolithic society, and more beneficial than having no society, that is a state of nature in which each person is only focused on furthering his or her own interests. The pluralist society is a collective interest shared by all citizens. In addition, this liberalism is presumed to be attractive to all persons, as it aspires to offer a justification for collectively-binding decisions that is neutral between different conceptions of the good. 
The primary structure of such a liberal pluralism takes the shape of a public and a private sphere. Both spheres are both decision spaces and sources of justification. The private sphere as a decision space provides a place where we can make decisions without being held accountable to other citizens or to the state. By contrast, the public sphere contains those actions that individuals and collectives are held accountable for, primarily by the state, but also by other citizens. We could say that assigning a decision to either sphere is to say who or what its subject is: the individual, or the collective.

The second element, the spheres as sources of justification, has perhaps assumed an even more prominent place in this book. The public sphere is the domain in which decisions are discussed and made, that are binding for all citizens. Against the background of a democratic society, such decisions require some form of democratic legitimization, both with respect to the decision itself and to its coercive effectuation. ${ }^{\mathrm{I}}$ That is to say, decisions in the public sphere require justifications that are publicly acceptable. And justifications that are not publicly acceptable, are likely to be convincing only in the private sphere, if at all.

The existence of those two spheres entails that issues are continually divided between the two. This is usually a matter of routine. We simply know that matters of taste are private, and traffic rules are public. However, sometimes, this distinction is not that obvious. In part III, I described many contestations of the divide, and I will come back to them shortly. Although Rawls adduces his burdens of judgement (see page 3I) in justification of a pluralism of ideas of the good, they do also on their own terms explain why the boundary between public and private is likely to be contested. In addition, I showed in part III that technoscientific change continually poses challenges to this boundary.

I explained that the difference between public and private can become explicit on three levels: the level of scope, the level of justification, and the level of content. The matter of scope concerns the question whether an issue belongs to the public or private spheres in terms of decision spaces. The matter of justification concerns which arguments we may adduce to support the decision, and thus relates to the public and private spheres as sources of justification. And finally, there is the content of a decision. This is its material outcome, and this again can be publicly coerced or left to private choice.

1 It can be argued that a democratic society need not be pluralist, and that a pluralist society need not be democratic. However, my investigation only concerns the typical Western pluralist democracy, without further justification of this choice. 


\section{Politics by All Means}

That we continually need to redefine the boundary between public and private, on each of these three levels, gives rise to a process that I have called purification: the process of defining things inside and outside politics. Purification primarily deals with the level of justification, but it cannot be seen apart from the levels of scope and content. In fact, purification is an essential element of politics and it takes place on the same level as politics itself: as liberal politics recognizes no higher authority than politics itself, it needs to establish its own rules. This includes the purification of arguments. And when things get difficult, this turns out to incur the accusations of fundamentalism and the like, even though there is no a priori reason why this should be so.

One of the mechanisms responsible for the difficulties is the fact that there are no a priori criteria of pertinence that tell whether arguments are appropriate. Instead, there are enacted clusters of ideas that make it, and others that are not successful. In addition, the matter of politics being its own authority, entails that the fuzzy criteria of pertinence that we actually use, are themselves the result of politics. What today is an object of discussion, will tomorrow be a precedent and provide a background against which tomorrow's problems are discussed. We may for example discuss today whether something is harmful or not, which will provide tomorrow's discussions on harm with a more accepted idea of harm: today's content will bear on tomorrow's scope and justification. It may appear somewhat relativistic that the concepts by means of which we structure society are themselves subject to continual modification. This is true in the sense that public justification today is different from public justification five or fifty years ago, but it is not to say that just anything goes. The lines of purification are contingent, not arbitrary. Modifying conceptions is hard work, because each discussant has different interests in rendering arguments appropriate or inappropriate. And therefore, the classification of arguments is itself hard work. And it would be naive to think that we can change them radically just over one night's sleep.

This relates to the fact that the condition of tolerance (see also page 29) is a source of disagreement rather than an appeasing arbiter. We need only tolerate things that are in themselves not that bad that we would urge their prevention by means of state power. But whether things are so bad is a question that we can only assess with reference to our comprehensive doctrine. In discussing this, we must transgress the public-private divide, and thus the whole matter of pertinence becomes explicit. Purification is then unavoidable. 
Political liberalism is the dominant vision today, concerning the divide between public and private, and the accompanying purification. It privatizes comprehensive doctrines and ideas of the good and admits them into the public sphere only under strict conditions. Thus, it ensures that collective decisions are based on political conceptions accessible to all. In recent history, this has proven to be a satisfying and successful way to deal with a pluralism of ideas of the good. It allows a society to leave its citizens as free as possible while at the same time providing a platform for deciding upon the many things that a state needs to have a normative position upon. But this book has shown that it does not work that well in practice, when technoscientific change invokes debate.

\subsection{Muddy debates}

Contrary to the liberal ideals sketched above, real debates sometimes fail to offer the comfort of a balanced discussion. We saw this in all cases, both on the normative level and on the level of the appropriateness of arguments. The cases contained all that we could think of: in addition to disputes over private choice and public responsibility, shifting concepts, disputes on public legitimacy and acceptance of arguments, and situations where existing concepts seem to change and where no alternative seems unproblematic. I will briefly recall elements from the cases here, and articulate how they deviate from the theoretical ideals of liberal debates. Moreover, I will explain once more how technoscientific progress is a source of trouble in the debate, and how it calls for the discussion of private ethics, which is at the same time problematic in public.

In general, the 'difficult debates' seem to develop along the following pattern. First, technoscientific change produces a situation that is anomalous in face of accepted normative frameworks. We don't know how to call it ethically figuratively speaking. That is, either the situation is so unprecedented that existing normative frameworks fail to give any advice at all, or they give advice that does not do justice to the real value of the novelty, at least in the eyes of some people. This means that either the normative frameworks need adaptation, or the novelty must be rejected. The latter is often not a real option. Novelties usually enjoy support, enough to make them impossible to simply reject. Moreover, they may have already materialized to some extent. Thus there will at least be an impetus to change the existing normative frameworks. 


\section{Politics by All Means}

This is when the second element comes in: changing (public) normative frameworks usually involves our comprehensive doctrines. As I argued in chapter 2, reestablishing public normativity and its boundaries generally involves parts of our normativity that are private. This is on the one hand a natural phenomenon, as we do this all the time. But it is also each time a source of tension, because of the pluralism that privatization was a solution for.

This has two important consequences. First, there is simply the possibility that some private normativities refuse to accept such change, both on the level of the normative content and on the level of the public-private divide. And second, this opens up the possibility that others consider these private notions to be inappropriate in public. Thus, because of this risk of inappropriateness, those adducing their private-ethical notions run the risk of calling onto themselves the blame of unreasonableness and irrationality. Such blames are exemplary for the vivid debates that we saw in part III.

A collective decision will generally produce a dissenting minority. A good democracy will allow such a minority to express its dissent. One particular motive through which it may do so, is by complaining that their arguments are excluded too easily. This is at least remarkable against the background of the recognition in chapter 2, by reference to Mill, that a minority may never be silenced. Apparently, below the obvious mechanism of a democracy enforcing a majority decision onto a minority, there is a mechanism that also suppresses the voices of dissent of that minority, or at least gives the minority the impression that their voices are not allowed to be heard. This is at odds with the liberal ideal.

What is more, similar to the difficulties that occur when expressing dissent from received public ethics, it seems to be difficult to deviate from the impetus of technoscientific change. Particularly, in the cases of enhancement and PGD, we saw that the critics of technology argued against both liberalism and the technologies involved. Those critics have to fight two powers, while proponents of technologies seem to have the received opinions about the lines of purification on their side. With biobanks this is not immediately clear, because support for biobanks often carries a critique of received ideas in liberalism. However, these critiques are in themselves highly congruent with the overall ideas of liberalism: that it requires some collective effort, to provide that we are optimally enabled to make decisions according to our individual moral understandings. 


\subsection{What the quarrel is all about}

The most straightforward class of normative disagreements is what I would call 'first-order' disagreements: disagreements that can be traced back to different normative stances, stemming from different comprehensive backgrounds. For example: whether enhancement endangers human dignity heavily depends upon one's conception of dignity, and in particular how this conception relates to the 'givenness' of life. Depending on this conception, enhancement may either endanger dignity, or rather serve it. The same holds for the way enhancement may serve or endanger justice: how one thinks that goods should be distributed in general precedes the question of how goods related to enhancement should be distributed. I showed that the ideas put forward in justification of enhancement build on the idea of making life better; what 'better' means in this context, is far from obvious and necessarily is bound up with private-ethical ideas. Only after settling that, can we discuss whether enhancement should be seen as the unjust treatment of our children, or rather as just another novel way for parents to do the best for their offspring.

In the case of PGD, much of the normative disagreement boiled down to balancing a discarded embryo against a life burdened with (carriership of) heritable breast cancer. People largely agreed that a life with breast cancer is bad, and that the embryo is something that we should treat with respect. However, balancing the two led different discussants to different conclusions. For some, the embryo is something that deserves, by its humanity or even its divine origin, that we fully protect it. Others think of it as disposable in very specific cases, the prevention of breast cancer being one of them. This matter is again a normative premise for the discussion of whether PGD is morally permitted or not.

Biobanks also turned out to raise delicate normative questions. Most prominent among those were questions of privacy and autonomy and questions of ownership. We may try to find a solution in the way that we typically deal with those issues: the answers that medical ethics provides for privacy and autonomy, and the answers that patents provide for ownership. However, many of the discussants felt that these answers would not suffice in the case of biobanks.

In addition, there is a second level of disagreement. At the basis of this normative disagreement, there is a mechanism directly related to technoscientific change. Some disagreements occur not simply because comprehensive doctrines collide, but because changes external to those doctrines enforce a repositioning 


\section{Politics by All Means}

of those doctrines. Below the level of normative disagreement, I articulated that technoscientific changes had the collateral effect of changing the concepts that populate our language. This is a fundamental problem. If concepts change, all talk turns awkward.

In the case of biobanks, the concept of ownership was destabilized. No precedent or existing cultural mechanism could be found that aligns comfortably with biobanks. In fact, by twisting the concept, biobanks were shown to render some principles obsolete that are firmly rooted in our culture: privacy, justice, and informed consent. Even if our comprehensive doctrines had fit well so far, they fail to do so any longer because technoscientific change has caused a mismatch between the received frameworks and the practical situation.

Similarly, I showed that enhancement increasingly enables us to manipulate our human nature. Considerations of justice may now pertain to human nature, which was unthinkable earlier. In such cases, justice is not just a matter of reconsidering how goods should be distributed, but also of reconsidering what those goods are in the first place. The latter is even more complex than the former, and accordingly requires even stronger reference to comprehensive doctrines.

And with PGD, it was feared by some that allowing this technology would change society's acceptance of people with diseases. Thus, the technology of PGD would change what it means to be a respected citizen, at least in the eyes of some. And perhaps more important, the status of the embryo was changed by the adjustment of policy on PGD. It was made one step less worthy of protection than it used to be. Regardless of whether one thinks this to be right or wrong, it cannot be seen apart from the socio-technical background of the Netherlands, in which IVF and abortion already had their regulated places. I argued that opponents of PGD found these established practices on their path. In this case it was not just one technology that produces a change, but rather a whole history of many technologies together.

This level of technoscientifically-induced change shows two things. To begin with, it shows that in general, existing moral routines failed to provide answers. This was what called for a discussion against the background of our complete comprehensive doctrines, including their private-ethical parts. This private element is what primarily causes friction. In addition, it shows that the technoscientific influence runs in two directions. On the one hand, it has a 'progressive' orientation in that it changes existing practices. It does so by inescapably introducing new 
configurations. And on the other hand, technoscientific influence works in a 'conservative' direction in that it establishes practices that are hard to modify once they are in place.

There is even a third level of disagreement that can be discerned: the level of what people (implicitly or explicitly) think of technology, either in general or in specific cases. Part of the visions reflect the confidence that technologies can be privatized and that they are beneficial in general. Such positions must presume that those technologies will satisfy the condition of tolerance, thereby holding on to an implicit, particular notion of this condition. They must presume that it will remain possible to live without the technology and that no significant proliferation and according societal pressure will occur. Accordingly, the effects of the technology are believed to be largely limited to the private sphere. Or, for that matter, one may argue exactly the opposite on each of these questions.

The claims that proponents of enhancement made, indeed largely fit the optimistic alternative of this picture. And the opponents made exactly the opposite claims. Certainly in the PGD debate, many of the opposing voices can be framed along the more pessimistic variant of these dimensions. They argued that the technology would become inescapable and thus against the privatizability of technologies. According to them, the technologies violate the condition of tolerance.

These underlying visions of technology explain why technology can play an important role, even if it is not (or not completely) developed into the stage of actual use. Technology sometimes takes the shape of an ideology: a set of abstract and concrete ideas, that are not exactly materially represented in the world today, but that largely shape our thoughts and actions, in part only implicitly. Of course, these ideas are intimately connected to the technologies that are here now: IVF and abortion in the case of PGD, large databases in the case of biobanks, and technologies in general in the case of enhancement; but often they do not coincide exactly. This is nevertheless clearly in line with the ANT approach that I suggested in chapter 3 .

\subsection{Purification by all means}

I proposed to see politics as a practice of purification. In order to convince a variety of different comprehensive doctrines, the arguments need to be sorted 


\section{Politics by All Means}

out, and only those that are convincing to all can remain. I argued that there are no $a$ priori rules to say which arguments are accepted and which are not, but rather that getting arguments in and out is hard work and an intrinsic element of politics at that. The dominant liberal style of this purification allows for relatively little reference to comprehensive doctrines. What we see indeed is that it takes continual effort to get unwanted elements out of the debate - or in, for that matter.

This answers one question that I posed in chapter 2: how we can tell in advance which arguments will be accepted and which will not. The answer is: we cannot conclusively tell in advance, but an educated guess would be that those ideas that most resemble the technoscientific conception of rationality have the best chances. That is, those arguments that can be corroborated by empirical enquiry; or that are clearly related to convincing harms; or that are clearly related to considerations of justice in its dominant conception; and so on. Again, God and dignity do not have the best cards in the present Dutch reality. This is all to say that the material definition of purification is strongly influenced by scientific rationality.

I argued that technoscience goes under a guise of neutrality, while at the same time a number of mechanisms keep it from being neutral. This concerns not only the level of normative considerations, but also the level of what can be said and what cannot. I observed that the proponents of enhancement had a host of rhetorical figures at their service. By appeals to the incremental nature of technoscientific progress, by rendering morality external to the realm of technoscience, and by pointing out precedents, the proponents tried to establish a neutral image of technoscience, while at the same time excluding arguments from the debate in a way quite similar to liberal purification.

I also observed that liberalism and technoscience have a preference for similar forms of knowledge, which I call immanent: claims that can be assessed and accepted by all human beings - as opposed to claims with a transcendent character that go beyond the observable material world, which often fail to convince between different comprehensive doctrines. Those immanent forms of knowledge are believed to serve neutrality. In liberalism, the neutrality is framed in terms of reasonableness. In technoscience the neutrality is framed in terms of value-free rationality. Thus, technoscience seems to produce a kind of circular legitimation: it is rational because it is value-free, and as it is value-free, it can serve as neutral input to making political decisions. And similarly, liberalism continuously reestablishes its own neutrality: as it is neutral, it will be accepted as the dominant way of 
making decisions, thus reinforcing its position, thus imposing its content onto what it means to be neutral. As technological and liberal purification coincide, it is likely that they mutually amplify their circular reinforcements. Thus, liberalism and technoscience go under similar veils of neutrality, and reinforce those by similar mechanisms. And in a way they are neutral, because they implicitly define neutrality.

This coincidence of technological and liberal neutrality finds its correlate in the observation that most of the critical stances towards technoscientific change also imply a critical stance to the typical liberal way of discussing ethical matters: the argument was frequently heard that the liberal vocabulary is too shallow to discuss such difficult matters. The difficulty of the matter is then often argued as a misjudgment of technology as unproblematic. Privatizing ethics turns out to be just as problematic as privatizing technologies.

There is at least some point in this critique: I argued that below the surface, technoscience does a lot more than it is willing to admit. I explained in chapter 3 that technoscience relates to us along a hermeneutic and an existential dimension. Along the first, technoscience tells us what to think, and along the second, it tells us what to do. Along these lines, technologies are just another player in purification. First, the hermeneutic influence of technology bears upon how plausible we think arguments are. In the PGD debate I argued that the existence of IVF and abortion has had an influence on how one can think about embryos in Dutch culture, and that therefore unconditional protection of embryos is harder to argue for. Biobanks and enhancement produced similar influences. And second, the existential dimension exerts weaker or stronger forces on what we do. This is one of the fears regarding enhancement: by existing, it may force us through social pressure to enhance our children, even if we disapprove of that. These two dimensions are detrimental to the neutrality of technoscience: both the existential and the hermeneutic dimensions offer possibilities for technoscience to express normativity.

By existing, either as artefact or as ideology, technoscience thus contributes to rendering some things speakable and other things unspeakable. After all, what is speakable and what is not, are enacted and narrative categories, and we saw that technoscience interferes in both our understanding and our actions. Therefore, technoscience bears on the purification of politics. This is remarkable, as I just explained that technoscience keeps up a neutral appearance. 


\section{Politics by All Means}

I offered an approach to technoscience in terms of actor-network theory (ANT). Central to this approach is that humans and non-human actors are assigned equal amounts of agency: what we see are collisions between actors and the effects of those collisions. It is not always possible to tell whether the effects are to be traced back to humans or to non-humans. Thus, any situation is the result of history in which controversies have been contested. These controversies have led to new configurations and connections, and these connections are what provide rigidity to the situation. This explains the conservative power in technoscience that I mentioned in section $7 \cdot 4$.

A similar conservative power in the realm of political thought is offered by the notion of the exemplary situation that I borrowed from Lolle Nauta (i984). This concept builds on the idea that solutions are solutions to temporally and spatially situated problems. In their own times and places, they are real solutions to real problems. But in different times and places, the solutions may appear less apt and less straightforward, or even plainly obsolete or wrong. I showed in the case of biobanks, that against the background of our present liberal society, giving up privacy and informed consent is close to a taboo, no matter how beautiful the promises of biobanks are. I argued how these mechanisms came to be rooted so firmly in modern society: they were initially devised as answers to serious problems in the - not so distant - past. But even though the genesis of the solution has faded somewhat, the solution itself can still be firmly in place. This produces a conservative purification of today's debate.

The assumed neutrality and rigidity that both liberalism and technoscience display, together with the fact that technoscience interferes in our normativity, brings me to what I have called the double bind of technoscience. On the one hand, technoscience keeps up the appearance of a neutral rationality and thus fights on the liberal side in the muddle of purification. It helps to repress a large part of the normativity. On the other hand however, technology brings about changes that are so radical at times, that it enforces exactly the kind of discussion that it seeks to repress: a discussion that requires reference to the private parts of our comprehensive doctrines, for all the reasons given in section 2.4. This was clearest in the debate on enhancement. The talk of enhancement urges a discussion on the life-ethical level because discussants are unable to reach agreement when keeping to political terms. But at the same time, it exports a rhetoric that does all to repress that life-ethical discussion. 
Indeed, neither along the hermeneutic nor the existential dimension, technology seems to keep to the boundaries between the public and the private sphere as we happen to have constructed them. Thus, on the one hand, technoscientific changes have an influence on our lives, including those parts of our life that are subject to our private ethics. On the other hand, our ways of doing politics do not allow much room for those private-ethical considerations to be spoken out loud. This is a delicate issue: indeed, neither Rouvoet nor Kass wanted to change existing morality; rather, they were forced to express their private-ethical convictions in public because the 'world outside' suddenly tried to change the morality that they earlier had consented to. That is, they do no longer agree to disagree upon certain issues, because they cannot from within their comprehensive doctrines. It was not this comprehensive doctrine that became unreasonable, but the friction and the accusation of unreasonableness were occasioned by a change in public morality.

There is one more mechanism inherent to purification, is what I have called the dialectics of purification. That is, purification is likely to produce its own countermovement. It is nearly inevitable, that if we try to move somebody or something out of the debate, he or she or it will resist. And if this actor is not powerful enough by itself, it is still possible that there are others with similar interests, who feel motivated to line up with the suppressed ally. The other way round, if something is moved into the debate, there will probably be actors who have an interest in keeping it out. I have observed two different forms of dialectics. First, we see a liberal purification that incites its countermovement. And second, we see that technoscientific change produces the exclusion of certain arguments, indeed inciting a countermovement of its own.

This double dialectical mechanism explains why we see private ethics in public all the time. Exactly because technology and liberalism enact a preference for certain arguments, conceptions of life ethics surface. Indeed, purification is not that successful. It might be successful in making some things harder to argue for, but it seems to lack effectiveness in conclusively silencing classes of arguments. Some arguments will meet more resistance than others, but most are heard nevertheless. After the media exposure that orthodox Christians received in the Dutch PGD debate, they cannot convincingly claim not to be heard. Fair enough, our decisions are nevertheless based upon majority vote, which overrules the minority and its heartfelt objections. Yet somehow, the objections have been heard - though sometimes not without being accused of irrationality or unreasonableness. 


\section{Politics by All Means}

This brings us to a question in conclusion to this book: how can we do better, if liberalism seems incapable of delivering its promise of not suppressing and silencing minority opinions? That is, even though minority opinions are apparently voiced all the time, they have a hard time holding up against the dominant technoscientific and liberal backgrounds. True neutrality seems lacking in both respects, and we may be able to gain something if at least this neutrality can be framed more convincingly.

\subsection{Liberalism or politics, technology or change?}

Before suggesting a solution to the problem of non-neutrality in the final section, I will discuss in this penultimate section some options that I am not convinced are viable. The difficulties observed so far may suggest some answers, not all of them equally fruitful. Nevertheless, there may be something to learn from them.

First, observing that technoscientific change is the cause of many frictions opens up the question of whether such frictions occur only in the case of technological progress, or rather that they can occur in any kind of change. Clearly, the vulnerability of politics and ethics to become unstable when dealing with technoscientific change is not dependent upon technology. Indeed, such instability is not limited to technological progress, as it does not take a steam engine to alter concepts and have politics baffled. Social and environmental changes may do just the same. The moral order has always been subject to change, and this has indeed always caused friction and controversy. We should however realize that change has probably never been as turbulent as it is in today's technological era. Moreover, technology is special in that it boasts a neutral appearance while hiding a significant normative potential; with other kinds of change, for example social change, the normative dimension may be more clear and explicit upfront. Thus, while technology is not a necessary condition for controversy, it is certainly a good candidate.

Second, the question could be raised of whether the problems that technological progress produces for politics are strictly restricted to liberalism - that is, today's dominant liberal style of political purification - or whether they would also occur in other forms of politics. The answer is again easy: no, the fact that technological change perturbs the political order is likely to affect any implementation of that political order and its practice of purification - not just the liberal implementation 
of it. ${ }^{2}$ Indeed, technological change always induces changes in our ideas, vocabularies, conceptions and morals, that run the risk of colliding with existing practices, morals, and habits. It always leads to a rearrangement of the lifeworld, which is comprised of more than only political and ethical discourses, and certainly more than just the liberal subsets of these. Nevertheless, since liberalism tends to privatize a lot, we must recognize that it may be more vulnerable than other streams in political philosophy.

One suggestion could be raised at this point: that we should trade our liberal purification for a communitarian approach, because that is more likely to be successful as it tends to privatize less. Possibly, such an approach would be less problematic with respect to the boundary between public and private, as we observed with technologies. However, while indeed a communitarian approach is less likely to be confronted with private considerations entering the public sphere - simply because it privatizes less - we have no reason to believe that communitarianism is better equipped for dealing with issues that perturb the language in which those issues must be dealt with. The monstrosity that technologies produce in face of the public-private distinction (see section 7.3, as well as page 89 about monstrosity) cannot simply be eliminated by just another approach to this public-private distinction. That is, choosing other categorizations does not eliminate the fundamental difficulty of categorizing some things. Nor does it change the fact that such monsters are able to mould the categorization.

There is nevertheless one thing that we may learn from the communitarian critique of liberalism: that there might be a point in having a collective vocabulary for discussing ethics, indeed because the disturbance caused by technology affects both public and private spheres. However, the alternatives offered by communitarians seem by their more comprehensive public morality unable to deal properly with the multitude of opinions on the good life, that I argued in chapter 2 to be desirable. Thus, we must look for a different solution: one that does justice to the destabilization that technology induces in our lifeworld, particularly of the boundary between public and private; that does justice to a pluralism of ideas of the good that liberalism indeed wants to foster; but that also mends the suspected non-neutrality in both the liberal debate and in technoscientific rationality.

2 This presumes that there is purification between public and private. However, this seems justified as even the purest communitarians recognize the existence of some private sphere. And even the most extreme libertarians recognize some public sphere. In addition, political philosophies that do not recognize a private sphere seem way out of the scope of this book. 


\section{Politics by All Means}

\subsection{Liberal technology}

The first step towards a social embedment of technoscience that aligns more successfully with political-liberal ideals is a revision of the burden of proof. I argued that the accusations of irrationality and unreasonableness were in most cases not to be explained as essentially connected to the accused positions, but rather to the fact that (mostly technoscientific) change came to them from within the public realm. This suggests that we should place the burden of proof with the initiators of the change, instead of demanding that the opponents use clear terms - a criterion that I argued does not live up to its neutral connotation - to explain how the change is possibly bad to them. Rather, the proponents should supply a justification for how they think the normative impact of the change can be justified.

The second step then is to recognize that this change not only concerns the public forms of ethics, but also possibly the private forms. At issue are both the notion of the private sphere as a decision space, and the notion as a source of justification. The latter is especially relevant as I observed that we typically need our private-normative ideas to shape the boundaries of the public sphere: the condition of tolerance. This entails that we cannot discard the private-ethical concerns too easily as irrelevant to public consideration. This of course carries the hazard of initiating talks that cannot be concluded, because the starting positions of discussants are fundamentally irreconcilable. This means that in the end, decisions will have to be taken by majority vote. This inherits from today's situation that the minority will have to accept a decision they do not agree with, but it mitigates the current situation on the dimension of suppressing the dissenting voices of those minorities.

And third, we need to recognize the impact of technoscientific change on whether things can be discussed or not in public, and on what those things actually mean. While the view of liberalism as a system in which many ideas of the good can flourish is kept up, I argued that it sometimes resembles a mud fight that silences some arguments and amplifies others. In addition, I showed that technoscientific elements influence the balance of what can be argued and what cannot. Moreover, confusion results from the changes in the meaning of concepts that go by unnoticed. Thus, the burden of proof is augmented by the demand for justifying changes in what can be said. This third step thus concerns the criteria of pertinence of arguments, whereas the second concerns the normativity itself. 
Indeed, one important thing that both liberalism, ethics of technology and technology assessment, seem to have paid too little attention to so far, is how technoscientific change relates to the public acceptance of discussing certain issues. There is something unfair to that. Liberalism pretends to harbor many ideas of the good, but fails to grant that all ideas of the good can properly defend themselves. That is, it pretends to have $a$ priori rules that grant all their say, while these rules fail in practice - quite often owing to technoscientific progress. Moreover, these rules that guide our practice, are continually transformed by technoscientific change.

I argued that the dialectics of purification, both in their liberal and their technoscientific origin, are responsible for the mud fights: they are the natural reaction of suppressed voices. This justifies two conclusions. First, it means that there is a justification for introducing a technology assessment with a wider scope than we have now, because the mud fights we see now are hardly desirable. And second, we may expect actors to recognize the value that such a broadened assessment yields. That is, even the proponents of technoscientific changes can benefit from a better discussion, as it will allow them to ensure a better social embedment for the technologies they advocate. And the opponents of change are likely to see in it an opportunity of voicing their dissent.

We could think of this as an institutionalized fundamental mode in the debate, as opposed to its normal mode. The normal mode entails a discussion in which concepts are fairly unproblematic and their received conceptions taken for granted. Contrarily, in the fundamental mode, the concepts themselves are put onto the agenda, because discussants suspect that they are used in a way detrimental to their interests We see that the debate sometimes enters a crisis, especially when existing notions, and particularly existing justifications, are twisted. We had better canalize this crisis. Moreover, as I argued that the resulting content of today's politics will provide (part of) the means for tomorrow's purification, the option of leaving the crisis unsettled is not that attractive. The crisis requires our engagement. Keeping these two modes of debate strictly separated would be to step in the modernist pitfall of purification: we are likely to be colonized by unclassifiable hybrids. Its value will remain in the recognition that we need fundamental discussions at times.)

As a small thought experiment, we could try to retake the PGD controversy in this way. It would first demand that we explicate how normative categories are different between the time before PGD and the time after PGD. We would then 


\section{Politics by All Means}

observe that there is been a shift in te meaning of the embryo. Even though it is still legitimate to think of it as either just a lump of cells or a full person, the former has become easier and the latter harder to argue for, if existent practices express it thus. By the introduction of PGD, the embryo has become a bit more disposable. It has become less of a full person.

The next question to ask then is whether and how this change can be justified. We need to account for the fact that public speech has been twisted, such that the embryo-as-a-full-person is harder to defend. Even though this vision has been voiced in the debate, and has been attacked and rebutted, I have not found any indication that it was properly explained how this vision has been rendered less tenable by technological progress. Insofar as it has been linked to technological progress, it was mostly poorly informed and therefore easily rebutted. For example, it was argued in a slippery-slope vein that PGD would lead us towards a perfectionist society. This argument was little convincing and simply discarded as failing to do justice to our free will and the authority of our ethics. The argument did not last long, and it failed to grasp the more delicate shifts that I have articulated in this book. True enough, it is likely that many will accept this shift as the cost of preventing heritable breast cancer, or at least the freedom to do so - there is not much reason to question the actual outcome of democratic decision making. Nevertheless, demanding that people explicitly subscribe to the shifts involved is already one level more contemplative than the actual 2008 debate: the latter displayed a collision of normative positions, but not much of a justification of them, let alone a justification of the shift in the concepts underlying those positions.

In addition, the crisis mode of debate can be further implemented by demanding that we also justify the shift in the possibility for certain positions to be voiced: it deserves articulation that pro-life positions will become less tenable, if PGD becomes an accepted technology. And indeed, we may demand that the proponents of PGD explain how the change is immune to the danger of creating a perfectionist society. Indeed, this danger has been argued to be negligible, but it has not explicitly been related to the slightly new meaning that has been given to the embryo. In fact, seeing this danger as negligible depends upon seeing the embryo as a disposable lump of cells. Against the alternative background of seeing the embryo as a full person, a society practicing PGD is already plain perfectionist. Even though the vast majority is willing to accept the change in the meaning of 
the embryo, it could have been explicated better how the perfectionist society can be avoided and how this can be reconciled with disposing embryos. This would at least have added some depth to the debate.

Thus, the suggested solution surpasses a deliberative model of democracy. Deliberative democracy allows for anything to be spoken, provided that it takes place in a situation free from coercion. Moreover, one criterion to deliberative democracy is that coerced decisions are to be justified in terms acceptable to those on whom the decisions are imposed. The suggested model goes beyond that, in that it needs not only to justify the decision itself, but also demands account of how this justification is transformed. In the end, this may produce quite similar winners and losers in the debate as we see them today. Indeed, the added value of this book is not in an intervention at the level of justification or at the normative level, but on the level of transformation of the justification. This transformation is technological to the bone. Adding some fairness there was worth the effort of this book. 


\section{Politics by All Means}




\section{Bibliography}

Agar, N. (2004), Liberal Eugenics - In Defence of Human Enhancement, Blackwell Publishing, Malden MA.

Akrich, M. (I992), The de-scription of technical objects, in: W. E. Bijker and J. Law (eds.), Shaping Technology/Building Society, MIT Press: 205-224.

Andorno, R. (2004), 'The right not to know: an autonomy based approach', in: Journal of Medical Ethics 30: 435-440.

Andrews, L. B. (2002), 'Genes and patent policy: rethinking intellectual property link rights', in: Nature Reviews Genetics 3(Oct): 803-808.

Andrews, L. B. (2006), 'The Patent Office as Thought Police', in: The Chronicle of Higher Education.

Angrist, M. and Cook-Deegan, R. M. (2006), 'Who Owns the Genome?', in: The New Atlantis, a Journal of Technology and Society 2006(Winter): 87-96.

Annas, G. J. (I993), 'Privacy rules for DNA databanks. Protecting coded 'future diaries", in: Journal of the American Medical Association 270(I9): 2346-2350.

Annas, G. J. (2004), Genetic privacy, in: D. Lazer (ed.), DNA and the criminal justice system: the technology of justice, MIT Press, Cambridge MA.

Barbour, V. (2003), 'UK Biobank: a project in search of a protocol?’, in: The Lancet link 36I(9370): I734-I738.

Baylis, F. and Robert, J. S. (2004), 'The inevitability of genetic enhancement technologies', in: Bioethics I8(I): I-26.

BBC (2003), 'Designer Baby' born to UK couple, http://news.bbc.co.uk/I/hi/uk/30026Io.stm, accessed 2009.02.05.

Beauchamp, T. L. and Childress, J. F. (2003), Principles of biomedical ethics, $5^{\text {th }}$ edn, Oxford University Press, Oxford.

Berg, K. (200I), 'The ethics of benefit sharing', in: Clinical Genetics 59: 240-243. 


\section{Politics by All Means}

Berlin, I. (I958), Two Concepts of Liberty, Inaugural lecture, Oxford University.

Bijker, W. E. (I995), Democratisering van de Technologische Cultuur, Inaugural lecture, University of Maastricht.

Blackburn, S. (200I), Being good: a short introduction to ethics, Oxford University Press, Oxford.

Borgmann, A. (I984), Technology and the character of contemporary life: a philosophical inquiry, University of Chicago Press, Chicago.

Bosman, F. G. (2008), 'Embryoselectie ondergraaft solidariteit', in: Trouw (2008.05.29): Vog.

Bostrom, N. (2003), The Transhumanist FAQ - A General Introduction, http://www.transhumanism.org/resources/faq.html, accessed 2009.02.06.

Bostrom, N. (2005), 'In Defense of Posthuman Dignity', in: Bioethics I9(3): 202-2I4.

Bowker, G. C. and Star, S. L. (I999), Sorting things out: classification and its consequences, Inside technology, MIT Press, Cambridge MA.

Brock, D. W. (I998), Cloning Human Beings: An Assessment of the Ethical Issues Pro and Con, in: M. C. Nussbaum and C. R. Sunstein (eds.), Clones and Clones, W.W. Norton \& Company, New York: I4I-I63.

Buchanan, A., Brock, D. W., Daniels, N. and Wikler, D. (2000), From chance to choice: genetics and justice, Cambridge University Press, Cambridge.

Busby, H. (2006), 'Biobanks, bioethics and concepts of donated blood in the UK', link in: Sociology of Health Q Illness 28(6): 850-865.

Busby, H. and Martin, P. (2006), 'Biobanks, National Identity and Imagined Communities: The Case of UK Biobank', in: Science as Culture I5(3): 237-25I.

Cambon-Thomsen, A., Rial-Sebbag, E. and Knoppers, B. M. (2007), 'Trends in ethical and legal frameworks for the use of human biobanks', in: European Respiratory Journal 30(2): 373-382.

Campbell, J. and Stock, G. (2000), A Vision for Practical Human Germline Engineering, in: J. Campbell and G. Stock (eds.), Engineering the Human 
Germline - An Exploration of the Science and Ethics of Altering the Genes We Pass to Our Children, Oxford University Press, New York / Oxford: 9-I6.

Cassier, M. (2002), 'Private property, collective property, and public property in link the age of genomics', in: International Social Science Journal 54(I): 83-98.

Castells, M. (I996), The rise of the network society, The information age; vol.I, Blackwell, Oxford.

Castle, D. and DeBusk, R. (2008), 'The Electronic Health Record, Genetic Information, and Patient Privacy', in: Journal of the American dietetic association 2008: I372-I374.

Center for Genetics and Society (2006), A Decade After Dolly, Center for Genetics and Society, Oakland.

Chadwick, R. (I999a), 'Genetics, choice and responsibility', in: Health, risk Q society $\mathrm{I}(3): 293-300$.

Chadwick, R. (I999b), 'The Icelandic database - do modern times need modern sagas?', in: British Medical Journal 3I9: 44I-444.

Chadwick, R. (2003), 'Genomics, Public Health and Identity', in: Acta Bioethica IX(2): 209-2I8.

Chadwick, R. and Berg, K. (200I), 'Solidarity and equity: new ethical frameworks for genetic databases', in: Nature Reviews Genetics 2: 318-32I.

Chadwick, R. and Wilson, S. (2004), 'Genomic Databases as Global Public Goods?', in: Res Publica Io(2): I23-I34.

ChristenUnie (2008), Standpunten $A t / m Z$, http://www.christenunie.nl/nl/standpuntentotaal, accessed 2008.I2.I9.

Collingridge, D. (I980), The Social Control of Technology, St.-Martin's Press, New York.

Dehue, T. (200I), 'Establishing the experimental society: The historical origin of social experimentation according to the randomized controlled design', in: American Journal of Psychology II4(2): 283-302.

Dekker, C. (2007), 'Stel grenzen aan het gesleutel aan de mens', in: NRC Handelsblad (2007.II.Io): I3. 


\section{Politics by All Means}

Dennett, D. C. (I995), Darwin's Dangerous Idea - Evolution and the Meanings of Life, Touchstone / Simon and Schuster, New York.

Dennett, D. C. (2003), 'The Mythical Threat of Genetic Determinism', in: The Chronicle of Higher Education .

Desmet Live (2008), Desmet Live, radio programme, http://cgi.omroep.nl/cgibin/streams?/ikon/desmetlive/05-20-08/debat.wmv, accessed 2009.0I.22.

Dickenson, D. (2004), Het eigendomsrecht op eicellen, in: M. Huijer and K. Horstman (eds.), Factor XX, Boom, Amsterdam: 153-169.

De Die-Smulders, C. E. M., Land, J. A., Dreesen, J. C. F. M., Coonen, E., Evers, J. L. H. and Geraedts, J. P. M. (2004), 'Resultaten van Io jaar preïmplantatiegenetische diagnostiek in Nederland', in: Nederlands Tijdschrift voor Geneeskunde I48(50): 249I-2496.

Van Dijck, J. (I998), Imagenation: popular images of genetics, New York University Press, New York.

Van Dijk, J. A. G. M. (I99I), De netwerkmaatschappij: sociale aspecten van nieuwe media, Bohn Stafleu Van Loghum, Houten.

Dobson, R. (2003), “'Saviour Sibling” is born after embryo selection in the United States', in: British Medical Journal 326(7404): I4I6.

Dubbeld, L. (2004), The regulation of the observing gaze: privacy implications of camera surveillance, Phd thesis, University of Twente.

Einsiedel, E. (2003), Whose Genes, Whose Safe, How Safe? - Publics' and professionals' Views of Biobanks, The Canadian Biotechnology Advisory Committee.

Ephimenco, S. (2008), 'Pijl en boog', in: Trouw (2008.05.3I): 2-3.

Etty, E. (2008), 'Krijg dan maar borstkanker', in: NRC Handelsblad (2008.06.03).

Everett, M. (2003), 'The social life of genes: privacy, property and the new genetics', in: Social Science Q Medicine 56(I): 53-65.

Evers, J. L. H. (2008), 'Rouvoet haalt gelijk over de rug van zieken', in: $N R C$ Handelsblad (2008.06.03). 
Feenberg, A. (I99I), Critical Theory of Technology, Oxford University Press, New York / Oxford.

Feenberg, A. (I999), Questioning technology, Routledge, London.

Feenberg, A. (2002), Transforming technology: a critical theory revisited, Oxford University Press, New York.

Fox, D. (2007), “The illiberality of 'liberal eugenics”, in: Ratio XX(I): I-25.

Fukuyama, F. (2002), Our Posthuman Future - Consequences of the Biotechnology Revolution, Farrar, Straus and Giroux, New York.

German National Ethics Council (2004), Biobanks for Research - Opinion, Nationaler Ethikrat (German National Ethics Council), Berlin.

Gieryn, T. F. (1983), 'Boundary Work and the Demarcation of Science from Non-Science: Strains and Interests in Professional Ideologies of Scientists', in: American sociological review: official journal of the American Sociological Society, 48(6): 78I-795.

Goslinga, H. (I995), 'We moeten concreter aangeven waaruit een noodsituatie bestaat', in: Trouw (I995.I0.I9).

De Grey, A. D. N. J. (2005), 'Life extension, human rights, and the rational refinement of repugnance', in: Journal of Medical Ethics 3I: 659-663.

Habermas, J. (I995), 'Reconciliation through the Public Use of Reason - Remarks link on John Rawls's Political Liberalism', in: Journal of Philosophy 92(3): IO9-I3I.

Harris, J. (2004), On cloning, Thinking in action, Routledge, London / New York.

Harris, J. (2007a), Enhancing Evolution: The Ethical Case for Making Better People, Princeton University Press, Princeton NJ.

Harris, J. (2008), 'Personal communication', in: NWO Masterclass at Tilburg University (2008.06.30).

Harris, S. $(2007 b)$, 'From cradle to grave', in: Engineering a Technology 2007(May): 38-4I.

Hayden, C. (2007), 'Taking as Giving: Bioscience, Exchange, and the Politics of Benefit-sharing', in: Social studies of science: an international review of research in the social dimensions of science and technology 37: 729-758. 


\section{Politics by All Means}

Health Council (2006), Preimplantatie genetische diagnostiek en screening, Health Council of the Netherlands, The Hague.

Heerma van Voss, S. and Reerink, A. (2008a), "Geloof is een andere vorm van wetenschap' - Minister André Rouvoet over coalitiepolitiek, geloven en seculiere intolerantie', in: NRC Handelsblad (2008.07.26): 4-5.

Heerma van Voss, S. and Reerink, A. (2008b), 'Van nuanceverschil tot rel - Ophef over embryoselectie gesust na inmenging van Balkenende', in: NRC Handelsblad (2008.05.30): 3 .

Heerma van Voss, S. and Stokmans, D. (2008), “Wij fanaten en tirannen? Ongelofelijk", in: NRC Handelsblad (2008.06.07): 4-5.

Heller, M. A. and Eisenberg, R. S. (I998), 'Can Patents Deter Innovation? The Anticommons in Biomedical Research', in: Science 280: 698-70I.

Herderschee, G. (2008), “Gezondheid niet overwaarderen”, in: De Volkskrant (2008.05.28): 3 .

Herderschee, G. and Sitalsing, S. (2008), 'De moraal van de ChristenUnie wint Wat bezielde Jet Bussemaker om embryoselectie op borstkanker goed te keuren?', in: De Volkskrant (2008.05.31): 3.

Het Parool (2008a), 'Die ziekte kan de familie uit - Prof. Evers opgelucht nu moeder kind kan krijgen zonder borstkankergen', in: Het Parool (2008.05.28): 5 .

Het Parool (2008b), 'Vicepremier Rouvoet woedend op Bussemaker;

Staatssecretaris heeft geen overleg gepleegd in kabinet over voorstel', in: Het Parool (2008.05.30): 2.

Hume, D. (I740), A Treatise of Human Nature - An Attempt to introduce the experimental Method of Reasoning into Moral Subjects.

Ihde, D. (I990), Technology and the lifeworld - from garden to earth, The Indiana series in the philosophy of technology, Indiana University Press, Bloomington IND.

James, B. (I997), 'Cloning Breeds Loathing and Fascination: The Trouble With Dolly', in: International Herald Tribune, Global Edition of the New York Times (I997.02.28). 
Jelsma, J. (1992), Technology and the role of ethics: a question of theory or a question of practice?, in: A. Musschenga, B. Voorzanger and A. Soeteman (eds.), Morality, Worldview and Law, Van Gorcum, Assen/Maastricht: 297-306.

Jochemsen, H. (1999), Een mens is meer dan zijn genen alleen, in: A. Kalden and M. van Zwieten (eds.), Ons gescreende lichaam - Kansen en risico's van de genetica, Uitgeverij Balans, Amsterdam: I07-II9.

Jochemsen, H. (2003), Grenzen aan de manipulaties - Een bezinning vanuit christlijk perspectief, in: C. Hillekens and K. Neuvel (eds.), Kind naar keuze Naar een nieuwe eugenetica?, Meinema, Zoetermeer: 47-64.

Kallenberg, F. (2008), 'Mist rond $\mathrm{CO}_{2}$-afvang', in: Milieudefensie Magazine 2008(5): 5 .

Kass, L. R. (1997/1998), 'The Wisdom of Repugnance', in: New Republic 2I6(22): 17-26. Page numbers refer to the 1998 revised reprint in Leon R. Kass and James Q. Wilson, The ethics of human cloning, AEI Press, Washington DC, pp. 3-59.

Kass, L. R. (1999), 'The Moral Meaning of Genetic Technology', in: Commentary I999(Sep): 32-38.

Kass, L. R. (2002a), Human Cloning and Human Dignity: an Ethical Inquiry, The President's Council on Bioethics, Washington DC.

Kass, L. R. (2002b), Life, liberty, and the defense of dignity: the challenge for bioethics, Encounter Books, San Francisco.

Kass, L. R. (2004), Reproduction and responsibility: The regulation of new biotechnologies, The President's Council on Bioethics.

Kass, L. R. (ed.) (2003), Beyond Therapy - Biotechnology and the Pursuit of Happiness, The President's Council on Bioethics, Washington DC.

Van Keken, K. (2008), 'De kastjes van het CDA verontrusten de oppositie Accent 'Asobox' voor wegpiraten', in: De Volkskrant (2008.09.23).

Kettis-Lindblad, A., Ring, L., Viberth, E. and Hansson, M. G. (2005), 'Genetic research and donation of tissue samples to biobanks. What do potential 


\section{Politics by All Means}

sample donors in the Swedish general public think?', in: European Journal of Public Health I6(4): 433-440.

Kirejczyk, M., Van Berkel, D. and Swierstra, T. E. (200I), Nieuwe voortplanting: afscheid van de ooievaar - Sociaal-hisotrische en normatief-politieke aspecten van de ontwikkeling van voortplantingstechnologie in Nederland, Studie 44, Rathenau Instituut, The Hague.

Latour, B. (1987), Science in action - how to follow scientists and engineers through society, Harvard University Press, Cambridge MA.

Latour, B. (I993a), La clef de Berlin et autres leçons d'un amateur de sciences, Éditions la Découverte, Paris.

Latour, B. (I993b), We have never been modern, Harvard University Press, Cambridge MA.

Latour, B. (I998), On Recalling ANT, in: J. Law and J. Hassard (eds.), Actor Network Theory and after, Blackwell.

Lever, A. (200I), 'Ethics and the Patenting of Human Genes', in: The Journal of Philosophy, Science Q Law I.

Locke, J. (1690), The Second Treatise of Civil Government.

Lukes, S. (1989), Making Sense of Moral Conflict, in: N. L. Rosenblum (ed.), Liberalism and the moral life, Harvard Univeristy Press: I27-I42.

MacIntyre, A. (I98I), After virtue: a study in moral theory, 2nd edn, University of Notre Dame Press, Notre Dame IND.

Macklin, R. (2002), Cloning and Public Policy, in: J. Burley and J. Harris (eds.), A Companion to Genethics, Blackwell, Malden MA: 206-2I5.

Macklin, R. (2003), 'Dignity is a useless concept - It means no more than respect link for persons or their autonomy', in: British Medical Journal 327(7429): I4I9-I420.

Maher, B. (2008), 'Poll results: look who's doping', in: Nature 452: 674-675. link

Van Merkerk, R. O. and Van Lente, H. (2005), 'Tracing emerging irreversibilities link in emerging technologies: The case of nanotubes', in: Technological Forecasting and Social Change 72(9): Io94-IIII. 
Merton, R. K. (I942), 'Science and Technology in a Democratic Order: The Ethos of Science', in: Journal of Legal and Political Sociology I: II5-26.

Ter Meulen, R. (2006), The enhancement of human capacities by medical and biological technologies - Will we be better off?, Inaugural lecture, University of Bristol.

Miah, A. (2008), Justifying Human Enhancement: The Accumulation of Biocultural Capital, in: S. M. E. Wint (ed.), Perspectives on Our Ethical Future: Boundaries to Human Enhancements, Royal Society for the encouragement of Arts, Manufactures and Commerce, London.

Midgley, M. (2000), 'Biotechnology and Monstrosity - Why We Should Pay Attention to the "Yuk Factor", in: The Hastings Center Report 30(5): 7-I5.

Mill, J. S. (I859/I99I), On Liberty, Oxford University Press, Oxford.

Mitcham, C. (1987), 'The Love of Technology Is the Root of All Evils', in: Epiphany Journal 8(I): I7-28.

Mitcham, C. (1997), Thinking Ethics in Technology - Hennebach Lectures and Papers 1995-1996, Colorado School of Mines.

Mulhall, S. and Swift, A. (1992), Liberals and Communitarians, Blackwell Publishers, Cambridge MA.

Musschenga, A. W. (1992), Politieke moraal en de vraag naar kwaliteit van leven, in: H. Schaeffer (ed.), Handboek Godsdienst in Nederland, Amersfoort: 280-292.

Máxima, Princess of the Netherlands (2007), Toespraak bij de presentatie van bij de presentatie van het WRR-rapport Identificatie met Nederland, September 24, 2007, The Hague.

Naser, C. (1999), High Speed Genetic Testing Technology and the Computerization of the Medical Record, in: A. K. Thompson and R. F. Chadwick (eds.), Genetic Information, Springer US: I05-I20.

Nauta, L. (1984), 'Historical roots of the concept of autonomy in Western philosophy', in: PRAXIS International I984(4): 363-377. 


\section{Politics by All Means}

Niermeijer, M. F., De Die-Smulders, C. E. M., Page-Christiaens, G. C. M. L. and De Wert, G. M. W. R. (2008), 'Erfelijke kankersyndromen en kinderwens: ouders en politiek in dialoog over pre-implantatiegenetische diagnostiek', in: Nederlands Tijdschrift voor Geneeskunde I52(27): I503-I506.

Nussbaum, M. C. (2004), Hiding from humanity: disgust, shame, and the law, Princeton University Press, Princeton NJ.

Ossorio, P. (2002), Legal and Ethical Issues in Biotechnology Patenting, in: J. Burley and J. Harris (eds.), A Companion to Genethics, Blackwell.

Pálsson, G. and Rabinow, P. (200I), 'The Icelandic genome debate', in: Trends in biotechnology I9(5): I66-I7I.

Parelsnoer Initiatief (2008), Kaderreglement v. 11.0, http://www.parelsnoer.org/uploaded/FILES/htmlcontent/Documenten/ Kaderreglement\%20viı.o.pdf, accessed 2009.02.05.

Petersen, A. (2005), 'The metaphors of risk: Biotechnology in the news', in: Health, risk \& society 7(3): 203-208.

Philipse, H. (2008), 'Rouvoets worsteling met geloof en public reason', in: NRC Handelsblad (2008.07.29): 7.

Pijlman, F. T. A., Krul, J. and Niesink, R. J. M. (2003), Uitgaan en veiligheid: feiten en fictie over alcohol, drugs en gezondheidsverstoringen, Trimbos Instituut, Educare Groningen, Utrecht.

Pinker, S. (2008), 'The Stupidity of Dignity', in: The New Republic .

Plasterk, R. H. A. (2000), Leven uit het lab, Prometheus / Ooievaar, Amsterdam.

Plasterk, R. H. A. (200I), 'De kloon-oorlog', in: De Volkskrant (200I.o8.Io): CI.

President's Commission (I98I), Defining Death, President's Commission for the Study of Ethical Problems in Medicine and Biomedical and Behavioral Research, Washington DC.

Raad voor Maatschappelijke Ontwikkeling (2004), Humane genetica en samenleving - Bouwstenen voor een ander debat, Advies 29, Raad voor Maatschappelijke Ontwikkeling, The Hague. 
Rawls, J. (I97I/ı999), A Theory of Justice, revised edn, Harvard University Press, Cambridge MA.

Rawls, J. (I993), Political Liberalism, Vol. 4 of The John Dewey Essays in Philosophy, paperback edn, Columbia University Press, NewYork / Chichester.

Regeerakkoord (2007), Regeerakkoord 'Samen werken, samen leven', http://www.regering.nl/Het_kabinet/Regeerakkoord, accessed 2008.I2.I9.

Rendtorff, J. D. (200I), Biobanks and the Rights to the Human Body, in: M. G. Hansson (ed.), The Use of Human Biobanks - Report I, Ethical, Social, Economical and Legal Aspects, Uppsala: 55-6o.

Resnik, D. B. (2007), 'Embryonic Stem Cell Patents and Human Dignity', in: Health Care Analysis I5: 2II-222.

Ripstein, A. (2006), 'Beyond the Harm Principle', in: Philosophy and Public Affairs 34(3): 215-245.

Rodden Robinson, T. (2005), Genetics for Dummies, Wiley, Hoboken NJ.

Rose, H. (200I), The Commodification of Bioinformation: The Icelandic Health Sector Database, Welcome Trust, London.

Rose, H. (2006), 'From Hype to Mothballs in Four Years: Troubles in the Development of Large-Scale DNA Biobanks in Europe', in: Community Genetics 9: I84-I89.

Rose, N. and Novas, C. (2003), Biological Citizenship, in: A. Onh and S. Collier (eds.), Global Anthropology, Blackwell.

Rosen, G. (2003), 'Who's Afraid of Leon Kass? (review of Life, Liberty and the Defense of Dignity)', in: Commentary II5(I): 28-33.

Sacks, O. (I992), ‘Tourette’s syndrome and creativity', in: British Medical Journal link 305(I9-26 December): I5I5-I5I6.

Sandel, M. J. (2002), What's Wrong with Enhancement, Meeting of the President's Council on Bioethics.

Sandel, M. J. (2007), The case against perfection: ethics in the age of genetic engineering, Belknap Press of Harvard University Press, Cambridge MA. 


\section{Politics by All Means}

Savulescu, J. (200I), 'Procreative Beneficence: why we should select the best children', in: Bioethics I5(5/6): 413-426.

Scholtens, B. (2008), 'Bijzondere techniek met veel ethische dilemma's', in: De Volkskrant (2008.05.28): 3 .

Sclove, R. (I995), Democracy and technology, The conduct of science series, Guilford Press, New York.

Seglow, J. (2003), 'Neutrality and Equal Respect: On Charles Larmore’s Theory of link Political Liberalism', in: The Journal of Value Inquiry 37: 83-96.

Selgelid, M. J. (2003), 'Ethics and eugenic enhancement', in: Poiesis Q Praxis: International Journal of Technology Assessment and Ethics of Science I(4): 239-26I.

Sheridan, H., Pasveer, B. and Van Hilvoorde, I. (2006), 'Gene-talk and sport-talk: link A view from the radical middle ground', in: European Journal of Sport Science 6(4): $223-230$.

Shickle, D. (2006), 'The consent problem within DNA biobanks', in: Studies in History and Philosophy of Science Part C: Studies in History and Philosophy of Biological and Biomedical Sciences 37(3): 503-519.

Silver, L. M. (I997), Remaking Eden: cloning and beyond in a brave new world, Avon Books, New York.

Simkin, B. (I992), 'Mozart's scatological disorder', in: British Medical Journal 305(19-26 December): I563-1567.

Smets, T., Bilsen, J., Cohen, J., Rurup, M. L., Keyser, E. D. and Deliens, L. (2008), link 'The medical practice of euthanasia in Belgium and The Netherlands: Legal notification, control and evaluation procedures', in: Health Policy (in press).

Smits, M. W. (2002), Monsterbezwering: de culturele domesticatie van nieuwe technologie, Boom, Amsterdam.

Steures, P., Van der Steeg, J. W., Hompes, P. G. A., Van der Veen, F. and Mol, B. W. J. (2006), 'Resultaten van intra-uteriene inseminatie in Nederland', in: Nederlands Tijdschrift voor Geneeskunde I5O(20): II27-II33. 
Stix, G. (2006), 'Biotechnology and the Law - Owning the Stuff of Life', in: Scientific American 294(2): 76-83.

$\mathrm{Su}, \mathrm{B}$. and Macer, D. (2004), 'Privacy versus public interest in developing human genetic databases', in: Eubios I4: 82-85.

Sullivan, D. M. and Salladay, S. A. (2007), 'Gene Therapy - Restoring Health or Playing God?', in: Journal of Christian nursing: a quarterly publication of Nurses Christian Fellowship 24(4): 199-205.

Swierstra, T. and Rip, A. (2007), 'Nano-ethics as NEST-ethics: Patterns of Moral Argumentation About New and Emerging Science and Technology', in: NanoEthics I(I): 3-20.

Swierstra, T. E. (I998), De sofocratische verleiding - Het ondemocratische karakter van een aantal moderne rationaliteitsconcepties, Kok Agora, Kampen.

Swierstra, T. E. (2000), Kloneren in de polder - Het maatschappelijk debat over kloneren in Nederland, februari 1997 - oktober 1999, Studie 39, Rathenau Intstituut, The Hague.

Swierstra, T. E. (2004), Slachtoffer of burger? - Een essay over het nader gebruik van lichaamsmateriaal ten behoeve van genomicsonderzoek, Nederlandse Vereniging voor Bioethiek.

Swierstra, T. E. (2009), Converging technologies, Rathenau Instituut, The Hague (in press).

Swift, A. (200I), Political philosophy: a beginner's guide for students and politicians, Polity Press, Cambridge.

Tansey, J. and Burgess, M. M. (2004), The foundations, applications and ethical dimensions of biobanks, W. Maurice Young Centre for Applied Ethics / University of British Columbia, Vancouver.

Taylor, C. (I999), Conditions of an Unforced Consensus on Human Rights, in: J. Bauer and D. Bell (eds.), The East Asian Challenge for Human Rights, Cambridge University Press, New York.

Van Teeseling, I. (200I), De kinderwens, in: S. de Joode (ed.), Zwanger van de kinderwens - Visies, feiten \& vragen over voortplantingstechnologie, Studie 46, Rathenau Instituut, The Hague: 25-48. 


\section{Politics by All Means}

Thomas, J. M. (2005), The unpredictability of science and its consequences, in: Jahrbuch Der Akademie Der Wissenschaften Zu Göttingen: 53-58.

Tijmstra, T., Bosboom, G. J. M. and Bouman, K. (2000), 'Ervaringen van vrouwen die besloten de zwangerschap uit te dragen na de diagnose 'Down-syndroom', in: Nederlands Tijdschrift voor Geneeskunde I44(44): 2104-2107.

Tracy, D. (I998), Human Cloning and the Public Realm: A Defense of Intuitions of the Good, in: M. C. Nussbaum and C. R. Sunstein (eds.), Clones and Clones: facts and fantasies about human cloning, W.W. Norton and Company, New York: I90-203.

Treffers, P. E. (2006), 'Abortus provocatus in Nederland in de 20 eeuw: van stilzwijgen naar revolutionaire verandering', in: Nederlands Tijdschrift voor Geneeskunde I50(I0): 567-573.

Troost, N. (2006), 'Blij met reactie Deense moslims - Rikke Hvilshøj, minister van Integratie, herkent zich in Nederlandse beleid', in: De Volkskrant (2006.03.08): 5 .

Trouw (2006), 'Klagers maken meer kerncentrales nodig", in: Trouw (2006.02.I6): I4-I5.

Trouw (2008a), 'Abortus ondanks gebruik pil of condoom', in: Trouw (2008.II.I2): 6-7.

Trouw (2008b), 'Europa is verdeeld over embryoselectie', in: Trouw $(2008.06 .06): 4-5$.

Trouw (2008c), 'Onenigheid over voorstel ruimere embryoselectie - Besluit Bussemaker ontmoet weerstand en lof in Den Haag', in: Trouw (2008.05.28): 2-3.

Turner, S. S. (2005), 'Critical Junctures in Genetic Medicine', in: Journal of business and technical communication, I9(3): 328-352.

Tutton, R. (2007), 'Constructing participation in genetic databases - Citizenship, link governance, and ambivalence', in: Science Technology \& Human Values 32(2): 172-195. 
Tweede Kamer (2007), 'Algemeen overleg 20 november 2007’.

Tweede Kamer (2008a), 'Brief van de Staatssecretaris van Volksgezondheid, Welzijn en Sport'.

Tweede Kamer (2008b), 'Handelingen Io4de vergadering'.

Tweede Kamer (2008c), ‘Handelingen 93ste vergadering’.

Tweede Kamer (2008d), 'Kamerstuk 29323, nr. 46’.

UK Biobank (2008), UK Biobank Home Page, http://www.ukbiobank.ac.uk/, accessed 2009.02.04.

Valkenburg, G. (2008), Techniek als betekenis, in: M. D. J. van Well (ed.), Deus et Machina, de verwevenheid van technologie en religie, Publicatie 72 , Stichting Toekomstbeeld der Techniek, The Hague: 2IO-2I5.

Valkenburg, G., Achterhuis, H. J. and Nijhof, A. H. J. (2003), 'Fundamental shortcomings of evidence-based medicine', in: Journal of management in medicine $\mathrm{I} 7(6): 463-47 \mathrm{I}$.

Vatican (2002), Communion and Stewardship: Human Persons Created in the Image link of God, Vatican International Theological Commission, http://www.vatican.va/roman_curia/congregations/cfaith/cti_documents/ rc_con_cfaith_doc_20040723_communion-stewardship_en.html, accessed 2009.0I.I4.

Verbeek, P. P. C. C. (2005), What things do: Philosophical reflections on technology, agency, and design, Pennsylvania State University Press, University Park PA.

Verbeek, P. P. C. C. $(2008 a)$, 'Mopperen met schone handen', in: Trouw (2008.02.09): 9 .

Verbeek, P. P. C. C. $(2008$ b), 'Obstetric Ultrasound and the Technological Mediation of Morality: A Postphenomenological Analysis', in: Human Studies 2008(I): II-26.

De Vries, G. (I987), 'Cultural differentiation and the separation of values and facts'.

De Vries, G. (I999), Zeppelins - Over filosofie technologie en cultuur, Van Gennep, Amsterdam. 


\section{Politics by All Means}

Wagendorp, B. (2008), 'Wrede God', in: De Volkskrant (2008.05·3I): 3.

Warren, S. and Brandeis, L. D. (I89o), 'The Right to Privacy', in: Harvard Law Review I93.

Weel, I. (2008), 'Klink daadkrachtig bezig met verbieden; CDA-bewindsman opereert op de achtergrond, maar is gezichtsbepalend in Balkenende IV', in: Trouw (2008.02.04): 4-5.

Wenz, P. (2005), 'Engineering Genetic Injustice', in: Bioethics I9(I): I-II.

De Wert, G. and De Beaufort, I. (2008), 'Sta nú ook andere varianten van PGD toe - Politiek compromis leidt tot voorbarige verboden die niet te beargumenteren zijn', in: NRC Handelsblad (2008-07-01): 6.

Winickoff, D. E. (200I), 'Biosamples, Genomics and Human Rights: Context and Content of Iceland's Biobanks Act', in: The Journal of BioLaw and Business 4(2): II-I7.

Winner, L. (I993), 'Upon Opening the Black Box and Finding It Empty: Social Constructivism and the Philosophy of Technology', in: Science, Technology, Q Human Values I8(3): 362-378.

World Medical Association (2000), Declaration of Helsinki - Ethical Principles for Medical Research Involving Human Subjects, World Medical Association, Edinburgh.

Yeo, M. (2004), Biobank Research: The Conflict Between Privacy and Access Made Explicit, The Canadian Biotechnology Advisory Council.

Van Zanten, C. (2007), 'ChristenUnie eenzaam in billboard-kwestie’, in: Elsevier (2007-04-04).

Van Zijverden, M. and Sips, A. (2008), Nanotechnologie in perspectief - Risico's voor mens en milieu, RIVM, Bilthoven.

Zwart, H. A. E. (I998), Why should remunerated blood donation be unethical?, in: H. A. Have, J. V. Welie and S. F. Spicker (eds.), Ownership of the human body - Philosophical Considerations on the Use of the Human Body and its Parts in Healthcare. 


\section{Summary}

Sometimes, technological change sparks interminable political controversy. In addition to disagreement about decisions themselves, these controversies are characterized by disagreement regarding the question of what arguments are appropriate to justify those decisions. This book has investigated the relation between technological change and those complex political matters. The theoretical background of this investigation deploys a vision of both modern liberal society and modern technology. This framework has been tested and accentuated in three case studies. Finally, some suggestions have been made as to how such controversies can be mended in the future.

\section{Our technological, liberal culture}

The three controversies have been sketched along two main lines. The first line concerns (i) the liberal character of modern society. This liberal character consists of the pluralist way of doing politics. On the one hand this way grants that many different ideas of the good life can be pursued peacefully alongside one another. On the other hand, it grants that adherents of different visions of the good life can together promote their collective interests. The second line concerns (ii) the character of modern technology. This includes all forms of technology we see around us: ranging from everyday appliances to all-encompassing infrastructures, and ranging from simple tools to complex industrial standards and norms. Technologies around us shows two faces: on the one hand, they influence our choices and may thus appear to limit our freedom of choice. On the other hand, we do develop and use those technologies ourselves and do so from our own choices. We thus experience plenty of room for free choice. These roles of technology also appear at the level of society and culture. The relation between this technological culture and the liberal ideals that aim to guide it forms the central focus of this book. 


\section{Liberalism}

(i) The ideology of liberalism aims to have citizens making a collective effort, in order to create a neutral playground, on which those citizens can pursue as many as possible ideas of the good life. In our culture, liberalism is shaped as the existence of two spheres: the public sphere and the private sphere. Both spheres are decision spaces as well as sources of justification. The public sphere as decision space consists of the total of decisions that are to be taken collectively. Those decisions apply to all citizens. They concern laws, policy, national budget etc. The public sphere as source of justification contains the arguments that can serve as the foundation of those decisions. These arguments must be such that each citizen can accept them as valid arguments. Typically, arguments that build on the prevention of harm, on ideas of justice and appeals to universal human rights will serve well as justifications in the public sphere.

In contrast, the private sphere contains all that is not part of the public sphere. As a decision space, the private sphere contains those decisions that only concern ourselves. This grants that we need not give account of those decisions to others, and therefore it does not matter (to others, that is) on what arguments we base those decisions. This is not to say that for ourselves, just anything goes. Quite the contrary, in the private sphere, our personal ethics, our religion and our taste are valid and appropriate arguments to build a decision upon. Thus, also as a source of justification, the private sphere shows quite a different character than the public sphere does.

This separation between the public and private spheres is principally a sensible one. In a pluralist society, it is impossible to reach total agreement on all normative issues. It would make little sense then, to pursue it nonetheless. It is more useful to limit the pursuit of agreement to a clear-cut domain. This domain is exactly the public sphere as decision space. In this public sphere, only matters of common concern are discussed and decided. On the one hand, this requires that we make decisions acceptable to all on only a limited domain. In support of those decisions, we only adduce justifications that are also acceptable to all. Moreover, the limited stretch of those decisions grants that we do not too much need our private sources of justification. On the other hand, everyone can enjoy the freedom of the private sphere, where those private sources of justification can be paid due respect.

Despite these upsides, a problem presents itself here. People may arrive at a situation in which they feel that the accepted public arguments are insufficient. 
They may then feel the need to adduce a wider range of arguments than only the accepted repertoire. This carries the danger that not all will accept those arguments. The private source of justification thus appealed to, is not straightforwardly convincing for the public decision space to which it is adduced.

This shows that a normative issue can lead to disagreement at two different levels, in addition to the level of the issue itself. First, people can disagree about which decision space the issue belongs to. And second, if the issue belongs to the public sphere, people can still disagree about which arguments are appropriate for discussing it. The process of selecting both the issues that are part of public decision making and the arguments that we can support those decisions with, I have termed purification. This is literally the effort people have to make as to cleanse the public debate of issues and arguments that they think are inappropriate.

I have subdivided this purification into three parts. For any normative issue, people first need to settle whether the issue belongs to the public sphere, and whether it needs discussing in the first place. I have termed this the question of (a) scope of politics. Second, people need agreement about which arguments are appropriate and which are not for arriving at a conclusion. I have called this (b) the justification of politics. And finally, there is the level of the decision itself. This, I have called (c) the content of politics. Disagreement can occur on the levels of (a) scope and (b) justification. In fact, people can also disagree on the level of (c) content, but that is irrelevant here. I have assumed that such disagreement always leads to the introduction of new arguments, which means that the actual debate will again be conducted at the levels of (a) scope and (b) justification. It will be observed that in practice, those levels are not always easy to tell from one another: an argument at either level may be refuted at the other.

\section{Technology}

(ii) Modern technology comes in many forms. We are surrounded by appliances and devices, of which many go by unnoticed because they have become a normal part of our world. This holds most strongly for our infrastructure: roads, means of transport, power and communication grids, etc. We only notice them when they do not work properly. But also our books and newspapers, our groceries from the supermarket, and the education our children enjoy, can only exist the way they do because of the technologies that support them. It is not an understatement that our culture coincides with technology. 


\section{Politics by All Means}

In general, we can recognize two relations to technology. On the one hand, technology co-determines our lives. It influences the choices we make and the thoughts we have. Some choices are enabled by technologies, whereas others are hampered or even precluded. And thoughts we have, are inspired by the world surrounding us, including the technologies populating that world. This may give us a feeling of impediment of our freedom of choice. But on the other hand, we do experience every day that a lot of freedom remains and that we do make genuine choices. We can guide our own lives. And we can influence the technologies surrounding us. Technology does not only limit our choices, but also seems to enhance our choices. We are able to harness technology in favor of our choices, while in other situations, that free choice seems subject to the rules of the same technologies.

Actor-network theory (ANT) offers an adequate methodology for charting this ambivalent relation. ANT understands the world as a whole of actors and relations between those actors. Not only human beings count as actors, but so do nonhumans like things, animals, and the natural matter surrounding us. Actors are not isolated entities, but are connected to each other through endless associations. These associations or networks define the identity of an actor. When an actor, whether human or non-human, initiates change, it is necessary to change the whole network around it. The actor will have to side with other actors and make sure those have the same interests. Thus, shaping alliances is a necessary part of any change. For example, creating a car that runs on hydrogen rather than gasoline requires more than just building such a car. We need an infrastructure to supply the car with fuel, we need policy and regulations that enable driving the car, we may need to use tricks in the tax system to make the car into a viable alternative to existing cars, etc.

Actors derive their identity from the networks they are part of. Thus, if something in the network changes, the identity of the actor changes as well. Even the gasoline car will be a different thing before and after the introduction of a hydrogen car: it will be part of a different context, and thus will relate differently to that context. That is to say, the network around it has changed. Stakes and interests are changed, some actors are eliminated and others appear, ideas get a different meaning. We can only understand actors properly if we also take account of the network surrounding them. Contrary to the intuitive notion of network, as in 'power grid' or 'internet' or 'telephone network', networks in ANT are not 
meant to serve the undistorted transport of information or energy or matter. In fact, they do not serve any goal at all; they just exert effects. The notion of (ANT) networks is mainly an instrument to understand and articulate changes.

We, humans, have our place in the networks just like all other actors. If we want to achieve something, this requires an effort, and this effort partly concerns changing the network. Consequently, if a network changes, this will change all elements, including ourselves. This may have consequences for our interests, our ideas and the opportunities we face. Moreover, the meanings we attribute to the world around us and how we evaluate that world may change. Thus the change affects how we evaluate ourselves. It affects our identity.

For the purposes of this book, it suffices to focus on two dimensions of the roles that technologies may play in the interactions between us and our world, (I) the hermeneutic and (2) the existential dimension. (I) The hermeneutic dimension concerns the influence of networks on our perception of the world. For example, observing environmental pollution cannot be seen apart from a number of other elements. The pollution itself is caused by a non-sustainable approach to our lifeworld. But we also need methods of measurement and theories to identify and discuss the pollution. Moreover, there must be a shared presumption that pollution is something bad, for otherwise it would never appear as something that needs attention. Thus, pollution the way we see it today was unthinkable fifty years ago, certainly seeing it exactly this way. If networks around us change, our perception changes too. Thus the meaning changes that we attribute to the world. Consequently, our normative stance towards that world changes.

(2) The existential dimension concerns the influence of networks on our choices and actions. The networks around us make some choices more probable than others, and some choices are even impossible merely because of the networks. We can drive across the Netherlands just to drink a cup of coffee with our relatives. This is only so because we have cars and highways which enable that. Moreover, the existence of those cars and highways take away distance as a legitimation to neglect our family relations. Thus, social pressure can force us to drive 200 kilometers for just one hour of socializing. Less straightforward is the example of a typical, academic working day: it can only exist the way it does, because supermarkets and the networks in their support can efficiently provide a meal. If living would today still require hunting and harvesting, little time would left for writing dissertations. Moral choices are similarly influenced: most of us think of it 


\section{Politics by All Means}

as immoral, to withhold children the standard vaccination programmes. However, this condemnation can only be understood against the background of the technical feasibility of those vaccinations. In a world without them, the condemnation would be meaningless. Probably, such an alternative world would equally value and demand good care for children. However, vaccination would not be part of the content of that care.

This provides a connection between (ii) technology and (i) the idea of liberal politics. The relations between people and other actors are technological in character, because networks containing technologies are everywhere and exert their influence everywhere. In those networks, technologies stand on an equal par with us. But the relations in those networks are also political in character, because some issues require collective decision and action. We have already seen that liberal politics discerns between private and public normativity. Taking into account the present idea of technology as networked, it becomes clear that technological change can challenge the divide between the public and private spheres. The change can challenge the boundary between the decision spaces. It can challenge the limits of the arguments that are felt appropriate as justification. Or new configurations can be so radically new that are unable in the first place to assign it any place in our symbolic order, neither with respect to the decision space nor with respect to the sources of justification. These three kinds of challenges are indeed recognized in the case-study chapters.

\section{Difficult discussions}

Three controversies are discussed in this book in which politics and technology interfere with each other and in which the divide between public and private is challenged. First, (A) human enhancement is discussed. Enhancement concerns all those interventions in the human body that are not absolutely necessary from a medical point of view, but that are aimed at improving the functioning of the human body and its performance. This controversy mainly concerns the question to what extent human nature must be subject to our manipulation. The second controversy concerns (B) biobanks. These are large systems in which genetic material as well as medical data are stored. Such systems allow for advanced study of the human genome. They raise ethical questions about the ownership of all that is inside them. These questions are largely unprecedented, which 
makes the discussions about biobanks into difficult ones. And finally, a debate in Dutch politics on $(\mathrm{C})$ preimplantation genetic diagnostics is reconstructed. This debate shows that also in everyday political practice, purification is visible. And indeed, technological change causes the purification to become more anxious. The following sections will discuss the cases along the three political dimensions, namely (a) scope, (b) justification and (c) content. Insofar as they are relevant, the (I) hermeneutic and (2) existential dimensions of technology will be discussed as well.

\section{Human enhancement}

Human enhancement is a term used for all those interventions in the human body that aim to improve that human body. This includes the modification of our children's genomes, such that they will exhibit the properties we like to see in them. If we want to discuss the question whether we should be allowed to design our children at our desire, we must first answer the question whether this needs discussion in the public sphere in the first place.

Some argue that enhancement is a private affair. Indeed, if we see it as a private affair, no agreement needs to be pursued. This is an attempt to purification at the level of (a) scope. Such attempts to privatization often build upon the argument that nobody will ever be forced to apply enhancement. At the same time, enhancement allows future parents to pursue the best for their children within their private spheres. This attempt to purification finds part of its opposition at the same level of scope. That is, others argue that enhancement is so bad, that it cannot be tolerated, even in the private sphere of others. Enhancement would express a despotic stance towards children, it would carry immense dangers as we do not know exactly how things will work out, or it would simply be the hubris of playing God.

When arguing whether enhancement should be private or not, arguments appear on stage that are not straightforward and acceptable to all. Not everybody thinks of playing God as problematic. Therefore, this argument is not straightforwardly appropriate for public debate. We see indeed that proponents of enhancement argue that these arguments do not belong to the public sphere. They believe that such arguments can at best serve individual decisions for those who appreciate them. Thus, the debate has shifted from the level of (a) scope to the level of (b) justification. 


\section{Politics by All Means}

In this controversy, technology seems not to play an important rol. That is, we do not really see artifacts interfering with our social life. Neither is it clear that networks are to be changed or resist such change, or that elements in networks enforce a certain course of action. Nonetheless, this controversy shows that the different positions in the debate can only be understood if we explicate the specific visions of technology they carry. People arguing that enhancement cannot be a private affair, also seem to have a vision of technology as leaving little room for individual control and free choice. They hold on to a deterministic vision of technology. These people fear that we call onto ourselves great dangers if we allow such out-of-control technologies, even if their use is confined to the private sphere. On the other hand, people arguing that enhancement is a private affair, seem to think of technology as unproblematic and in service of our free choice. They deploy a rather instrumentalist view of technology and trust that technologies will never get the upper hand over us. They confide that we will always retain our freedom of choice, and be able to take our own ethics as our guide.

The chapter on enhancement has shown that there is a relation between one's vision of technology, the extent to which they think of enhancement as privatizable - indeed, a matter of (a) scope - and the kind of arguments they adduce to defend or challenge that privatizability - a matter of (b) justification. Persons thinking more pessimistically about technology tend to see it as less privatizable, and tend to put forward a wider repertoire of arguments. And on the contrary, people who see technology as privatizable, also have in general a more optimistic vision of technology and its controllability. This provides an interesting link between liberal purification and the purification that follows from technological promises. In ANT terms, we could state that liberalism and technology form a good alliance. They have the same interests with respect of the exclusion of actors.

The chapter has also shown that purification is not straightforward. Whenever arguments are pushed out of the debate, this is likely to hamper the interests of other actors. Therefore, they will resist the exclusion. In the controversy on enhancement, we see indeed that an important group of discussants aims to reintroduce arguments into the public sphere that are excluded - unjustly so, to their eyes. Resistance thus targets the supposed superficiality of liberal politics. 


\section{Biobanks}

Biobanks contain large quantities of body materials and medical data. Using computers, researchers can investigate correlations between our genome and its expression. Partly, these correlations are too weak to find them otherwise. One could think of inclinations for genetic diseases, susceptibility for infectious diseases, but also individual sensibility to nutritious elements, allergens, and talents like muscular strength, intelligence etc.

Given the medical-scientific character of biobanks, it is likely that medical ethics is an appropriate framework to asses them from. In case of biobanks, medical ethics would prescribe that potential participants in biobank research are educated sufficiently about the research, its consequences and its aims. The potential participant may then freely decide whether he or she will indeed enroll. The principle of autonomy is paramount in medical ethics, and even the shadow of coercion or paternalism should ring alarm bells.

This provides a first answer to both (a) scope and (b) justification. Indeed, regarding scope, medical ethics has provided the routine that broad limits are set by laws and regulations, while the fine details are to be decided by the patient in close consult with the practitioner. Regarding justification, medical ethics highly values principles like autonomy and protection of the individual. Arguments are assessed against the background of these principles.

However, this approach is unfortunate in the case of biobanks. First, it is difficult if not impossible to educate the potential participant. To understand the full potential of the research, the participant must almost be educated up to the level of a genetic scientist. Second, much of the future research is inexplicable, since even the scientists themselves cannot fully predict it. Third, for biobank research, it is highly inefficient if each participant were to decide individually upon enrollment. Biobanks would be served much better if complete populations contributed, thus making it in effect a public and hence political matter rather than a private one. Biobanks are not served with fractions of populations. Thus, the received (c) content of medical ethics is not beneficial for biobank research.

Also the accepted (b) justification for medical ethics is at closer look unapt for biobank research. The hegemony in medical ethics of the principles of autonomy and protection are justified by the huge damage an individual can suffer from medical research on his or her body, when his or her body is not properly protected against the much more powerful institutions of medical research. However, many 


\section{Politics by All Means}

have argued that this potential damage is completely insignificant in the case of biobanks, and certainly so when balanced against the benefits of biobank research. Again, this friction can only be understood in connection to (a) the scope of politics and the complementary private sphere. From the perspective of biobanks, it should not be a private choice at all, whether a person contributes or not.

This is interesting for the articulation of the relation between politics and technology. Apparently, the technical configuration of biobanks renders political routines and their justification obsolete. More specifically, medical ethics is no longer useful. This reveals, more than the case of enhancement, the two dimensions of our relations with technologies. (I) The hermeneutic dimension of biobanks consists of presenting an idea of what genes and genomes are, and how their ownership must be understood. Primarily, genes are information that only becomes valuable after the effort made by scientists. Our individual identity and how it correlates to our genome more or less fade out of scope here. In addition, genes are something that we can support the common good of medical-scientific progress with; not something that we can keep for ourselves and make a profit with - if that were possible in the first place. Through this hermeneutic dimension, technologies thus suggest how we normatively evaluate (c) the content of political decisions.

(2) The existential dimension of biobanks consists of the fact that we are at least coerced to take a position regarding the ownership of genes, and to make a decision as to the contribution to biobanks and the collective good they promote. And in fact, biobanks also express an answer to these questions: they implicitly propagate the vision that it is good to contribute to collective interests. Thus, biobanks express a specific vision of citizenship.

The controversy on biobanks shows at least three principal stances in actors. First, there is the typical way of doing science, which values the work of biobanks. This perspective entails that we should invest in the search for knowledge. And we should we willing to give up some of our autonomy and privacy, if that helps mankind a step forward. Second, there is the typical way of doing medical ethics, which holds autonomy paramount. The patient is entitled to protection, and anything that threatens it, is a plain taboo. When applied to biobanks, this amounts to the sheer impossibility to demand from citizens that they donate some of their tissue, even painless and at the cost of no real effort, other than under compleet voluntary consent. And third there are traditions of altruism, compassion 
and collective effort. In practice, many people do not care that much to have full control over everything, especially if it stands in the way of helping others. They do not object to donating some body material and medical information. These three movements each contribute their own part to the controversy.

At the same time, none of them seems to be able to tip the balance. This seems to be owing to the following mechanism. Each of the three positions hides an idea of ownership. The scientific stance holds that genes belong to nobody, and can only become valuable by scientific effort. The assets should be part of the public good, just like science itself is. The medical-ethical paradigm in its turn implies that genes are the property of the individual, and that the individual has ultimate authority over them. And the traditions of altruism express that genes may be our property, while at the same time we also have a duty to help others with that property.

None of these ideas of ownership seems to do justice to the peculiar way we own our genes. Our genes belong ambiguously to ourselves as individuals, to our family, to our nation and to mankind at large. The scientific vision does not pay due respect to the intuition that our genes are ours. And contrarily, medical ethics seems to pay even disproportionate respect to that same intuition. None of these visions aligns nicely with the technical configuration of biobanks. And in its turn, this technical configuration depends upon our human nature, and what we think of how it should be researched. This human nature and our preferences for researching it thus co-define what kinds of ethics can successfully be argued and what kinds cannot. Thus, genomes influence whether things can be spoken in public or not.

Thus, biobanks promote ideas of ownership that are not in line with received ideas of ownership figuring in public discussions. In the expression of those ideas, (I) the hermeneutic dimension of technology is clearly recognizable. The hermeneutic dimension directly influences (b) the justification of politics. Technology destabilizes concepts that play a central role in politics. This is salient, as these concepts are also used in judging biobanks. Thus, biobanks undermine their own assessment. And since (b) justification is destabilized here, we may expect that also on the levels of (a) scope and (c) content, agreement will not be trivial. 


\section{Preimplantation genetic diagnostics}

Preimplantation genetic diagnostics or PGD is an intervention in which embryos are selected for implantation into the mother's womb, based on their genetic properties. PGD is conducted in the course of an IVF (in vitro fertilization or test-tube fertilization) procedure, and will generally serve the prevention of severe genetic diseases. Early 2008, a vivid controversy flared up in the Lower House of the Dutch Parliament. The debate concerned the extension of the permission for PGD. From that time onwards, PGD would also be allowed in prevention of heritable breast cancer. For some, this was a bridge too far: as heritable breast cancer has a less-than-Io०\% certainty of developing, embryos will be discarded that would have had a healthy life.

One of the questions emerging in parliament was indeed whether politics should interfere in these decisions in the first place. Why not trust that medical ethics can settle the hard cases? Indeed, many parties argued that the decision whether or not to apply PGD should be a private one, to be made by the parents, in line with the autonomy that rules medical ethics at large. In opposition, some Christian parties including coalition partner ChristenUnie, argued that it was certainly a political task to draw a line here, as this specific form of PGD would be unacceptable even in the private sphere of parents. This part of the controversy was thus a disagreement on (a) scope.

Opponents of the ChristenUnie made quite an effort to argue that the reasons adduced by the ChristenUnie against PGD are private considerations, and hence cannot be part of political decision making. They argue that the Bible and politics do not go together well. However, the ChristenUnie argued that the Bible is just as valid a source of knowledge as are libertarian and socialist dogmas that the other parties adhere to. According to the ChristenUnie, all these sources should be equally welcomed to the debate, rather than the present situation of unbalanced exclusion of religious arguments. Much like the case of enhancement, the debate on biobanks showed a shift from the level of (a) scope to the level of (b) justification.

The controversy on PGD can only be understood if we take account of the background against which it occurred. In the Netherlands of the year 2008, medical interventions like IVF and abortion are widely accepted. Even though most people will not regard abortion as something beautiful per se, most people will highly value the freedom that women have when deciding upon such difficult matters. They are willing to accept that abortion may at times be the best of 
evils. Something similar holds for IVF. The vast majority regards it as a proper solution to infertility. The problem that it incurs the discarding of embryos is not a major consideration for most people. These two practices express that the unborn life does not enjoy unconditional protection, but that this protection knows some exceptions. The extended use of PGD, as well as existing practices of IVF and abortion have offered us the idea that the prevention of severe genetic diseases is feasible and desirable, even if an embryo needs to be sacrificed at times. Against this background, it is not easy to argue that the embryo is anything beyond a mere lump of cells. This is a fine example of the hermeneutic dimension of technology. Moreover, the example shows that we can only understand technology against its proper background, and in connection to and interaction with the (human and non-human) actors around it.

The fact that technologies are ready to use, makes that it will be difficult not to use them. This is not to say that PGD is just an easy operation, or that it will be absolutely impossible not to use it. But it is to say that some choices are rendered more probable than others. In a situation in which it is difficult to argue that the embryo is anything beyond a mere lump of cells, it will be even harder to argue that PGD is an undesirable intervention in prevention of heritable breast cancer. Nothing will be coerced, but a moral judgment is near when parents decide not to protect their child against cancer by means of PGD. Through this social pressure, the practice of PGD exercises its (2) existential dimension.

In this case of PGD, the relation between politics and technology is clearly visible. Both along the hermeneutic and the existential dimension, the technical configuration has determined part of the political vocabulary. And much like the biobank case, this happens in the same debate that also discusses the technology itself. That is to say, the present technological background has determined some of the content of both (b) justification and (a) scope, while it is itself an object of that justification and scope.

In conclusion, this case shows that there is a clear relation between (ii) technology and (c) content. Indeed, the final political content largely coincides with the technological configuration. This is not to say that technology has simply dictated our political decisions. Neither has the debate been conducted in vain, because the political situation after the debate is different from the situation before. Before anything else, the technology has forced politics to discuss certain issues, including how we will deal with those issues in the future. This concerns both the 


\section{Politics by All Means}

extent to which we want to discuss the issues politically, and what arguments we will use in that discussion. Considerations of (a) scope and (b) justification have been consolidated into (c) content. What we will think of medical issues in the future, is also the result of today's debate.

\section{Liberal technology}

The controversies discussed in this book showed three important things. First, there is a permanent tension as to the question whether things belong to the public sphere or not. Getting things into the public sphere, or rather getting them out, is a matter of hard work. Moreover, this hard work is an inherent element of the political debate itself. This holds both for getting an issue on or off the agenda, and for getting arguments in and out. That is, it holds for both (a) scope and (b) justification. I have suggested the term purification for this activity of shaping and cleansing the debate.

Second, technology and technological change contribute to this tension between appropriate and inappropriate issues and arguments. Indeed, technology makes that some things are easy to say, whereas other things are impossible. This is owing to the fact that technology offers us a way of looking at the world, that is (I) the hermeneutic dimension. In addition, it is owing to (2) the existential dimension, which conceptualizes that technology offers us answers to choices. Both mechanisms pertain to both (a) scope and (b) justification. Moreover, influence of technology on (c) the content of politics is visible. Especially in the PGD debate, the political conclusions strongly reflect the normativity embodied in the technological configuration.

Third, technologically-induced changes often require public discussion, even though technology itself often feeds the impression of being neutral and therefore no object of concern. Technology just promises to enhance our choices, and to be a world apart from the ethical considerations justifying those choices. Especially critical stances towards technology are hard to defend against such a background.

So far, discussion has been focused on how modern technology interferes in our relation with the lifeworld, and how it relates to our normativity. This relation offers ample opportunity for interference between technology and how we normally deal with normativity, that is according to liberal ideals. The case studies have shown that technology offers us a way of looking at the world. This means 
that ways of looking that comply less with this picture offered by technology, become less tenable and arguable, and sometimes even appear irrational. That is remarkable against the background of liberal ideals. Indeed, liberal principles state that political debate should not appeal to rationality but rather to reasonableness. In this sense, reasonableness is the attitude of willingness to explain positions and to listen to explanations of others. Rationality on the contrary, is an appeal to the conditions that knowledge must suffice to be accepted as true or right. In a pluralist society, appeals to rationality are rather a source of disagreement than a road to consensus. Nonetheless, everyday politics seems to be strongly influenced by what the majority thinks rationality to be. The world views presented by our technologies contribute to that influence.

At the same time, modern technology pretends to export a neutral rationality. Perhaps it is exactly for this reason that in much liberal literature, no critical notions of technology are found. Both liberalism and technology promise that everyone can pursue his or her own ideal of the good life. Thus, technology and liberalism form a powerful alliance, championing an image of neutrality and reasonableness. But on the other hand, it is undeniable that technologies exert an influence, and a morally relevant one at that. Thus, technology is not neutral. This influence can be recognized as changes in our world view, as changes in the meanings that we attribute to concepts, and as changes in our language and hence in the language of politics. Thus, technology causes disagreement. That is, if the meanings of concepts change below the surface, a confusion of tongues is at hand. This confusion will occur at all levels of political talk. As concepts and norms change, this will emanate on what can be spoken and what cannot in the public sphere, and on the arguments that can be adduced if so.

Existing practices of ethics of technology and technology assessment can be improved and extended. Attention is already paid to the normative influence of technology. In addition, attention could be paid to the influence that technology exerts on the possibility and impossibilities of speaking out certain arguments, and to the influence that technology has on the meaning of concepts. This incurs a shift in the burden of proof. We can no longer demand that everybody explains his or her objections in reasonable, liberal terms - even if we do still believe that those terms are neutral and therefore reasonable. Even though the embryo seems something clear, against the background of existing practices, the ChristenUnie position is much harder to defend than the secular positions aired in the debate. 


\section{Politics by All Means}

Rather than demanding that people explain their position in such terms, we may demand that proponents of the change explain why the change in speakability and meaning of concepts would be justified. They must be called to account for the fact that their proposals take away one more piece of the protectworthiness of the embryo.

First, we will have to admit that most of these changes go by implicitly and unnoticed. Therefore, it will be difficult to know who we must call to account. This does however not take away the need to do so. It would be unfair if we demand that people express themselves in neutral terms, while the meanings of those very same terms change below the surface, because other people initiate a technological change. The first ones will no longer recognize the use of the terms and fail to express themselves. The proposed principle corrects for that, be it perhaps idealistically.

Second, we must admit that in the end, the majority usually gets its ways. This is not a priori unproblematic from a democratic point of view. However, it does put onto the majority the duty to enable the losing minority to express their views, without drawing the shortest straw at the beginning, because a majority enforces concepts that they do not share. The aim of this book has been to add some fairness on this point. Rather than avoiding difficult talks, we should give them a proper and balanced place in the debate. The outcomes of the debate will then enjoy even more support. 


\section{Samenvatting (Dutch summary)}

\section{Politiek met alle middelen. Een zoektocht naar technologisch liberalisme.}

Technologische ontwikkelingen zorgen soms voor schijnbaar onoplosbare controverses in de politiek. Behalve door onenigheid over de te nemen beslissingen, kenmerken deze controverses zich door onenigheid over de vraag welke argumenten aan de basis van die beslissingen op hun plaats zijn in de discussie. In dit boek is de samenhang tussen technologische vooruitgang en zulke lastige politieke vragen onderzocht. Het theoretisch kader aan de basis van dit onderzoek beschrijft zowel de liberale samenleving als moderne technologie. Dit kader is getoetst en nader aangescherpt in enkele casushoofdstukken. Tenslotte is een aantal suggesties gedaan voor aanpassingen waardoor in de toekomst dergelijke discussies mogelijk soepeler kunnen worden afgewikkeld.

\section{Onze technologische, liberale cultuur}

De controverses in dit boek zijn langs twee hoofdlijnen in kaart gebracht. De eerste lijn behelst een visie op (i) de liberale aard van de moderne samenleving. Deze liberale aard verwijst naar de manier waarop wij een pluralistische politiek bedrijven. Enerzijds kunnen daarin veel verschillende ideeën van het goede leven vreedzaam naast elkaar worden nagestreefd. Anderzijds kunnen aanhangers van al die verschillende ideeën van het goede leven toch samen hun gemeenschappelijke belangen behartigen. De tweede lijn omvat (ii) het karakter van moderne technologie. Dat betreft alle vormen van techniek die we om ons heen vinden: van alledaagse apparaten tot complete infrastructuren en van simpele gereedschappen tot ingewikkelde technische standaarden. Technologie lijkt twee gezichten te hebben: enerzijds beïnvloedt zij ons en beperkt zij onze keuzes, anderzijds ontwikkelen wij die technologie zelf en blijft er genoeg ruimte voor vrije keuze over. Deze moderne technologie speelt ook op cultureel niveau een grote rol. De relatie tussen deze technologische cultuur en de liberale idealen die daarin leven,vormt het centrale onderwerp van dit boek. 


\section{Politics by All Means}

\section{Liberalisme}

(i) Liberalisme stelt zich ten doel om met collectieve inspanning een neutrale speelruimte te creëren, waarin zoveel mogelijk ideeën van het goede leven vreedzaam naast elkaar kunnen floreren. Het liberalisme van onze samenleving komt tot uiting in het bestaan van twee sferen: de publieke sfeer en de privésfeer. Beide sferen zijn zowel beslissingsruimte als bron van rechtvaardiging. De publieke sfeer als beslissingsruimte bestaat uit het totaal van de beslissingen die wij gezamenlijk nemen. Deze beslissingen zijn op iedereen van toepassing. Het gaat dan over wetten, beleid, en de begroting van de staat. De publieke sfeer als bron van rechtvaardiging bestaat uit de argumenten waarmee we de beslissingen onderbouwen. Deze argumenten moeten van dusdanige aard zijn dat iedereen ze kan accepteren als geldige argumenten. Te denken valt aan argumenten die bouwen op het voorkomen van schade aan mensen, argumenten die bouwen op ideeën van rechtvaardigheid, en argumenten die een beroep doen op de universele mensenrechten.

De privésfeer bevat alles wat geen deel uitmaakt van de publieke sfeer. Als beslissingsruimte bevat zij die beslissingen die alleen op onszelf van toepassing zijn. Om die reden zijn we ook geen verantwoording schuldig aan anderen, en doet het er dus (tenminste naar buiten toe) ook niet toe waar we die beslissingen op baseren. Dat wil niet zeggen dat we voor onszelf zomaar alles goed zullen vinden. Integendeel, in de privésfeer zijn onze persoonlijke ethiek, onze religie en zelfs onze smaak zeer geldige gronden om een argument op te baseren. Als bron van rechtvaardiging kan de privésfeer dus een heel ander karakter vertonen dan de publieke sfeer.

Deze scheiding tussen publiek en privé is in beginsel een zinvolle. In een pluralistische samenleving is het onmogelijk om op alle normatieve vlakken eensgezindheid te bereiken. Het is dan niet zinvol er toch naar te streven. Daarom is het van belang om het streven naar eensgezindheid te beperken tot een afgebakend gebied. Dat afgebakende gebied is de publieke sfeer als beslissingsruimte. Daarin worden alleen zaken van algemeen en gedeeld belang besproken en vastgelegd. Enerzijds kunnen we dan in dat afgebakende, publieke gebied streven naar beslissingen die door iedereen geaccepteerd kunnen worden. Daartoe voeren we dus ook rechtvaardigingen aan die op zo'n draagvlak kunnen rekenen. En omdat de reikwijdte van de publieke sfeer maar beperkt is, hebben we onze private rechtvaardigingsbronnen er ook niet al te hard nodig. Anderzijds 
kan iedereen zich in de resterende private ruimte ontplooien op basis van juist die persoonlijke achtergrond, met een eigen opvatting van wat een goed leven is.

Een mogelijk probleem dient zich hier meteen aan. Mensen kunnen in een situatie komen waarin ze niet voldoende uit de voeten kunnen met de gangbare publieke manieren van rechtvaardiging. Dan kunnen zij de behoefte voelen zich in de publieke ruimte te beroepen op een breder scala aan argumenten dan het gebruikelijke, geaccepteerde repertoire van de publieke rechtvaardigingen. Daarbij lopen ze het gevaar dat die minder gangbare argumenten niet acceptabel zijn voor iedereen. De private bron van rechtvaardiging waarop dan een beroep gedaan wordt, is niet vanzelfsprekend overtuigend in de publieke beslissingsruimte waar hij aangevoerd wordt.

Een normatieve kwestie kan op tenminste twee niveaus tot onenigheid leiden. Ten eerste kunnen wij het oneens zijn over in welke beslissingsruimte de kwestie thuishoort. En mocht zij in de publieke ruimte thuishoren, dan kunnen we het in tweede instantie nog oneens zijn over welke rechtvaardiging daarbij past. Het selecteren van onderwerpen die ertoe doen in de publieke ruimte, en van de argumenten die we daarbij kunnen aanvoeren, heb ik purificatie genoemd. In letterlijke zin is dat de inspanning die we moeten leveren om het debat te zuiveren van argumenten en onderwerpen die we er niet in vinden thuishoren.

Ik heb deze purificatie in de volgende drie onderdelen gesplitst. Bij een normatieve kwestie zullen we ons eerst moeten afvragen (a) of deze in de publieke ruimte thuishoort. Ik heb dit het bereik (scope) van de politiek genoemd. Vervolgens zal er eensgezindheid moeten zijn over (b) welke argumenten daarbij van toepassing kunnen zijn en welke niet. Dit heb ik rechtvaardiging (justification) genoemd. En tenslotte is er de dimensie (c) van het besluit zelf. Dat is de dimensie van inhoud (content). Onenigheid kan optreden op de dimensies van (a) bereik en (b) rechtvaardiging. Weliswaar kunnen we het ook goed oneens zijn over (c) inhoud, maar dat is hier niet relevant. Ik heb namelijk aangenomen dat onenigheid over inhoud altijd leidt tot het aanvoeren van nieuwe argumenten, zodat het feitelijke debat zich altijd zal afspelen op de niveaus van rechtvaardiging en bereik. In de casushoofdstukken blijkt inderdaad dat onenigheid optreedt op de niveaus van zowel (a) bereik als (b) rechtvaardiging. Daarbij valt op dat deze niveaus in de praktijk lang niet altijd even goed van elkaar te onderscheiden zijn: een argument op het ene niveau wordt soms weerlegd met een argument op het andere niveau. 


\section{Politics by All Means}

\section{Technologie}

(ii) Moderne technologie kent allerlei verschillende verschijningsvormen. We hebben allerlei apparaten om ons heen, waarvan we er vele niet eens opmerken omdat ze zo volstrekt gewoon geworden zijn. Dat geldt nog het sterkst voor onze hele infrastructuur van wegen, vervoermiddelen, elektriciteits- en communicatienetwerken, enzovoort. We merken er pas wat van als ze eens niet werken. Maar ook onze massaal gedrukte boeken en kranten, het voedsel in de supermarkt, en het onderwijs dat we genieten, kunnen alleen op deze manier bestaan door de vele technologieën die eraan ten grondslag liggen. We zouden kunnen zeggen dat onze hele cultuur samenvalt met technologie.

We zullen in het algemeen twee verhoudingen tot technologie herkennen. Aan de ene kant bepaalt technologie mede ons leven. Zij heeft een invloed op keuzes die we maken en op wat we denken: bepaalde keuzes worden mogelijk gemaakt door technologie en andere juist minder goed of zelfs helemaal niet mogelijk. Hierin kunnen we soms een belemmering van onze keuzevrijheid ervaren. Aan de andere kant maken we elke dag min of meer vrije keuzes en ervaren we ook dat er juist veel keuzevrijheid voor ons overblijft. We kunnen zelf ons leven sturen. We kunnen zo ook de technologieën om ons heen beïnvloeden. Van belemmering lijkt lang niet altijd sprake, en vaak zal technologie onze keuzevrijheid juist lijken te vergroten. Mensen hebben dus de mogelijkheid om technologie in dienst te stellen van de vrije keuze, terwijl op andere momenten die vrije keuze ondergeschikt lijkt te zijn aan diezelfde technologie.

Actornetwerktheorie (ANT) reikt een adequate manier aan om deze dubbelzinnige verhouding te kunnen beschrijven. ANT vat de wereld op als een geheel van actoren en relaties tussen die actoren. Deze actoren zijn niet alleen mensen, maar ook niet-mensen zoals dingen, dieren en de natuurlijke materie om ons heen. Actoren staan niet op zichzelf, maar zijn aan elkaar verbonden en vormen zo uitgestrekte netwerken. Deze netwerken bepalen de identiteit van een actor. Als actoren, of ze nu menselijk of niet menselijk zijn, iets willen bereiken, zullen ze ervoor moeten zorgen dat voldoende andere actoren dezelfde belangen hebben: om een verandering te bereiken zal het hele netwerk moeten meegaan in die verandering. Het smeden van allianties is noodzakelijk om iets te bereiken en de netwerken de juiste kant op te sturen. Om bijvoorbeeld een auto te produceren die op waterstof in plaats van benzine rijdt, is het niet voldoende alleen zo'n auto te ontwerpen. We moeten dan ook zorgen dat er een infrastructuur is om die auto 
van brandstof te voorzien, we moeten regulering bedingen die het rijden met zo'n auto mogelijk maakt, we moeten misschien fiscale kunstgrepen toepassen om te zorgen dat de auto kan concurreren met de benzineauto, enzovoort.

Actoren ontlenen hun identiteit aan het netwerk waarin ze zich bevinden. Als er dus veranderingen in netwerken optreden, geven die op hun beurt een nieuwe identiteit aan de actoren die er deel van uitmaken. De benzineauto zal een andere zijn na de introductie van de waterstofauto, omdat hij in een andere context terechtkomt en zich dus anders zal verhouden tot die context. De auto is opeens onderdeel van een nieuw netwerk. Belangen worden verschoven, actoren worden geëlimineerd en nieuwe staan op, en ideeën krijgen een andere lading. We kunnen actoren dus alleen goed in beeld brengen als we de omliggende netwerken eveneens goed in beeld brengen. De netwerken in ANT dienen dus niet het doel van het onvervormd overbrengen van informatie, energie, of materie, zoals we dat wellicht intuïtief verwachten bij het begrip 'netwerk'. De netwerken in ANT dienen geen doel, maar hebben slechts effecten. Het netwerkbegrip dient als instrument om veranderingen in kaart te brengen en ze te kunnen begrijpen.

Wij mensen hebben in deze netwerken een plaats net als alle andere actoren. Als wij iets willen bereiken, dan zal dat een inspanning kosten en het netwerk veranderen. En als de situatie verandert, zal dat een effect hebben op alle elementen, ook op onszelf. Dat betekent dat onze belangen kunnen veranderen. Ook onze ideeën en onze handelingsmogelijkheden zullen door de veranderingen beïnvloed worden. En als de situatie verandert, veranderen ook de betekenissen die wij aan de wereld geven en hoe wij die wereld beoordelen. Daarom verandert ook hoe wij onszelf beoordelen. Zo verandert dus ook onze identiteit.

De interacties tussen ons en de wereld om ons heen beperk ik hier tot twee dimensies, namelijk (I) de hermeneutische en (2) de existentiële. (I) De hermeneutische dimensie betreft de invloed van netwerken op onze waarneming van de wereld. Als we bijvoorbeeld milieuvervuiling om ons heen waarnemen, is die vervuiling niet los te zien van een aantal andere elementen. De vervuiling is het gevolg van bepaalde niet-duurzame benaderingen van onze leefwereld. Maar ook hebben we bijvoorbeeld meetmethoden en theorieën nodig waarmee we die vervuiling kunnen waarnemen en inzichtelijk maken. En bovendien moet er op zijn minst een basaal cultureel idee van 'onwenselijkheid van milieuvervuiling' zijn, want anders zou de vervuiling niet als een misstand op de voorgrond kunnen treden. En daarmee is die vervuiling dus iets wat we op die manier pakweg 


\section{Politics by All Means}

honderd of zelfs maar vijftig jaar geleden nog helemaal niet konden zien, en zeker niet op de manier waarop we haar nu kunnen zien. Als de netwerken waarin wij ons bevinden veranderen, dan verandert daarmee onze waarneming van de wereld. Dan verandert ook de betekenis die wij aan de wereld geven, en dus ook hoe wij normatief in die wereld staan.

(2) De existentiële dimensie betreft de invloed van netwerken op ons handelen. De actoren om ons heen maken dat bepaalde keuzes meer voor de hand liggen dan andere, en dat sommige keuzes zelfs onmogelijk zijn. Dat we even aan de andere kant van het land op de koffie kunnen gaan is alleen mogelijk omdat we auto's en snelwegen hebben. En omdat die auto's en wegen bestaan, kan afstand geen excuus meer zijn om onze familie te verwaarlozen. Dan kan sociale druk optreden die maakt dat we inderdaad de keuze maken om tweehonderd kilometer te rijden voor een uurtje gezelligheid. Iets minder vanzelfsprekend is bijvoorbeeld dat een typische werkdag van een academicus vandaag alleen kan bestaan omdat de supermarkt efficiënt voedsel kan aanleveren. Als er eerst nog gejaagd en geoogst zou moeten worden, zou er weinig tijd meer zijn om boeken te schrijven. Ook morele keuzes worden beïnvloed: velen vinden het immoreel om kinderen de gangbare inentingen te onthouden. Dit oordeel kan echter alleen geveld worden tegen een achtergrond waarin inenting technisch onproblematisch is. In een wereld waarin die inentingen niet bestaan, heeft het immers geen enkele betekenis om ze onze kinderen te onthouden. In zo'n wereld kunnen we evengoed op morele gronden pleiten voor goede zorg voor onze kinderen, maar inenten zal geen deel kunnen uitmaken van die goede zorg.

Hiermee is dus een verbinding gelegd tussen (ii) technologie en (i) de idee van liberale politiek. De verhoudingen tussen mensen zijn technologisch van aard, omdat netwerken met technologieën erin overal zijn en overal hun invloed uitoefenen. Technologieën bevinden zich op gelijke voet met ons in die netwerken. En de verhoudingen binnen die netwerken zijn ook politiek van aard, omdat we bepaalde beslissingen samen moeten nemen. Het was al duidelijk dat de liberale politiek onze normativiteit verdeelt in een publiek en een privaat deel. In combinatie met het begrip van technologie als onderdeel van netwerken wordt duidelijk dat technologische veranderingen deze scheiding tussen publiek en privé op scherp kunnen stellen. Dat kan zijn omdat een nieuwe configuratie niet samenvalt met onze scheiding tussen beslissingsruimten. Het kan zijn omdat een nieuwe configuratie vraagt om argumenten die uit de verkeerde 
rechtvaardigingsbron lijken te komen. Of het kan zijn dat de configuratie zo nieuw is dat we haar überhaupt geen plaats kunnen geven, noch qua beslissingsruimte, noch qua rechtvaardigingsbron. Deze drie soorten uitdagingen zien we inderdaad optreden in de casushoofdstukken.

\section{Lastige discussies}

In dit boek worden drie controverses behandeld waarin politiek en technologie over elkaar heen buitelen en waarin de scheiding tussen publiek en privé onder druk komt te staan. Ten eerste wordt (A) enhancement ofwel verbeteringsgeneeskunde behandeld. Van enhancement spreken we bij alle ingrepen in het menselijk lichaam die niet noodzakelijk zijn vanuit medisch oogpunt, maar die gericht zijn op het verbeteren van het menselijk lichaam en zijn prestaties. In deze controverse staat de vraag centraal of we het moeten toestaan dat we de menselijke natuur onderwerp maken van onze manipulatie. Het tweede casushoofdstuk gaat over (B) biobanken. Dit zijn grote systemen waarin veel genetisch materiaal en medische gegevens zijn opgeslagen voor geavanceerde bestudering van ons genoom. Met name het bezit van lichaamsmateriaal en informatie over dat materiaal roept vragen op die in veel opzichten nieuw zijn, en die de biobank-controverse tot een lastige maken. En tenslotte wordt een debat in de Nederlandse politiek over (C) pre-implantatie genetische diagnostiek behandeld. Dit debat laat zien dat ook in de alledaagse politieke praktijk purificatie herkenbaar is, en dat technologische vooruitgang ervoor zorgt dat deze purificatie heviger wordt. In de nu volgende paragrafen zullen deze drie casussen systematisch worden besproken langs de drie politieke dimensies, te weten (a) bereik, (b) rechtvaardiging en (c) inhoud. Voor zover relevant komen daarbij zowel (I) de hermeneutische als (2) de existentiële dimensie van technologie aan de orde.

\section{Verbeteringsgeneeskunde}

Enhancement betreft alle ingrepen in het menselijk lichaam gericht op het verbeteren van de eigenschappen van de mens. Hieronder valt ook het eventueel aanpassen van het genoom van onze kinderen, opdat zij de eigenschappen zullen bezitten die wij als ouders graag in hen zien. Als we de vraag willen bespreken of we onze kinderen naar believen mogen ontwerpen, dienen we eerst de vraag te beantwoorden of we het er in de publieke sfeer überhaupt over moeten hebben. 


\section{Politics by All Means}

Sommigen voeren argumenten aan enhancement als een private aangelegenheid te zien. Als het privé is, hoeven we er immers ook geen eensgezindheid in na te streven. Dit is een poging tot purificatie die zich afspeelt op het niveau van (a) bereik. Zulke pogingen tot privatisering zijn in het geval van enhancement meestal gebaseerd op de gedachte dat anderen geen last van de enhancement zullen ondervinden en er ook nooit toe gedwongen worden. Tegelijkertijd stelt enhancement wel toekomstige ouders in staat om in hun privésfeer het beste voor hun kinderen na te streven. Deze poging tot purificatie vindt haar tegenbeweging deels op hetzelfde niveau van bereik. Anderen betogen namelijk dat enhancement zo slecht is, dat we het ook niet in de privésfeer van anderen kunnen tolereren. Enhancement zou een despotische houding jegens kinderen uitdrukken, het zou immense gevaren met zich meebrengen omdat we de gevolgen niet kunnen overzien, of het zou ons op de stoel van God zetten.

$\mathrm{Bij}$ het verwoorden waarom enhancement wel of niet privé is, worden argumenten aangevoerd die niet voor iedereen vanzelfsprekend zijn. Lang niet voor iedereen is het problematisch om op de stoel van God te gaan zitten. Deze argumenten zijn dus niet vanzelfsprekend geschikt voor publieke rechtvaardiging. We zien inderdaad dat voorstanders van enhancement betogen dat deze argumenten niet in de publieke ruimte thuishoren. Zij vinden deze argumenten hoogstens geschikt als rechtvaardiging in de privésfeer voor degenen die er waarde aan hechten. Hiermee is het debat dus verschoven naar het niveau van (b) rechtvaardiging.

In deze controverse speelt technologie een schijnbaar onbeduidende rol. Het ook niet duidelijk zichtbaar dat netwerken veranderd moeten worden of zich verzetten tegen die veranderingen, of dat bijvoorbeeld artefacten een bepaalde gang van zaken afdwingen. Niettemin zijn onder de verschillende posities in het enhancementdebat verschillende visies op technologie te herkennen. Als mensen benadrukken dat enhancement geen privéaangelegenheid kan zijn, lijkt het er vaak op dat ze ook een beeld van technologie hebben waarin weinig ruimte is voor sturing en vrije keuze. Zij hanteren een deterministisch beeld van technologie. Deze mensen vrezen dat grote ellende over onszelf afroepen als we een dergelijke niet-stuurbare technologie toelaten, ook als het gebruik van die technologie wordt beperkt tot de privésfeer. En aan de andere kant, mensen die enhancement wel als een privézaak beschouwen, zijn geneigd om over technologie te denken alsof die altijd probleemloos ten dienste van onze keuzes staat. Zij hanteren een 
instrumentalistisch beeld van technologie en geloven dat die technologie nooit zelfstandig de overhand zal krijgen. We zullen in hun ogen dus altijd onze keuzevrijheid houden en onze ethiek daarin als leidraad nemen.

Het hoofdstuk over enhancement heeft laten zien dat er een samenhang is tussen deze opvatting van technologie die personen hanteren, de mate waarin zij die technologie als privatiseerbaar zien - een vraag van (a) bereik dus en het type argumenten dat zij willen aanvoeren om die privatiseerbaarheid te verdedigen of te ontkrachten - een kwestie van (b) rechtvaardiging dus. Mensen die pessimistischer over technologie denken, zullen die minder als privatiseerbaar zien, en een groter scala aan argumenten willen toelaten. En mensen die technologie wel als privatiseerbaar zien, denken vaak ook optimistischer over die technologie en de stuurbaarheid ervan. Daarmee is een belangrijke correlatie aangetoond tussen de liberale purificatie en de purificatie die uit technologische beloften naar voren komt. In termen van ANT zouden we kunnen stellen dat technologie en liberalisme een goede alliantie vormen. Ze hebben dezelfde belangen waar het gaat om het uitsluiten van actoren.

Het hoofdstuk heeft ook aangetoond dat purificatie niet vanzelfsprekend succesvol is. Als argumenten of onderwerpen uit de publieke sfeer gedrukt worden, is de kans groot dat het belang van sommige actoren daarmee geschaad wordt. Zij zullen zich dan verzetten tegen de uitsluiting. In de controverse over enhancement zien we inderdaad dat diverse deelnemers aan het debat ervoor pleiten om verdrukte onderwerpen en argumenten juist wél in de publieke sfeer toe te laten. Het verzet richt zich daarmee op de vermeende oppervlakkigheid van het gangbare politieke taalgebruik.

\section{Biobanken}

Biobanken bevatten grote hoeveelheden materiaal en medische gegevens. Met behulp van computers kan daarbinnen naar correlaties gezocht worden tussen ons genoom en de manier waarop dat genoom tot uitdrukking komt. Deze correlaties zijn voor een deel zo zwak dat we ze nu nog niet kunnen zien. Te denken valt aan een aanleg voor genetische ziekten, de vatbaarheid voor infectieziekten, maar ook individuele gevoeligheid voor bepaalde voedingsstoffen of allergenen, en de aanleg voor eigenschappen als intelligentie, spierkracht, enzovoort.

Gezien het medisch-wetenschappelijke karakter van biobanken, ligt het voor de hand om de medische ethiek te raadplegen voor het reguleren ervan. In het geval 


\section{Politics by All Means}

van biobanken zou de medische ethiek voorschrijven dat de deelnemer uitgebreid wordt voorgelicht over de gevolgen en de doelen van het biobankonderzoek. Vervolgens heeft de deelnemer de volledige vrijheid om wel of niet in te stemmen met deelname aan het onderzoek. Van dwang of paternalisme kan immers geen sprake zijn als het basisprincipe van autonomie gerespecteerd wordt.

Daarmee is meteen een eerste antwoord gegeven op zowel (a) bereik als (b) rechtvaardiging. Immers, met betrekking tot bereik hebben we in de medische ethiek de routine ontwikkeld dat de brede kaders worden voorgeschreven door wetten en richtlijnen, terwijl de finesses van de beslissing, na goede informering door de arts, bij de patiënt zelf liggen. En met betrekking tot rechtvaardiging behoort het tot onze routine dat we de waardering van autonomie en bescherming van het individu belangrijk vinden. Daar meten we onze argumenten aan af.

Deze aanpak blijkt echter geen uitkomst te bieden in het geval van biobanken. Om te beginnen is het lastig, zo niet totaal onmogelijk om de deelnemer goed voor te lichten. Om alles te begrijpen zou de deelnemer bijna moeten worden opgeleid tot klinisch geneticus. Bovendien is veel van het toekomstig onderzoek nu nog niet goed uit te leggen omdat de wetenschappers daarover zelf ook nog te weinig weten. Daarbij komt dat het voor biobanken ongunstig is als ieder voor zich kan bepalen of hij of zij materiaal ter beschikking wil stellen. Voor biobanken zou het veel beter zijn als de vraag over deelname geen private vraag was, maar een van publiek belang. Het wordt dan dus een vraag binnen het bereik van de politiek. Dan kan de biobank zich bezighouden met complete populaties in plaats van met fragmenten ervan. De gebruikelijke (c) inhoud van medische ethiek pakt dus niet heel gelukkig uit voor biobanken.

Ook de gangbare (b) rechtvaardiging in de medische ethiek houdt geen stand. Die rechtvaardiging is gebaseerd op de grote schade die een individu kan lijden als hij of zij niet goed beschermd wordt tegen de veel machtigere medischwetenschappelijke instituties. Velen betogen echter dat die mogelijke schade in het geval van biobanken erg zal meevallen, en zeker niet zal opwegen tegen de enorme voordelen die we er op collectief niveau van kunnen hebben. Deze frictie is wederom niet los te zien van (a) het bereik van de politiek en de privésfeer. Vanuit het perspectief van de biobank geredeneerd, zou het juist helemaal geen private keuze moeten zijn of mensen willen deelnemen of niet.

In de relatie tussen politiek en technologie is dit een interessant gegeven. Kennelijk dicteert de technische configuratie van de biobank ons dat politieke routines 
en de rechtvaardiging daarvan achterhaald zijn. In het bijzonder blijkt dat medische ethiek niet langer bruikbaar is. Hierbij zijn, meer dan in de enhancement-casus, de twee dimensies van technologie zichtbaar. (I) De hermeneutische dimensie van biobanken behelst dat ons een idee wordt aangereikt van hoe genen en het bezit ervan te interpreteren zijn. Genen zijn met name informatie die wat waard wordt door de inspanning van wetenschappers. Onze identiteit en hoe die samenhangt met onze genen verdwijnen daarbij eigenlijk buiten beeld. Ook zijn genen iets waarmee we een bijdrage kunnen leveren aan onze gemeenschappelijke belangen, en niet iets wat we voor onszelf moeten houden en te gelde maken - als dat al zou kunnen. Langs deze hermeneutische dimensie heeft de technologie dus invloed op hoe wij (c) de inhoud van politieke besluiten normatief beoordelen.

De (2) existentiële dimensie van biobanken behelst dat we tenminste gedwongen worden een standpunt in te nemen met betrekking tot de eigendom van genen, en een keuze te maken om al dan niet bij te dragen aan het collectieve belang. Of sterker, biobanken maken deze keuze eigenlijk al voor ons: ze dragen uit dat het beter is aan dat collectieve belang bij te dragen. Daarmee drukken biobanken dus een bepaald ideaal van burgerschap uit.

In de controverse rond biobanken zijn onder actoren minstens drie dynamieken te onderscheiden. Ten eerste is er onze typische manier van wetenschap bedrijven die belang hecht aan biobanken. Vanuit dit perspectief geldt dat we moeten investeren in de zoektocht naar kennis. We kunnen best een stukje van onze privacy en autonomie opgeven, als we daarmee de hele mensheid vooruit helpen. Ten tweede is er onze typische manier van medische ethiek bedrijven, die autonomie boven alles stelt. De patiënt heeft recht op bescherming, en alles wat zijn of haar autonomie aantast, is taboe. Toegepast op biobanken levert dit welhaast de onmogelijkheid op om van burgers te verlangen dat ze een beetje lichaamsmateriaal afstaan, of het moet volstrekt vrijwillig en uit motieven van liefdadigheid zijn. En ten derde is er een aantal tradities van vrijgevigheid en naastenliefde. Veel mensen hechten niet zoveel belang aan ultieme zeggenschap, maar vinden het belangrijker om iets goeds te doen voor anderen. Zij zijn dus bereid om zonder bezwaar en beetje materiaal en informatie af te staan. Al deze elementen geven op hun eigen manier input aan de controverse.

Geen van deze dynamieken blijkt in staat de overhand te krijgen. Deze onoplosbaarheid lijkt voort te komen uit de volgende spanning. Achter elk van deze posities gaat een idee van eigendom schuil. De wetenschappelijke variant 


\section{Politics by All Means}

drukt uit dat genen niemands eigendom zijn, maar alleen wat waard worden door wetenschappelijke inspanningen. Dat moet vervolgens ten goede komen aan het algemeen nut. Het medisch-ethische beschermingsparadigma drukt uit dat genen eigendom van het individu zijn, en dat dit individu dus de ultieme zeggenschap heeft over wat ermee moet gebeuren. En de tradities van vrijgevigheid drukken uit dat genen misschien wel ons eigen eigendom zijn, maar dat er tevens een plicht bestaat om met dat eigendom anderen te helpen.

Geen van al deze ideeën blijkt echter goed te passen op het 'bezitten' van genen. Onze genen behoren op een ambigue wijze toe aan ons als individu, aan onze familie, onze natie en aan de hele mensheid. Geen van de genoemde benaderingen blijkt in staat om goed aan te sluiten bij deze ambiguïteit. De wetenschappelijke visie doet geen recht aan de intuïtie die we hebben dat onze genen van ons zijn. En de medisch-ethische visie lijkt juist door te schieten in het respecteren van die intuïtie. Dat deze denkwijzen niet goed aansluiten, ligt aan de technische configuratie van de biobank. Deze technische configuratie is op haar beurt afhankelijk van onze menselijke natuur en hoe we die denken te moeten onderzoeken. Die natuur en onze voorkeur om die in termen van genen te onderzoeken bepalen zo mede welke vormen van ethiek goed over het voetlicht te brengen zijn. Samen met de technologische configuratie van de biobank bepalen zij dus mede welke dingen gezegd kunnen worden en welke dat niet kunnen.

Biobanken drukken dus een bepaald idee van eigendom uit dat niet in lijn is met ideeën van eigendom die gangbaar zijn in de discussie. In het uitdrukken van die ideeën is (I) de hermeneutische dimensie van technologie te herkennen. Die hermeneutische dimensie heeft hier rechtstreeks een invloed op (b) de rechtvaardiging in politiek. Technologie destabiliseert begrippen die een centrale rol in die rechtvaardiging spelen. Saillant is daarbij dat die rechtvaardiging met instabiele begrippen ook de discussie over biobanken zelf betreft. Biobanken ondermijnen dus hun eigen beoordeling. En omdat de rechtvaardiging hier gedestabiliseerd wordt, mogen we verwachten dat ook (a) het bereik en (c) de inhoud niet vanzelfsprekend zullen zijn.

\section{Pre-implantatie genetische diagnostiek}

Pre-implantatie genetische diagnostiek of PGD is een procedure waarbij embryo's geselecteerd worden op genetische eigenschappen. PGD wordt uitgevoerd als onderdeel van een IVF-procedure (in vitro fertilisatie of reageerbuisbevruchting), 
en zal in de meeste gevallen worden toegepast om ernstige, genetisch bepaalde ziekten te voorkomen. Over dit onderwerp barstte in het voorjaar van 2008 een vurig debat los in de Tweede Kamer. Inzet van het spel was een uitbreiding van de toestemming voor de toepassing van PGD. Voortaan zou die ook toegestaan zijn ter voorkoming van erfelijke borstkanker. Deze stap was voor sommigen een brug te ver, omdat de aanleg voor borstkanker niet met Io०\% zekerheid tot ontwikkeling van de ziekte leidt, en er dus embryo's zullen worden weggegooid die wellicht een gezond leven zouden hebben gehad.

Een van de vragen was of de politiek zich hier überhaupt mee dient te bemoeien. We zouden immers ook kunnen zeggen dat de medische ethiek voldoende toegerust is om deze lastige vragen aan te pakken. Inderdaad stelden veel partijen dat de beslissing om PGD uit te voeren een private moet zijn, in lijn met de autonomie die centraal staat in de medische ethiek. Daar tegenover stonden echter enkele christelijke partijen, waaronder coalitiedeelnemer ChristenUnie, die meenden dat het wel degelijk aan de politiek was hier een grens te stellen. Dit deel van de controverse betrof de vraag van (a) bereik.

De tegenstanders van de ChristenUnie spanden zich in om aan te geven dat de aangevoerde redenen voor een verbod op PGD zodanig privaat van aard zijn, dat deze geen rol kunnen spelen in publieke besluitvorming. Wat hen betreft horen argumenten uit de Bijbel niet het politieke debat thuis. De ChristenUnie voerde daartegen aan dat hun Bijbelse referentiekader net zoveel bestaansrecht heeft als de libertijnse of socialistische dogma's waar andere partijen zich op baseren. Wat de ChristenUnie betreft zouden al deze achtergronden juist welkom moeten zijn in het debat, terwijl het er nu veelal op uitdraait dat alleen de seculiere geluiden in het debat terechtkomen. Net als in het geval van enhancement, treedt ook hier dus een verschuiving op naar het niveau van (b) rechtvaardiging.

We kunnen de controverse rond PGD alleen begrijpen als we ook naar de context kijken waarin zij zich afspeelt. In het Nederland van 2008 zijn medischtechnologische praktijken als IVF en abortus breed geaccepteerd. Hoewel veel mensen abortus niet als iets moois zien, zal de meerderheid van hen het er toch over eens zijn dat het goed is dat mensen er zelf over kunnen beslissen. Zij accepteren dat abortus in voorkomende gevallen de minste van alle kwaden is. Eenzelfde acceptatie geldt voor IVF. Dit wordt door de grote meerderheid gezien als een goede oplossing voor bepaalde vormen van onvruchtbaarheid. Zij vinden het geen zwaarwegend probleem dat er bij de procedure embryo's verloren 


\section{Politics by All Means}

gaan. Deze twee praktijken zijn doortrokken van het idee dat het ongeboren leven geen onvoorwaardelijke bescherming geniet, maar dat er op deze bescherming uitzonderingen mogelijk zijn. De nieuwe toepassing van PGD en de reeds bestaande technologieën hebben ons samen het idee aangereikt dat de preventie van ernstige genetische aandoeningen haalbaar en wenselijk is, ook als dat af en toe een embryo kost. In dat licht is het moeilijk te beargumenteren dat het embryo meer zou kunnen zijn dan een gevoelloos klompje cellen. Dit is een duidelijk voorbeeld van de (I) hermeneutische dimensie van technologie. Het voorbeeld toont ook aan dat we technologie slechts kunnen begrijpen in haar context, in samenhang met de mensen eromheen en wat die ermee doen.

Het feit dat die technologieën klaarliggen maakt het moeilijker om te besluiten ze niet te gebruiken. Daarmee is niet gezegd dat PGD een lichte ingreep zou zijn of dat het volstrekt onmogelijk zou zijn om van de toepassing van PGD af te zien. Wel betekent het dat bepaalde keuzes vanzelfsprekender worden dan andere. Als het al moeilijk wordt het embryo te zien als iets anders dan een klompje cellen, dan wordt het des te moeilijker om te beargumenteren waarom je geen PGD zou toepassen als er sprake is van een verhoogd risico op erfelijke borstkanker. Er wordt niets verplicht gesteld, maar een afkeurend moreel oordeel hangt wel in de lucht als ouders er niet voor kiezen hun kind door middel van PGD tegen kanker te beschermen. Langs deze weg van sociale druk geeft de praktijk van PGD gestalte aan (2) de existentiële dimensie.

In deze PGD-casus is de samenhang tussen politiek en technologie goed zichtbaar. Langs zowel de hermeneutische als de existentiële dimensie heeft de technologische achtergrond als het ware een deel van het vocabulaire van de politiek bepaald. En net als bij biobanken gebeurt dat terwijl de technologie van PGD zelf ook een onderwerp van gesprek in de politiek is. Met andere woorden, de aanwezige technologische achtergrond heeft een bepaalde invulling gegeven aan zowel (b) rechtvaardiging als (a) bereik, terwijl het zelf ook een object van die rechtvaardiging en dat bereik is.

Deze casus laat tenslotte ook zien dat er een duidelijke relatie is tussen (ii) technologie en (c) inhoud. Immers, de uiteindelijke politieke inhoud valt vrijwel samen met de technologische mogelijkheden. Dat betekent niet dat de technologie simpelweg onze besluitvorming heeft gedicteerd. Het debat is ook niet voor niets gevoerd, want de politieke situatie erna is een andere dan die ervoor. De technologie heeft de politiek met name gedwongen bepaalde zaken ter discussie 
te stellen, inclusief over hoe wij in de toekomst om willen gaan met deze vragen. De vraag is dan tot op welke hoogte we er politiek over willen spreken, en welke argumenten willen we daarbij aanvoeren en welke niet. Deze elementen van (a) bereik en (b) rechtvaardiging zijn geconsolideerd in elementen van (c) inhoud. Hoe we in de toekomst denken over bereik en rechtvaardiging is mede een resultaat van de discussie van vandaag.

\section{Liberale technologie}

De controverses hebben drie belangrijke punten laten zien. Ten eerste is er een permanente spanning over de vraag of bepaalde zaken wel in de publieke sfeer thuis horen. Het geaccepteerd krijgen van zaken in de publieke sfeer, of ze juist erbuiten houden, is een kwestie van hard werken. Bovendien is het een inherent onderdeel van het politieke gesprek zelf. Dat geldt voor zowel het al dan niet op de agenda krijgen van een bepaald onderwerp als voor het al dan niet op tafel krijgen van bepaalde argumenten. Het betreft dus zowel (a) bereik als (b) rechtvaardiging. Dit vormgeven van het debat heb ik purificatie genoemd: iedere gespreksdeelnemer streeft een bepaald ideaal van een zuiver debat na.

Ten tweede blijkt dat technologie in die spanning en purificatie een bijdrage levert. Ook technologie zorgt er namelijk voor dat bepaalde dingen makkelijker te zeggen zijn dan andere. Dat komt doordat technologie ons een interpretatie van de wereld aanreikt, en omdat ze ons antwoorden aanreikt op keuzes in ons handelen. Ook dit heeft zijn invloed op zowel (a) bereik als (b) rechtvaardiging. Maar bovendien is ook zichtbaar dat technologie in staat is een bepaalde (c) inhoud voor te dragen. Met name in het PGD-debat is zichtbaar dat de uiteindelijke politieke uitkomst nagenoeg samenvalt met de technische configuratie.

Ten derde valt op dat de veranderingen die technologie teweegbrengt vaak aanleiding zijn om dingen in de publieke ruimte te willen bespreken, terwijl die technologie zelf tegelijkertijd de indruk wekt dat er niets te bespreken valt. Technologie belooft slechts onze keuzes beter te faciliteren, en los te staan van de ethische beraadslaging die we voor die keuzes nodig hebben. Met name posities die een kritische beoordeling van technologie bevatten, zijn binnen die structuur moeilijk over het voetlicht te krijgen.

Tot nu toe is beschreven hoe moderne technologie zich mengt in onze omgang met de wereld en zich verhoudt tot onze normativiteit. Deze verhouding 


\section{Politics by All Means}

geeft alle aanleiding tot interferentie tussen technologie en hoe wij normaal gesproken omgaan met normativiteit, namelijk volgens de liberale beginselen. In de casestudies is gebleken dat technologie ons een de manier van kijken naar de wereld aanreikt. Alternatieve manieren van kijken zijn tegen die achtergrond moeilijker houdbaar, en in het ergste geval komen ze er zelfs vanaf als irrationeel. Dat is opvallend. De liberale beginselen schrijven voor dat politieke gesprekken in redelijkheid moeten plaatsvinden en zich niet op rationaliteit moeten beroepen. Daarbij wordt redelijkheid opgevat als een houding van proberen samen iets te bereiken. Rationaliteit daarentegen behelst een idee van de voorwaarden waaraan kennis moet voldoen om waar te zijn, en in een pluriforme samenleving is een beroep op rationaliteit vaak aanleiding tot onenigheid. Toch blijkt de alledaagse politieke redelijkheid sterk te zijn beïnvloed door de hoe de meerderheid over rationaliteit denkt. Het wereldbeeld aangereikt door technologieën draagt nog eens extra bij aan die invloed.

Toch lijkt moderne technologie een neutrale rationaliteit uit te willen dragen. Wellicht is het om precies die reden dat in veel liberale ideeën geen kritische houding jegens technologie te vinden is. Zowel technologie als liberalisme beloven dat iedereen op zijn of haar eigen manier het goede leven kan nastreven; ze vormen zo een krachtige alliantie die een beeld van neutraliteit en redelijkheid hoog houdt. Aan de andere kant kunnen we er niet omheen dat technologie veranderingen teweegbrengt die moreel relevant zijn, en dus niet neutraal. Deze invloed is te zien in veranderingen in ons wereldbeeld, in de veranderende betekenis die wij aan concepten toekennen, en in onze veranderende taal en dus de veranderende taal van de politiek. Hiermee veroorzaakt technologie dus onenigheid. Immers, als onder de oppervlakte van het gesprek betekenissen van woorden en principes beginnen te verschuiven, is het niet verwonderlijk dat er in dat gesprek spraakverwarring optreedt, met alle gevolgen van dien. Deze spraakverwarring vindt wederom plaats op alle niveaus van politiek. Doordat onze concepten en normen veranderen, treedt een verschuiving op in de zaken die wel en niet besproken kunnen worden in de publieke sfeer, en in de argumenten die daarbij al dan niet aangevoerd kunnen worden.

Op dit punt kunnen bestaande praktijken van techniekethiek en onderzoek naar technologie en maatschappij (technology assessment) dus kunnen worden uitgebreid en verbeterd. Er is al enig oog voor de normatieve invloed van technologie. In aanvulling daarop zou aandacht besteed kunnen worden aan 
de invloed van technologie op de mogelijkheid tot het uitspreken van argumenten, en aan de invloed van technologie op de betekenis van bepaalde begrippen. Dit behelst ten dele een verschuiving van de bewijslast. We kunnen niet langer eisen dat eenieder in liberale termen uitlegt wat zijn of haar bezwaren zijn, ook al zijn we nog zo overtuigd dat die termen neutraal en dus redelijk zijn. Ook al lijkt het embryo nog zo'n helder begrip, tegen de achtergrond van bestaande praktijken is de positie van de ChristenUnie een stuk moeilijker te verwoorden dan die van seculiere debatdeelnemers. In plaats van eisen dat mensen zich in zulke termen uitdrukken, kunnen we beter verlangen dat voorvechters van een verandering aangeven waarom de onderliggende verschuiving in betekenissen en de mogelijkheid bepaalde argumenten aan te voeren gerechtvaardigd zou zijn. Zij dienen dus aan te geven waarom het wenselijk is dat de uitbreiding van PGD het embryo nog een stapje minder beschermwaardig maakt.

Ten eerste zullen we daarbij moeten erkennen dat veel van deze verschuivingen subtiel en impliciet plaatsvinden. Derhalve zal het lastig zijn om aan te wijzen wie we ter verantwoording moeten of kunnen roepen. Dat neemt echter de noodzaak ervan niet weg. Het zou oneerlijk zijn als we van mensen verlangen dat ze zich uitdrukken in neutrale termen, terwijl diezelfde neutrale termen van betekenis veranderen, omdat anderen een technologische ontwikkeling in gang zetten. De eersten zullen zich in het gebruik van die termen niet meer herkennen en zich dus niet meer kunnen uitdrukken. Het voorgestelde principe trekt dat recht - zij het wellicht hoogst idealistisch.

Ten tweede zullen we moeten erkennen dat in alle behandelde debatten uiteindelijk de meerderheid gewoon haar zin krijgt. Dat is vanuit democratisch oogpunt niet direct problematisch. Wel kunnen we pogen om met de voorgestelde aanpassingen ervoor te zorgen dat de verliezende minderheid beter in staat wordt gesteld haar standpunt te verdedigen, zonder daarbij reeds bij voorbaat ten prooi te vallen aan een meerderheid die betekenissen van concepten opdringt zodat de minderheid zich nooit ten volle zou kunnen verdedigen. Het doel van dit boek is om op dit laatste punt wat eerlijkheid toe te voegen. Door de lastige discussies niet uit de weg te gaan maar juist te een beredeneerde plaats te geven kan de uiteindelijke beslissing mogelijk op een breder draagvlak rekenen. 


\section{About the author}

Govert Valkenburg (I977) obtained degrees in electrical engineering (MSc) and philosophy of science, technology and society (MA) at the University of Twente. In addition, he obtained a degree in classical vocals (BMus) at the ArtEZ Conservatory in Enschede. Currently, he works as a researcher in philosophy of technology at Maastricht University. He concentrates on the interaction between technoscientific, political and social change. He particularly focuses on mobility, sustainability and the controversy on climate change. Alongside, he unfolds a modest career as a solo singer, mostly in the Baroque repertoire.

http://www.govertvalkenburg.nl/ 
Simon Stevin Series in Ethics of Technology

Editors: Philip Brey, Peter Kroes and Anthonie Meijers

3TU Centre for Ethics and Technology Publications:

\section{Books and Dissertations}

Volume I: Lotte Asveld, Respect for Autonomy and Technology Risks, 2008

Volume 2: Mechteld-Hanna G. Derksen: Engineering Flesh. Towards Professional Responsibility for "Lived Bodies" in Tissue Engineering, 2008.

Volume 3: Govert Valkenburg: Politics by All Means. An Enquiry into Technological Liberalism, 2009

Research Documents: 


\section{Simon Stevin (1548-1620)}

'Wonder en is gheen Wonder'

This series in the philosophy and ethics of technology is named after the Dutch / Flemish natural philosopher, scientist and engineer Simon Stevin. He was an extraordinary versatile person. He published, among other things, on arithmetic, accounting, geometry, mechanics, hydrostatics, astronomy, theory of measurement, civil engineering, the theory of music, and civil citizenship. He wrote the very first treatise on logic in Dutch, which he considered to be a superior language for scientific purposes. The relation between theory and practice is a main topic in his work. In addition to his theoretical publications, he held a large number of patents, and was actively involved as an engineer in the building of windmills, harbours, and fortifications for the Dutch prince Maurits. He is famous for having constructed large sailing carriages.

Little is known about his personal life. He was probably born in 1548 in Bruges (Flanders) and went to Leiden in I58I, where he took up his studies at the university two years later. His work was published between I58I and I6I7. He was an early defender of the Copernican world view, which did not make him popular in religious circles. He died in 1620 , but the exact date and the place of his burial are unknown. Philosophically he was a pragmatic rationalist for whom every phenomenon, however mysterious, ultimately had a scientific explanation. Hence his dictum 'Wonder is no Wonder', which he used on the cover of several of his own books. 
Politics by All Means 


\section{Index}

abortion, 88, I95

acceptability, 47

acceptance, 47

actor, 80

actor-network theory, see ANT

Agar, Nicholas, II3, II5, II9, I3O, I3I

Akrich, Madeleine, 76

alcohol abuse, 4I, IO4, II4

allemannsretten, $\mathrm{I} 66$

anomaly, 6I

anonymization, I75, I7 6

ANT, 66, 79, 80, 83, 85, 97, 215, 232

anticommons, tragedy of the, I7O

appropriate argument, 27

aspirational fiction, $38,52,55$

autonomy, 7, I4, 36, 37, I43, I55, I56, I58, I62, I67, I70, I77, I82, I86, 208, 265

Baylis, Françoise, ııo

benevolence, I54

Big Brother, 152

bio-informatics, I49

biobank, 23, I49

biological determinism, Io9

black box, 8I

Blackburn, Simon, II7

blood donation, I78

Borgmann, Albert, 69, II5, II6

Bostrom, Nick, I2I, I23, I2 8

boundary object, $6_{3}$

boundary work, 138

brain death, 78

Brave New World, 3, I05, I23

Brock, Dan W., 8, i26

Buchanan, Allen, 8, II2, II7, II9, I20, I22

burdens of judgment, 3I, 44, 46, 7I, 223

Busby, Helen, I62, I78

Campbell, John, iıо

Castells, Manuel, 83

categorization, 60

CDA, 2OI
Chadwick, Ruth, I62, I63, I82, I87

choice paradigm, 9I, I30, I32, I44, I54, I83, I87

ChristenUnie, 20I

church wars, 55

citizenship, I6I, I87

classification, 90

cloning, 3--5, 7, 8, I0, I2--15, I9, 27, 39, 43, $46, \mathrm{II} 3, \mathrm{I2} 6, \mathrm{I33}, \mathrm{I90}$

coercion, 39, 2II

cold nuclear fusion, 94

collective agency, 82

Collingridge dilemma, 82

Collingridge, David, 82

commodification, 69, I6I

communitarian turn, I62, I79

communitarianism, 47, I44

comprehensive doctrine, 32,44

concept, 44, 45, 6I

conception, 44

conception of the good, 33

condition of tolerance, $29,36,37,57,87, \mathrm{I} 32$, I36, I37, I98, 205, 208, 209, 224, 229, 236

constructivism, 37, 42, 44, 52, 55, 56, 84

content, 50

contingency, 34, 37, 42, 43, 49, 50, 54, 56, 97, I43, I65, I88, 215, 224

counter-purification, I4I, I44

criteria of pertinence, $58,224,236$

crosstalk, I4I, I45

decision space, 36, 37, 223

democracy, 38,50

democratization, 67

designer baby, I03

despotism, 8, III, I33, I37

destabilization, I8, I73, I8I, I86--I90, 228, 235

determinism, 66, I29, I39

device paradigm, 69 , II 5

dialectics of purification, 63, I43, 233 
Dickenson, Donna, I64

difference principle, 53, I2 I

dignity, I2, III, II2, I38, I70, I76, 227, 230

Dijck, José van, 76

Dijk, Jan van, 83

discourse, II

distribution scheme, 53

distributive justice, 53, II7, I60

Dolly, 3, I9, 89

double bind, I45, 232

Down's syndrome, 107

dystopia, I22

embracement, 58, I28, I29, I39, I4I

emerging irreversibility, 82

emotional, I7, I8

emotivism, 73

endorsement, 48

enhancement, see human enhancement

Enlightenment, 72, 92

evidence-based medicine, 8I

exemplary situation, 182,232

existential dimension, 233

existential role, 77

extending life, I05, I28

externality, 92

fact, 72

familial breast cancer, 203

fatalism, I27

Feenberg, Andrew, 68, 92, I47

focal practice, II5

Fox, Dov, II4

Frankenstein, 89

future diary, 153,158

gene-pool impact, ııо

genetic determinism, I09, II3, I59

genetic liberalism, I25, I29

genetic protectionism, I32

germ-line engineering, 8, пाо

Gieryn, Thomas F., 75

giftedness, II2

global justice, I22

God, II6, II7, I38, 230

good life, I6, 2I, 3I, 33, I43, I85, 22 I

Grey, Aubrey De, I2 8 habituation, 20

harm, II, I9, 39, 86, I30

Harris, John, 8, II4

health care, 86

hermeneutic circle, 78

hermeneutic dimension, 233

hermeneutic role, 77

homoeopathy, 45

horizon pollution, 4I

hubris, 5, III, II7, I32, I37

human enhancement, 23, 57, 59, 86, 103, I33, 22I, 227, 229, 23I

human nature, I3, 22I

Hume, David, 72

hybrid, 60, 62, I90, 237

hyperparenting, $\mathrm{I} 33$

Iceland, I50

ideal discourse, 47

ideas of the good, 27

identity, 5, I76

Ihde, Don, 77

immanence, 74, 92, 230

in vitro fertilization, see IVF

incrementalism, III, I26, I29

independence, 7I, I39

individuality, $5, \mathrm{I} 76$

inevitability, 84

infertility, I97

information society, 76

informed consent, I4, I55, I74, I97

initial position, II 6

innate deafness, 107

inscription, 76

institutions, 40, I75

institutions, generalized, 40

institutions, science and technology as, 40

instrumental technology, 66

instrumentalism, 66, 92, I29, I39, I4I, I43

irrationality, I7, I38, I44, I46, 217, 226

is-ought fallacy, 72

IVF, I93, I96

Jelsma, Jaap, 92

Jochemsen, Henk, I09, I34, I35, I44

junk DNA, I49

justice, 38, 52, 122, 227

distributive, see distributive justice 
justice as entitlement, 54

justice as fairness, 53

justification, 3I, 43, 49, 52, 213, 222, 239

Kass, Leon, 5, I4, I7, 20, 56, 62, II2, I28, I33, I35, I36, I43, I94

Latour, Bruno, 27, 60, 62, 76, 8I, 82

liberal eugenics, II3

liberalism, 22I, 222

genetic, see genetic liberalism

political, see political liberalism

liberty, I30

life-science technologies, 2I

Locke, John, I64, I73

Lukes, Steven, I84, I86

MacIntyre, Alasdair, 48

Macklin, Ruth, 7

macroperception, 77

majority vote, 48

Mannvernd, I5I, I6I

materiality, 73, I74, I76, 215, 230

maximin principle, 53 , I2I

meaning of life, II5, II6, I35

mechanistic world view, 73

medical ethics, I24, I54

meliorism, I98

Mengele, I82

Merton, Robert K., 74

meta-argument, 9

methodological atheism, I35

methodological device, 79

Miah, Andy, I2o

microperception, 77

Midgley, Mary, 6, I35, I46

Mill, John Stuart, 30, 39

minotaur, 89

Mitcham, Carl, II5

modus vivendi, 48

monster, 4,89

monstrosity, see monster

monstrosity, in technoscience, 89--9I

moratorium, II

mud fight, 58

muddle, politics as a, 43

Muhammad, 4I, 5I

Musschenga, Bert, 62
Naser, Curtis, I53, I59

natural order, 136

naturalness, 4

Nauta, Lolle, I82, 232

negative freedom, 93, I8I

network, 80, 82, 93

network society, 84

neutrality, 50, 7I--75, 82, 92, I32, I35, 230, 232

no-harm paradigm, I80

non-maleficence, I54

normativity, 32, 78, 9I

Novas, Carlos, I6I

Nozick, Robert, 54

Nussbaum, Martha C., 6

omnipresence, 83

orthogonality, 7I, I39

Ossorio, Pilar, 169

overlapping consensus, 49

ownership, I63, I67, I73, I89

Panopticon, I52

Parelsnoer, I5I, I57

parenthood, 46

patents, 167

paternalism, I75

penetrance, I94, 201

perfectionism, 3, I08, I34, 204, 238

personal, I4, I5

pertinence

criteria of, see criteria of pertinence

Petersen, Alan, 73

PGD, I93, 218

phenotype space, IIo

Pinker, Steven, 7

Plasterk, Ronald, I2

pluralism, $\mathrm{I} 6,30$

pluralism of ideas of the good, 29

pluralism of religions, 55

polarization, 30

polder model, 200, 2II

political conception, 43, 2I3, 2I4

political constructivism, 55

political liberalism, I6, 37, 38, 55, 225

politics, 9

need for, 37

positional goods, II8, II9, I42 
positive freedom, 93, I8I

posthumanism, I2 6

postponement, 94, III, I26, I29, I38

precedent, I23, I27

argument from, 132, 138

preimplantation genetic diagnostics, see PGD

principle of equal opportunity, I22

privacy, 158

private, I8

private ethics, 9, 34, 36

private sphere, $36,37,86,221,223$

privatization, I6, 27, 210, 212

proliferation, 20, 9०, II8

protection paradigm, $\mathrm{I} 82$

protectionism, I25, I36, I42

public affairs, 9

public ethics, 9, 44

public reason, $2 \mathrm{I} 2$

public sphere, 36, 86, 22I, 223

purification, II, I3, I9, 27, 87, 9I, I06, I30, I4I, I74, 205, 224, 23I, 233 Latour, 62

PvdA, 20I

Pálsson, Gísli, I65

Rabinow, Paul, I65

randomized clinical trial, 82

rationality, I8, 32, 45, 214, 216, 230

Rawls, John, 28, 3I, 32, 38, 40, 43, 46, 49, 55, I22

reasonableness, 46, 49, 59, 214, 226

reductionism, 73, I98

reductionistic world view, 73

Reformation, 55

relevant situation, 85

religion, I3, I5, 33, 2I2, $2 \mathrm{I} 3$

religious, 15

Rendtorff, Jacob Dahl, I62

repugnance, 5,6

right to reproduce, 5

rigidity, 8I, 82, I74, I80, 232

Robert, Jason Scott, IIo

Rose, Nikolas, I6I

Rosen, Gary, I4

routine, I8, 42, 5I, 57, I25

Sandel, Michael, II2, II5, I33, I43

Savulescu, Julian, II4 science, I9, 82

Sclove, Richard, 67, 78, 83, 92

scope, 85 , I24

script, 76

seamless web, 89

Seglow, Jonathan, $5 \mathrm{I}$

segregation, 30

self-defeat, ıг8

Selgelid, Michael J., II8

separatism, I26, I29, I38

sickle-cell anemia, ııо

Silver, Lee, I03, I2I, I26, I34

slippery slope argument, 204

socio-technical network, 85

solving the wrong problem, 59

sorcerer's apprentice, II7, I37

source of justification, 36, 37, 223

spatiality, 83

Stix, Gary, I7I

Stock, Gregory, IIo

Swierstra, Tsjalling, 9, I7, I27, I57, I64, I73, I77, I79, I82, I88

Swift, Adam, 9

symmetry, 79, 80

Taylor, Charles, 49

technical constitution, I79

technocracy, 88

technological culture, 59, 60

technological determinism, 68

technological fix, 67

technology, I9, 82

technology as ideology, 229

technoscience, 82, 89, I7I, I87, 230--232

teleology, $\mathrm{I} 35$

telomeres, I05

Thomas, Sir John Meurig, 93

tolerance, 32 condition of, see condition of tolerance

Tracy, David, 6, 52

transcendence, 230

transhumanism, I25, I26

transience, 94, III, I26

Turner, Stephanie, $\mathrm{I}_{5}$

Tuskegee, I82

Tutton, Richard, I6I

Tweede Kamer, 200 
UK Biobank, I5I

ultra-wicked problem, I9०

uncertainty, I08, III

universalization, 33, I39

unpredictability, 93

value, 72

Vatican, II6

Verbeek, Peter-Paul, 70, 77, II6, I23

visualization technologies, 88

Vries, Gerard de, 73, 74

vulnerability, I55

Wenz, Peter, II9

Whitaker, Jamie, I03, III, I24

wicked problem, I90

Winner, Langdon, 74

world view, 33

X ray, 93

yuck factor, 6

Zwart, Hub, I62 
Our liberal society can be thought of as the co-existence of two spheres: a public and a private sphere. In the public sphere, we make decisions together, to govern the society we are all part of. Those decisions require a justification that all can accept. In the private sphere, we make decisions that are only our own business. Therefore, we need not give account to others, and it does not matter much whether or not our reasons for those decisions are convincing to them. While this division may seem clear, it will always be fuzzy in practice: we may disagree whether decisions should be taken collectively or individually, and for collective decisions, we may disagree which arguments are appropriate and which are not.

Technology is present in all aspects of our lives: our work, our communication, our food, our health care. If technologies change, it is likely that something in us changes as well. Indeed, if new medical technologies arise, this may make us think differently about disease - also in a moral sense. And if new technologies enable new ways of analyzing our genomes, this may make us think of our genomes and our genetic identities in a new, different way.

This book discusses how technological changes induce new ways of thinking, and what consequences this may have for the liberal structure of our society and its boundary between public and private. It explains how technological change raises discomfort in dealing publicly with ethical issues.

\section{"Wonder en is gheen wonder'}

\section{- Centre for Ethics and Technology}

